RICE UNIVERSITY

\title{
Rock Salt vs. Wurtzite Phases of Co1-xMnxO: Control of Crystal Lattice and Morphology at the Nanoscale
}

by

\section{Sean Robert Walsh}

A THESIS SUBMITTED

IN PARTIAL FULFILLMENT OF THE

REQUIREMENTS FOR THE DEGREE

\section{Doctor of Philosophy}
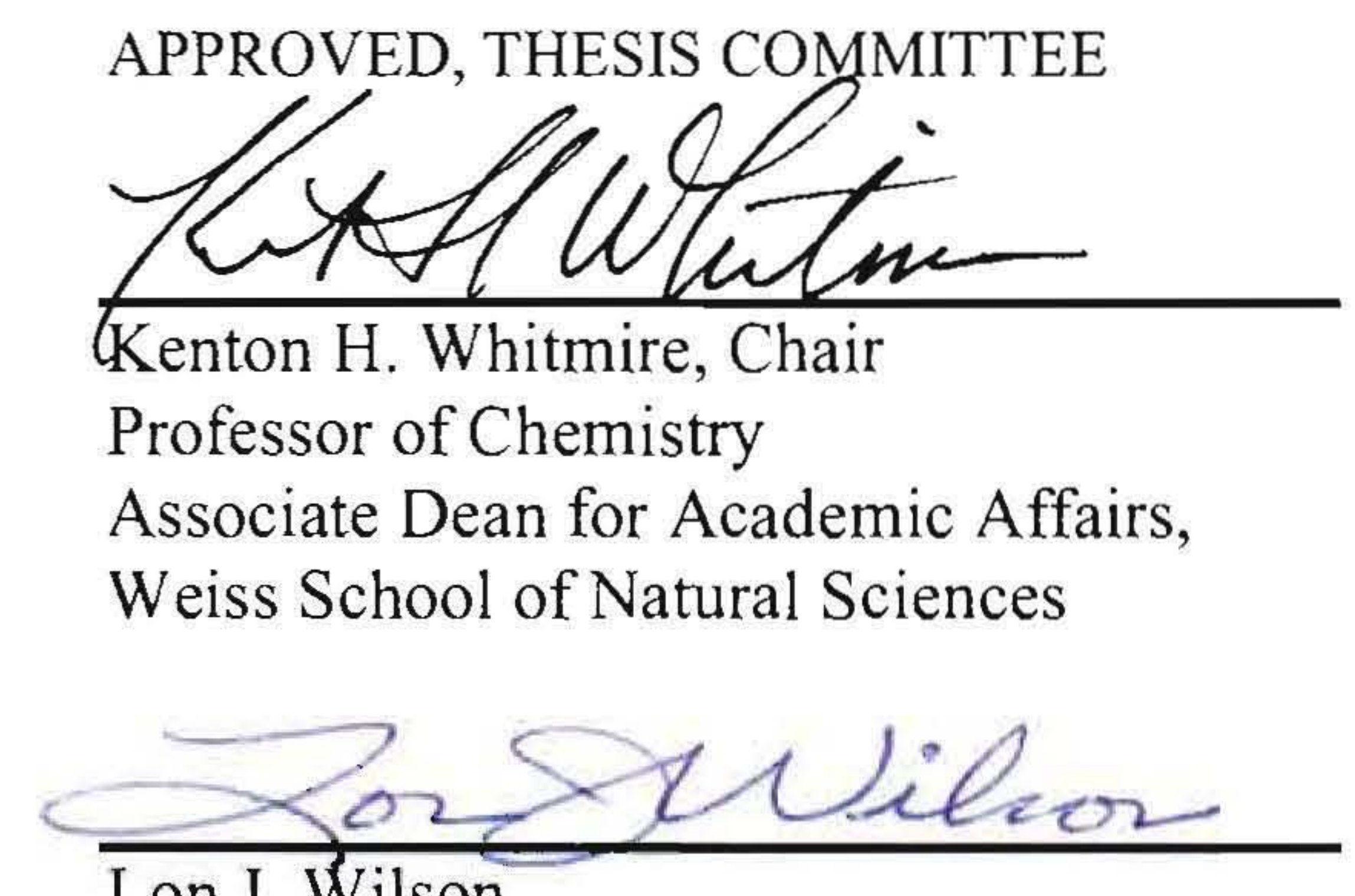

Lon J. Wilson

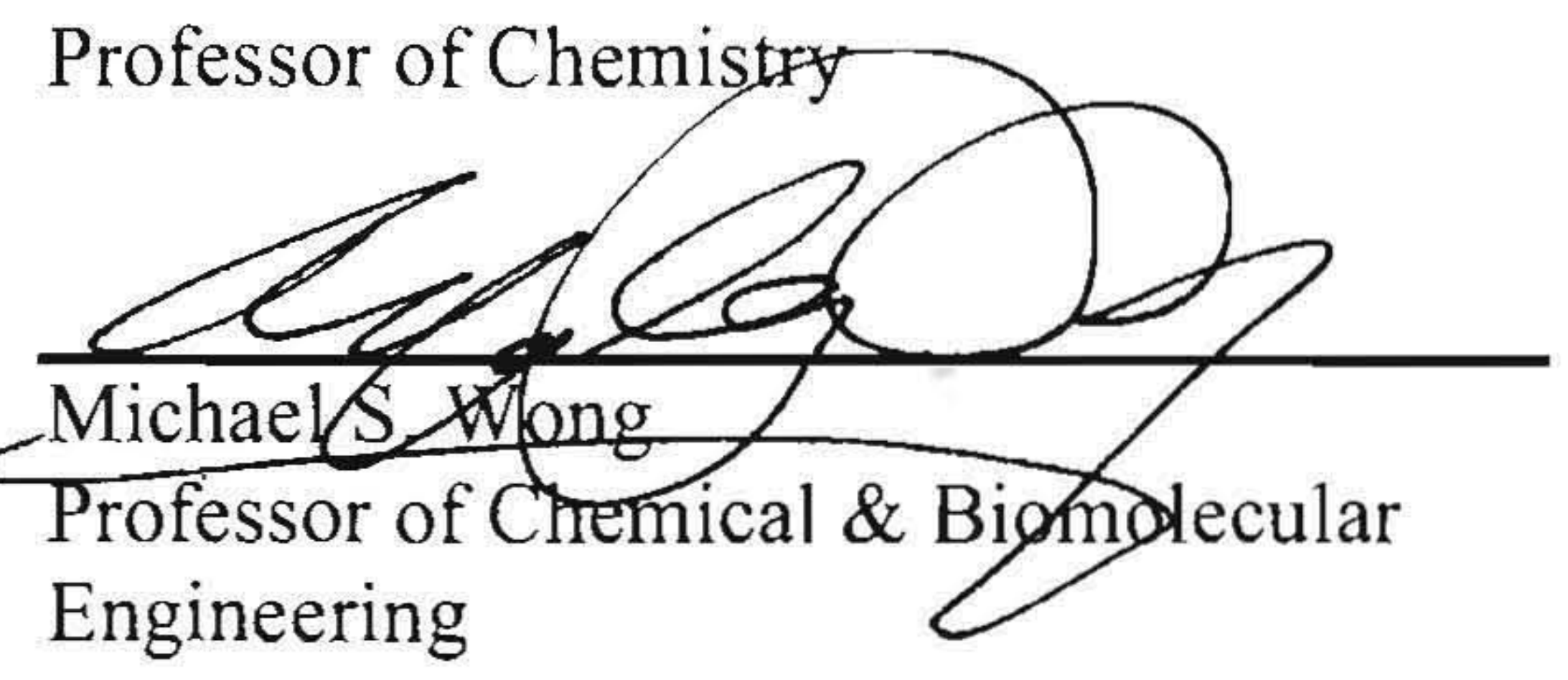

HOUSTON, TEXAS

December 2012 


\begin{abstract}
Rock Salt vs. Wurtzite Phases of $\mathrm{Co}_{1-\mathrm{x}} \mathrm{Mn}_{\mathrm{x}} \mathrm{O}$ : Control of Crystal Lattice and Morphology at the Nanoscale
\end{abstract}

by

\title{
Sean Robert Walsh
}

Diamond cuboid-, rhombohedron- and hexagon-shaped nanocrystals as well as branched rods of the solid solution $\mathrm{Co}_{1-\mathrm{x}} \mathrm{Mn}_{\mathrm{x}} \mathrm{O}(0.01 \leq \mathrm{x} \leq 0.9)$ have been synthesized via a solvothermal synthetic route from manganese formate and cobalt acetate at elevated temperature. Rhombohedra and hexagons have dimensions no larger than $50 \mathrm{~nm}$ on the longest axis, rods have branches up to $150 \mathrm{~nm}$ long and cuboids grow up to $250 \mathrm{~nm}$ on a side. X-ray and electron diffraction and transmission electron microscopy analyses show that these nanoparticles are single crystals of wurtzite-type and rock salt-type $\mathrm{Co}_{1-\mathrm{x}} \mathrm{Mn}_{\mathrm{x}} \mathrm{O}$. Varying the surfactant, water and precursor ratios allows control of particle size, morphology and stoichiometry. Extending growth time at high temperatures $\left(>370^{\circ} \mathrm{C}\right)$ leads to the disappearance of the wurtzite phase due to Ostwald ripening. Longer reaction times at temperatures between $345-365^{\circ} \mathrm{C}$ lead to more crystalline wurtzite-lattice particles. These results show that nanoparticle morphologies and crystal lattices arise from crystal growth and Ostwald ripening at different rates selecting for either small, smooth-surfaced wurtzite lattice particles or large, dendritically-grown rock salt lattice particles. 


\section{Acknowledgements}

I have not had the smoothest of paths through graduate school, with many of my issues being of my own making. I would first like to thank my advisor Professor Kenton $\mathrm{H}$. Whitmire for being willing to give me second and third chances at transforming from a prone-to-procrastination and, frankly, lazy Kentucky almost-hillbilly who lucked into a good undergraduate institution to becoming a successful graduate student and researcher; this is not a debt that I will ever be able to repay. I also would like to thank Professor Lon J. Wilson for being willing to be on my thesis committee, as well as being someone who always seemed to have an appropriate insight for the situation at hand, as well as a crack about Notre Dame's struggles in whatever sport was in season that day. I also thank Dr. Michael Wong for joining this thesis committee.

Other members of the Whitmire lab, namely Dr. Christina Hofmann, Dr. Anna Kelly, Dr. Trinanjana Mandal and Dr. Adam Colson, have been wonderful people to know and work with. Adam especially has been a true friend and constant source of both chemistry and non-chemistry discussions, news, enlightenment and humor.

I would like to thank the scientists of the Shared Equipment Authority, particularly Richard Crouse and Dr. Wenh Guo, for their daily efforts to ensure that the instruments we need are well maintained and ready for experiments. I would also like to thank the Rice Chemistry Department and 
Dr. Seiichi Matsuda for their assistance in ensuring I reached this point of my education.

During my time at Rice I have met a great number of people that I consider to be dear friends, and I would not have made it through these five years without them. Dr. David Fortunato, Dr. Brent Carey, Dr. Purvez Capitan, Eileen Meyer, and John Stanley are all people I will never forget and hope to never lose track of - they accompanied me through one of the biggest learning experiences of my life, and certainly the best bad decision I've ever made, managing Valhalla. I would especially like to thank my parents, Robert and Colleen Walsh, for their support for my whole life leading up to this point. I don't know where I would be without their love and guidance. I would also like to thank my uncle and aunt, Tom and Astrid Walsh, whose presence in Houston during my time at Rice has ensured that I would always have someone to fall back on in times of immediate need, but also knew when to let me walk on my own. 


\section{Table of Contents}

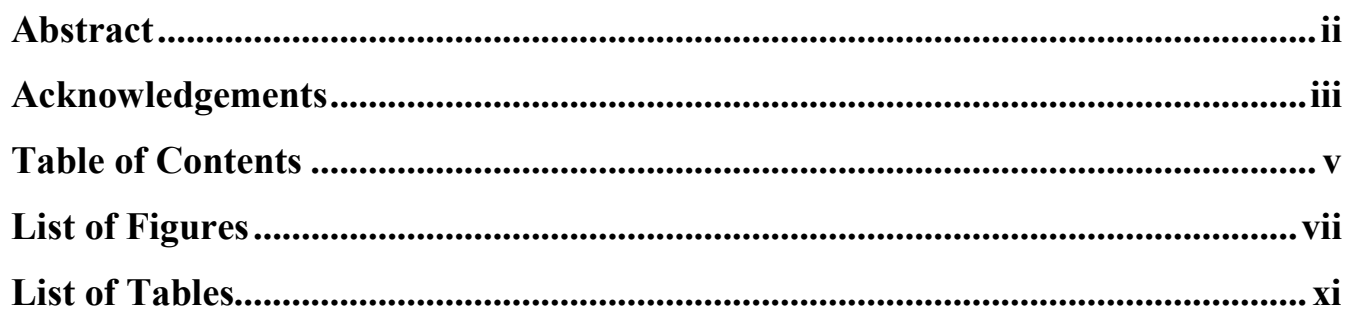

Chapter 1. Introduction ...................................................................................... 1

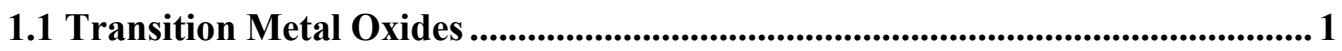

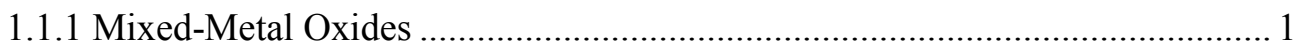

1.2 Materials at the Nanoscale................................................................................................. 4

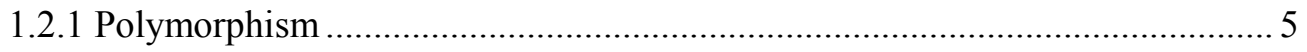

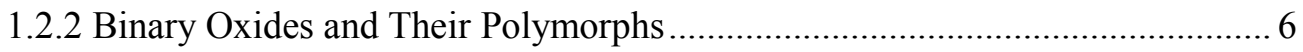

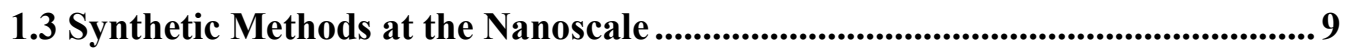

1.4 Thesis Topic: Cobalt-Manganese Oxides ......................................................... 11

Chapter 2. Experimental ......................................................................................... 13

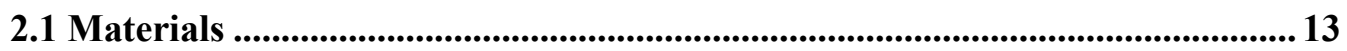

2.2 Procedure for Synthesis of $\mathrm{Co}_{1-\mathrm{x}} \mathrm{Mn}_{\mathrm{x}} \mathrm{O}$ nanoparticles .................................... 14

2.3 Analysis of Nanoparticles ................................................................................ 16

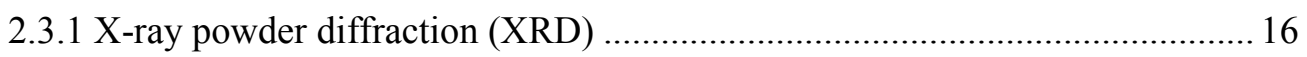

2.3.2 Transmission electron microscope (TEM) ..................................................... 16

2.3.3 Inductively Coupled Plasma Optical Emission Spectroscopy (ICP-OES)...... 17

Chapter 3. Results .................................................................................................... 18

3.1 Crystal Lattice Determination ........................................................................................ 18

3.2 Issues with reproducibility of synthesis................................................................. 19

3.3 Effect of altering Co:Mn precursor ratio.................................................................. 24

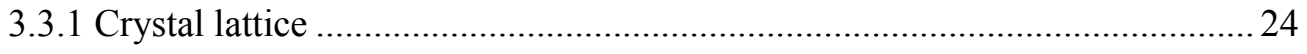

3.3.2 Nanoparticle morphology............................................................................ 33

3.4 Effect of varying TOA:OA volume ratio...................................................................4 40

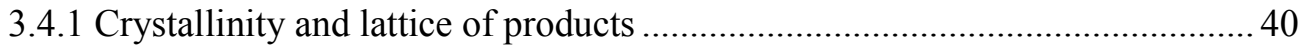




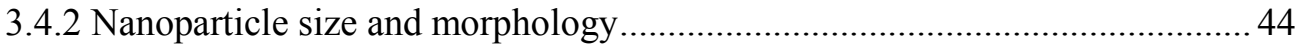

3.5 Effect of Adding $\mathrm{H}_{2} \mathrm{O}$ to Reaction Solution.............................................................50

3.6 Effect of Changing Molecular Precursor: OA Ratio..............................................56

3.7 Effect of Extending Growth Time............................................................................6 62

3.8 Effect of Varying the Solution Heating Rate ............................................................ 68

3.9 Grain size dependence on Co-Mn stoichiometry ............................................... 74

Chapter 4. Discussion................................................................................................. 84

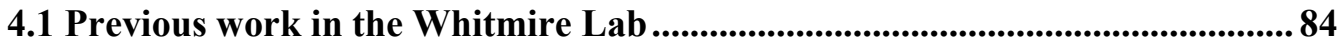

4.2 Identification of nanoparticle crystal lattice .......................................................8 84

4.3 Change in crystal lattice with metal content .......................................................85

4.4 Effect of Co:Mn ratio on morphology of products............................................86

4.5 Oleic acid and its role in oxide formation ..............................................................8 88

4.6 Oleic acid and its effect on nanoparticle morphology .......................................90

4.7 Effect of Added Water on Nanoparticle Morphology .....................................93

4.8 Effect of molecular precursor:OA ratio on nanoparticle structure..................95

4.9 Extending reaction growth time...........................................................................99

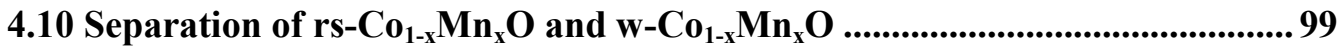

4.11 Nanoparticle growth processes...................................................................... 100

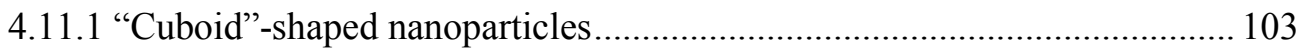

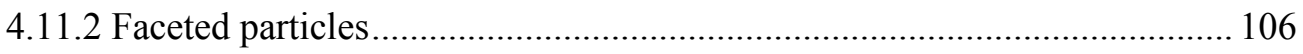

4.12 Presence of Multiple Phases .......................................................................................... 110

4.13 Grain size dependence on Co-Mn stoichiometry .............................................. 113

4.14 Heating effects and heterogeneous vs. homogeneous nucleation ................... 113

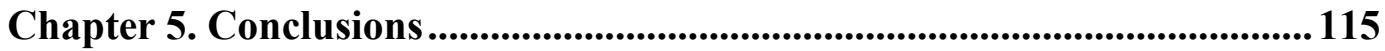

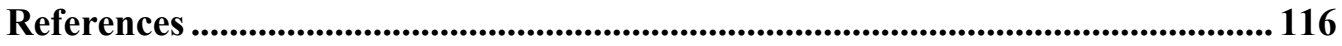




\section{List of Figures}

Figure 1.1. Spinel lattice viewed to emphasize coordination environment of $\mathrm{M}$ and $M^{\prime}$ in the spinel structure. $M$ is shown as blue spheres, $M$ ' as orange spheres and $\mathrm{O}$ as black spheres. Image made in Diamond software using $\mathrm{MnFe}_{2} \mathrm{O}_{4}$ CIF file from the American Mineralogical Database.

Figure 1.2. Idealized cubic perovskite unit cell. The crosshatched circle is A, filled black circles are B. Each octahedron vertex is an oxygen atom. Adapted from Deer. ${ }^{1}$

Figure 1.3. Zinc Blende and Wurtzite crystal structures. Shown are the ABCABC cubic close pack layer ordering and $A B A B A B$ hexagonal close pack layer ordering.

$\begin{array}{ll}\text { Figure 1.4. Rock salt lattice of } \mathrm{MnO} . & 7\end{array}$

$\begin{array}{lr}\text { Figure 2.1. Reaction setup for nanoparticle synthesis } & 15\end{array}$

Figure 3.1. Example XRD pattern for polycrystalline $\mathrm{rs}_{-} \mathrm{Co}_{1-\mathrm{x}} \mathrm{Mn}_{\mathrm{x}} \mathrm{O}$ nanoparticles.

Lattice indices marked are marked above each peak. Reference peak positions for $\mathrm{MnO}(a=4.44 \AA)$ and $\mathrm{rs}-\mathrm{CoO}(a=4.26 \AA)$ are shown in green and red respectively.

Figure 3.2. (a) $\mathrm{Co}_{1-\mathrm{x}} \mathrm{Mn}_{\mathrm{x}} \mathrm{O}$ nanoparticles and (b) the indexed polycrystalline SAED pattern from the sample shown in Figure 3.1. Both images were taken by Dr. Irene Rusakova at the University of Houston.

Figure 3.3. XRD pattern of metallic cobalt resulting from failed nanoparticle synthesis. Cubic close pack and hexagonal close pack lattice cobalt phases (PDF\#00-015-0806 and PDF\#04-002-1029) are shown as reference in orange and blue respectively.

Figure 3.4. XRD pattern of mixture of $\mathrm{rs}^{-} \mathrm{Co}_{1-\mathrm{x}} \mathrm{Mn}_{\mathrm{x}} \mathrm{O}$ and metallic cobalt cubic and hexagonal phases). Oxide peaks are marked in green; ccp and hep metallic cobalt peaks are orange and blue respectively.

Figure 3.5. XRD pattern of a mixture of multiple rock salt-structure oxide phases. Reference phases with lattice constant $a=4.403 \AA$ and $4.326 \AA$ are shown in green and purple respectively. 
Figure 3.6. Glassware setup for distillation of OA. Not shown: aluminum foil wrapping.

Figure 3.7. XRD patterns for select nanoparticle samples of varying Co-Mn content as determined by ICP-OES analysis. $\mathrm{MnO}$ and $\mathrm{CoO}$ are shown in red and green respectively.

Figure 3.8. Change in (220) peak position with increasing cobalt content in sample. Sample data is in black diamonds; $\mathrm{MnO}$ and $\mathrm{CoO}$ positions are in red squares. The direct-line correlation between $\mathrm{MnO}$ and CoO is shown as a red line.

Figure 3.9. Change in calculated unit cell volume versus cobalt content of sample. Sample data is in black diamonds; $\mathrm{MnO}$ and $\mathrm{CoO}$ positions are in red squares. The direct correlation between $\mathrm{MnO}$ and $\mathrm{CoO}$ (as expected from Vegard's Law) is shown as a red line.

Figure 3.10. Example powder XRD pattern for all products recovered by centrifugation in hexanes for TOA:OA ratios of 7:1 to 5:3; trace amounts of Co metal are present in some, but not all, samples.

Figure 3.11. Example powder XRD pattern of nanoparticles recovered from the supernatant of reaction with $5 \mathrm{~mL}$ TOA and $3 \mathrm{~mL} \mathrm{OA.} \mathrm{ZnO}$ (PDF\#04008-8199) is shown in green; zinc blende $\mathrm{CoO}(\mathrm{ZB}-\mathrm{CoO})$ is shown above in black.

Figure 3.12. Powder XRD pattern of the product of a reaction run in $8 \mathrm{~mL}$ TOA, with no OA present. Face-centered cubic-lattice $\mathrm{MnO}$ and $\mathrm{CoO}$ are shown in red and blue, respectively, whereas hexagonal-lattice $\mathrm{ZnO}$ is shown in green.

Figure 3.13. HR-TEM images and SAED patterns of cubic lattice and hexagonal lattice nanoparticles. The sample in (a) was synthesized in $6 \mathrm{~mL}$ TOA: 2 mL OA; the SAED pattern in (b) indexes to a single cubic phase Fmm (225), $a=4.3 \AA$. The sample in (c) is from the supernatant of the $5 \mathrm{~mL}$ TOA: $3 \mathrm{~mL}$ OA reaction; the SAED pattern in (d) indexes to a single hexagonal phase $\mathrm{P} 6_{3} \mathrm{mc}(186), a=3.3 \AA$ and $c=5.2 \AA$. 
Figure 3.14. XRD pattern of product recovered from supernatant of reaction with $1 \mathrm{mmol}$ metal precursors. Reference pattern for hexagonal ZnO-type lattice is shown in green; for face centered cubic MnO-type lattice in blue.

Figure 3.15. XRD pattern of product recovered from precipitate of reaction with 1 mmol metal precursors. The lack of sharp peaks indicates a noncrystalline, amorphous solid.

Figure 3.16. Change in XRD patterns for the material collected from the supernatant of reactions with extended growth times under conditions 6 mL TOA: $2 \mathrm{~mL} \mathrm{OA}$, no water and $0.5 \mathrm{mmol}$ each of $\mathrm{Co}(\mathrm{OAc})_{2}$ and $\mathrm{Mn}(\mathrm{HCOO})_{2}$. Reference pattern for a rock salt-structure lattice with $a=$ $4.3 \AA$ is shown in blue; reference $\mathrm{P}_{3}$ mc lattice with $a=3.2 \AA$ and $c=5.2$ Å shown in green.

Figure 3.17. Reaction temperature vs. time profile for a standard nanoparticle synthesis reaction. The reaction conditions and results for this particular reaction are discussed along with Table 3.18.

Figure 3.18. Reaction temperature vs. time comparison for a failed nanoparticle synthesis.

Figure 3.19. Reaction temperature vs. time comparison for a reaction that still yielded some nanoparticles.

Figure 3.20. Sharpening of $\mathrm{w}-\mathrm{Co}_{1-\mathrm{x}} \mathrm{M}_{\mathrm{n}} \mathrm{XO}$ nanoparticle XRD peaks with increasing particle size and crystallinity. Representative TEM image of each sample is shown on the right. The largest particles are 25-30 $\mathrm{nm}$ in diameter, the smallest $5 \mathrm{~nm}$. Reference peaks for hexagonal $\mathrm{ZnO}$ are shown in gray at the bottom.

Figure 3.21. Crystallite size (average of Scherrer fit for the (111) and (200) peaks) vs. Co content from ICP-OES with quadratic fit to the data.

Figure 3.22. Crystallite size (average of Scherrer fit for the (111) and (200) peaks) vs. Co content from ICP-OES with cubic fit to the data.

Figure 3.23. Crystallite size (average of Scherrer fit for the (111), (200) and (220) peaks) vs. Co content from ICP-OES with quadratic fit to the data. 
Figure 3.24. Crystallite size (average of Scherrer fit for the (111), (200) and (220) peaks) vs. Co content from ICP-OES with cubic fit to the data.

Figure 3.25. Crystallite size (average of Scherrer fit for the (111), (200) and (220) peaks) vs. Co content from ICP-OES. These are $\mathrm{Co}_{1-\mathrm{x}} \mathrm{Mn}_{\mathrm{x}} \mathrm{O}$ particles where $0.1 \leq \mathrm{x} \leq 0.9$. The fit is linear.

Figure 4.1. Crystal growth rate vs. crystal growth driving force. Curve A depicts spiral growth, curve B two-dimensional layer-by-layer growth and curve C adhesive growth. From Sunagawa $\mathrm{p} 46 .^{92}$

Figure 4.2. Different morphologies achieved under different growth mechanisms from the same cubic seed crystal bounded only by the (111) face. From Sunagawa $\mathrm{p} 52 .{ }^{92}$

Figure 4.3. TEM images (a) and (c) with SAED patterns (b) and (d) of nanoparticles from reaction of $7 \mathrm{~mL}$ TOA: $1 \mathrm{~mL}$ OA with $1 \mathrm{mmol}$ each of $\mathrm{Co}(\mathrm{OAc})_{2}$ and $\mathrm{Mn}(\mathrm{HCOO})_{2}$. (e) and (f) Schematic illustration of the growth conditions and internal texture of a diamond cuboid (figure derived from literature). ${ }^{92}$

Figure 4.4 Schematic of the growth process of a spherulite formed by split growth. From Sunagawa, p158. ${ }^{92}$

Figure 4.5 Schematic of the growth process for two octahedrons forming interpenetrating cubic crystals. From Sunagawa, p136. ${ }^{92}$

Figure 4.6 Illustration of steps of growth from a cubic lattice nucleus in the [100] directions via a spiral mechanism. Adapted from Sunagawa, p 79. ${ }^{92} \quad 108$

Figure 4.7 SAED pattern of surface-oxidized nanoparticle along the [001] axis (a) and dark field TEM images of a nanoparticle taken with $g_{\text {rock salt }}=200$ (b) and $\mathrm{g}_{\text {spinel }}=2 \overline{2} 0$ (c). SAED pattern of a nanoparticle displaying longrange superlattice ordering $(\mathrm{d})$ with dark field TEM images with $\mathrm{g}_{\text {intense }}=$ 220 (e) and $g_{\text {weak }}=110$ (f).

Figure 4.8 Bright field TEM (a) and SAED pattern down the [011] axis showing superlattice ordering (b) of a nanoparticle synthesized $6 \mathrm{ml}$ TOA: $2 \mathrm{ml} \mathrm{OA}$ with no water and a 2:1 Co:Mn precursor ratio; final product stoichiometry was c- $\mathrm{Co}_{0.75} \mathrm{Mn}_{0.25} \mathrm{O}$. 


\section{List of Tables}

Table 1.1. Crystallographic data for binary oxides with the rock salt structure ${ }^{2} \ldots .8$

Table 1.2. Crystallographic data for binary oxides with the wurtzite structure ...... 9

Table 1.3. Single-metal oxides synthesized at the nanoscale ${ }^{8}$....................... 11

Table 3.1 Example of a cell refinement report for an XRD pattern using JADE 9

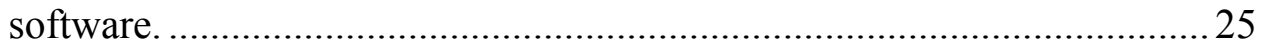

Table 3.2. XRD data from JADE and ICP-OES elemental analysis of samples... 26

Table 3.3. XRD data from JADE and ICP-OES elemental analysis of samples,

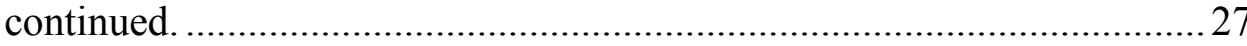

Table 3.4. XRD data from JADE and ICP-OES elemental analysis of samples,

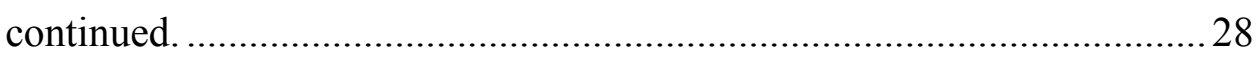

Table 3.5. XRD data from JADE and ICP-OES elemental analysis of samples, continued.

Table 3.6. TEM images of nanoparticles synthesized with a 9:1 ratio of Mn:Co molecular precursors

Table 3.7. TEM images of nanoparticles synthesized with a 5:1 ratio of Mn:Co molecular precursors

Table 3.8. TEM images of nanoparticles synthesized with a 2:1 ratio of $\mathrm{Mn}$ :Co molecular precursors ................................................................ 35

Table 3.9. TEM images of nanoparticles synthesized with a 1:1 ratio of $\mathrm{Mn}$ :Co molecular precursors 36

Table 3.10. TEM images of nanoparticles synthesized with a 1:2 ratio of Mn:Co molecular precursors

Table 3.11. TEM images of nanoparticles synthesized with a 1:5 ratio of Mn:Co molecular precursors 38

Table 3.12 TEM images of nanoparticles synthesized with a 1:9 ratio of Mn:Co molecular precursors

Table 3.13. TEM images of nanoparticles synthesized in $8 \mathrm{~mL}$ TOA and $0 \mathrm{~mL}$ $\mathrm{OA}$ 
Table 3.14. TEM images of nanoparticles synthesized in $7 \mathrm{~mL}$ TOA and $1 \mathrm{~mL}$

$\mathrm{OA}$ 46

Table 3.15. TEM images of nanoparticles synthesized in $6.5 \mathrm{~mL}$ TOA and $1.5 \mathrm{~mL}$

Table 3.16. TEM images of nanoparticles synthesized in $5 \mathrm{~mL}$ TOA and $3 \mathrm{~mL}$

$\mathrm{OA}-$ supernatant from centrifugation in hexanes $\left(\mathrm{w}-\mathrm{Co}_{1-\mathrm{x}} \mathrm{Mn} \mathrm{n}_{\mathrm{x}} \mathrm{O}\right) \ldots \ldots \ldots . . . .48$

Table 3.17. TEM images of nanoparticles synthesized in $5 \mathrm{~mL}$ TOA and $3 \mathrm{~mL}$

$\mathrm{OA}$ - precipitate from centrifugation in hexanes $\left(\mathrm{rs}-\mathrm{Co}_{1-\mathrm{x}} \mathrm{Mn} \mathrm{x}\right)$.

Table 3.18. TEM images of nanoparticles synthesized with $20 \mu \mathrm{L}(1.11 \mathrm{mmol})$ added

Table 3.19. TEM images of nanoparticles synthesized with $36 \mu \mathrm{L}(2 \mathrm{mmol})$ added

Table 3.20. TEM images of nanoparticles synthesized with $54 \mu \mathrm{L}$ (3 mmol) added

Table 3.21. TEM images of nanoparticles synthesized with $\mathrm{Co}(\mathrm{OAc})_{2} \cdot 4 \mathrm{H}_{2} \mathrm{O}$ that was not dried beforehand

Table 3.22. TEM images of nanoparticles synthesized with a 9:1 ratio of Mn:Co molecular precursors with $100 \mu \mathrm{L} \mathrm{H} 2 \mathrm{O}$ added; SAED pattern is for the doubly branched particle at the bottom

Table 3.23. TEM images of nanoparticles synthesized with $1 \mathrm{mmol}$ metal precursors that precipitated upon centrifugation in hexanes

Table 3.24. TEM images of nanoparticles synthesized with $1 \mathrm{mmol}$ metal precursors recovered from hexanes centrifugation supernatant..... 58

Table 3.25. TEM images of nanoparticles synthesized with $3 \mathrm{mmol}$ metal precursors

Table 3.26. TEM images of nanoparticles synthesized with $4 \mathrm{mmol}$ metal precursors

Table 3.27. 5 minutes growth for reaction with $6 \mathrm{~mL}$ TOA, $2 \mathrm{~mL}$ OA with no water and $0.5 \mathrm{mmol}$ of each precursor. This material (5-SN) was recovered from the supernatant after centrifugation in hexanes. 
Table 3.28. 5 minutes growth for reaction with $6 \mathrm{~mL}$ TOA, $2 \mathrm{~mL}$ OA with no water and $0.5 \mathrm{mmol}$ of each precursor. This material (5-PP) was recovered from the precipitate after centrifugation in hexanes.

Table 3.29. 10 minutes growth for reaction with $6 \mathrm{~mL}$ TOA, $2 \mathrm{~mL}$ OA with no water and $0.5 \mathrm{mmol}$ of each precursor. This material (10-SN) was recovered from the supernatant after centrifugation in hexanes.

Table 3.30. 10 minutes growth for reaction with $6 \mathrm{~mL}$ TOA, $2 \mathrm{~mL}$ OA with no water and $0.5 \mathrm{mmol}$ of each precursor. This material (10-PP) precipitated upon centrifugation in hexanes.

Table 3.31. TEM images of reactions that had inconsistent heating. The pairs of images on each row are from different reactions, with different starting conditions.

Table 3.32. Scherrer analysis data after processing raw XRD data in JADE 9...75

Table 3.33. Scherrer analysis data after processing raw XRD data in JADE 9, cont'd.......

Table 3.34. Scherrer analysis data after processing raw XRD data in JADE 9, cont'd.

Table 3.35. Scherrer analysis data after processing raw XRD data in JADE 9, cont'd.

Table 3.36. Scherrer analysis data after processing raw XRD data in JADE 9, cont'd.

Table 4.1 TEM images of CoO nanoparticles synthesized in $6 \mathrm{~mL}$ TOA, $2 \mathrm{~mL}$ $\mathrm{OA}, 2 \mathrm{mmol} \mathrm{Co}(\mathrm{OAc})_{2}$ and no water. 


\section{Chapter 1. Introduction}

\subsection{Transition Metal Oxides}

Transition metal oxides have been studied for centuries due to their abundance, stability and wide range of properties, structures and combinations. There are 28 naturally occurring transition metals that form oxides (i.e. the $d$ block minus gold and technetium) and the number of possible permutations of crystal lattices, oxidation states, electronegativities, bonding types, coordination numbers, atomic or ionic radii is truly staggering. Adding in all of the $s$ and $p$ block elements that can (and do) mix in with the transition metals leads to even more interesting and varied substances. While mineralogists, crystallographers and materials chemists have made great strides in discovering, characterizing and investigating the properties of this class of materials, the sheer number of potential compounds means that there are still myriad avenues for exploration. ${ }^{1-3}$

\subsubsection{Mixed-Metal Oxides}

Oxides with more than a single cationic metal species are very common. Generally, there are two structural forms from which they arise: (1) materials with two dissimilar cations and (2) materials with two similar metals. The first type leads to compounds such as spinel $\left(\mathrm{MgAl}_{2} \mathrm{O}_{4}\right)$ and perovskite $\left(\mathrm{CaTiO}_{3}\right)$, in which the structure is the result of the two cations always occupying different, ordered lattice positions. The spinel structure, more generally $\mathrm{MM}_{2}{ }_{2} \mathrm{O}_{4}$, where $\mathrm{M}$ is a $2+$ cation and $M^{\prime}$ is a $3+$ cation, has a face-centered cubic unit cell, space 
group $F d 3 m$, with $\mathrm{Z}=8$. This means that there are 32 oxygen ions and 24 metal ions per unit cell, with $\mathrm{M}$ and $\mathrm{M}$ ' either octahedrally or tetrahedrally coordinated by oxygen. In the "regular" spinel form shown in Figure 1.1, all $8 \mathrm{M}$ cations are in the tetrahedral sites and the $16 \mathrm{M}^{\prime}$ cations are wholly in the octahedral sites; in “inverse spinels" $\mathrm{M}$ and $8 \mathrm{M}^{\prime}$ are octahedrally coordinated with $8 \mathrm{M}^{\prime}$ ' cations in the tetrahedral sites. Common examples of spinels are magnetite $\left(\mathrm{Fe}^{2+}\right)\left(\mathrm{Fe}^{3+}\right)_{2} \mathrm{O}_{4}$, jacobsite $\left(\mathrm{Mn}^{2+}\right)\left(\mathrm{Fe}^{3+}\right)_{2} \mathrm{O}_{4}$ and franklinite $\left(\mathrm{Zn}^{2+}\right)\left(\mathrm{Fe}^{3+}\right)_{2} \mathrm{O}_{4}$. In the perovskite structure, more generally $\mathrm{ABO}_{3}$ where $\mathrm{A}$ is a large $2+$ cation and $\mathrm{B}$ a smaller 4+ cation, the size mismatch between the A and B cations leads to a body-centered crystal lattice, which may be cubic, tetragonal or orthorhombic depending on the distortion. The B cations are positioned at the corners of the lattice octahedrally coordinated by oxygen, while the A cation occupies the body center in 12-fold coordination. This is shown in Figure 1.2. Spinel and perovskite crystal structures are the result of mismatches between the two different metals combined in the material. In the case of spinels, the mismatch is in the oxidation state, leading to a different preferred coordination environment. In perovskites the larger size of the $\mathrm{A}$ cation forces the $\mathrm{BO}_{6}$ octahedra apart and frequently at different stacking angles from the perfect cubic alignment, as noted above. 


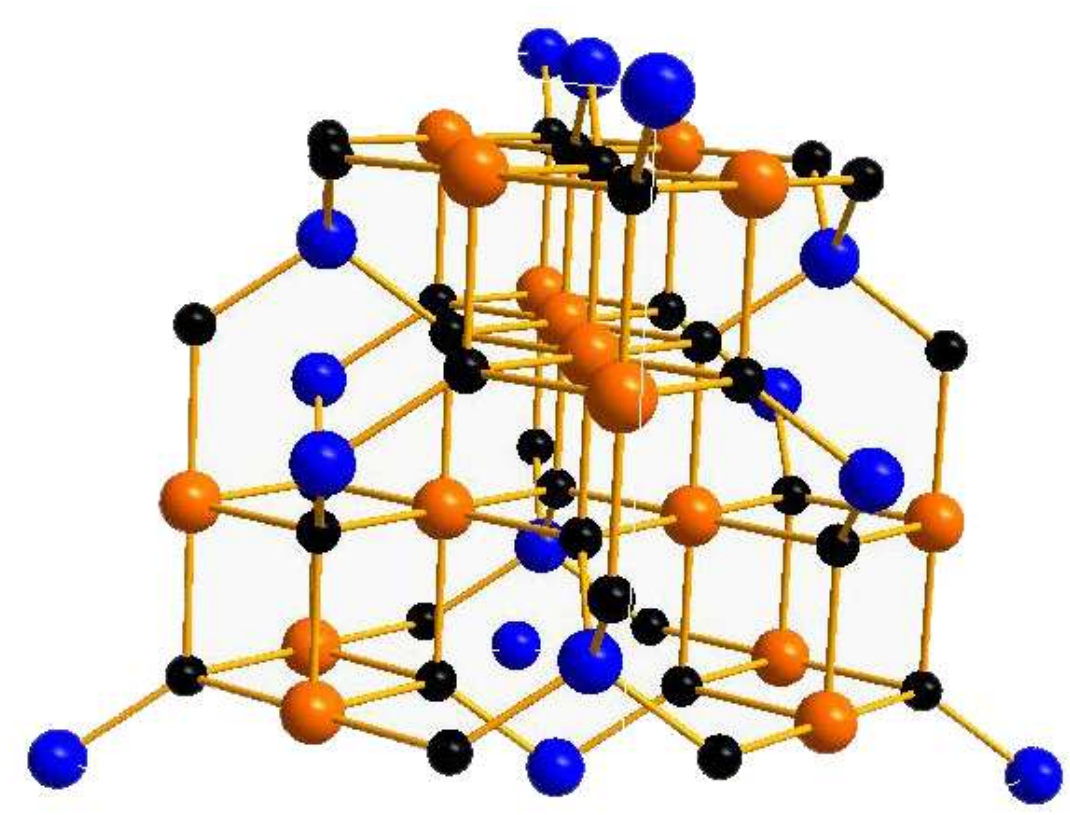

Figure 1.1. Spinel lattice viewed to emphasize coordination environment of $M$ and $M^{\prime}$ ' in the spinel structure. $M$ is shown as blue spheres, $M$ ' as orange spheres and $O$ as black spheres. Image made in Diamond software using $\mathrm{MnFe}_{2} \mathrm{O}_{4} \mathrm{CIF}$ file from the American Mineralogical Database.

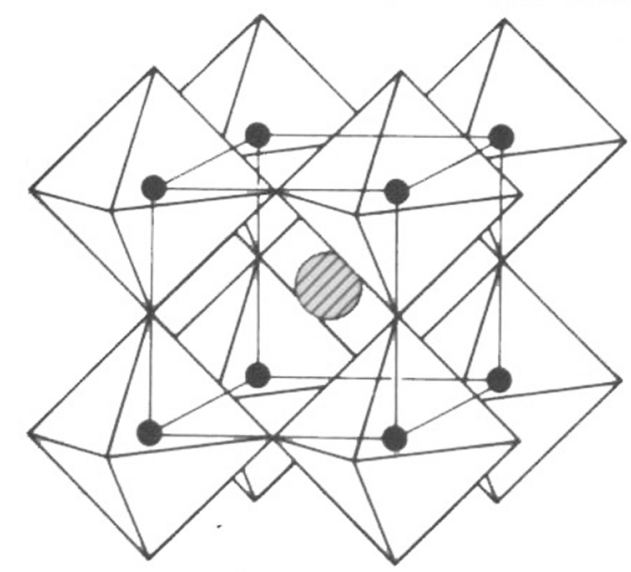

Figure 1.2. Idealized cubic perovskite unit cell. The crosshatched circle is A, filled black circles are B. Each octahedron vertex is an oxygen atom. Adapted from Deer. ${ }^{1}$ 
In the case where two metals of similar size, charge and electronegativity are present in the same oxide material, the insertion of multiple cations may not interrupt the original structure of the single oxide nearly as much as in the case of spinels or perovskites. Instead, a "solid solution" of the two pure oxides forms, with one metal included into the lattice by replacing the other (substitutional) or interstitially. In a true solid solution the placement of each different metal cation is random and with no positional bias. There are solid solutions that do show ordering with respect to the placement of each constituent part of the lattice, what are referred to in metallurgy as "superlattices," which are distinct from the nanoscience/metamaterials term that refers to extended arrays of components on surfaces. ${ }^{4}$

\subsection{Materials at the Nanoscale}

Research in the past two decades has revealed that unstable or difficult-tosynthesize phases of materials may become accessible when "bottom-up" methods are used. ${ }^{5-8}$ Existing transition metal oxides have been investigated for a wide array of interesting properties including superconductivity, ${ }^{9}$ colossal magnetoresistance, ${ }^{10}$ metal-insulator transitions ${ }^{11}$ and the ability to catalyze many

different reactions. ${ }^{12-14}$ There is often structural similarity between materials with similar properties, leading to the conclusion that crystal structure has a significant effect on material properties. It is therefore of interest to explore metal oxide materials and synthetic methods at the nanoscale to discover new structural phases that may have other appealing properties. 


\subsubsection{Polymorphism}

The ability of a single material to assume different arrangements of atoms is called polymorphism or polytypism. In the realm of transition metal oxides perhaps the best-known example of this is $\mathrm{TiO}_{2}$, which preferentially forms the anatase structure over that of rutile at the nanoscale, ${ }^{15}$ this is far from the sole case where this is found. Another mineralogical example is the mineral sphalerite, $\mathrm{ZnS}$, which has a face-centered cubic crystal lattice, space group $F-43 m$, in its low-temperature form. ${ }^{1,2,16,17}$ In this arrangement, four S atoms coordinate every $\mathrm{Zn}$ atom in a tetrahedral manner, with every $\mathrm{S}$ atom being likewise surrounded by four $\mathrm{Zn}$ atoms. The anions form arrays of close-packed spheres; cations sit in interstitial sites between the anions. The close-packed anion layers most commonly adopt one of two regular repeating arrangements: $\mathrm{ABAB}$ or $\mathrm{ABCABC}$. More complex arrangements are also possible, however. In the case of sphaerulite the $\mathrm{ABCABC}$ layering system is used, which is a cubic close packing of atoms. This is called the "zinc blende" structure and is the prototypical crystal structure for many other materials, as will be discussed. Upon heating to $1020^{\circ} \mathrm{C}$, sphalerite shifts from the zinc blende structure to the "wurtzite" structure. ${ }^{1}$ The wurtzite structure also consists of tetrahedrally-coordinated $\mathrm{Zn}$ and $\mathrm{S}$ atoms, but the crystal lattice is a hexagonal lattice, space group $P 6_{3} m c$, in which the anion layers are arranged $\mathrm{ABAB}$ in what is called hexagonal close packing of atoms. The differences between the zinc blende and wurtzite structure are illustrated in Figure 1.3. Zinc blende-wurtzite polymorphism has been a topic of significant research interest because many semiconductors of interest have one or both of 
these structures, such as AlN, GaN, InN, AlP, AlAs, GaP, GaAs, ZnS, ZnSe, ZnTe, CdS and CdSe. ${ }^{18}$

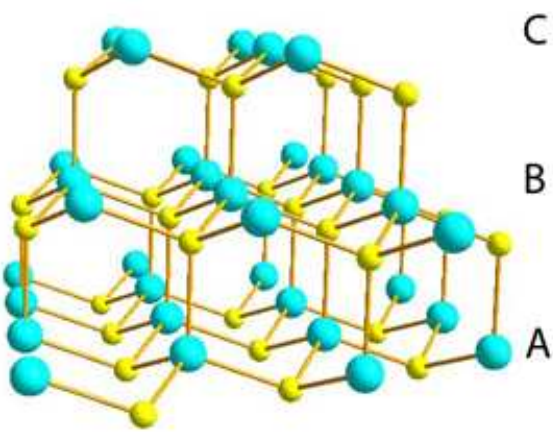

Zinc Blende
C

B

\section{A}

$\mathrm{Zn}_{\mathrm{S}} \mathrm{e}$
A

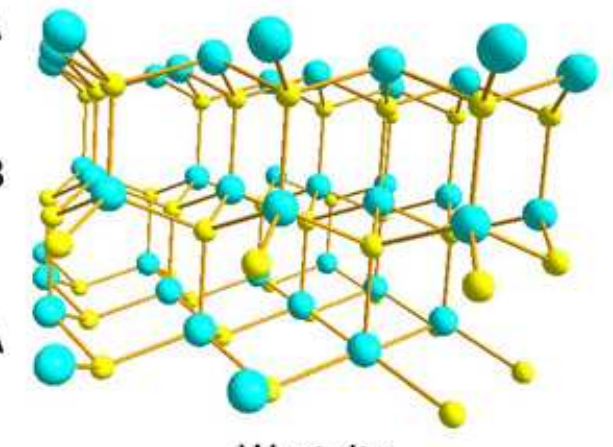

Wurtzite

Figure 1.3. Zinc Blende and Wurtzite crystal structures. Shown are the $\triangle B C A B C$ cubic close pack layer ordering and $\triangle B A B A B$ hexagonal close pack layer ordering.

\subsubsection{Binary Oxides and Their Polymorphs}

The binary oxides are a class of compounds with formula $\mathrm{M}_{\mathrm{x}} \mathrm{O}_{\mathrm{y}}$, where $\mathrm{M}=$ any metal; the simplest stoichiometry is for the divalent ( +2 charge) metal ions. These materials, unlike the other chalcogenides mentioned in Section 1.2.1, do not tend to form stable zinc blende or wurtzite structures, showing a marked preference for the structure referred to variously as the "rock salt," "halite" and "NaCl" structures. This structure has a face-centered cubic crystal lattice, space group $F m 3 m$, in which both the cation and anion are octahedrally-coordinated and stacked in cubic closed packed layers; see Figure 1.4 for a graphical representation. Lattice constants, formula weights and ionic radii of some binary

oxides that assume the rock salt structure are shown in Table 1.1. Among the 
binary transition metal oxides that have a perfect 1:1 $\mathrm{M}: \mathrm{O}$ ratio $(\mathrm{MnO}, \mathrm{FeO}, \mathrm{CoO}$, $\mathrm{NiO}$ ), the unit cell becomes smaller and the density increases as the ionic radius of the metal ion decreases. Titanium, vanadium and chromium do not have wellinvestigated binary oxides due to their strong preference to be in the $3+$ oxidation state over $2+$, which leads to vacancies and defects in the lattice. The alkaline metals and $2^{\text {nd }}$ and $3^{\text {rd }}$ row transition metals deviate from the pattern also due to their much larger size.

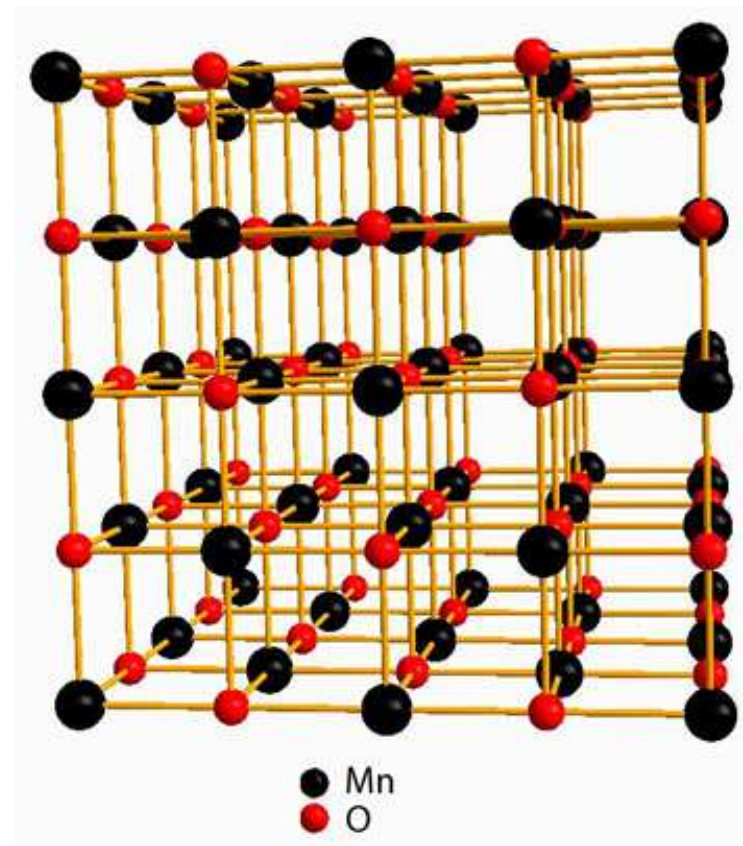

Figure 1.4. Rock salt lattice of MnO. 
Table 1.1. Crystallographic data for binary oxides with the rock salt structure $^{2}$

\begin{tabular}{|c|c|c|c|c|c|}
\hline $\begin{array}{l}\text { Chemical } \\
\text { Formula }\end{array}$ & $\begin{array}{l}\text { Formula } \\
\text { Weight }\end{array}$ & $a(\AA)$ & $\begin{array}{l}\text { Unit Cell } \\
\text { Volume }\left(\AA^{3}\right)\end{array}$ & $\begin{array}{l}\text { Density } \\
(\text { calc, } \\
\left.\mathrm{g} / \mathrm{cm}^{3}\right)\end{array}$ & $\begin{array}{l}\text { Ionic radius }(6- \\
\text { coord. HS, } \\
\text { pm) }\end{array}$ \\
\hline $\mathrm{TiO}^{*}$ & 63.90 & 4.204 & 74.23 & 5.711 & 100 \\
\hline $\mathrm{V}_{0.9} \mathrm{O}^{* 20}$ & 61.85 & 4.1121 & 69.53 & 5.91 & 93 \\
\hline $\mathrm{MnO}$ & 70.937 & 4.446 & 87.88 & 5.365 & 97 \\
\hline $\mathrm{FeO}$ & 71.848 & 4.3108 & 80.11 & 5.956 & 92 \\
\hline rs-CoO & 74.93 & 4.2612 & 77.37 & 6.433 & 88.5 \\
\hline $\mathrm{NiO}$ & 74.703 & 4.1769 & 72.43 & 6.850 & 83 \\
\hline "rs-ZnO"21 & 81.39 & 4.272 & 77.96 & 6.93 & 88 \\
\hline "rs-ZnO"22 & 81.39 & 4.203 & 74.25 & 7.273 & 88 \\
\hline $\mathrm{MgO}$ & 40.312 & 4.211 & 74.67 & 3.585 & 86 \\
\hline $\mathrm{CaO}$ & 56.079 & 4.1684 & 111.32 & 3.346 & 114 \\
\hline $\mathrm{CdO}$ & 128.41 & 4.6953 & 103.51 & 8.24 & 109 \\
\hline $\mathrm{PdO}$ & 122.40 & 5.65 & 180.36 & 4.508 & 100 \\
\hline $\mathrm{PtO}$ & 211.09 & 5.15 & 136.59 & 10.265 & 94 \\
\hline \multicolumn{6}{|c|}{$\begin{array}{l}*=\text { Both } \mathrm{M} \text { and } \mathrm{O} \text { vacancies unavoidable; are not stoichiometric oxides } \\
\text { "rs-ZnO" parameters are generated from samples that were under high pressures, } \\
\text { grown epitaxially or derived computationally; no standard temperature and } \\
\text { pressure values exist }\end{array}$} \\
\hline
\end{tabular}

Zinc oxide, $\mathrm{ZnO}$, proves to be a special case. It is found in nature as the mineral zincite, which has the wurtzite crystal structure. Both zinc blende and rock salt polymorphs exist, with the zinc blende form being the only one that has been found to be stable at standard temperature and pressure. $\mathrm{W}-\mathrm{ZnO}$ is a semiconductor with a $3.4 \mathrm{eV}$ band gap that has shown many different properties, such as photoluminescence, photoconduction, piezoelectricity, and has been investigated for use many different devices in both the bulk and at the nanoscale, such as: nanowire lasers, field effect transistors, chemical sensing, ${ }^{23-34}$ Cobaltous oxide $(\mathrm{CoO})$ is the only other naturally occurring transition metal oxide that displays a similar structure transition, being most stable in the rock salt phase but 
also existing in wurtzite and zinc blende forms. Some crystallographic data for both indexed and hypothetical wurtzite oxides are shown in Table 1.2.

Table 1.2. Crystallographic data for binary oxides with the wurtzite structure

\begin{tabular}{|l|l|l|l|l|l|l|}
\hline $\begin{array}{l}\text { Chemical } \\
\text { Formula }\end{array}$ & $\begin{array}{l}\text { Formula } \\
\text { Weight }\end{array}$ & $a(\AA)$ & $c(\AA)$ & $\begin{array}{l}\text { Unit } \\
\text { Cell } \\
\text { Volume } \\
\left(\AA^{3}\right)\end{array}$ & $\begin{array}{l}\text { Density } \\
\left(\mathrm{g} / \mathrm{cm}^{3}\right)\end{array}$ & $\begin{array}{l}\text { Ionic radius }(4- \\
\text { coord., } \mathrm{pm})^{16,19}\end{array}$ \\
\hline $\mathrm{BeO}^{2}$ & 25.012 & 2.6984 & 4.277 & 26.970 & 3.080 & 41 \\
\hline $\mathrm{MgO}^{35}(\mathrm{H})$ & 40.312 & 3.169 & 5.175 & & & 71 \\
\hline $\mathrm{MnO}^{36}(\mathrm{H})$ & 70.937 & 3.284 & 5.178 & 48.36 & 4.871 & 80 \\
\hline $\mathrm{w}^{-\mathrm{CoO}^{37}}$ & 74.93 & 3.2440 & 5.2030 & 46.76 & 5.322 & 72 \\
\hline $\mathrm{w}-\mathrm{ZnO}^{2}$ & 81.38 & 3.250 & 5.207 & 47.62 & 5.675 & 74 \\
\hline $\mathrm{CdO}(\mathrm{H})$ & 128.41 & 3.660 & 5.856 & & 92 \\
\hline
\end{tabular}

\subsection{Synthetic Methods at the Nanoscale}

Just as there are a large number of metal oxides that exist, both singlemetal and mixed-metal, there are also a number of methods exist for making them at the nanoscale. Solution-phase synthetic methods with "bottom-up" and "soft chemical" processes the most common type, such as the sol, sol-gel, micelle, hydrothermal, and solvothermal methods - with the distinctions between each term not necessarily being well defined. Generally, each of these involves a molecular metal precursor reacting to begin polymerization and formation of metal $\mu$-oxo (M-O-M) bridges that create a "sol," or colloidal suspension, that serves as an intermediate to the solid crystalline oxide material. The primary differences arise in the precursors used and the process that initiates M-O-M bridge formation, which can be dependent on the precursor. Inorganic metal salts and metal alkoxides are prone to hydrolysis, which lend them to sol, sol-gel, 
micelle and hydrothermal routes to metal oxides. These processes utilize $\mathrm{pH}$, ionic strength and, in the case of hydrothermal reactions, high temperatures and pressures to control the growth of crystals and ensure particle uniformity and the constraint of particle size. Metal carboxylates and alkoxides can be used in the nonhydrolytic sol-gel and the solvothermal routes, which utilize hydroxylation and aprotic condensation reactions in the presence of high-boiling coordinating solvents to form oxo bridges and control the growth of crystal faces. ${ }^{5,7,8,15,38-41}$

Table 1.3 contains some example metal oxide nanomaterials that have been synthesized using some of the various methods mentioned above. In this chart, the methods listed are: hydrolytic sol-gel (HSG), nonhydrolytic sol-gel (NSG), hydrothermal (HT) and solvothermal (ST). Surfactants are: trioctylphosphine oxide (TOPO), oleylamine (Oam), tri-N-octylamine (TOA), oleic acid $(\mathrm{OA})$ and sodium acetate $(\mathrm{NaOAc})$. Solvents are 1-octadecene (ODE) and oleylamine (OE). 
Table 1.3. Single-metal oxides synthesized at the nanoscale ${ }^{8}$

\begin{tabular}{|c|c|c|c|c|}
\hline Material & Precursor & Surfactant & Solvent & Method \\
\hline $\mathrm{TiO}_{2}$ & 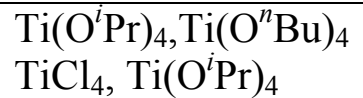 & $\begin{array}{l}\mathrm{Me}_{4} \mathrm{NOH} \\
\mathrm{TOPO}\end{array}$ & $\begin{array}{l}\mathrm{H}_{2} \mathrm{O},{ }^{i} \mathrm{PrOH} \\
\text { heptadecane }\end{array}$ & $\begin{array}{l}\mathrm{HSG}^{42,43} \\
\mathrm{NSG}^{44}\end{array}$ \\
\hline $\mathrm{ZrO}_{2}$ & $\mathrm{Zr}\left(\mathrm{O}^{1} \mathrm{Pr}\right)_{4}, \mathrm{ZrCl}_{4}$ & TOPO & & $\mathrm{NSG}^{45}$ \\
\hline $\mathrm{Cu}_{2} \mathrm{O}$ & $\begin{array}{l}\mathrm{Cu}(\mathrm{acac})_{2} \\
\mathrm{Cu}(\mathrm{OAc})_{2}\end{array}$ & $\begin{array}{l}\text { OAm } \\
\text { TOA, OA }\end{array}$ & & $\begin{array}{l}\text { ST } \\
\text { ST }\end{array}$ \\
\hline $\mathrm{MnO}$ & $\begin{array}{l}\mathrm{Mn}(\mathrm{HCOO})_{2} \\
\mathrm{Mn}(\mathrm{OAc})_{2} \\
\mathrm{Mn}(\mathrm{acac})_{2} \\
\mathrm{Mn}_{2}(\mathrm{CO})_{10}\end{array}$ & $\begin{array}{l}\text { TOA, OA } \\
\text { TOA, OA } \\
\text { OAm, } \mathrm{H}_{2} \mathrm{O} \\
\text { OAm, TOP }\end{array}$ & & $\begin{array}{l}\mathrm{ST}^{46,47} \\
\mathrm{ST} \\
\mathrm{ST} \\
\mathrm{ST}\end{array}$ \\
\hline $\mathrm{Mn}_{3} \mathrm{O}_{4}$ & $\mathrm{Mn}(\mathrm{HCOO})_{2}$ & OAm & & $\mathrm{ST}$ \\
\hline$\alpha-\mathrm{Fe}_{2} \mathrm{O}_{3}$ & $\mathrm{FeCl}_{3} \cdot 6 \mathrm{H}_{2} \mathrm{O}$ & $\mathrm{NaCl}, \mathrm{NaOAc}$ & $\mathrm{H}_{2} \mathrm{O}$ & $\mathrm{HT}^{48}$ \\
\hline$\gamma-\mathrm{Fe}_{2} \mathrm{O}_{3}$ & $\begin{array}{l}\mathrm{FeCl}_{3} \cdot 6 \mathrm{H}_{2} \mathrm{O} \\
\mathrm{Fe}(\mathrm{CO})_{5}\end{array}$ & $\begin{array}{l}\mathrm{OA} \\
\mathrm{OA}\end{array}$ & $\begin{array}{l}\text { ODE } \\
\text { OE }\end{array}$ & $\begin{array}{l}\mathrm{ST}^{49} \\
\mathrm{ST}^{49}\end{array}$ \\
\hline $\mathrm{Co}_{3} \mathrm{O}_{4}$ & $\begin{array}{l}\mathrm{Co}\left(\mathrm{NO}_{3}\right)_{2} \cdot \\
6 \mathrm{H}_{2} \mathrm{O}, \mathrm{C}_{6} \mathrm{H}_{13} \mathrm{OH}\end{array}$ & - & octanol & $\mathrm{ST}$ \\
\hline
\end{tabular}

\subsection{Thesis Topic: Cobalt-Manganese Oxides}

The Whitmire lab has explored the synthesis and applications of anisotropic $\mathrm{MnO}, \mathrm{FeO}$ and mixed $\mathrm{Fe}_{1-\mathrm{x}} \mathrm{Mn}_{\mathrm{x}} \mathrm{O}$ nanoparticles. ${ }^{47}$ Based on our discoveries and considering the possible applications of other mixed oxides, we have turned to the manganese-cobalt oxide system. These materials in particular have been examined for their uses in catalysts, ${ }^{50,51}$ lithium-ion battery electrodes, ${ }^{52-56}$ supercapacitors ${ }^{57-60}$ and for their interesting magnetic properties. Of primary interest for lithium-ion batteries are the spinel-type oxides, i.e. $\mathrm{Mn}_{3} \mathrm{O}_{4}$, $\mathrm{LiMnO}_{2}, \mathrm{Co}_{3} \mathrm{O}_{4}, \mathrm{LiCoO}_{2}$ and solid solutions thereof. ${ }^{61-66}$ At the nanoscale the rock salt phases of $\mathrm{MnO}$ and $\mathrm{CoO}$ (cubic crystal lattice, space group $F m \overline{3} m$ ) are much more stable than in the bulk minerals and may be synthesized very easily. We have shown that they may be partially oxidized to the spinel forms without loss of nanoparticle morphology. ${ }^{67,68}$ 
Manganese and cobalt have also been probed as dopants for $\mathrm{ZnO}$ due to the doped material's potential for high-temperature ferromagnetism and its semiconducting properties. ${ }^{69}$ These unique and interesting properties were tied to the wurtzite structure (hexagonal crystal lattice, space group $P 6_{3} m c$ ). As discussed, $\mathrm{ZnO}$ is not alone in having the wurtzite structure among the binary oxides, however. Wurtzite-type $\mathrm{CoO}(\mathrm{w}-\mathrm{CoO})$ and zinc blende-type $\mathrm{CoO}$ (zb$\mathrm{CoO}$ ) were first reported in $1962^{70}$ and have since been studied experimentally and theoretically for similar applications. ${ }^{37,71-77}$ The two forms were always found together when originally synthesized (by thermal decomposition of cobalt (II) acetate tetrahydrate) but more recent reports have shown that solution synthetic processes will preferentially select for $\mathrm{w}-\mathrm{CoO}$, especially at the nanoscale and in thin films. This has led to samples being of much higher purity than those synthesized using bulk methods. Additionally, theoretical studies have been done on a hypothetical wurtzite-type $\mathrm{MnO}$ to determine the effect of $\mathrm{Mn}^{2+}$ substitution on the magnetic and electronic properties of the wurtzite structure. ${ }^{36}$ There have been only a few of reports of rock salt-type mixed cobalt-manganese oxide in the literature, and those materials were synthesized via electrodeposition. ${ }^{78-80}$

We report herein the synthesis of rock salt-type $\mathrm{Co}_{1-\mathrm{x}} \mathrm{Mn}_{\mathrm{x}} \mathrm{O}$ and the metastable phase wurtzite-type $\mathrm{Co}_{1-\mathrm{x}} \mathrm{Mn}_{\mathrm{x}} \mathrm{O}\left(\mathrm{rs}^{-} \mathrm{Co}_{1-\mathrm{x}} \mathrm{Mn}_{\mathrm{x}} \mathrm{O}\right.$ and $\left.\mathrm{w}-\mathrm{Co}_{1-\mathrm{x}} \mathrm{Mn} \mathrm{n}_{\mathrm{x}} \mathrm{O}\right)$ using a mixture of tri- $N$-octylamine and oleic acid. By controlling reaction variables closely, a wide variety of nanoparticle sizes, morphologies and stoichiometries can be formed. 


\section{Chapter 2. Experimental}

\subsection{Materials}

Tri-n-octylamine (TOA; 98\%), oleic acid (OA; 90\%), manganese (II) formate hydrate $\left(\mathrm{Mn}(\mathrm{HCOO})_{2} \cdot \mathrm{xH}_{2} \mathrm{O}\right)$ and cobalt (II) acetate tetrahydrate $\left(\mathrm{Co}(\mathrm{OAc})_{2} \cdot 4 \mathrm{H}_{2} \mathrm{O}\right)$ were purchased from Sigma Aldrich Chemical Company. TOA and $\mathrm{Mn}(\mathrm{HCOO})_{2} \cdot \mathrm{xH}_{2} \mathrm{O}$ were dried separately under vacuum at $110^{\circ} \mathrm{C}$ for four hours before use and stored under argon. OA was dried under vacuum at $110^{\circ} \mathrm{C}$ for four hours then distilled under vacuum and stored under argon in the dark. $\mathrm{Co}(\mathrm{OAc})_{2} \cdot 4 \mathrm{H}_{2} \mathrm{O}$ was dried immediately before use under vacuum for two hours at $160^{\circ} \mathrm{C}$, accompanied by a color change from pink to purple. The temperature needed to completely dehydrate $\mathrm{Co}(\mathrm{OAc})_{2} \cdot 4 \mathrm{H}_{2} \mathrm{O}$ has been reported to be $150^{\circ} \mathrm{C}$. HPLRS-grade $\mathrm{H}_{2} \mathrm{O}$ was purchased from EMD Chemicals, Inc.; it was stored in a Schlenk flask and degassed by bubbling with argon for 15 minutes with stirring. After degassing and in between uses the water was stored under argon. Surfactants (TOA and OA) were added to the reaction flask using disposable plastic syringes; water was added using a VWR 20-1000 $\mu \mathrm{L}$ micropippetor. 


\subsection{Procedure for Synthesis of $\mathrm{Co}_{1-\mathrm{x}} \mathrm{Mn}_{\mathrm{x}} \mathrm{O}$ nanoparticles}

All reactions were carried out under an inert argon atmosphere using standard Schlenk techniques. In a typical reaction, $\mathrm{Co}(\mathrm{OAc})_{2} \cdot 4 \mathrm{H}_{2} \mathrm{O}$ was initially dried in a $100 \mathrm{~mL}$ 3-neck round bottom flask with attached reflux condenser and outlet to a bubbler (see Figure $\mathrm{x}$ below). The anhydrous $\mathrm{Mn}(\mathrm{HCOO})_{2}, \mathrm{TOA}$ and $\mathrm{OA}$ were then added to the flask along with a magnetic stir bar. The solution temperature was measured by insertion of a steel-jacketed electronic thermocouple (Fisher Scientific Traceable Thermometer) through a septum on one neck of the flask. The septum/thermocouple interface was wrapped in several layers of parafilm to prevent gas leaking into or out of the system. The solution was then rapidly heated $\left(>20^{\circ} \mathrm{C} / \mathrm{min}\right)$ with a heating mantle until decomposition occurred, which was marked by the solution changing color from its original purple. Consideration was made for the quality and durability of the heating mantle used, as some nanoparticles would not be formed if the heating mantle could not achieve the decomposition temperature, sometimes in excess of $380^{\circ} \mathrm{C}$, for the required time. The solution temperature was held within $10^{\circ} \mathrm{C}$ of the decomposition point until nanoparticle growth was halted by removal of the heating mantle, with the solution color further changing based on the size, composition and crystal lattice of the particles being formed. Typically, wurtzitetype nanoparticles of $\mathrm{Co}_{1-\mathrm{x}} \mathrm{Mn}_{\mathrm{x}} \mathrm{O}$ resulted in a dark green solution that did not vary in color during growth. This color has been reported for pure w-CoO ${ }^{37,70,71}$ and some Mn-doped w-ZnO materials. ${ }^{1}$ Different starting ratios of Co and $\mathrm{Mn}$ 
precursors led to several different colors of rock salt-type $\mathrm{Co}_{1-\mathrm{x}} \mathrm{Mn}_{\mathrm{x}} \mathrm{O}$ nanoparticles - majority cobalt samples were yellow, majority manganese samples were pale green and balanced samples were green-gray. After two minutes of cooldown, ethanol was added to ensure that growth was fully halted. Samples were recovered by centrifugation then washed twice in hexanes. If the hexane supernatant was not clear and colorless, an equal volume of ethanol was added to it and it was centrifuged separately to precipitate nanoparticles.

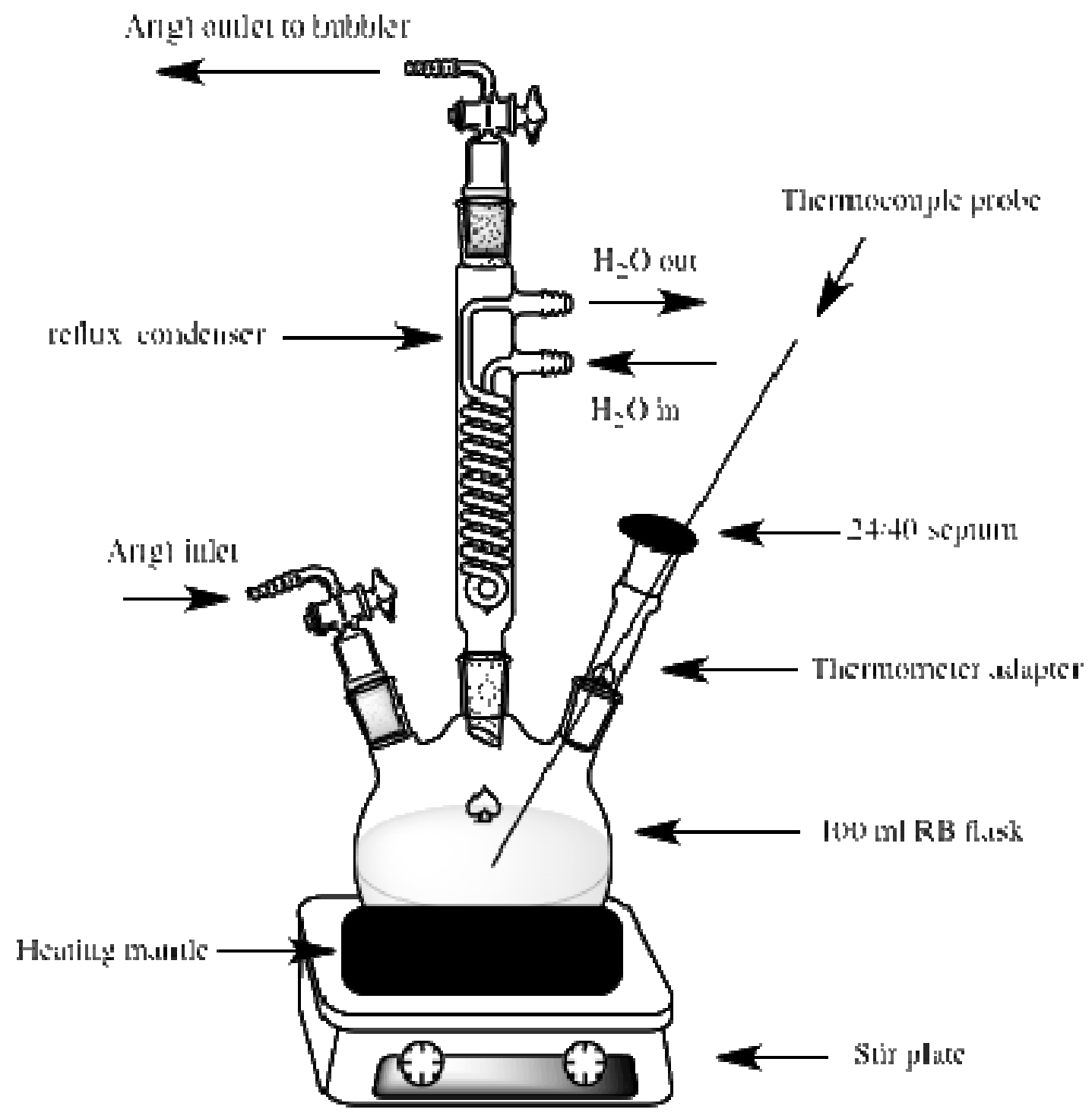

Figure 2.1. Reaction setup for nanoparticle synthesis 


\subsection{Analysis of Nanoparticles}

\subsubsection{X-ray powder diffraction (XRD)}

X-ray powder diffraction (XRD) experiments were performed using a Rigaku D/Max Ultima II instrument at $40 \mathrm{kV}$ and $40 \mathrm{~mA}$ with unfiltered $\mathrm{Cu} \mathrm{K} \alpha$ radiation $(\lambda=1.5406 \AA)$. Typical spectral width (resolution) was 0.02 degrees, with scan times ranging from 8 degrees/minutes to 0.2 degrees/minute based on the amount of sample and its crystallinity. Samples were prepared by drying the centrifugation product in air overnight, then grinding the powder in a mortar and pestle. Samples were deposited on a glass slide for analysis. The resulting XRD patterns were analyzed using MDI JADE 9 and its functions, including peak finding/fitting, whole-pattern fitting and unit cell refinement.

\subsubsection{Transmission electron microscope (TEM)}

Transmission electron microscope (TEM) analysis was performed at Rice using JEOL 2010 and 1230 electron microscopes operating at $100 \mathrm{kV}$ and $80 \mathrm{kV}$, respectively. Dark field transmission electron microscopy, high-resolution transmission electron microscope (HR-TEM) and selected area electron diffraction (SAED) experiments were performed by Dr. Irene Rusakova at the University of Houston on a JEOL operating at $200 \mathrm{kV}$. Samples were dispersed in THF and drop-cast onto 400 mesh copper-supported carbon film grids for lowresolution bright field TEM imaging. 


\subsubsection{Inductively Coupled Plasma Optical Emission Spectroscopy (ICP-OES)}

Inductively Coupled Plasma Optical Emission Spectroscopy (ICP-OES) analysis was done on a Perkin Elmer Inductively Coupled Plasma Optical Emission Spectrometer. Standard solutions of manganese, cobalt, iron and nickel were acquired from Sigma Aldrich Chemical Company. Iron and nickel were included to determine if leeching of metal ions from the thermocouple probe into nanoparticles occurred; in no cases was this discovered. ICP samples were prepared by digesting the dried nanoparticle powder in $70 \%$ nitric acid, then diluting to make $5 \%$ by weight nitric acid solutions. 


\section{Chapter 3. Results}

\subsection{Crystal Lattice Determination}

Initial reactions used the following conditions: $6 \mathrm{~mL}$ (13.7 mmol) TOA, 2 $\mathrm{mL}(6.3 \mathrm{mmol}) \mathrm{OA}, 249 \mathrm{mg}(1 \mathrm{mmol}) \mathrm{Co}(\mathrm{OAc})_{2} \cdot 4 \mathrm{H}_{2} \mathrm{O}, 145 \mathrm{mg}(1 \mathrm{mmol})$ $\mathrm{Mn}(\mathrm{HCOO})_{2}$ and 2 minutes of growth time after nanoparticle formation. The polycrystalline XRD pattern for the product of this reaction, shown in Figure 2.2, corresponded to a face-centered cubic lattice with space group $\mathrm{Fm} \overline{3} \mathrm{~m}$ and lattice parameter $a=4.36 \AA$.

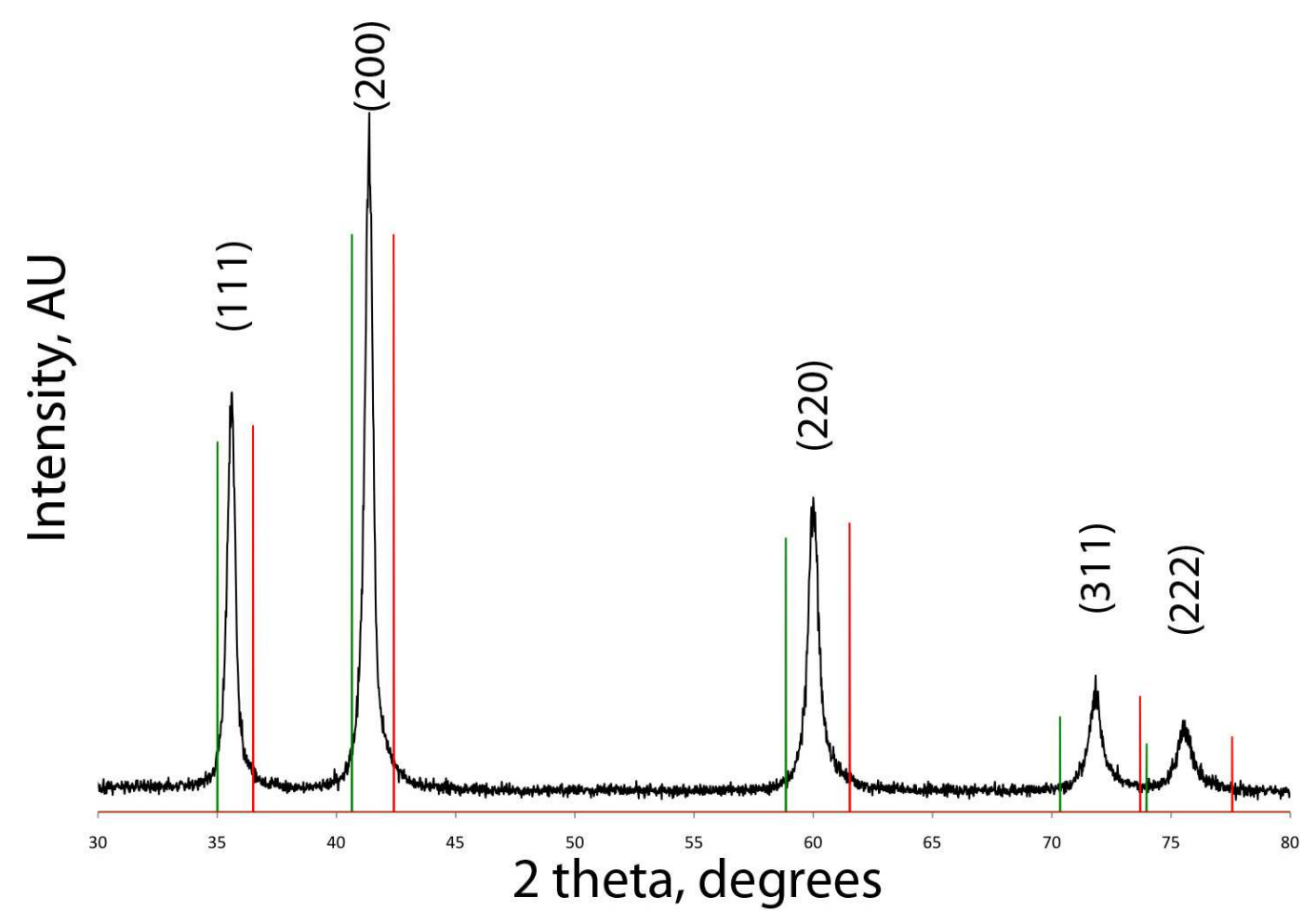

Figure 3.1. Example XRD pattern for polycrystalline rs- $\mathrm{Co}_{1-\mathrm{x}} \mathrm{Mn}{ }_{\mathrm{x}} \mathrm{O}$ nanoparticles. Lattice indices marked are marked above each peak. Reference peak positions for $\mathrm{MnO}(a=4.44 \AA)$ and rs-CoO $(a=4.26 \AA)$ are shown in green and red respectively. 

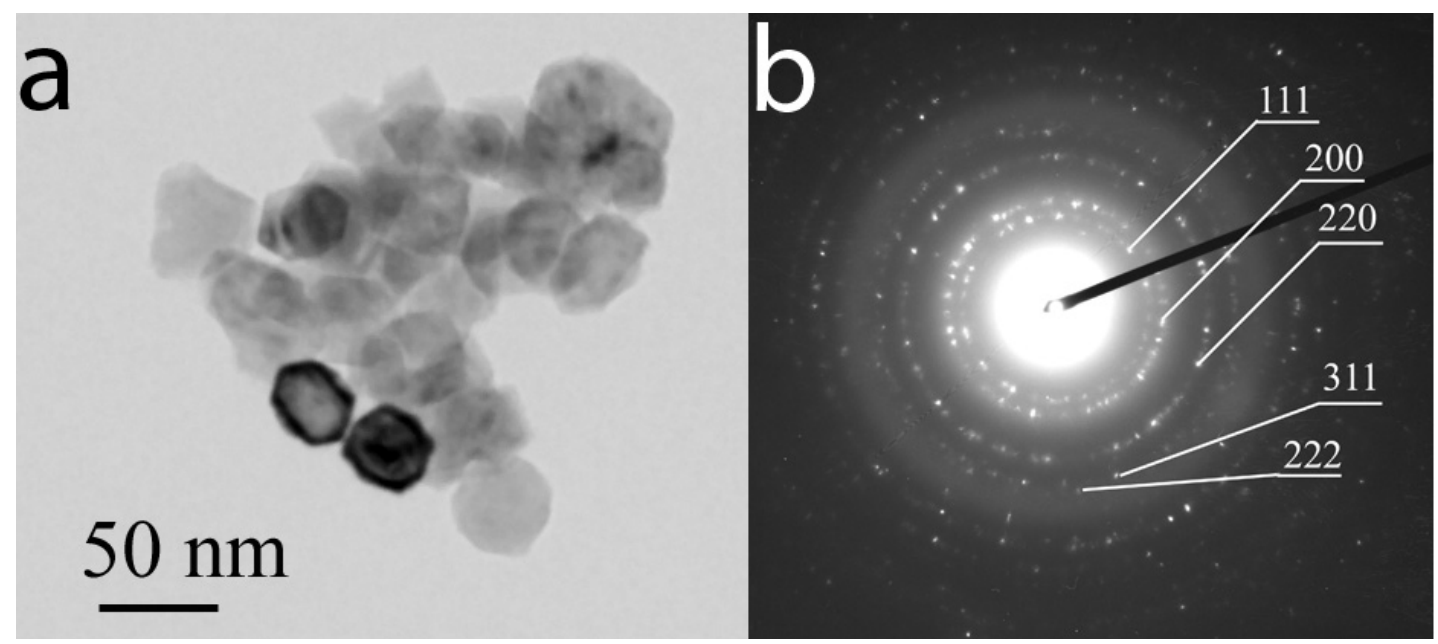

Figure 3.2. (a) $\mathrm{Co}_{1-\mathrm{x}} \mathrm{Mn}_{\mathrm{x}} \mathrm{O}$ nanoparticles and (b) the indexed polycrystalline SAED pattern from the sample shown in Figure 3.1. Both images were taken by Dr. Irene Rusakova at the University of Houston.

\subsection{Issues with reproducibility of synthesis}

Further attempts to explore the $\mathrm{Co}_{1-\mathrm{x}} \mathrm{Mn}_{\mathrm{x}} \mathrm{O}$ system were met with limited success. Several issues arose that resulted in the failure of reactions to produce nanoparticles. Examples included: (1) the reaction solution turning clear and colorless, with a shiny gray material precipitating; (2) formation of more than one oxide phase; and (3) inconsistent heating by the heating mantle. The issue of heating was addressed by ensuring the mantle used was fresh and did not have fluctuations in its output, especially at temperatures above $330^{\circ} \mathrm{C}$, the typical nanoparticle formation temperature range. The gray precipitate was identified by $\mathrm{XRD}$ as a mixture of metallic cobalt phases (see Figure 2.4) and was found to be present on some occasions when the reaction appeared to have given the desired oxide nanoparticles (Figure 2.5). The presence of multiple oxide phases was indicated by the presence of severe peak broadening or overlapping peaks, as shown in Figure 2.6. 


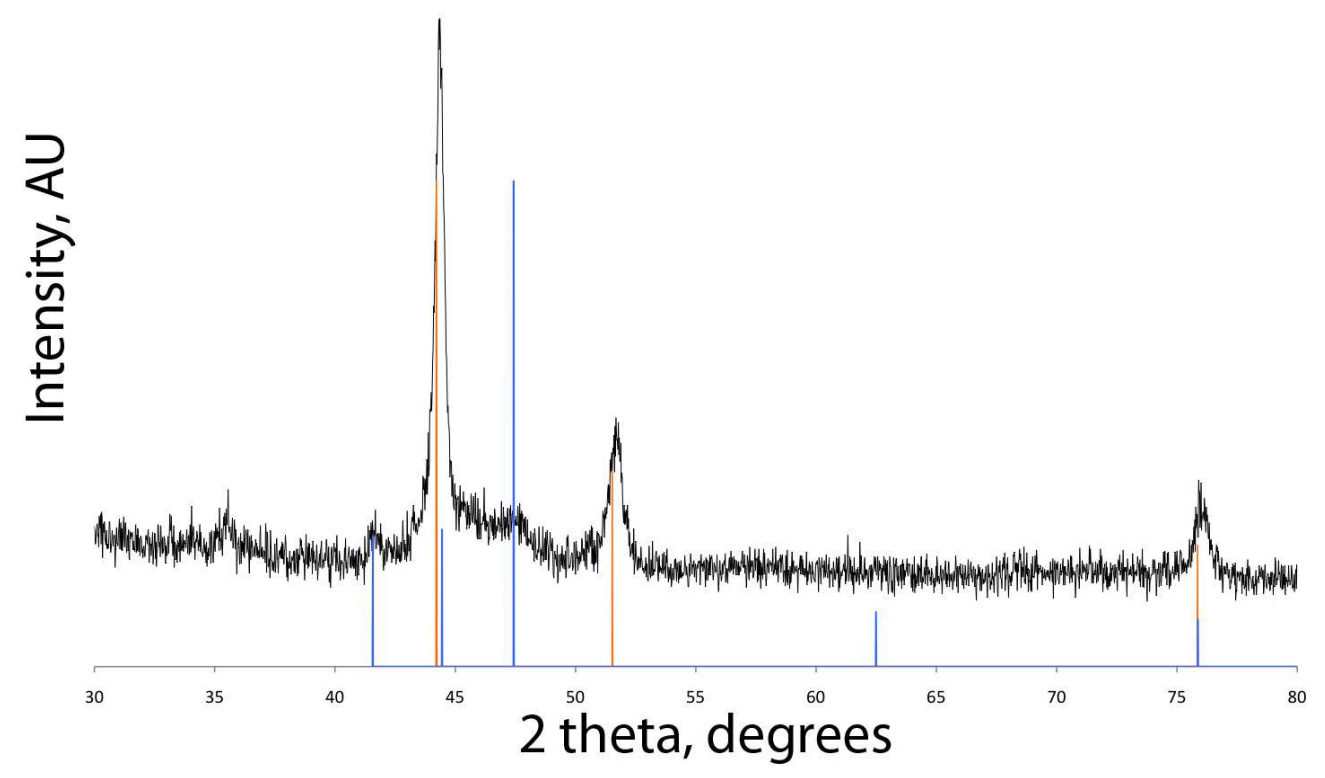

Figure 3.3. XRD pattern of metallic cobalt resulting from failed nanoparticle synthesis. Cubic close pack and hexagonal close pack lattice cobalt phases (PDF\#00-015-0806 and PDF\#04-002-1029) are shown as reference in orange and

blue respectively.

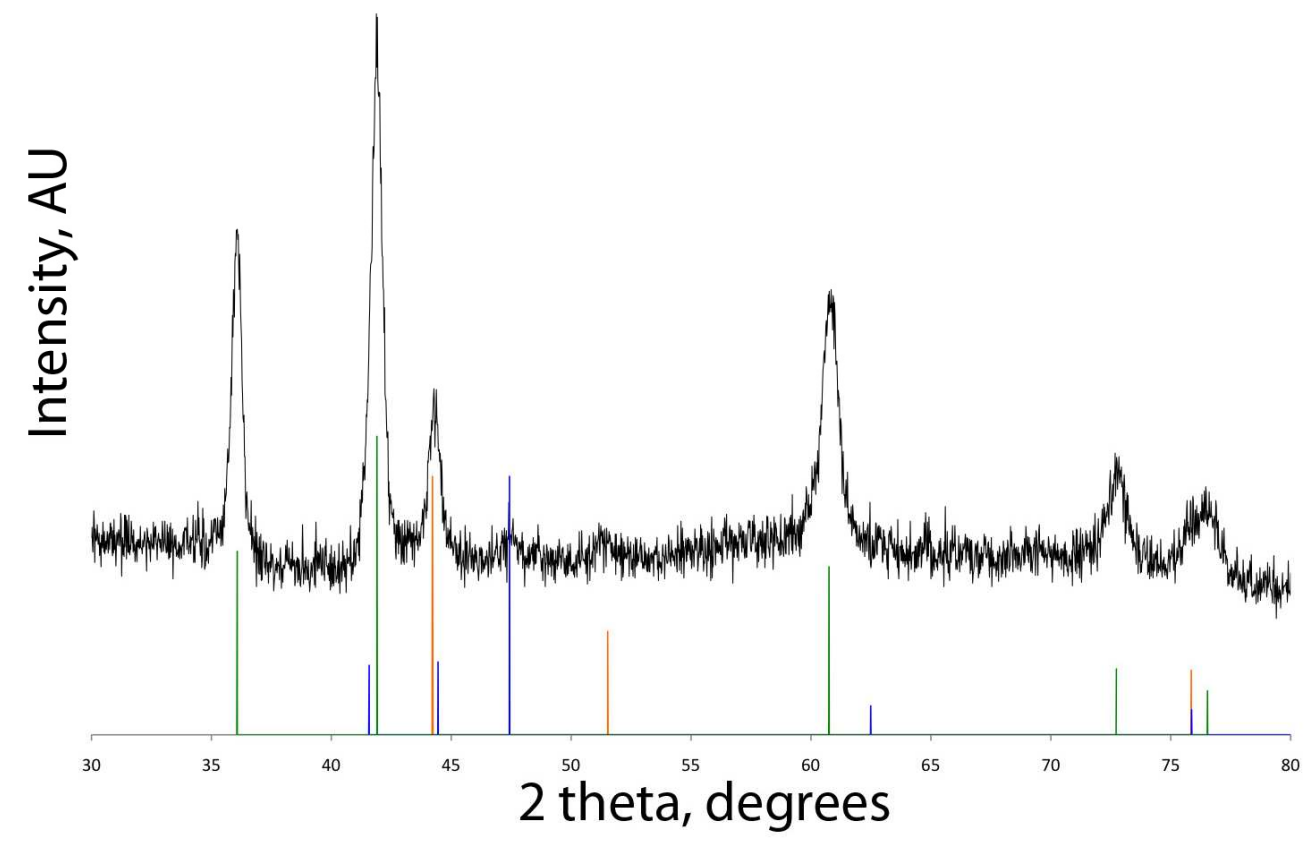

Figure 3.4. XRD pattern of mixture of $\mathrm{rs}^{-\mathrm{Co}_{1-\mathrm{x}}} \mathrm{Mn}_{\mathrm{x}} \mathrm{O}$ and metallic cobalt cubic and hexagonal phases). Oxide peaks are marked in green; ccp and hcp metallic cobalt peaks are orange and blue respectively. 


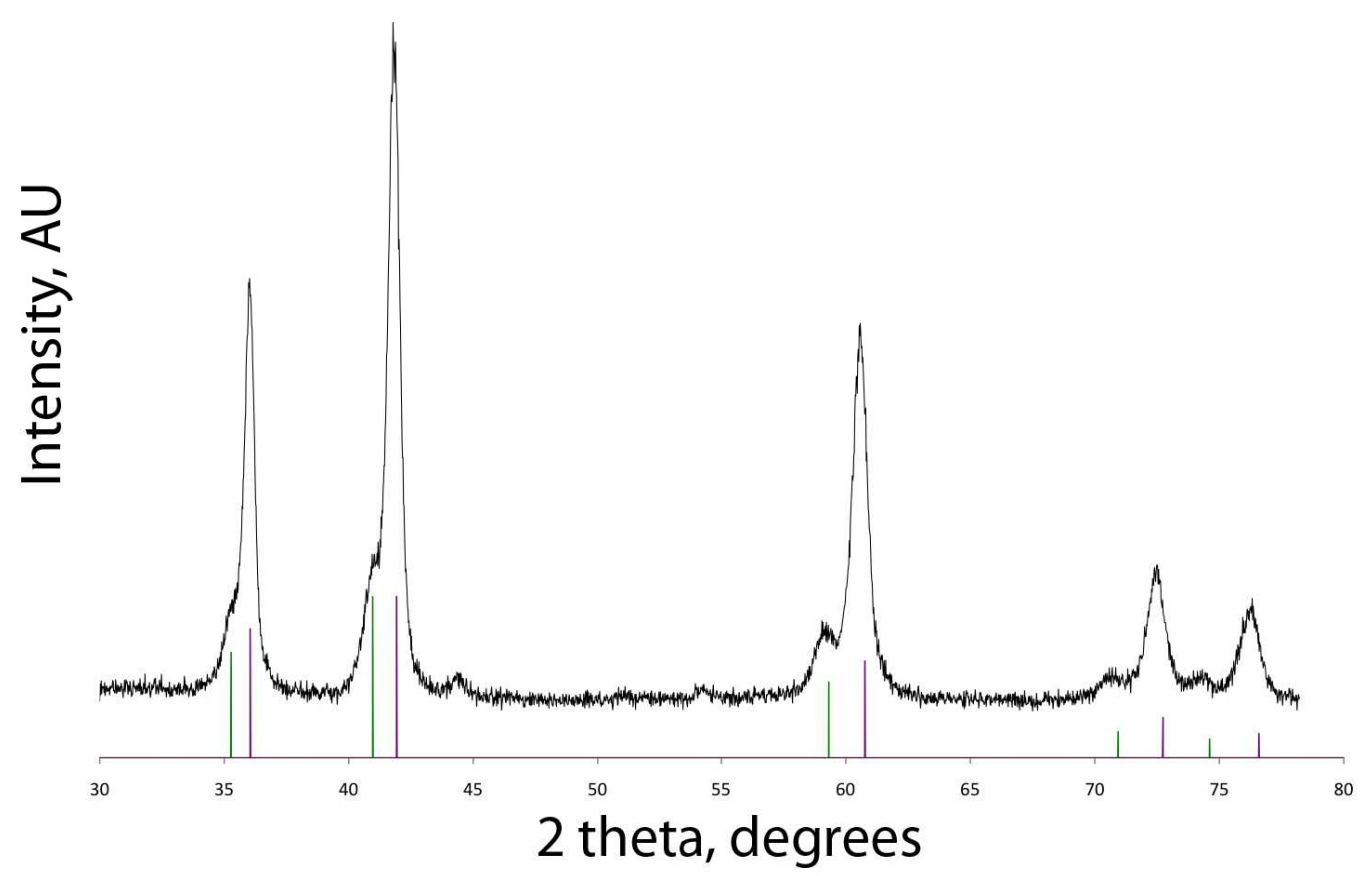

Figure 3.5. XRD pattern of a mixture of multiple rock salt-structure oxide phases. Reference phases with lattice constant $a=4.403 \AA$ and $4.326 \AA$ are shown in green and purple respectively.

The problem of reproducing nanoparticle syntheses was determined to be linked to the quality of OA used in the reaction. Initially, the TOA and OA used was dried under vacuum at $110^{\circ} \mathrm{C}$ for 4 hours. Both of these sol-vents were clear and colorless when first received. After some time (at least one month) however, the OA gained a yellow tint. Attempts to re-dry the OA failed to remove the yellow coloration. Further inspection of the literature concerning OA revealed a quality of OA that had been neglected in the original experiments: upon exposure to oxygen, light or a combination of the two, OA reacts at the central alkene functionality. This may lead to the formation of peroxides and secondary alcohols in the case of oxygen and a bis-OA dimer in the case of light; each being signaled by a color change to yellow and then on to brown. ${ }^{81-85}$ 
The separation of pristine OA from its degradation byproducts was achieved by careful vacuum distillation of the mixture at $10^{-2}$ torr. First, the OA was placed into a $250 \mathrm{~mL}$ Schlenk flask with a magnetic stir bar and dried for $2 \mathrm{~h}$ at $110^{\circ} \mathrm{C}$. The setup for the distillation is shown in Figure 3.6. Due to OA's extremely high boiling point $\left(360^{\circ} \mathrm{C}\right.$ at 760 torr, $\sim 270^{\circ} \mathrm{C}$ at $10^{-2}$ torr) and low volatility all glassware except for the receiving flask was wrapped tightly with aluminum foil to ensure continuous mass transfer. The rate of transfer was constrained to approximately $1 \mathrm{drop} / \mathrm{sec}$; the entire process of distilling $150 \mathrm{~mL}$ OA took, on average, four hours. To prevent the OA from becoming contaminated again, the flask of OA was stored in a cabinet in the dark, under argon gas, only being exposed to light for at most five minutes per day. After taking these precautions, nanoparticle synthesis reactions saw a significant reduction in the rate of reaction failure due to the production of metallic cobalt. A similar separation was performed with TOA, but no deter-minable effect on reaction results was found. 


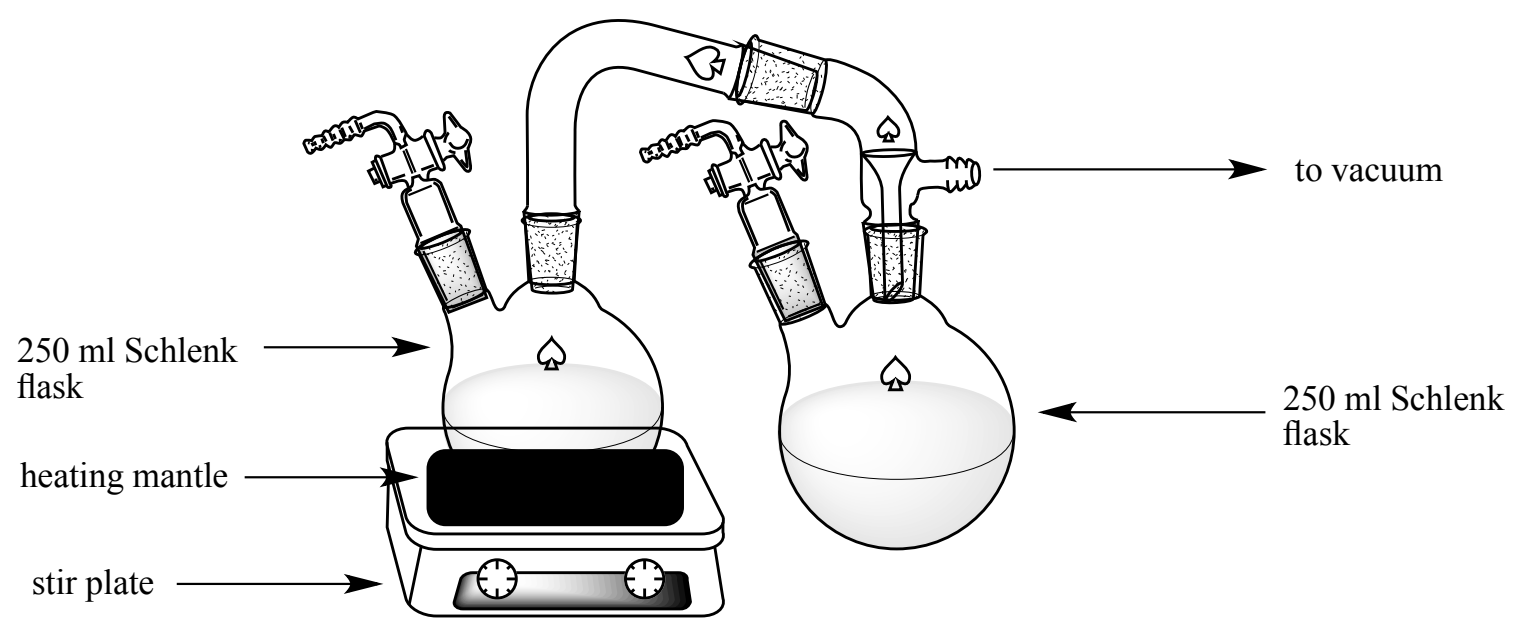

Figure 3.6. Glassware setup for distillation of OA. Not shown: aluminum foil wrapping.

These observations indicated that OA played a significant role in ensuring that nanoparticle syntheses gave the desired oxide product(s). Additionally, it became evident that the reproducibility of reaction products was a concern. To guarantee the reproducibility of results, each reaction condition was performed at least twice. Reaction parameters explored were: the ratio of TOA to OA in the reaction solution, the ratio of $\mathrm{Co}(\mathrm{OAc})_{2}$ to $\mathrm{Mn}(\mathrm{HCOO})_{2}$, the presence of water, the ratio of molecular precursors to $\mathrm{OA}$ and growth time (within $10^{\circ} \mathrm{C}$ of the solution color change temperature). As noted above, the control reaction contained $6 \mathrm{~mL}$ TOA, $2 \mathrm{~mL}$ OA, $1 \mathrm{mmol}$ each of $\mathrm{Co}(\mathrm{OAc})_{2}$ and $\mathrm{Mn}(\mathrm{HCOO})_{2}$, no water and allowed two minutes of growth after nanoparticle formation. All potential reaction variables were held constant between reactions while changing the variable of interest. 


\subsection{Effect of altering Co:Mn precursor ratio}

\subsubsection{Crystal lattice}

The first variable investigated was the starting molar ratio of cobalt and manganese precursors. These experiments were performed with a constant total molar amount of metal precursor equal to $2 \mathrm{mmol}$. Reactions were done in $6 \mathrm{~mL}$ TOA, $2 \mathrm{~mL} \mathrm{OA}$, with no water present and 2 minutes of nanoparticle growth time after the solution color change. Seven different reaction conditions were explored: 1:9 Co:Mn, 1:5 Co:Mn, 1:2 Co:Mn, 1:1 Co:Mn, 2:1 Co:Mn, 5:1 Co:Mn and 9:1 Co:Mn. Example XRD patterns of four samples with a variety of cobaltto-manganese content ratios are shown in Figure 3.7. All of these reactions gave products that had rock salt-type face-centered cubic crystal lattices (rs$\left.\mathrm{Co}_{1-\mathrm{x}} \mathrm{Mn}_{\mathrm{x}} \mathrm{O}\right)$.

Using JADE 9, XRD peaks and patterns of cubic-lattice products were fitted to Gaussian curves and used to refine unit cell data. Both peak positions and unit cell volumes were plotted against the Co fraction of the oxide, taken from ICP-OES. In the cases where metallic cobalt was present in the XRD pattern, whole-pattern fitting (WPF) refinement was utilized to determine the amount of cobalt in the oxide phase and correct the elemental analysis. The (220) peak was chosen as the indicator for the peak position graph due to its moderateto-high intensity and the fact that it shifts position the most based on changing unit cell parameters. Attempts to determine lattice constants for hexagonal lattice products were frustrated by low crystallinity and small crystallite sizes, which caused most diffraction patterns to have poor signal to noise ratios and very broad 
peaks. An example peak fitting report is shown in Table 3.1 with the unit cell calculated from the sample shown in Figure 3.2. Note that the while the peak positions are proportional to the relative amounts of cobalt and manganese in the sample, there is some variance between samples. This can be seen in Figure 3.8, which shows data correlating the (220) peak position as found in JADE and sample cobalt content as derived from ICP-OES measurements. As mentioned above, unit cell parameters were calculated in JADE via peak data. Unit cell volumes determined in this manner were compared to cobalt content, as shown in Table 3.2 to Table 3.5 and Figure 3.9. Additionally, while the ratio of cobalt and manganese molecular precursors does significantly influence the ratio of cobalt and manganese in the final oxide product, the starting and final ratios are not necessarily equal.

Table 3.1 Example of a cell refinement report for an XRD pattern using JADE 9 software.

\begin{tabular}{|c|c|c|c|c|c|c|c|c|c|}
\hline \multicolumn{10}{|c|}{ Cell Type = Cubic, Fm-3m (225) } \\
\hline \multicolumn{10}{|c|}{ Initial Cell $=4.3 \times 4.3 \times 4.3<90.0 \times 90.0 \times 90.0>$} \\
\hline \multicolumn{10}{|c|}{ Refined Cell $=4.356223(0.000663) \square$} \\
\hline \multicolumn{10}{|c|}{ Vol $=82.67 \square^{3}$, Density $(\mathrm{c})=($ Chemical Formula $=($ Unknown $), Z=4.0)$} \\
\hline \multicolumn{10}{|c|}{ Two-Theta Error Window $=0.3(\mathrm{deg})$, Zero Offset $=0.0(\mathrm{deg})$, Displacement $=0.0(\mathrm{deg})$} \\
\hline \multicolumn{10}{|c|}{ ESD of Fit $=0.0697^{\circ}, \mid$ Delta 2 -Theta $\left|=0.05406^{\circ},\right|$ Delta $d \mid=0.00235(\AA), \mathrm{F}(5)=18.5(5)$} \\
\hline (hkl) & 2T(cal) & $2 \mathrm{~T}$ (cor) & 2T(obs) & Delta & $\mathrm{d}(\mathrm{cal})$ & $\mathrm{d}($ cor $)$ & $\mathrm{d}(\mathrm{obs})$ & Del-d & $\mathrm{I} \%$ \\
\hline (111) & 35.669 & 35.574 & 35.574 & 0.095 & 2.5151 & 2.5216 & 2.5216 & 0.0065 & 60.9 \\
\hline$(200)$ & 41.422 & 41.348 & 41.348 & 0.073 & 2.1781 & 2.1818 & 2.1818 & 0.0037 & 100.0 \\
\hline$(220)$ & 60.019 & 60.002 & 60.002 & 0.016 & 1.5402 & 1.5405 & 1.5405 & 0.0004 & 73.3 \\
\hline (311) & 71.813 & \begin{tabular}{|l|l}
71.833 \\
\end{tabular} & 71.833 & -0.019 & 1.3135 & 1.3131 & 1.3131 & 0.0003 & 28.0 \\
\hline (222) & 75.547 & 75.481 & 75.481 & 0.066 & 1.2575 & 1.2585 & 1.2585 & 0.0009 & 9.3 \\
\hline
\end{tabular}


$\stackrel{\circ}{\sim}$

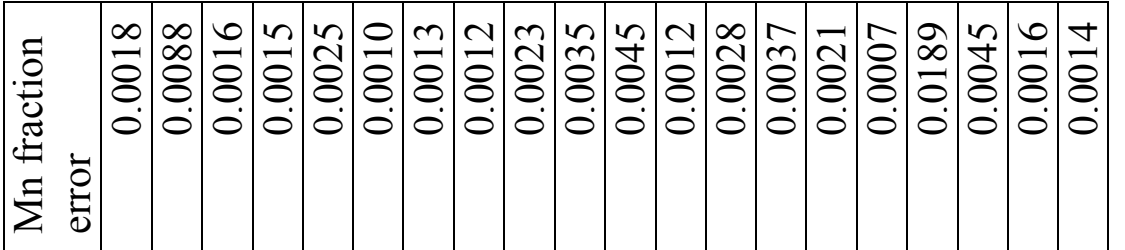

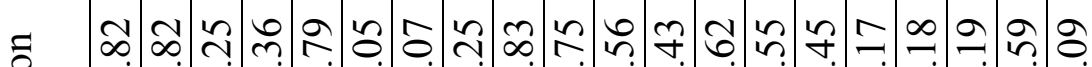

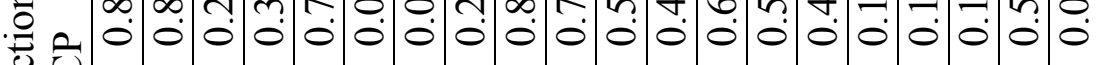
范

$\sum \stackrel{\Xi}{\Xi}$

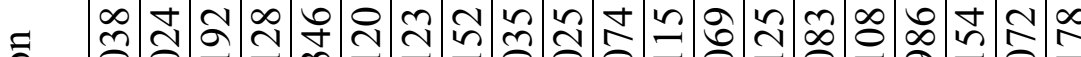

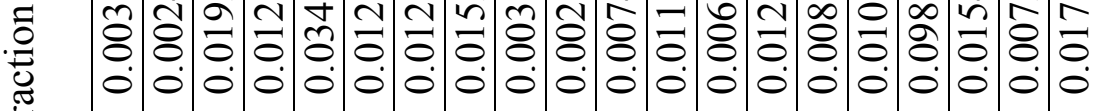

元

论

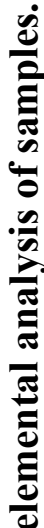

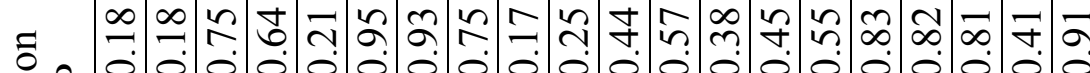

m

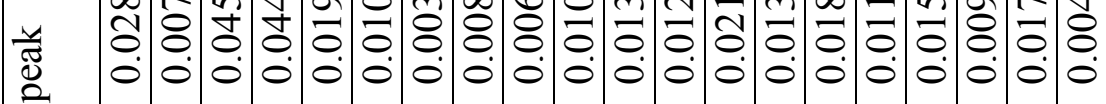

ชิ:

ปู

ontoo l m t

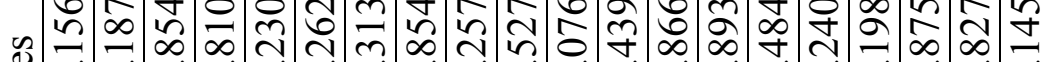

d. 긍

ฮั

อิ

ㅇํำ:

ปู :

뇡

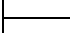

nิ?

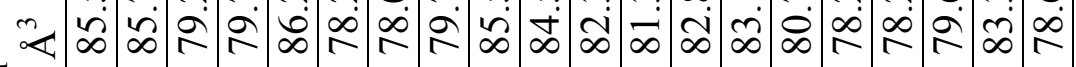

อี

$\bar{\nabla} 0$

.Е

$\square \%$

लें

$\frac{0}{\sigma}$

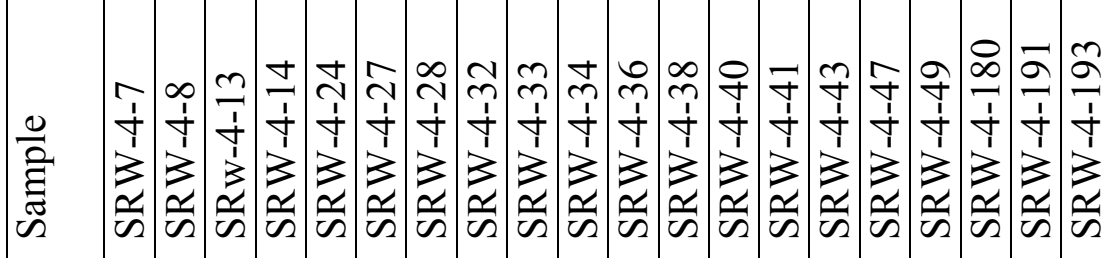


ก

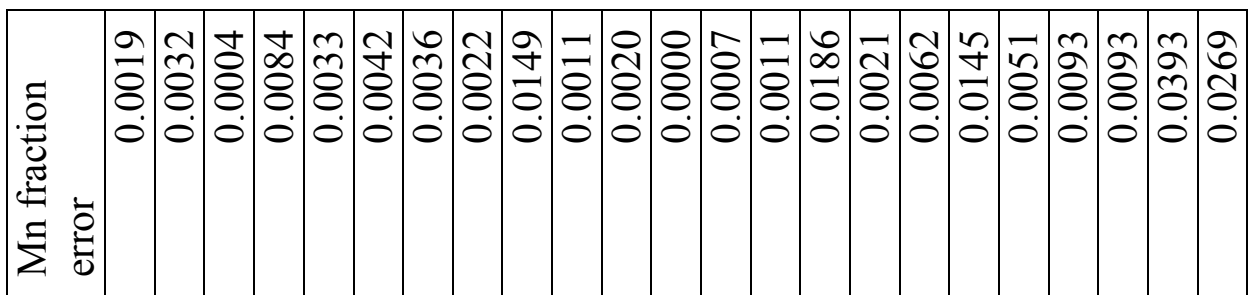

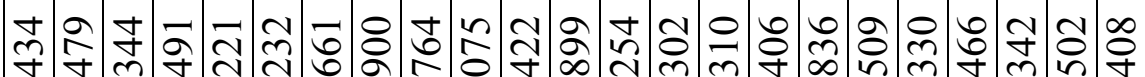
: : $\sum \underset{\Sigma}{\Xi}$



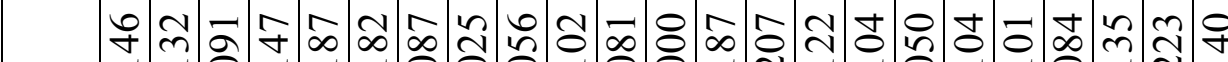
○.

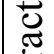

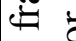
ن

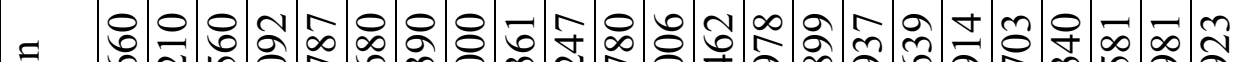

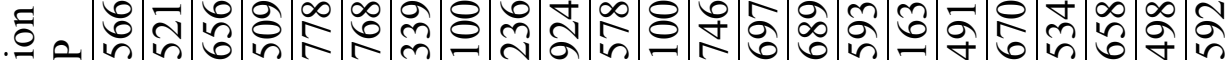
莓

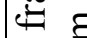
웅

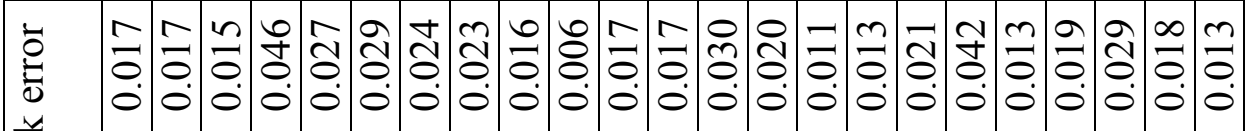
蓆

$\stackrel{2}{2}$

尺े

ป

ฮี

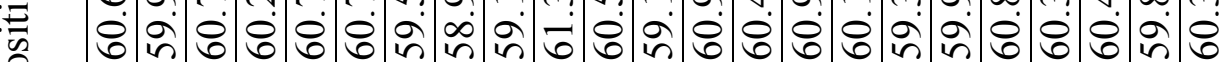
0 0 n 8 in $\frac{v}{0}$

m

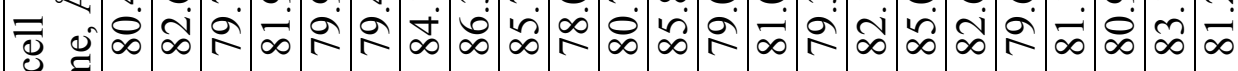
茜

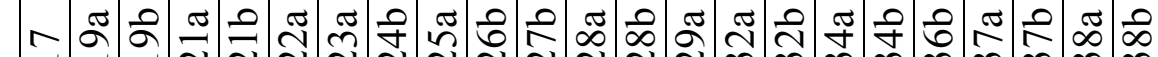

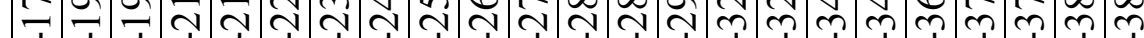

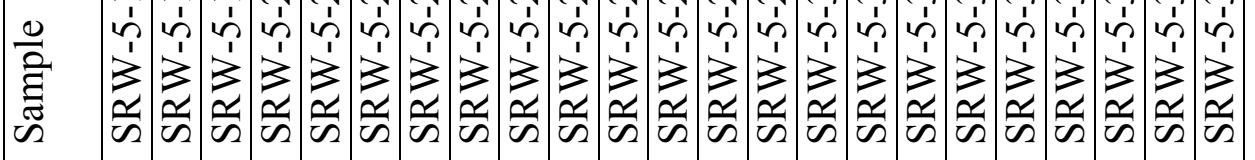




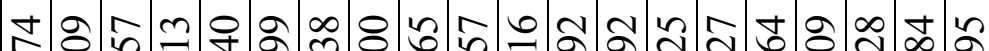

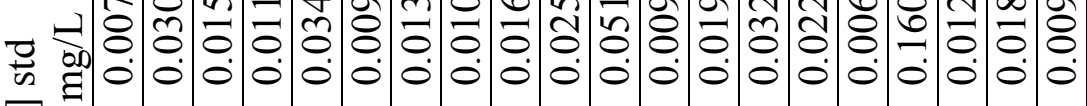
要尊

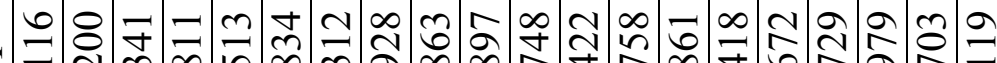

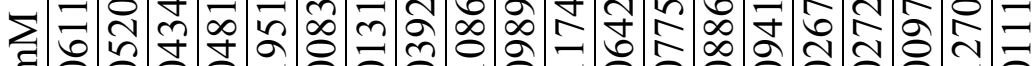

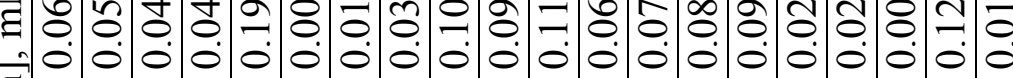

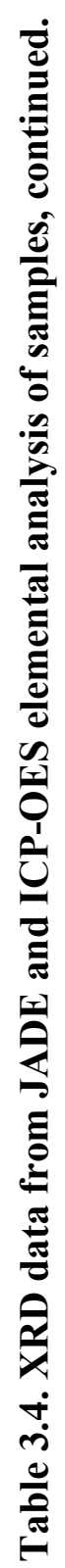
定

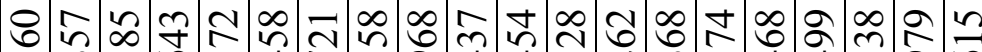

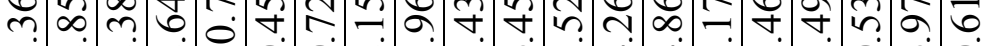

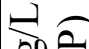

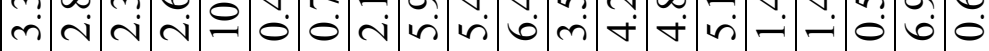
일은 完爮

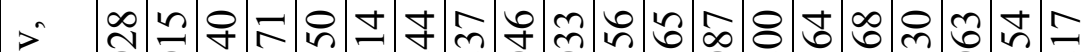
妾

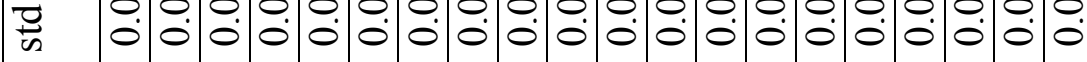
8

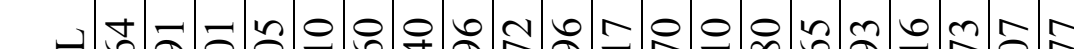

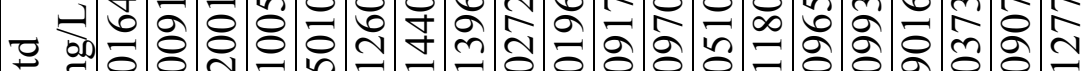

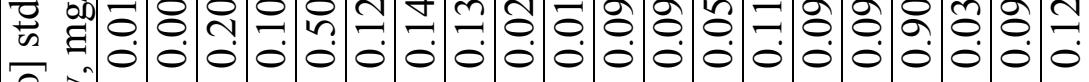
3.

bomanomentoman-arco

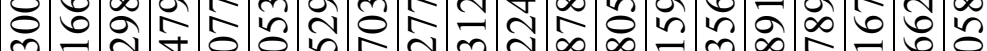
$\dot{s} z_{1}^{2}$

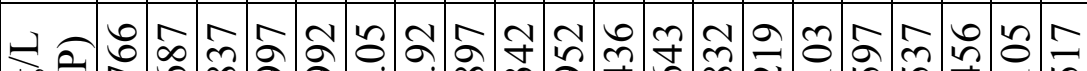

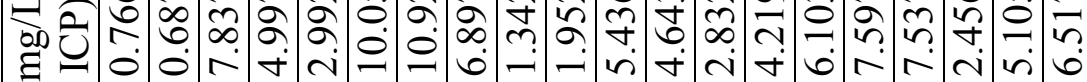
$\dot{0}$ 항 o

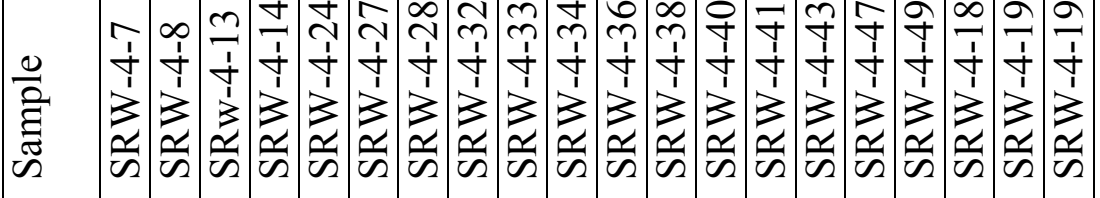


กิ

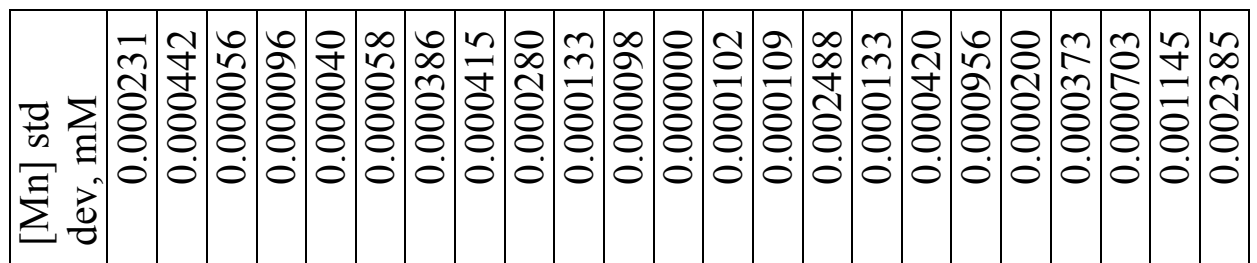

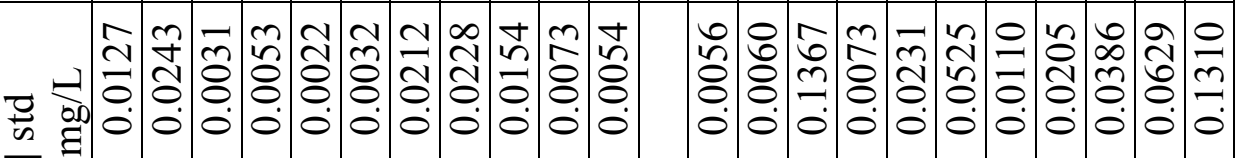

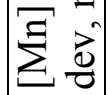

슷유

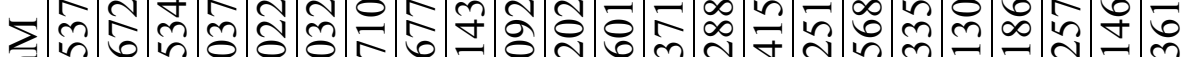
घ

$$
\text { '̊. }
$$

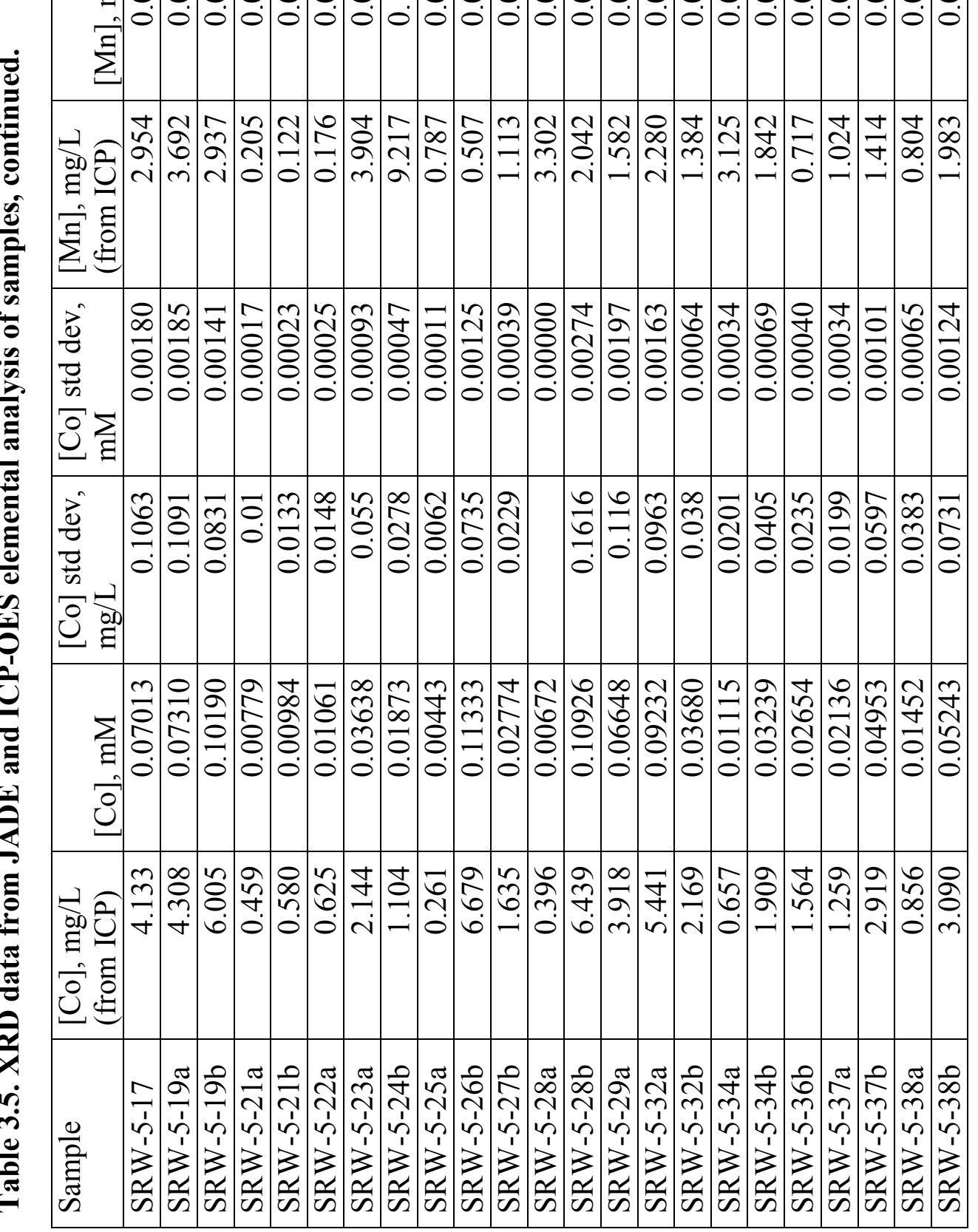




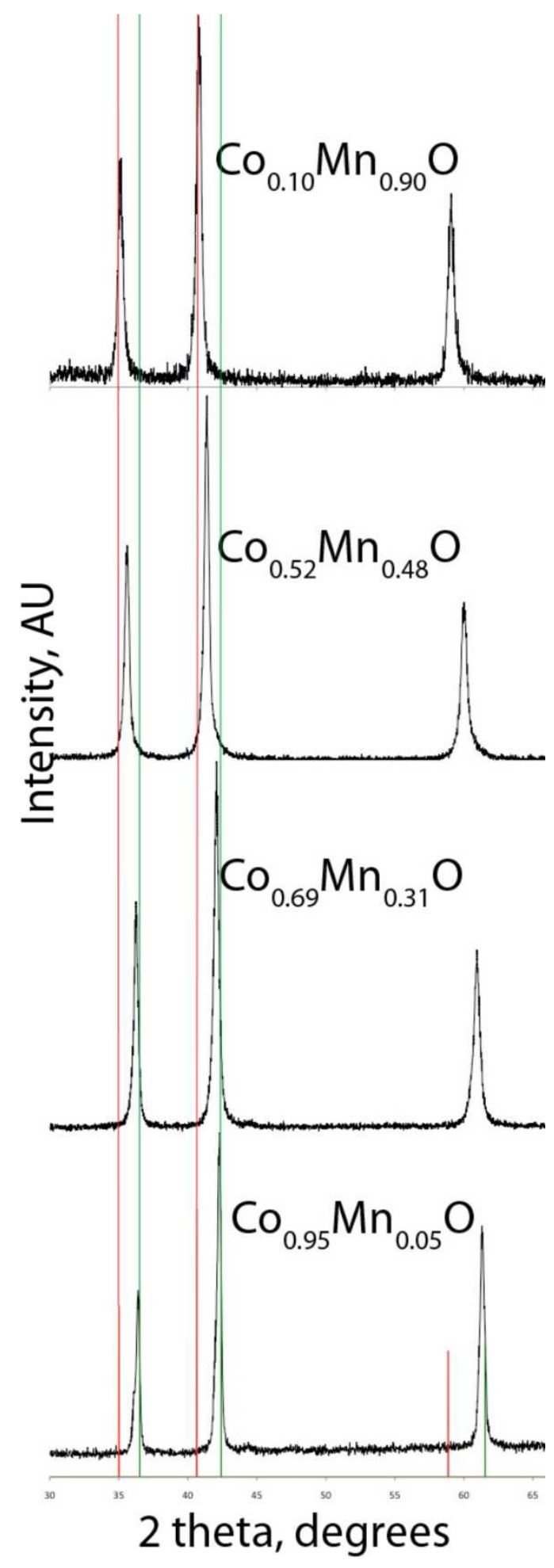

Figure 3.7. XRD patterns for select nanoparticle samples of varying Co-Mn content as determined by ICP-OES analysis. MnO and $\mathrm{CoO}$ are shown in red and green respectively. 


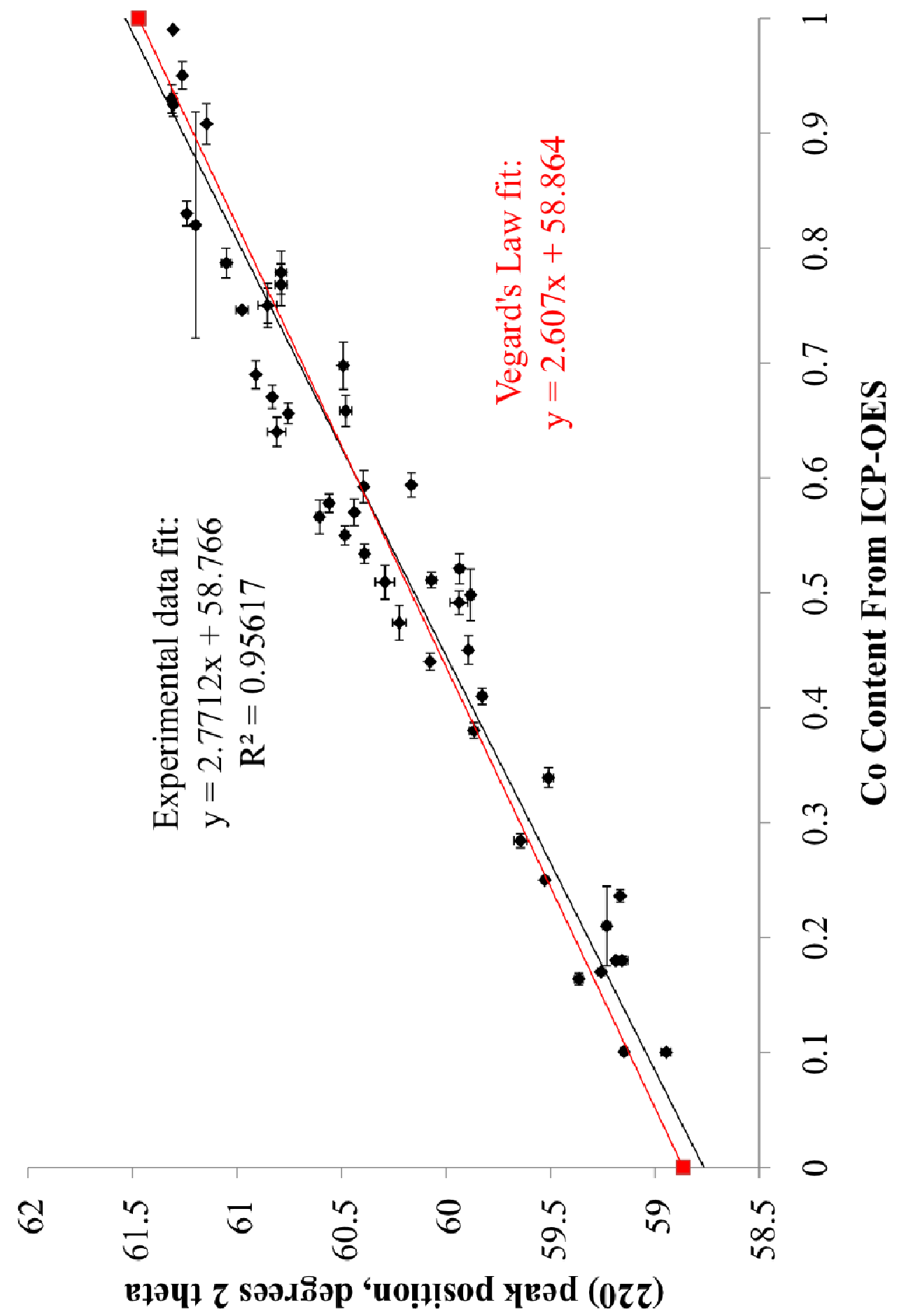

Figure 3.8. Change in (220) peak position with increasing cobalt content in sample. Sample data is in black diamonds; $\mathrm{MnO}$ and $\mathrm{CoO}$ positions are in red squares. The direct-line correlation between $\mathrm{MnO}$ and $\mathrm{CoO}$ is shown as a red line. 


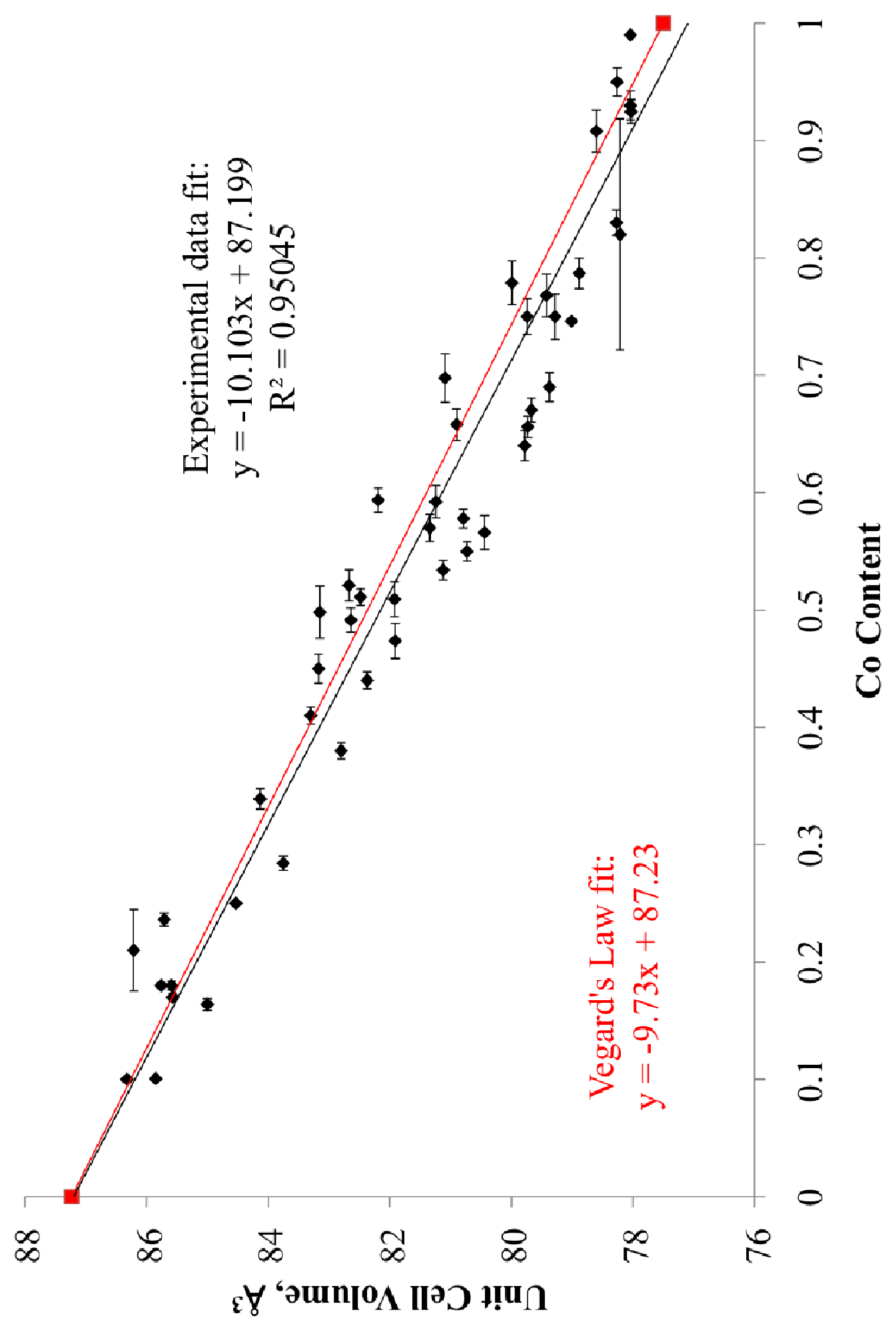

Figure 3.9. Change in calculated unit cell volume versus cobalt content of sample. Sample data is in black diamonds; $\mathrm{MnO}$ and $\mathrm{CoO}$ positions are in red squares. The direct correlation between $\mathrm{MnO}$ and $\mathrm{CoO}$ (as expected from Vegard's Law) is shown as a red line. 


\subsubsection{Nanoparticle morphology}

Nanoparticle shapes and sizes were considerably impacted by the ratio of Mn:Co molecular precursors in the reaction. These reactions were done with 6 $\mathrm{mL}$ TOA, $2 \mathrm{~mL} \mathrm{OA}, 2 \mathrm{mmol}$ total molecular precursors, no water and with 2 minutes of growth time after decomposition of the molecular precursors. The results are shown in Table 3.6 through Table 3.12 below. The temperature at which a solution color changed increased slightly as the relative amount of cobalt precursor increased, from $355^{\circ} \mathrm{C}$ at $1: 9 \mathrm{Co}: \mathrm{Mn}$ precursor ratio, $365^{\circ} \mathrm{C}$ at $1: 1$ Co:Mn and $370^{\circ} \mathrm{C}$ at 9:1 Co:Mn. Images marked with an asterisk in all tables were taken by Dr. Irene Rusakova at the University of Houston.

Table 3.6. TEM images of nanoparticles synthesized with a 9:1 ratio of Mn:Co molecular precursors

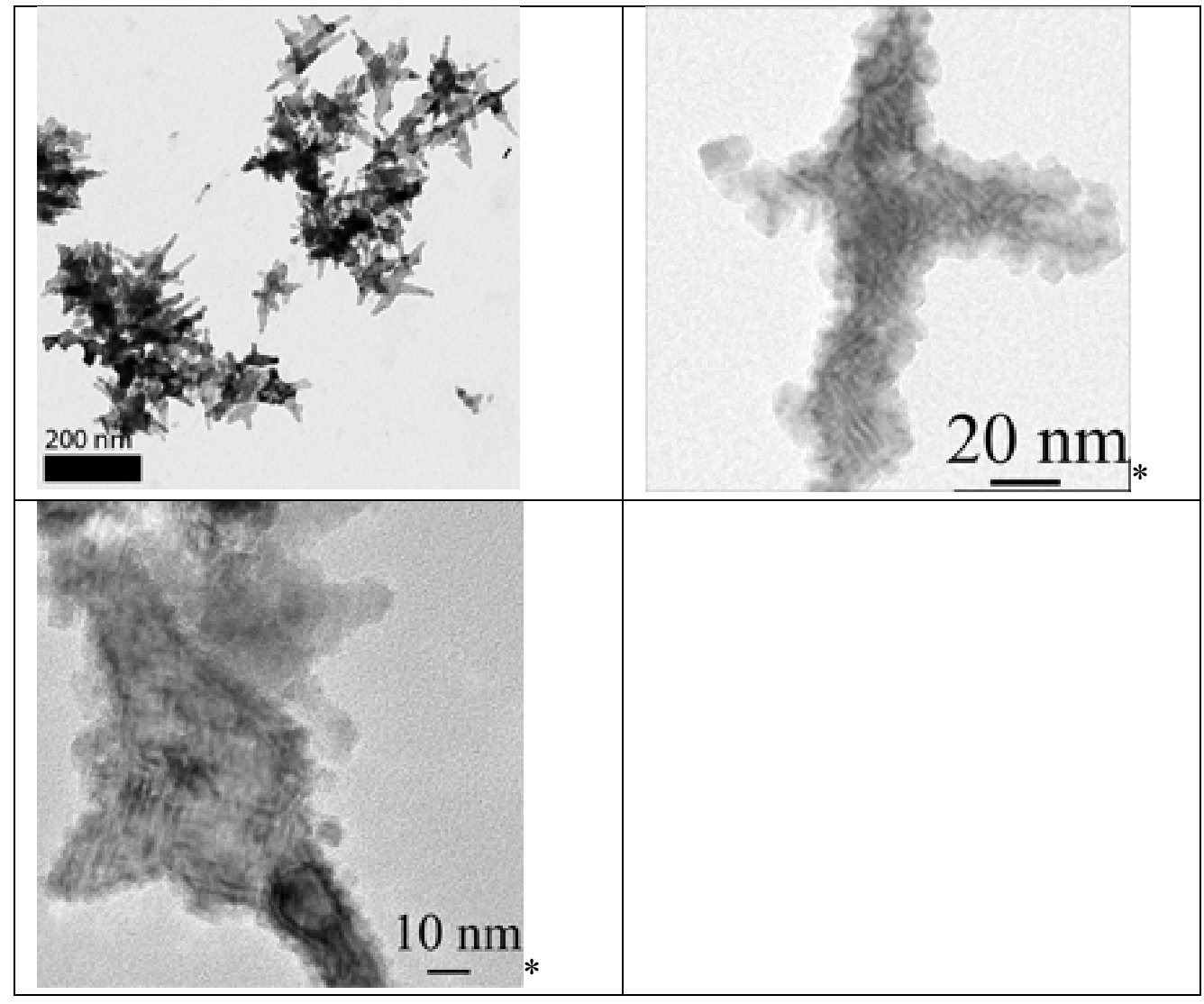


Table 3.7. TEM images of nanoparticles synthesized with a 5:1 ratio of Mn:Co molecular precursors

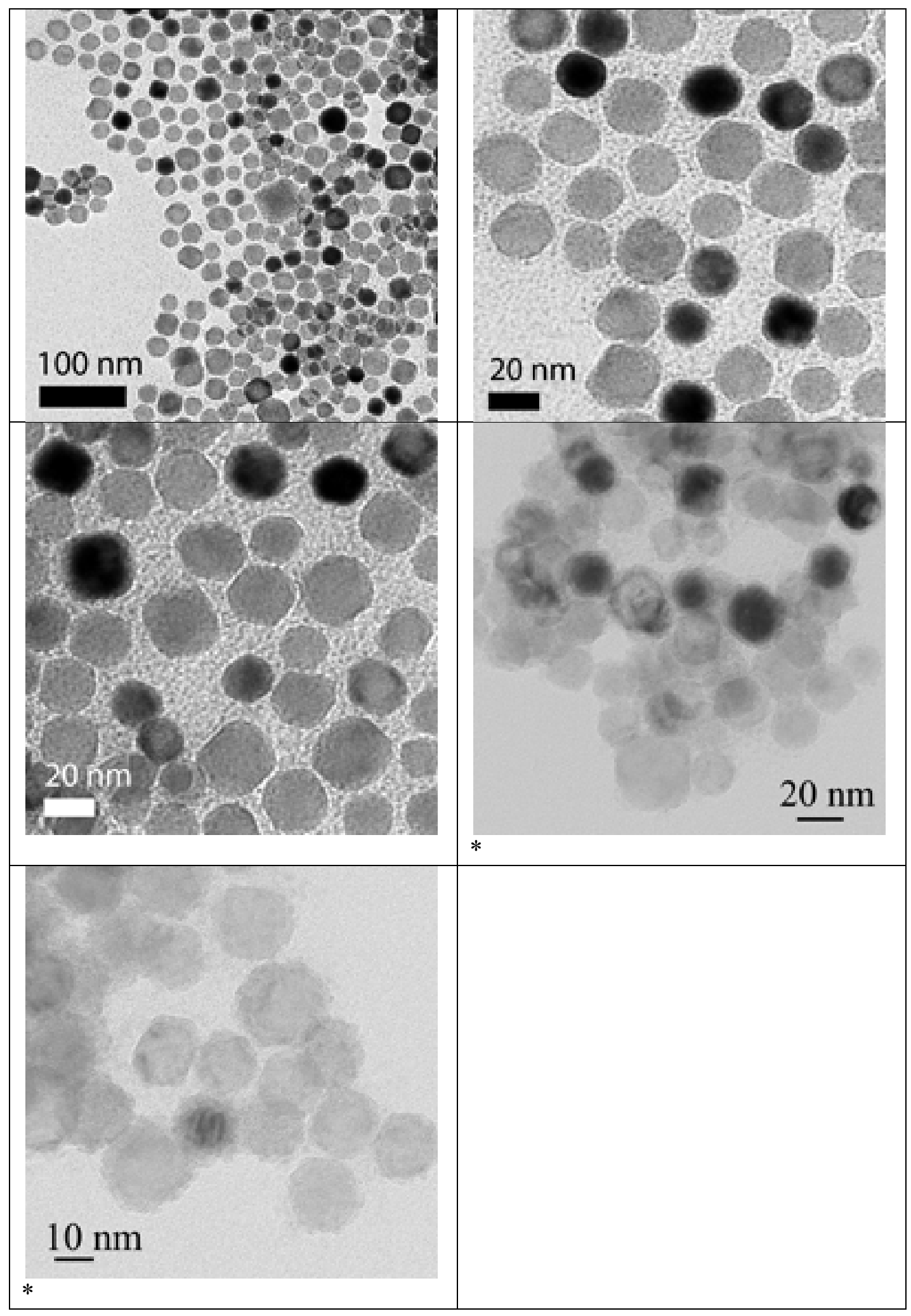


Table 3.8. TEM images of nanoparticles synthesized with a 2:1 ratio of Mn:Co molecular precursors

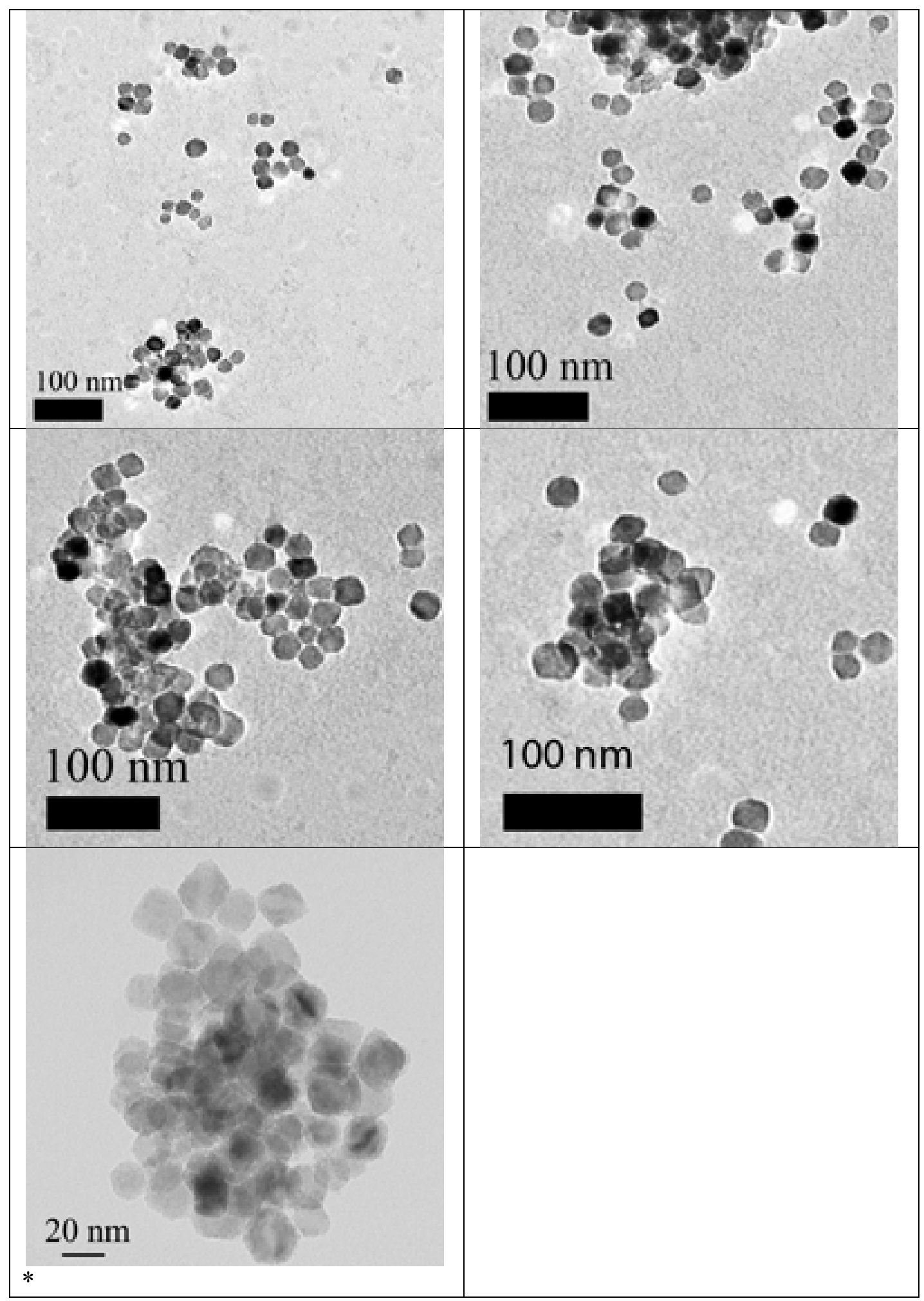


Table 3.9. TEM images of nanoparticles synthesized with a 1:1 ratio of Mn:Co molecular precursors

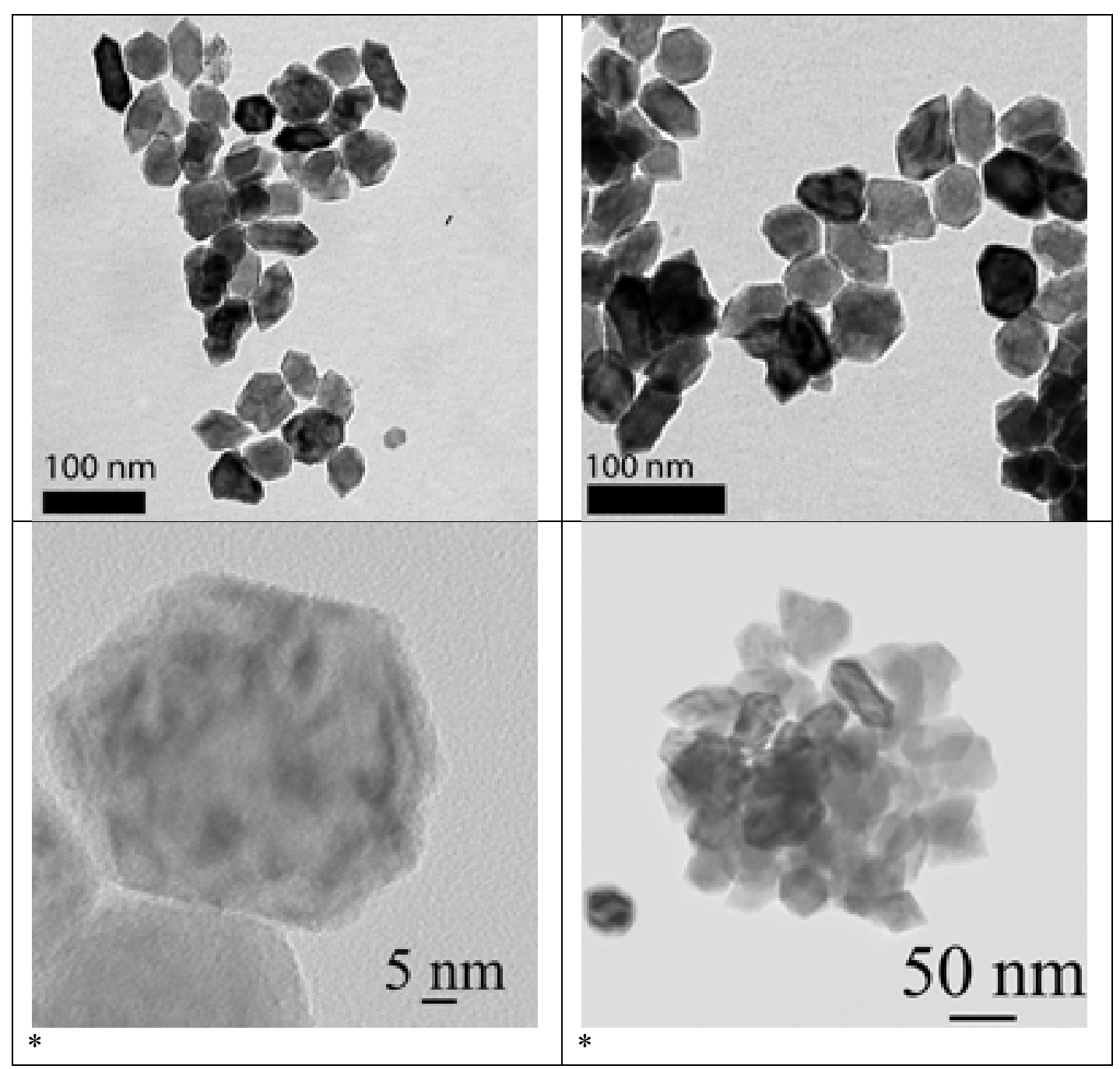


Table 3.10. TEM images of nanoparticles synthesized with a 1:2 ratio of Mn:Co molecular precursors

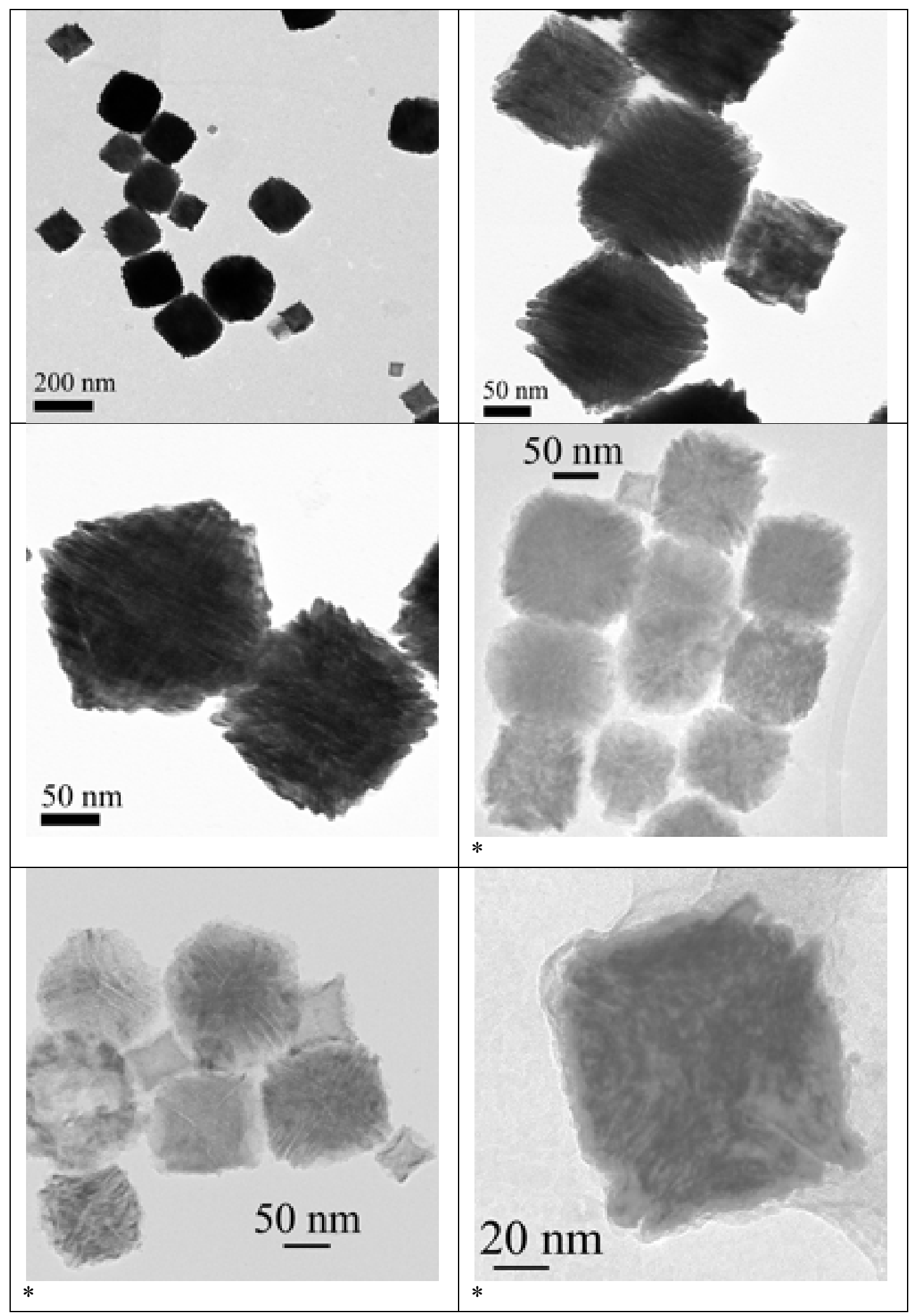


Table 3.11. TEM images of nanoparticles synthesized with a 1:5 ratio of Mn:Co molecular precursors

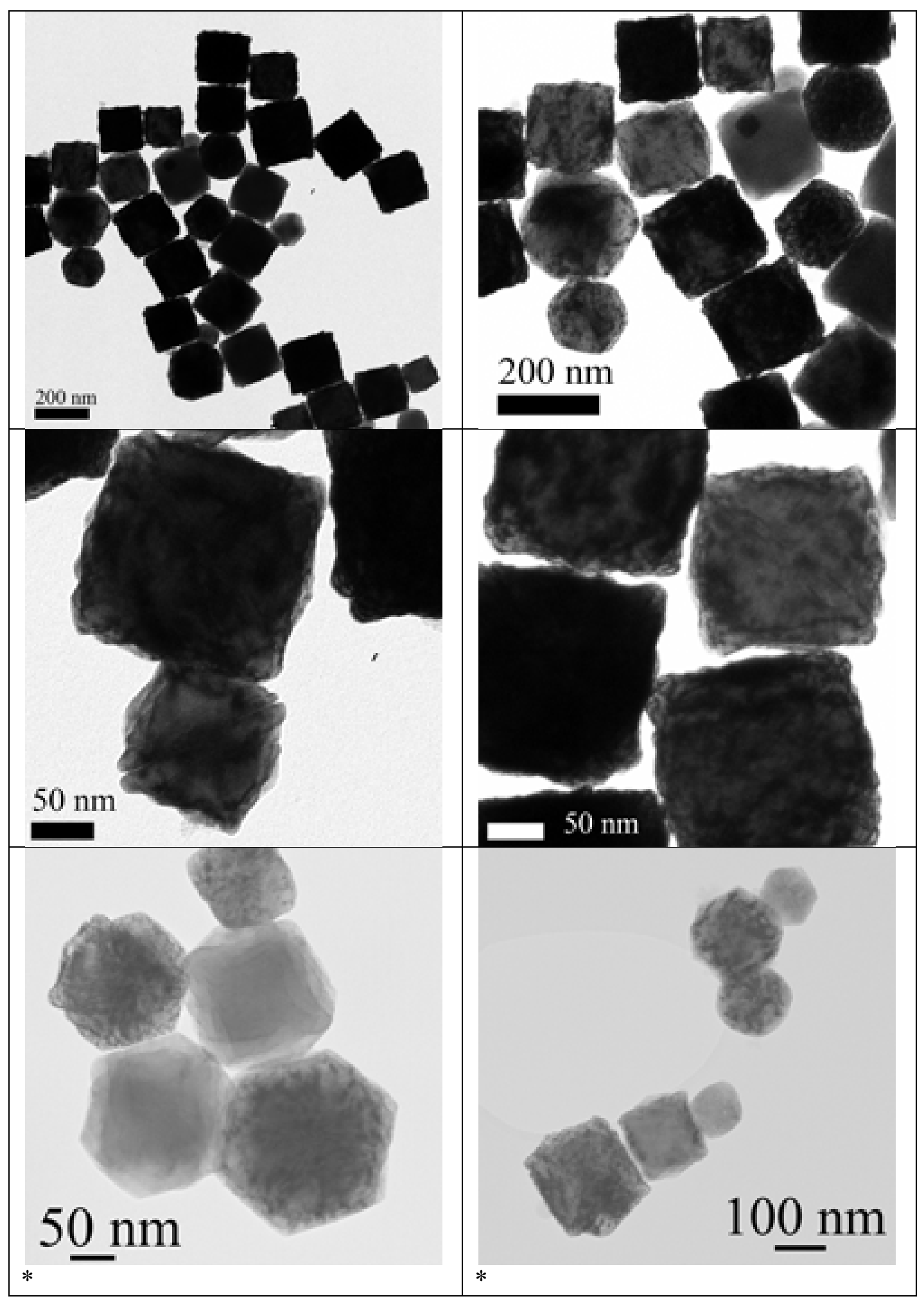


Table 3.12 TEM images of nanoparticles synthesized with a 1:9 ratio of Mn:Co molecular precursors

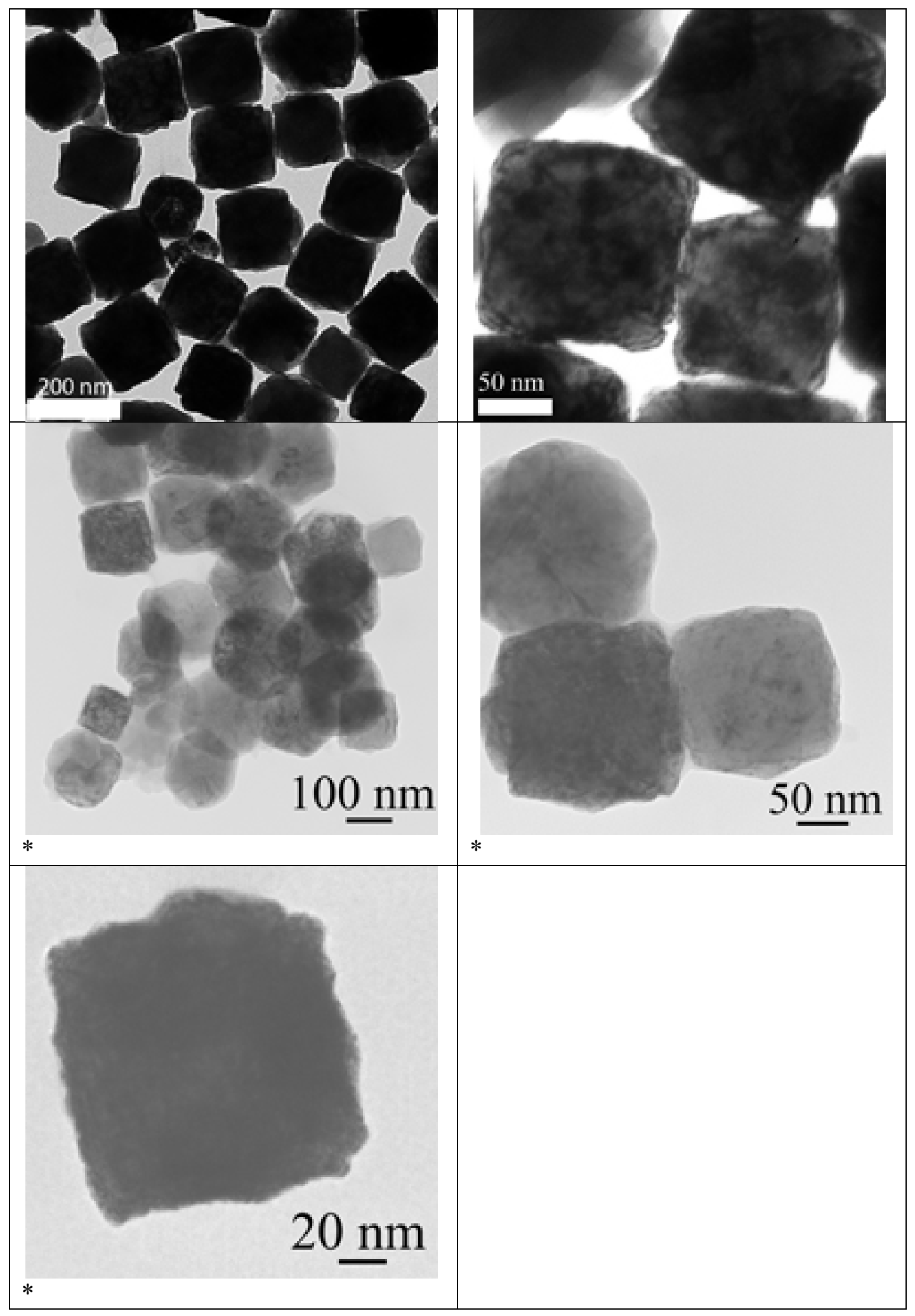




\subsection{Effect of varying TOA:OA volume ratio}

\subsubsection{Crystallinity and lattice of products}

The most immediately noticeable change in the way the $\mathrm{Co}_{1-\mathrm{x}} \mathrm{Mn}_{\mathrm{x}} \mathrm{O}$ system reacts to alterations in the TOA:OA ratio is in the decomposition /nanoparticle formation temperature. Decomposition of precursors without OA occurred at $305^{\circ} \mathrm{C}$, giving a black solution. When $\mathrm{OA}$ is introduced at a $7: 1$ TOA:OA volume ratio, the decomposition occurs at $335-340^{\circ} \mathrm{C}$ and is marked by a solution color change to light blue that becomes dark yellow over the growth time. With $6.5 \mathrm{~mL}$ TOA: $1.5 \mathrm{~mL} \mathrm{OA}$, decomposition occurred at $360-365^{\circ} \mathrm{C}$, with the final solution color being green-gray; the $6 \mathrm{~mL}$ TOA: $2 \mathrm{~mL}$ OA solution turned green-gray at $365-370^{\circ} \mathrm{C}$. The $5 \mathrm{~mL}$ TOA: $3 \mathrm{~mL} \mathrm{OA}$ reaction changes color at the highest temperature, over $370^{\circ} \mathrm{C}$, and the solution turns a dark emerald green. Attempts to use $5.5 \mathrm{~mL}$ TOA: $3.5 \mathrm{~mL}$ OA solutions did not lead to reproducible results; $4.5 \mathrm{~mL}$ TOA: $3.5 \mathrm{~mL}$ OA solutions (and those with higher volumes of $\mathrm{OA}$ ) did not reproducibly lead to decomposition of molecular precursors at temperatures up to $390^{\circ} \mathrm{C}$.

All of these experimental conditions except for the $5 \mathrm{~mL}$ TOA: $3 \mathrm{~mL}$ OA case always gave nanoparticles that could be precipitated via centrifugation in hexanes after the initial ethanol washing. In approximately $25 \%$ of the reactions performed with $5 \mathrm{~mL}$ TOA and $3 \mathrm{~mL}$ OA no precipitate at all was recovered upon centrifugation in hexanes; in all cases a significant amount of material remained in the supernatant. This was indicated by to the supernatant being so darkly 
colored as to be opaque. This material was recovered by adding an equal volume of ethanol to the centrifuge tube and centrifuging again.

Example XRD patterns of these products are shown in Figure 3.10 and Figure 3.11. Nanoparticles that precipitated in hexanes for all reactions where OA was present (Figure 3.10) always had the same face-centered cubic lattice structure seen in earlier reactions. Nanoparticles recovered from the supernatant (Figure 3.11), however, had a significantly different diffraction pattern. JADE 9 search-matching software identified these patterns as matching the crystal lattice of $\mathrm{ZnO}$ (PDF\#04-008-8199, hexagonal, P6 ${ }_{3} \mathrm{mc}$, no. 186, $a=3.2648 \AA, c=$ 5.21939 $\AA, Z=2$ ), a metal oxide with the wurtzite crystal structure. Elemental analysis using ICP-OES indicated that no zinc was present, only manganese and cobalt. Also, not all products had XRD patterns with identical peak positions. Examination of the literature showed that a hexagonal-lattice form of $\mathrm{CoO}$ has been reported a handful of times, and while no powder diffraction file (PDF) has been catalogued, the calculated lattice parameters from published papers are $a=$ $3.244 \AA$ and $c=5.203 \AA .^{37,70}$ 


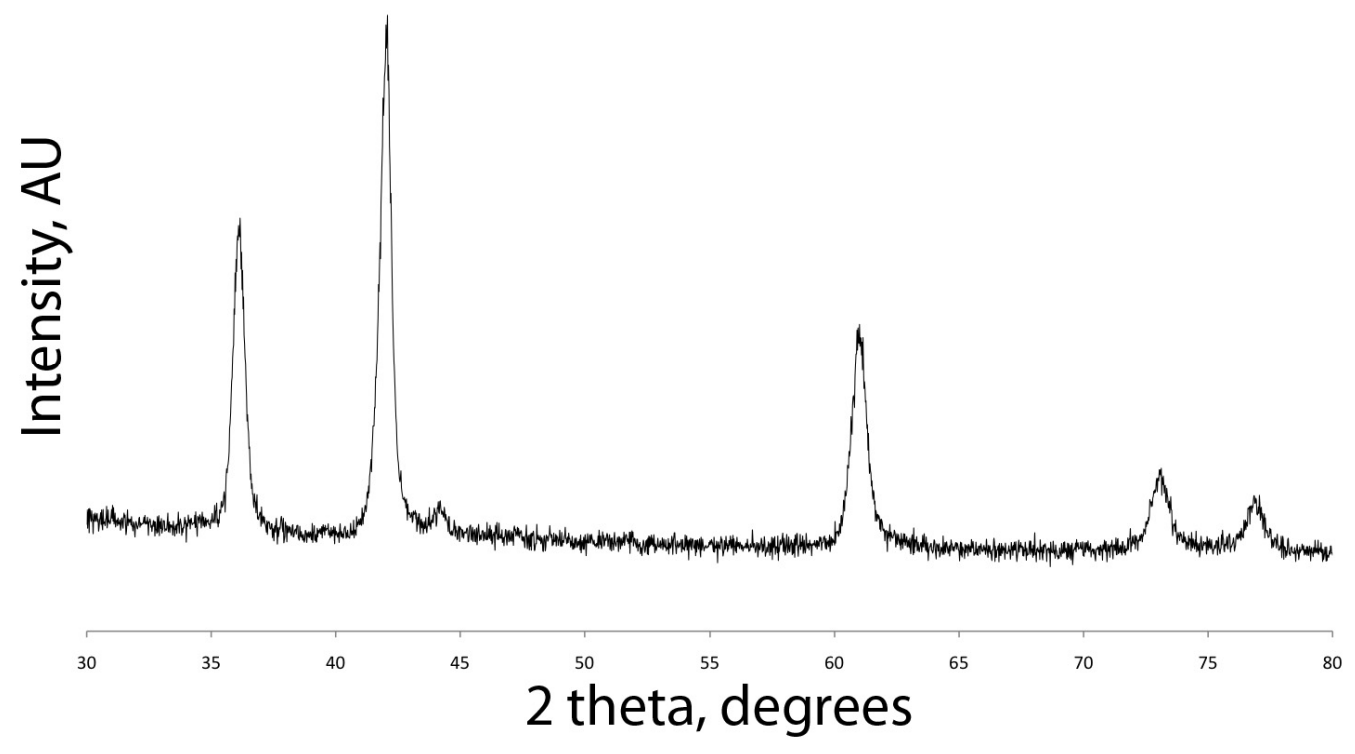

Figure 3.10. Example powder XRD pattern for all products recovered by centrifugation in hexanes for TOA:OA ratios of 7:1 to 5:3; trace amounts of Co metal are present in some, but not all, samples.

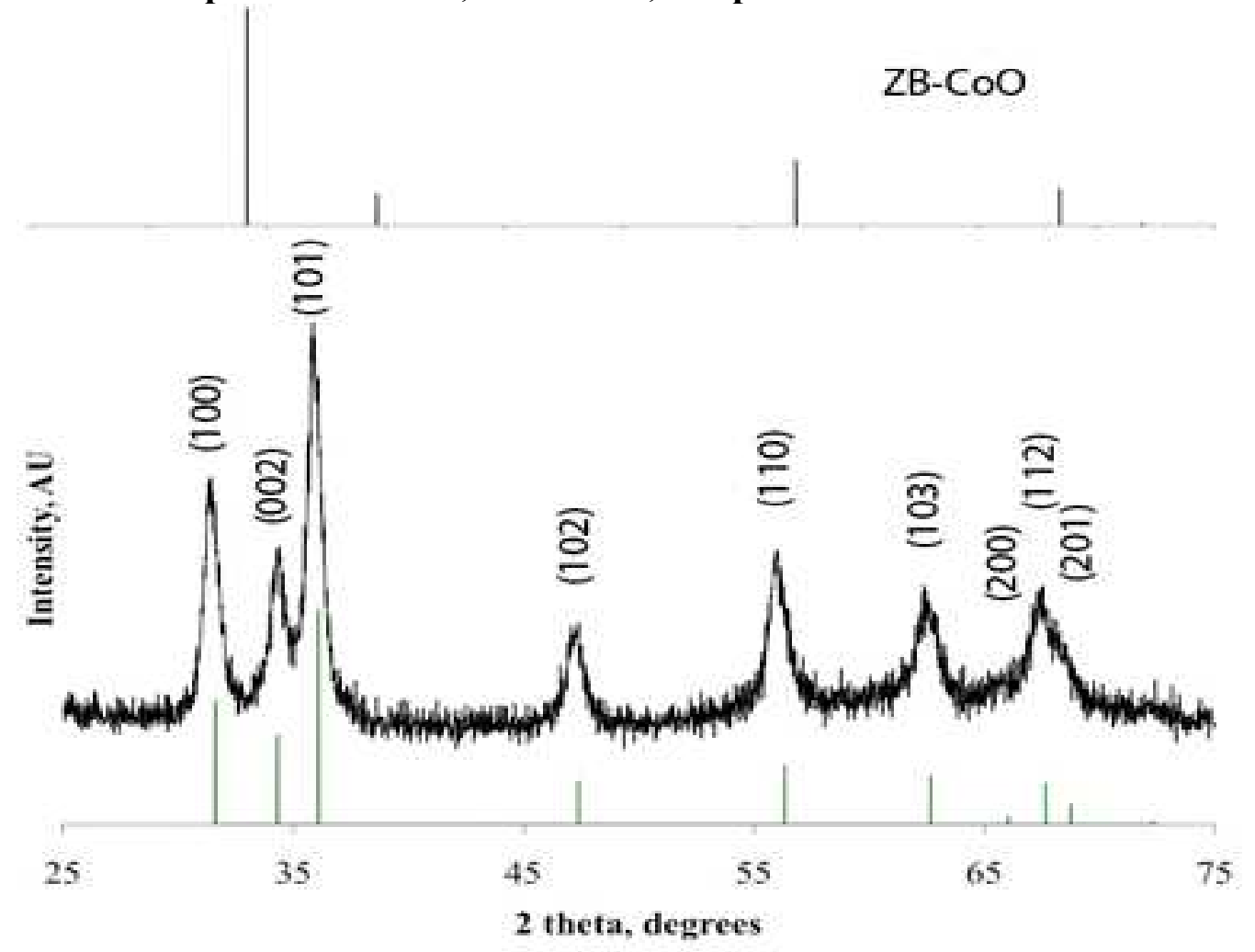

Figure 3.11. Example powder XRD pattern of nanoparticles recovered from the supernatant of reaction with $5 \mathrm{~mL}$ TOA and $3 \mathrm{~mL} \mathrm{OA}$. ZnO (PDF\#04008-8199) is shown in green; zinc blende $\mathrm{CoO}(\mathrm{ZB}-\mathrm{CoO})$ is shown above in black. 
Experiments performed where no OA was added to the reaction gave results that were initially difficult to explain. An example XRD pattern of such a reaction is shown in Figure 3.12. It was only after the realization that a hexagonal-lattice oxide $\left(\mathrm{w}-\mathrm{Co}_{1-\mathrm{x}} \mathrm{Mn}_{\mathrm{x}} \mathrm{O}\right)$ was also part of the $\mathrm{Co}_{1-\mathrm{x}} \mathrm{Mn}_{\mathrm{x}} \mathrm{O}$ phase diagram that these results became understandable. Without $\mathrm{OA}$ in a reaction, the molecular precursors form their individual oxides, without forming the solid solution desired. It is possible that some mixing occurs, as there is not a pattern that corresponds directly to pure $\mathrm{CoO}$, but there are clearly two cubic-lattice and one hexagonal-lattice materials present. There is no indication of the presence of a zinc-blende polymorph in the XRD pattern.

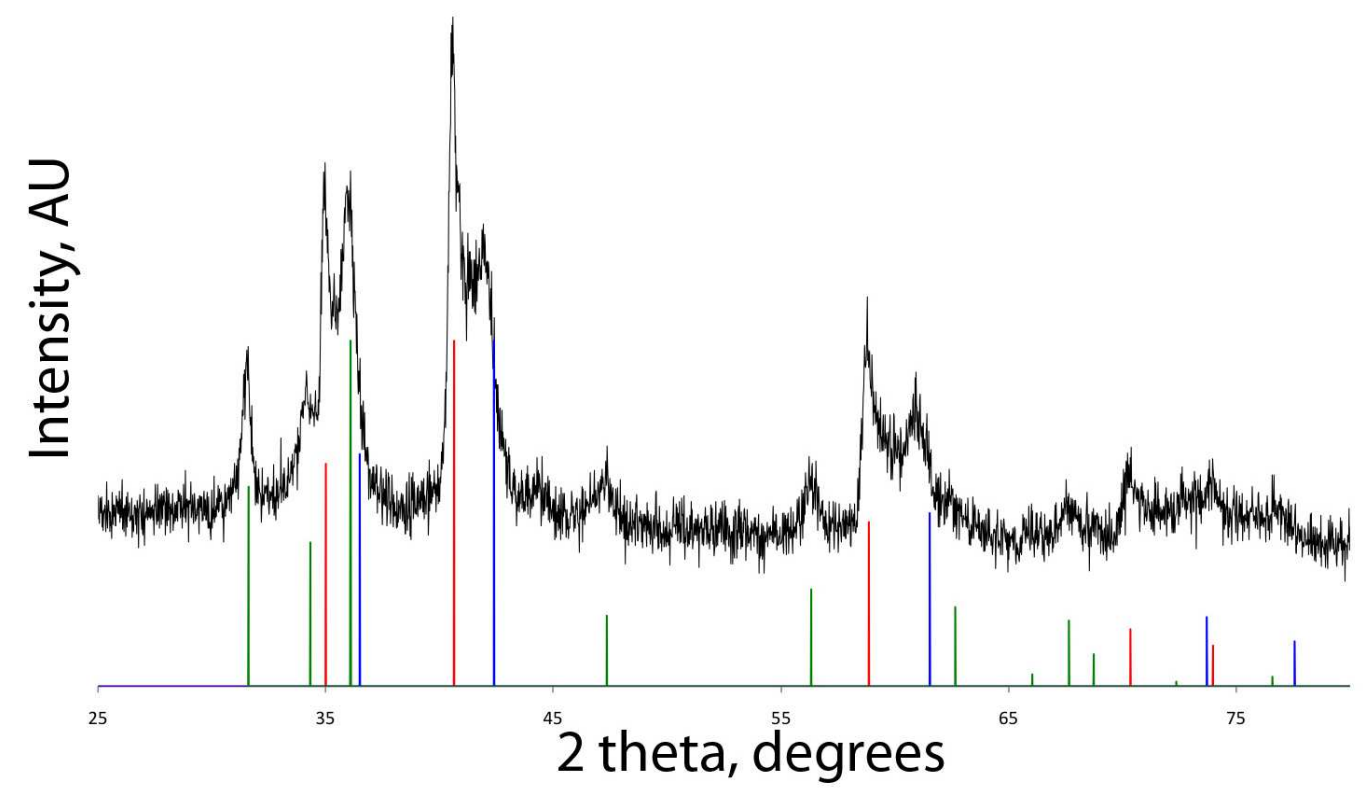

Figure 3.12. Powder XRD pattern of the product of a reaction run in $8 \mathrm{~mL}$ TOA, with no OA present. Face-centered cubic-lattice $\mathrm{MnO}$ and $\mathrm{CoO}$ are shown in red and blue, respectively, whereas hexagonal-lattice $\mathrm{ZnO}$ is shown in green. 


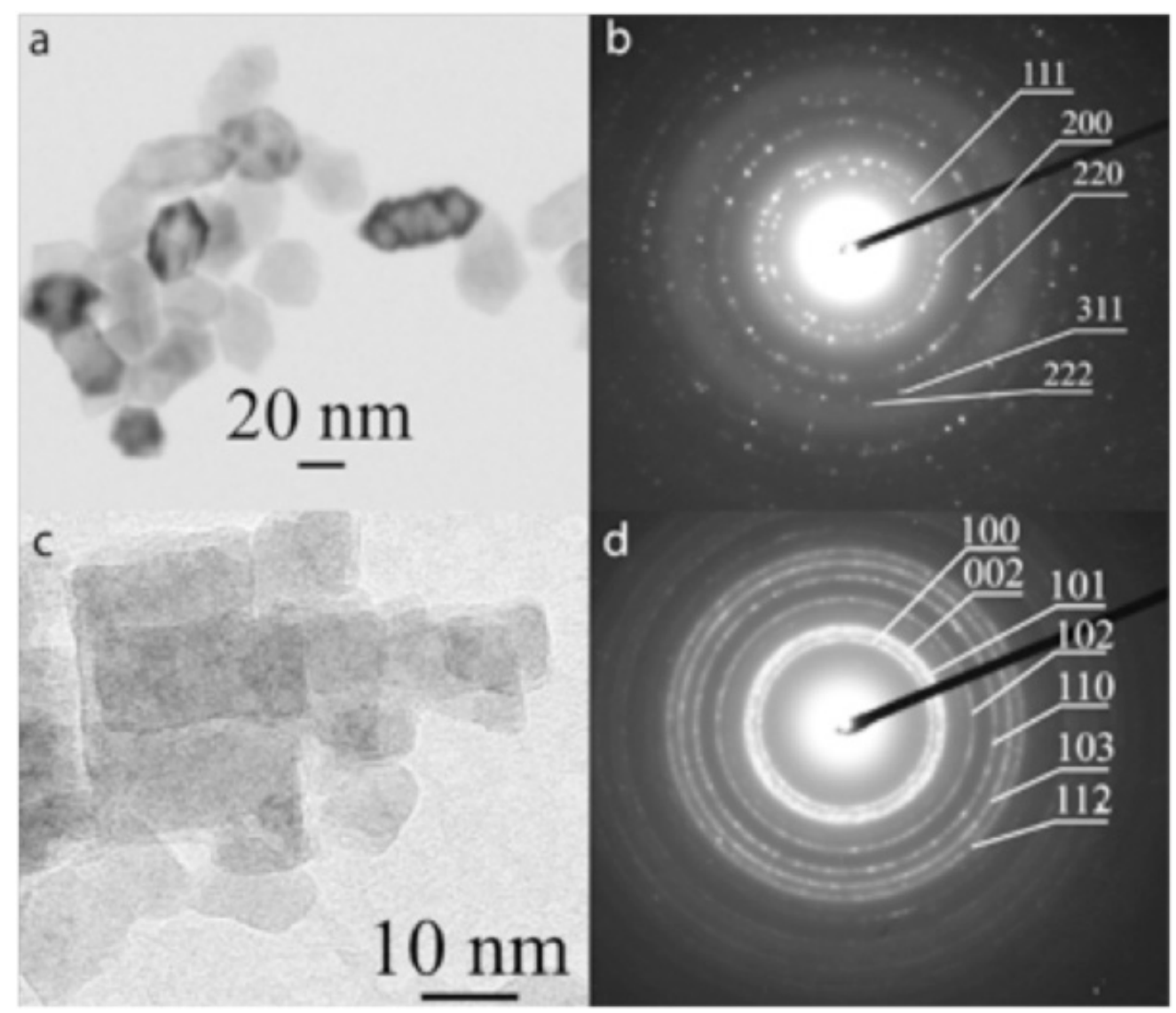

Figure 3.13. HR-TEM images and SAED patterns of cubic lattice and hexagonal lattice nanoparticles. The sample in (a) was synthesized in $6 \mathrm{~mL}$ TOA: $2 \mathrm{~mL} \mathrm{OA}$; the SAED pattern in (b) indexes to a single cubic phase Fm im (225), $a=4.3 \AA$. The sample in (c) is from the supernatant of the 5 mL TOA: $3 \mathrm{~mL} O A$ reaction; the SAED pattern in (d) indexes to a single hexagonal phase $\mathrm{P}_{3} \mathrm{mc}$ (186), $a=3.3 \AA$ and $c=5.2 \AA$.

\subsubsection{Nanoparticle size and morphology}

Several TEM images of each reaction condition are shown in Table 3.13 through Table 3.17 below. These reactions were done with $1 \mathrm{mmol}$ $\mathrm{Co}(\mathrm{OAc})_{2}, 1 \mathrm{mmol} \mathrm{Mn}(\mathrm{HCOO})_{2}$, no water and with 2 minutes of growth time after decomposition of the molecular precursors. Images marked with an asterisk (*) were obtained by Dr. Irene Rusakova at the University of Houston. 
Table 3.13. TEM images of nanoparticles synthesized in $8 \mathrm{~mL}$ TOA and 0 mL OA

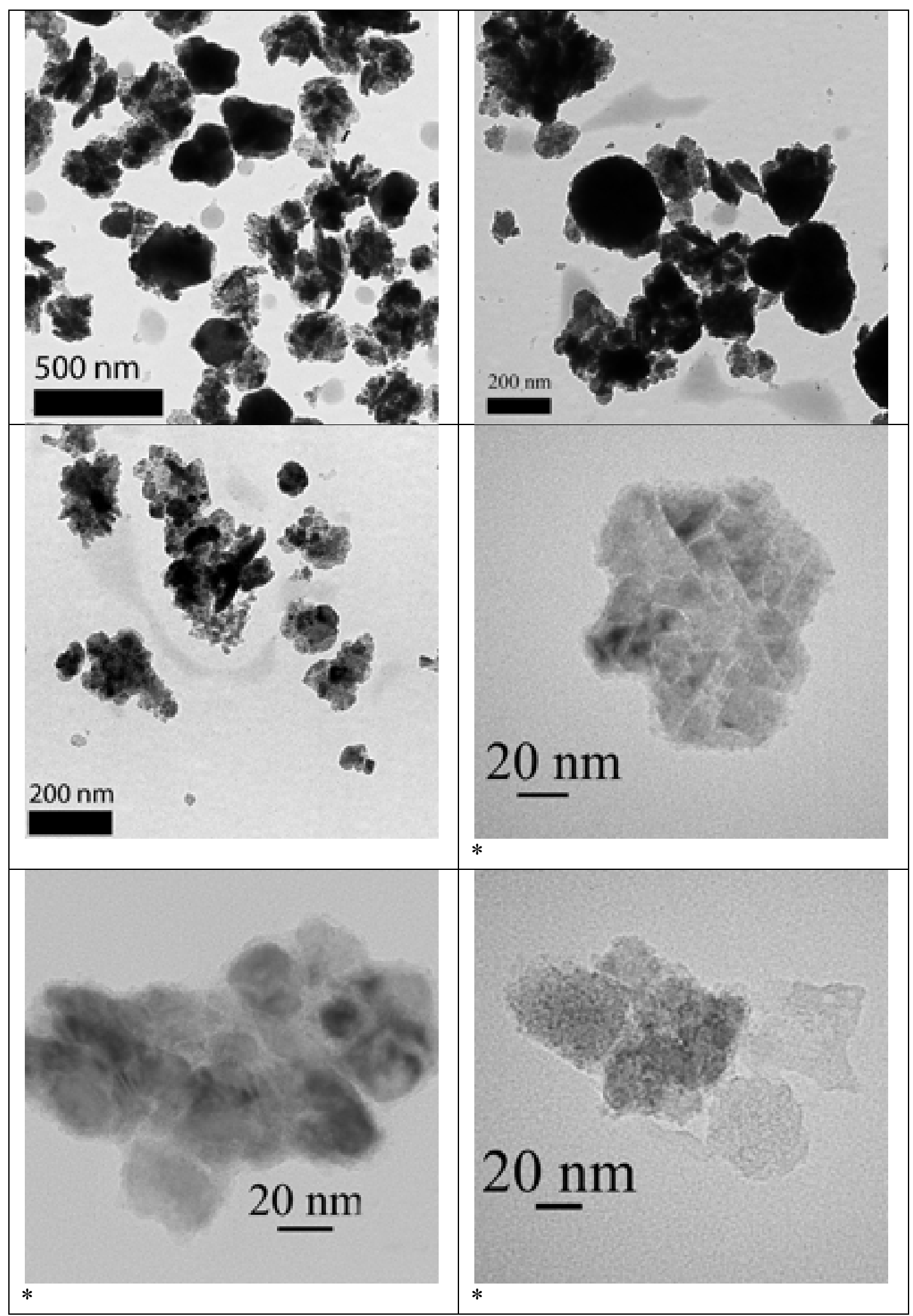


Table 3.14. TEM images of nanoparticles synthesized in $7 \mathrm{~mL}$ TOA and 1 mL OA

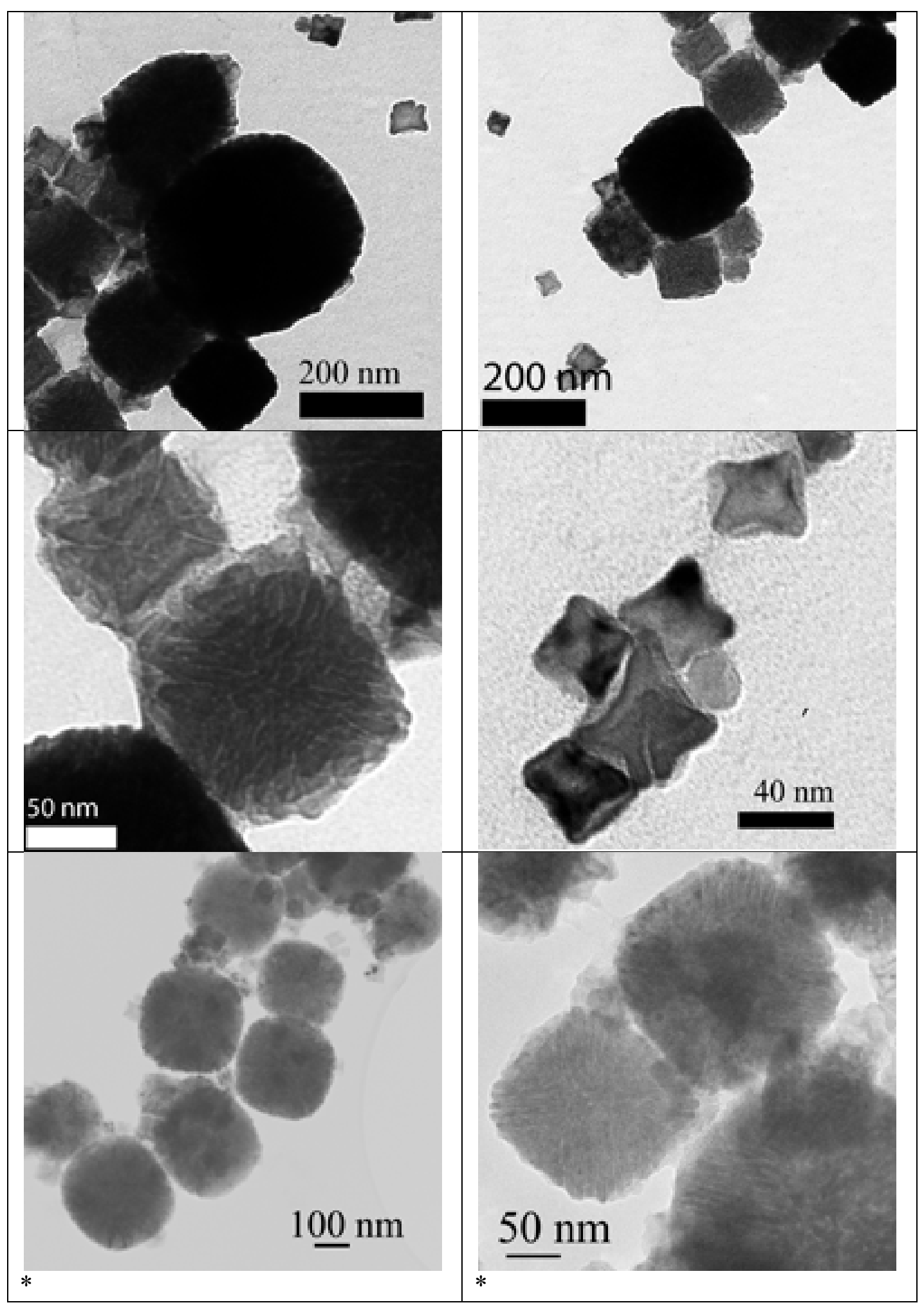


Table 3.15. TEM images of nanoparticles synthesized in $6.5 \mathrm{~mL}$ TOA and 1.5 $\mathbf{m L}$

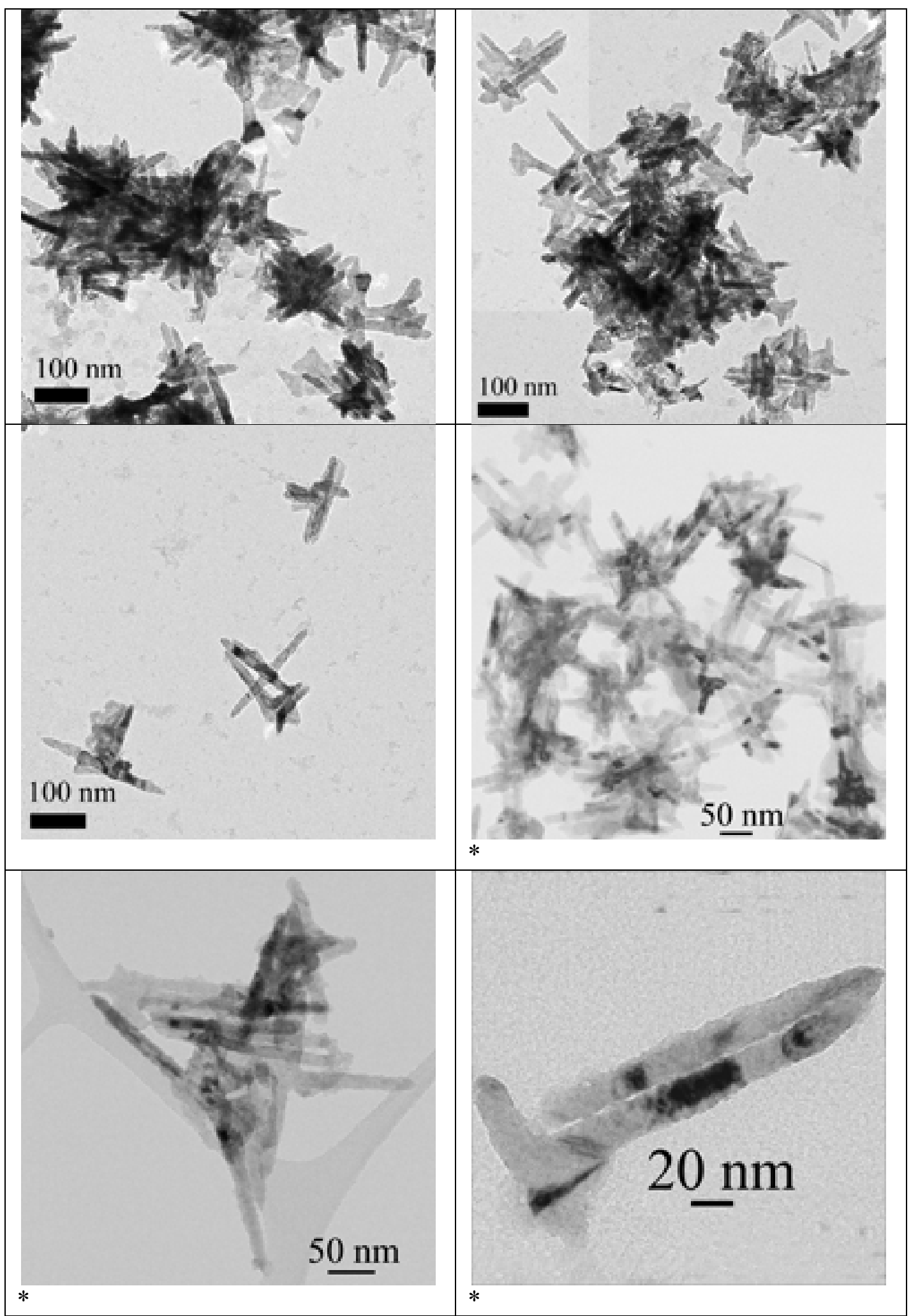


Table 3.16. TEM images of nanoparticles synthesized in $5 \mathrm{~mL}$ TOA and 3 mL OA-supernatant from centrifugation in hexanes $\left(w-\mathrm{Co}_{1-\mathrm{x}} \mathrm{Mn}_{\mathrm{x}} \mathrm{O}\right)$

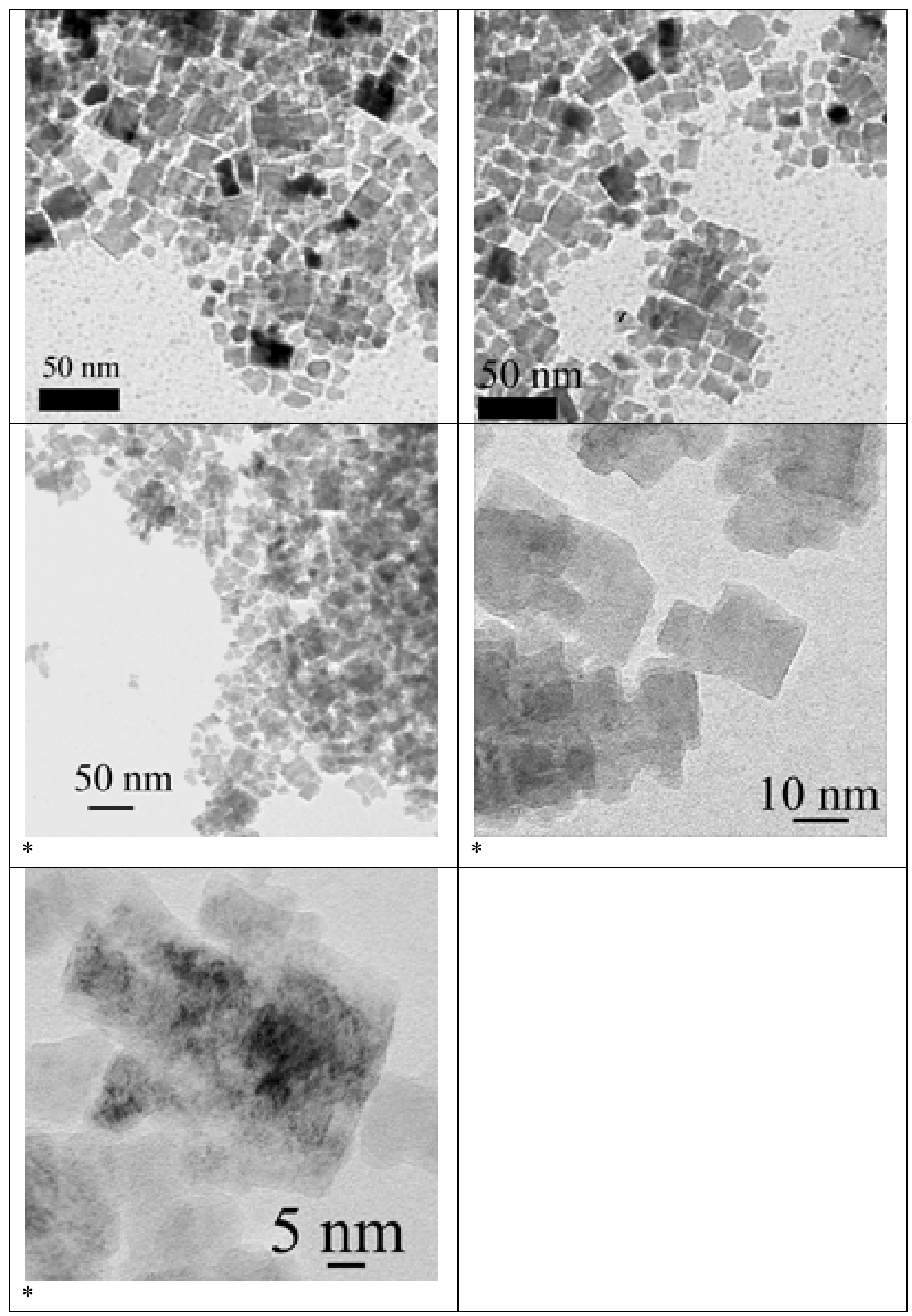


Table 3.17. TEM images of nanoparticles synthesized in $5 \mathrm{~mL}$ TOA and 3 $\mathrm{mL} \mathrm{OA} \mathrm{-} \mathrm{precipitate} \mathrm{from} \mathrm{centrifugation} \mathrm{in} \mathrm{hexanes}\left(\mathrm{rs}-\mathrm{Co}_{1-\mathrm{x}} \mathrm{Mn}_{\mathrm{x}} \mathrm{O}\right)$

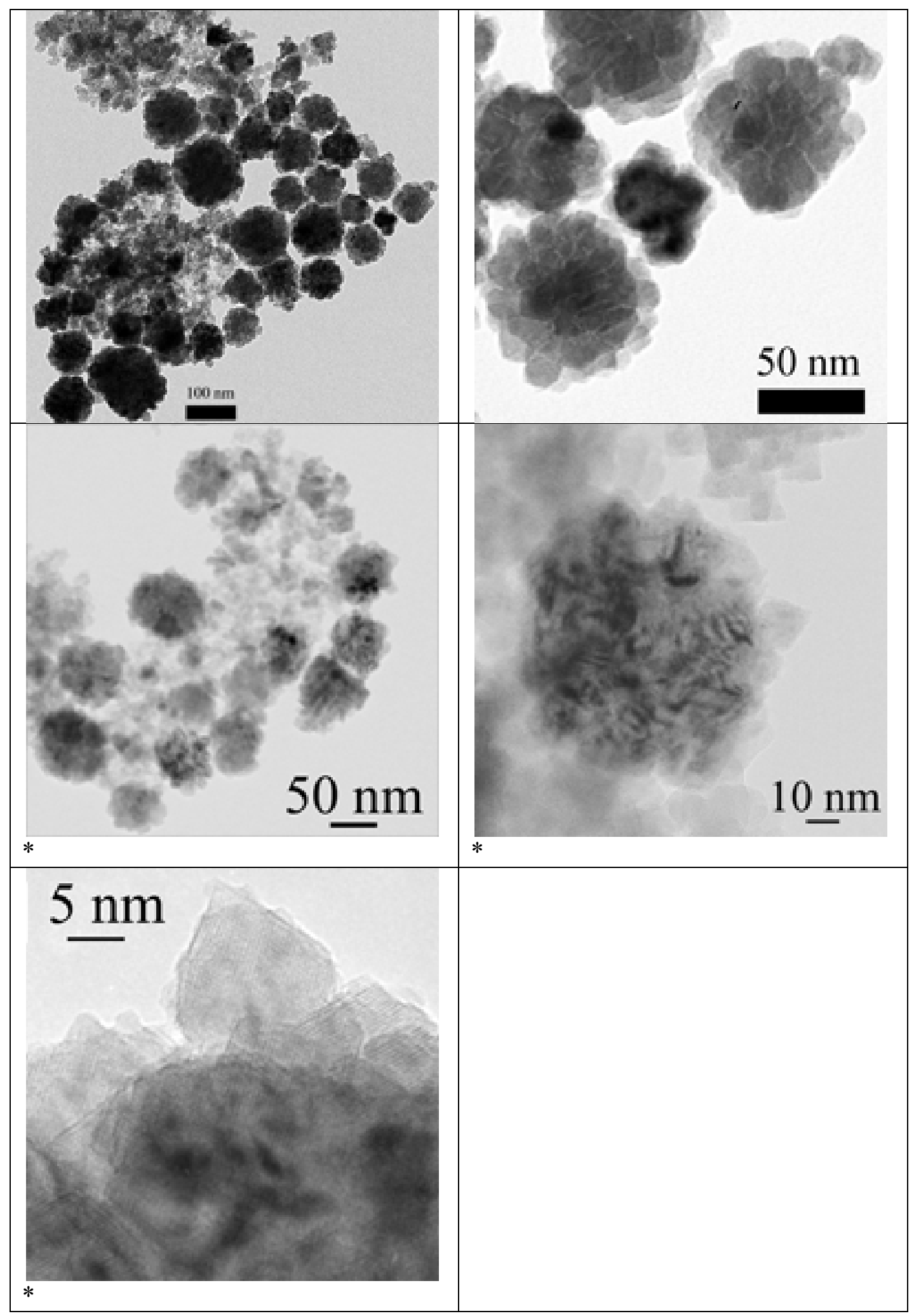




\subsection{Effect of Adding $\mathrm{H}_{2} \mathrm{O}$ to Reaction Solution}

After investigating how altering the ratios of surfactants and metal precursors affected nanoparticle products, the next variable examined was the presence of water in the reaction solution. In these cases degassed HPLC-grade water was added to the solution immediately after drying the metal precursors and adding the surfactants TOA and OA. These reactions were done with $1 \mathrm{mmol}$ of each metal precursor, $6 \mathrm{~mL}$ TOA, $2 \mathrm{~mL} \mathrm{OA}$ and 2 minutes of growth after nanoparticle formation began. The volumes of water added were rounded to the nearest mmol of water, with a minimum of $20 \mu \mathrm{L}(1.11 \mathrm{mmol}$, Table 3.18$)$ due to the limitation of the micropipette used. Other amounts investigated were 2, 3 and $4 \mathrm{mmol}_{2} \mathrm{O}$, shown in Tables 3.19, 3.20 and 3.21. The former were achieved by adding $36 \mu \mathrm{L} \mathrm{H}_{2} \mathrm{O}$ and $54 \mu \mathrm{L} \mathrm{H}_{2} \mathrm{O}$ respectively; the latter by not drying the cobalt precursor, $\mathrm{Co}(\mathrm{OAc})_{2} \cdot 4 \mathrm{H}_{2} \mathrm{O}$. All nanoparticles formed in these reactions had the rock salt-type face-centered cubic crystal lattice. The final Co-to-Mn ratios of the anhydrous and $1.11 \mathrm{mmol} \mathrm{H}_{2} \mathrm{O}$ reactions are approximately $1: 1\left(\mathrm{Co}_{0.49} \mathrm{Mn}_{0.51} \mathrm{O}\right)$, the $2 \mathrm{mmol} \mathrm{H}_{2} \mathrm{O}$ reaction has a stoichiometry of $\mathrm{Co}_{0.58} \mathrm{Mn}_{0.42} \mathrm{O}$, the $3 \mathrm{mmol}_{2} \mathrm{O}$ reaction has a stoichiometry of $\mathrm{Co}_{0.75} \mathrm{Mn}_{0.25} \mathrm{O}$ and the reaction with $4 \mathrm{mmol} \mathrm{H}_{2} \mathrm{O}$ has a stoichiometry of $\mathrm{Co}_{0.69} \mathrm{Mn}_{0.31} \mathrm{O}$. Using reaction conditions similar to those by which $\mathrm{MnO}$ hexapods ${ }^{47}$ were synthesized (6 mL TOA, $2 \mathrm{~mL}$ OA, 9:1 Mn:Co precursor ratio, $100 \mu \mathrm{L}$ added $\mathrm{H}_{2} \mathrm{O}$ ) gives rise to the variety of shapes shown in Table 3.22. 
Table 3.18. TEM images of nanoparticles synthesized with $20 \mu \mathrm{L}(1.11$ mmol) added

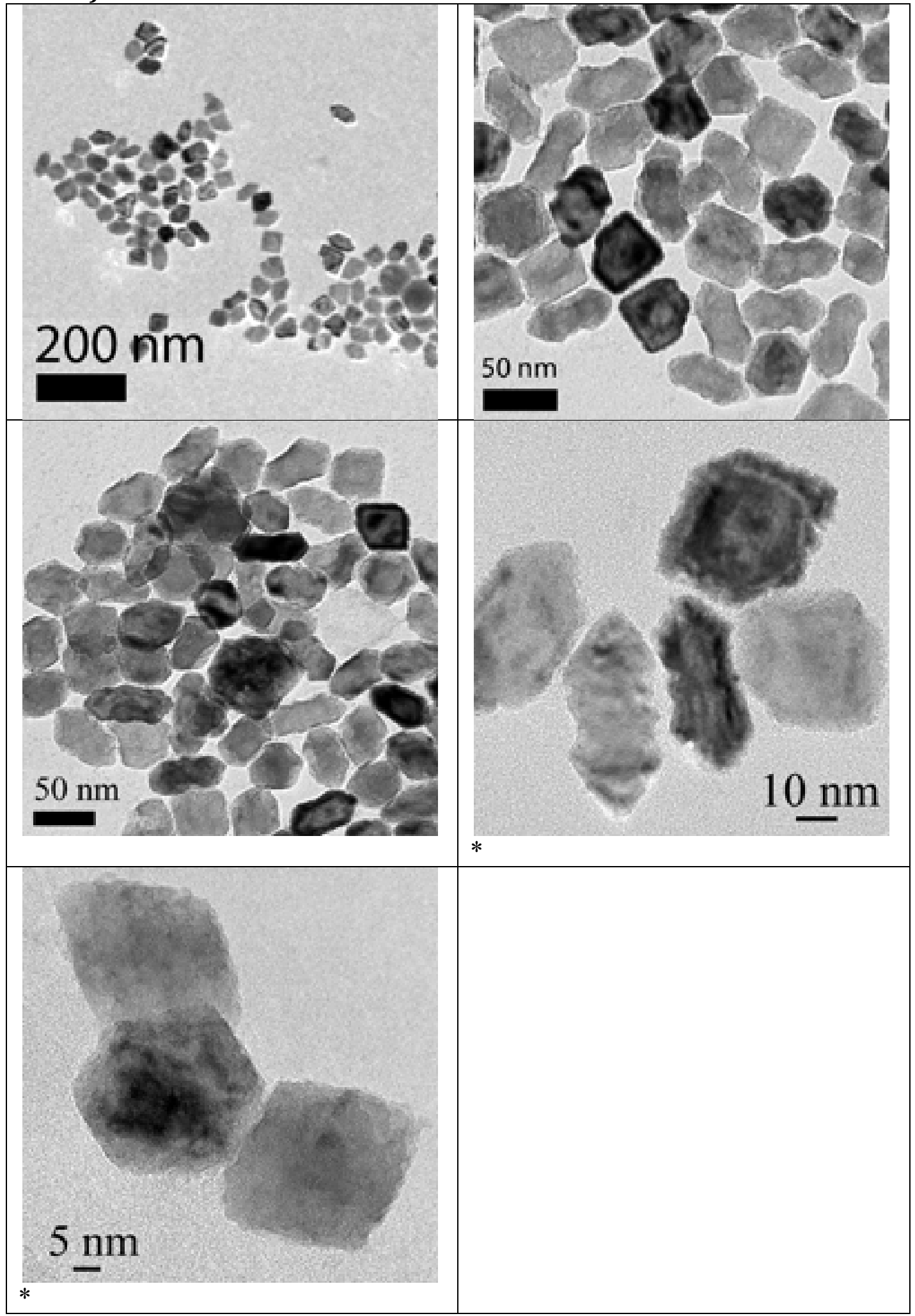


Table 3.19. TEM images of nanoparticles synthesized with $36 \mu \mathrm{L}(2 \mathrm{mmol})$ added

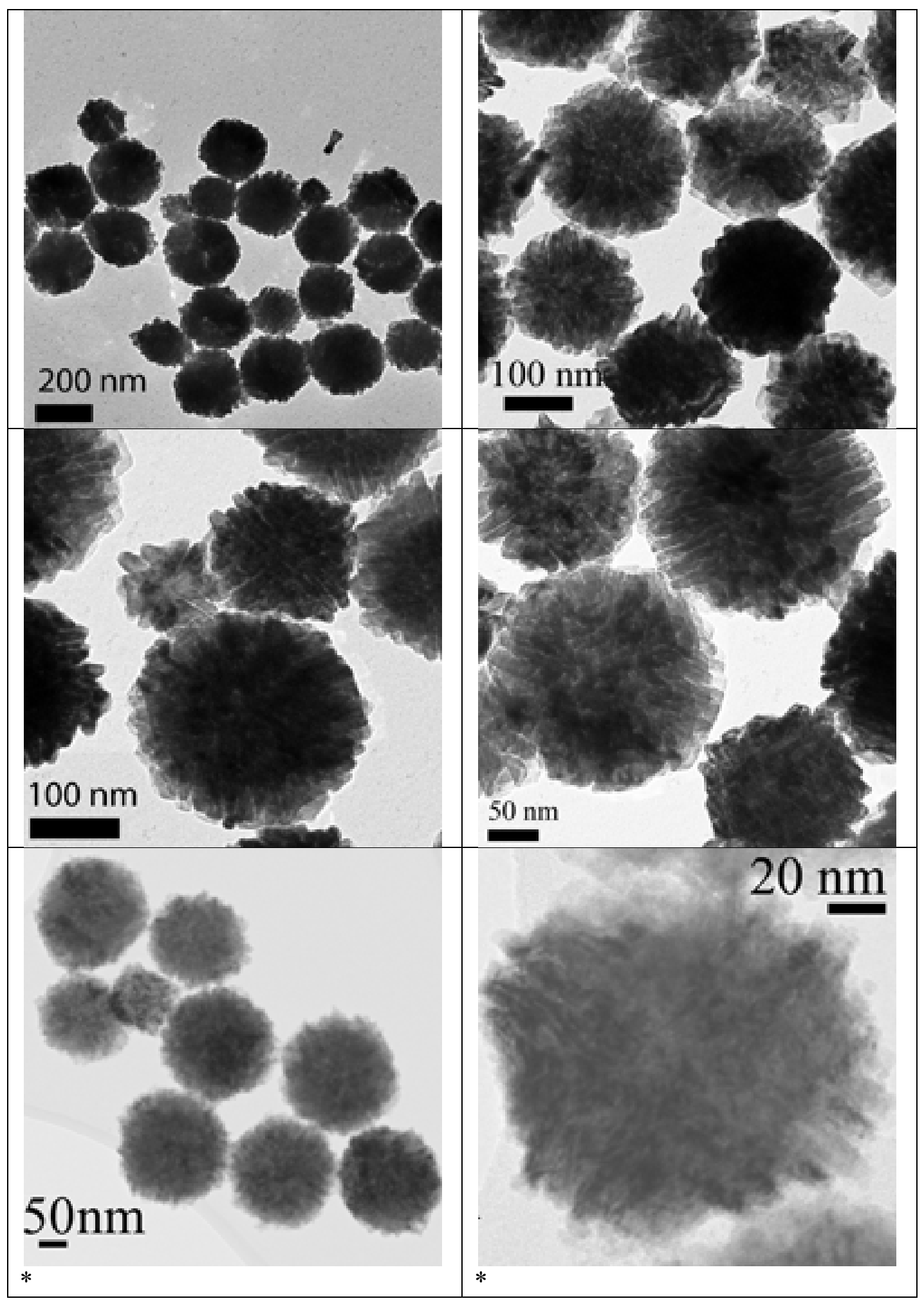


Table 3.20. TEM images of nanoparticles synthesized with $54 \mu \mathrm{L}$ (3 mmol) added

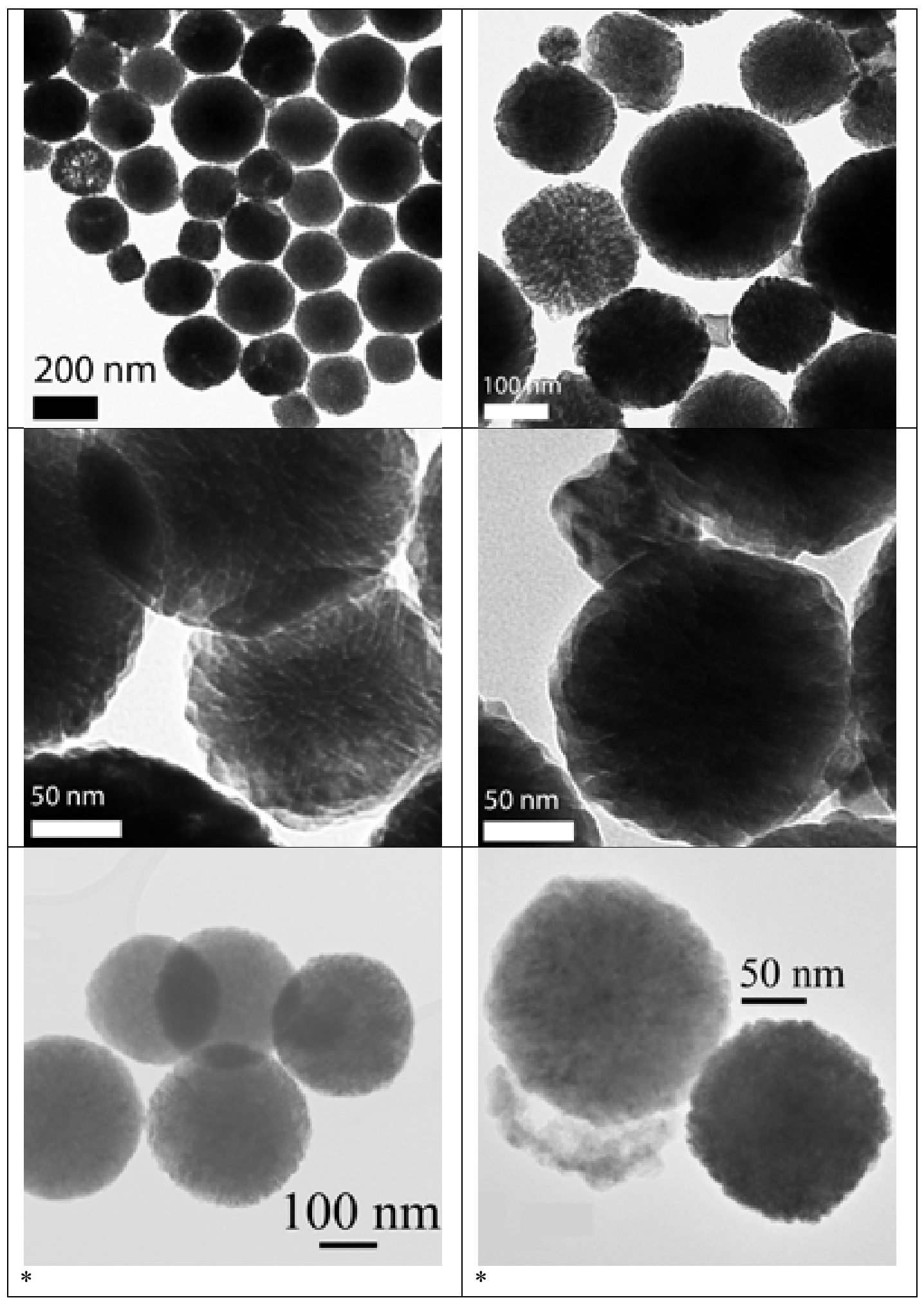


Table 3.21. TEM images of nanoparticles synthesized with $\mathrm{Co}(\mathrm{OAc})_{2} \cdot 4 \mathrm{H}_{2} \mathrm{O}$ that was not dried beforehand

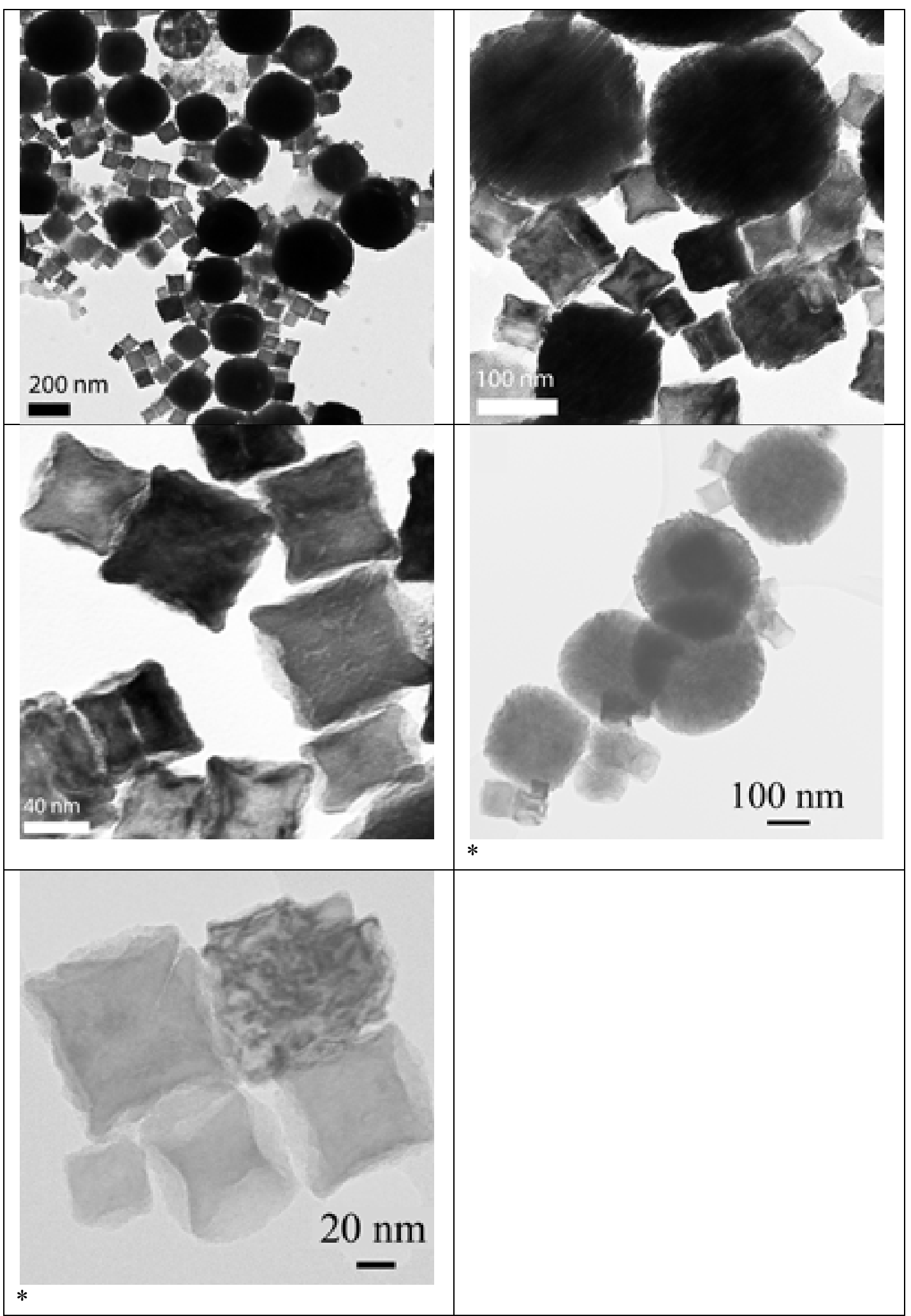


Table 3.22. TEM images of nanoparticles synthesized with a 9:1 ratio of $\mathrm{Mn}$ :Co molecular precursors with $100 \mu \mathrm{L} \mathrm{H2O}$ added; SAED pattern is for the doubly branched particle at the bottom

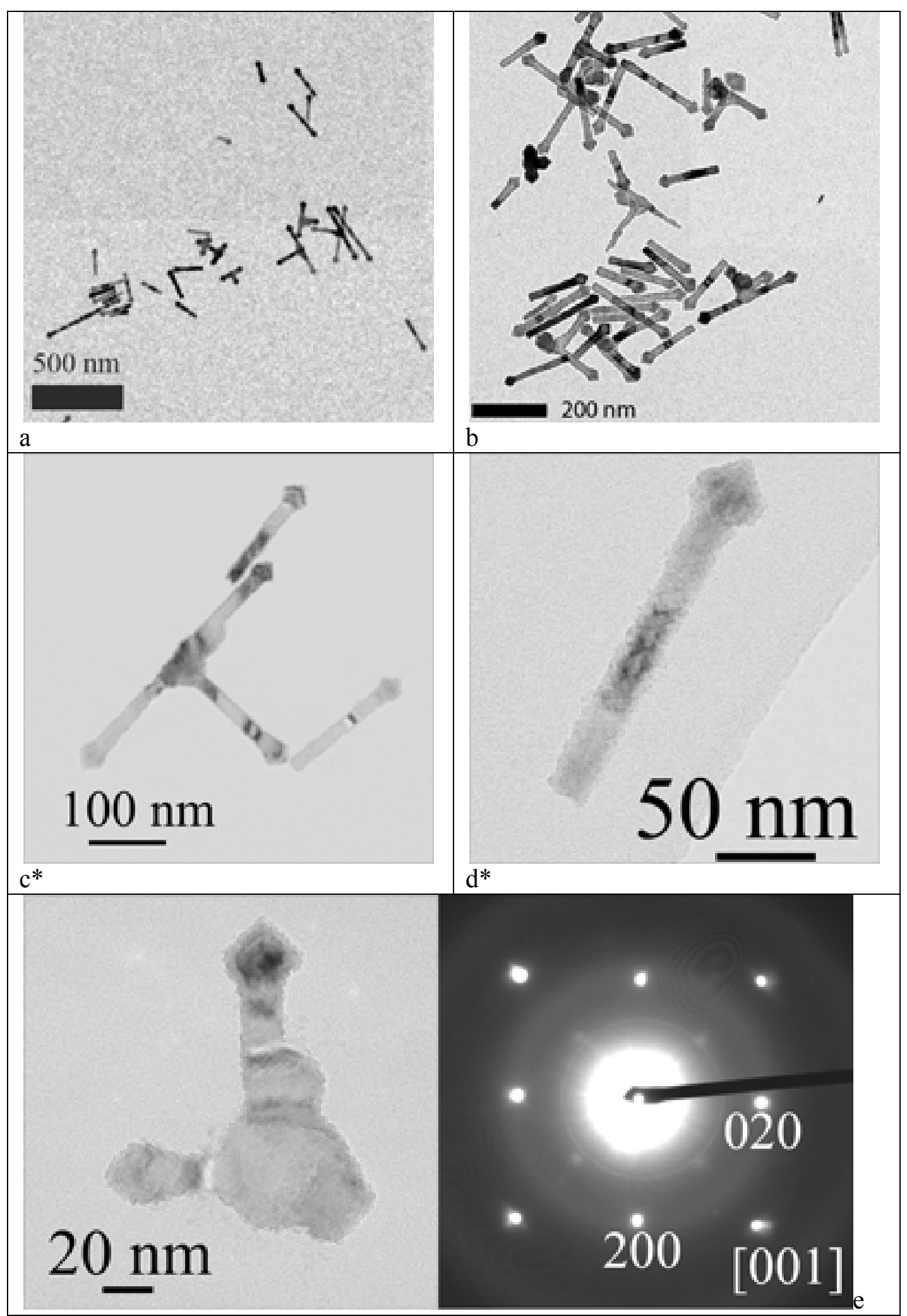




\subsection{Effect of Changing Molecular Precursor: OA Ratio}

This series of reactions tested the way changing the amount of metal precursors in the reaction altered nanoparticle crystal structure and morphology. All experiments were done with a 1:1 ratio of $\mathrm{Mn}: \mathrm{Co}$ in $6 \mathrm{~mL}$ TOA, $2 \mathrm{~mL}$ OA (6.2 mmol), no added water and with 2 minutes of growth after nanoparticle formation. Amounts investigated were 1, 2, 3 and 4 total mmol of metal precursors. These results are shown in Tables 3.23 through 3.26; the results for reaction condition of $2 \mathrm{mmol}$ precursor has already been shown in Table 3.9. Reactions with $2 \mathrm{mmol}$ metal precursors or more gave products with the rs- $\mathrm{Co}_{1-\mathrm{x}} \mathrm{Mn}_{\mathrm{x}} \mathrm{O}$ structure. With $0.5 \mathrm{mmol}$ of each precursor present (i.e., $1 \mathrm{mmol}$ total metal carboxylate precursor: $6.3 \mathrm{mmol} \mathrm{OA}$ ), two products are recovered from the reaction, very much like those found when reacting $5 \mathrm{~mL}$ TOA: $3 \mathrm{~mL}$ OA with $1 \mathrm{mmol}$ of each metal precursor. As in that experiment, the solution color change occurred above $370^{\circ} \mathrm{C}$ with a transition to dark emerald green. One difference is that only a very small amount of material (less than $1 \mathrm{mg}$ ) was recovered after centrifugation in hexanes and no x-ray diffraction could be obtained from the sample. The supernatant product was a mixture of rs- and w$\mathrm{Co}_{1-\mathrm{x}} \mathrm{Mn}_{\mathrm{x}} \mathrm{O}$. These XRD results are shown in Figures 3.14 and 3.15. Increasing the amount of precursor to $2 \mathrm{mmol}$ (Table $\mathrm{x}$ ) decreases the solution color change temperature to $\sim 365^{\circ} \mathrm{C}$ and gives a green-gray solution; for $3 \mathrm{mmol}$ solution color changes at $340^{\circ}-345^{\circ} \mathrm{C}$ to green-yellow; and with $4 \mathrm{mmol}$ at $330^{\circ}-335^{\circ} \mathrm{C}$ to gray. Each of the products shown in Tables 3.25 and 3.26 precipitated upon centrifugation in hexanes and had x-ray diffraction patterns that indexed to rs- $\mathrm{Co}_{1-}$ 
${ }_{x} \mathrm{Mn}_{\mathrm{x}} \mathrm{O}$. Stoichiometries for the samples shown in Tables Table 3.25 and Table 3.26are $\mathrm{Co}_{0.67} \mathrm{Mn}_{0.33} \mathrm{O}$ and $\mathrm{Co}_{0.54} \mathrm{Mn}_{0.46} \mathrm{O}$, respectively.

Table 3.23. TEM images of nanoparticles synthesized with 1 mmol metal precursors that precipitated upon centrifugation in hexanes

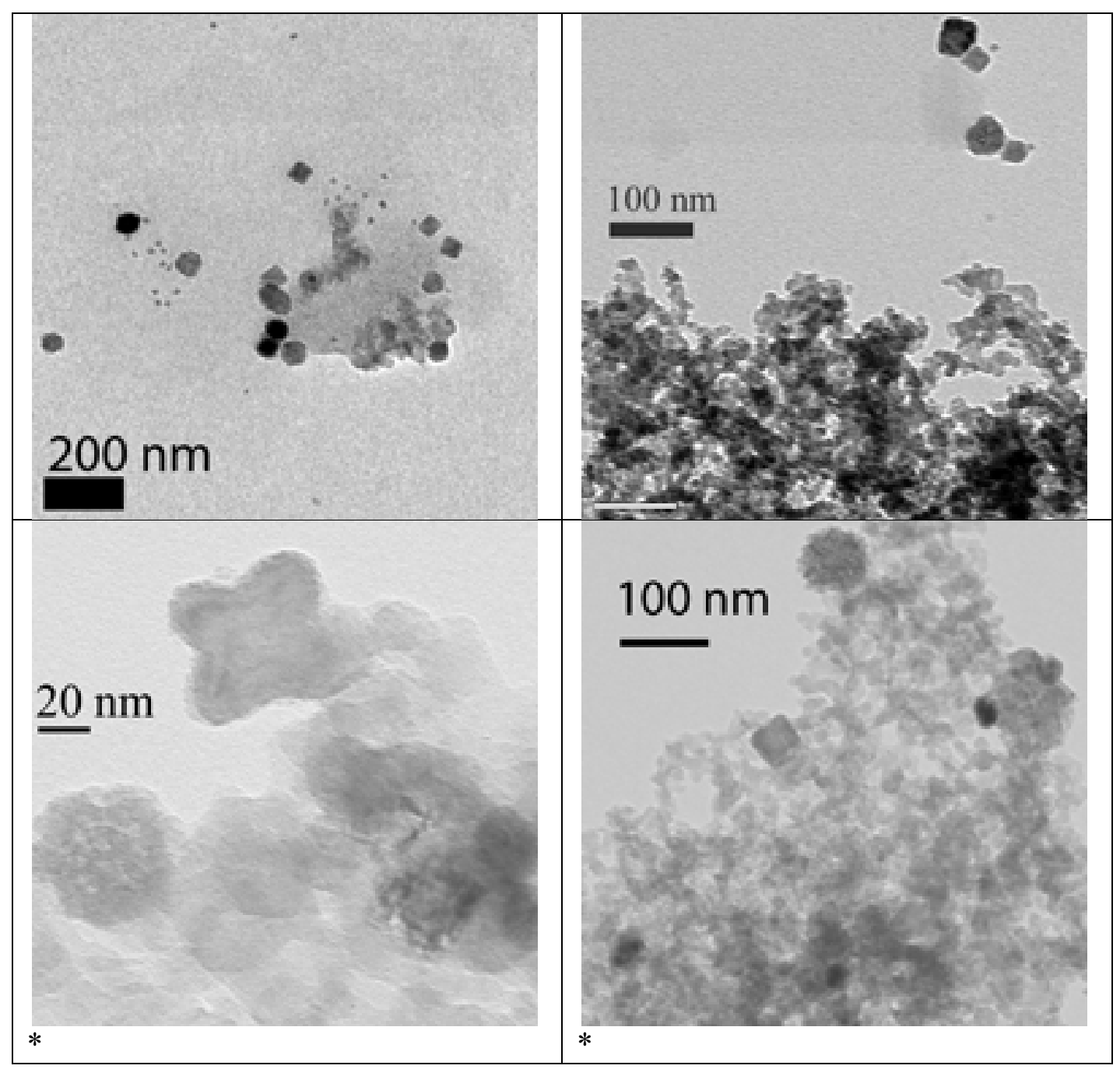


Table 3.24. TEM images of nanoparticles synthesized with $1 \mathrm{mmol}$ metal precursors recovered from hexanes centrifugation supernatant

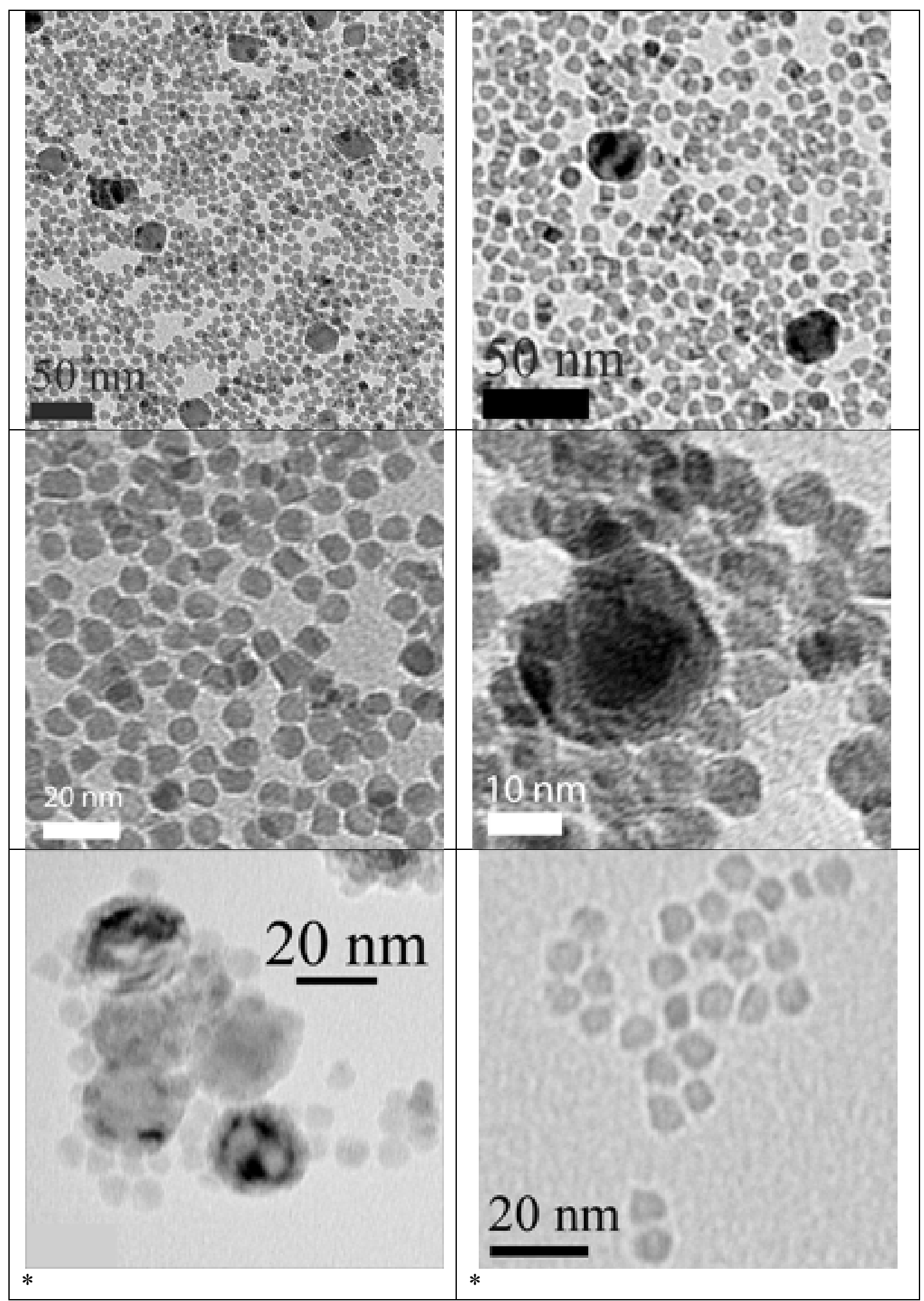


Table 3.25. TEM images of nanoparticles synthesized with 3 mmol metal precursors

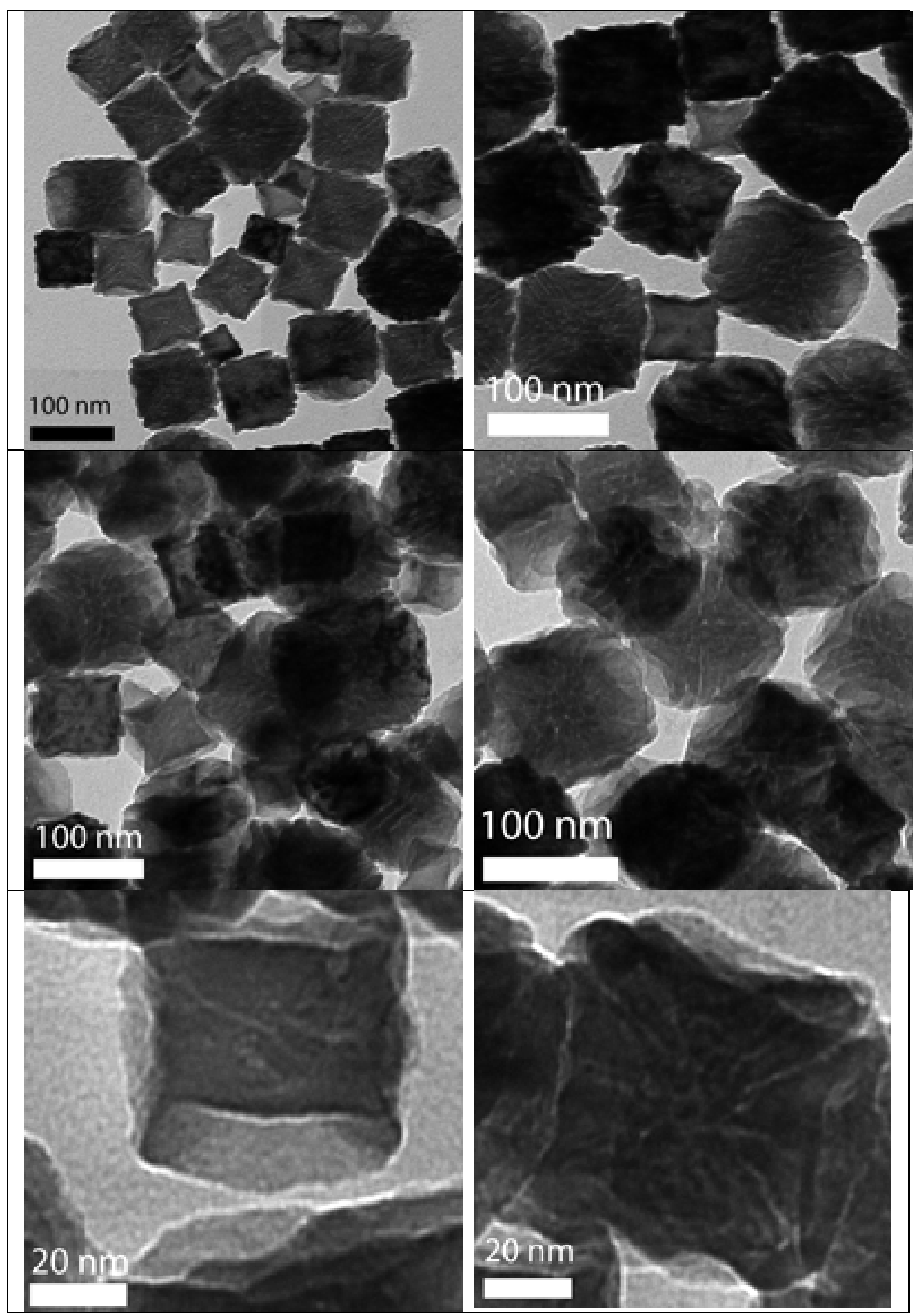


Table 3.26. TEM images of nanoparticles synthesized with 4 mmol metal precursors

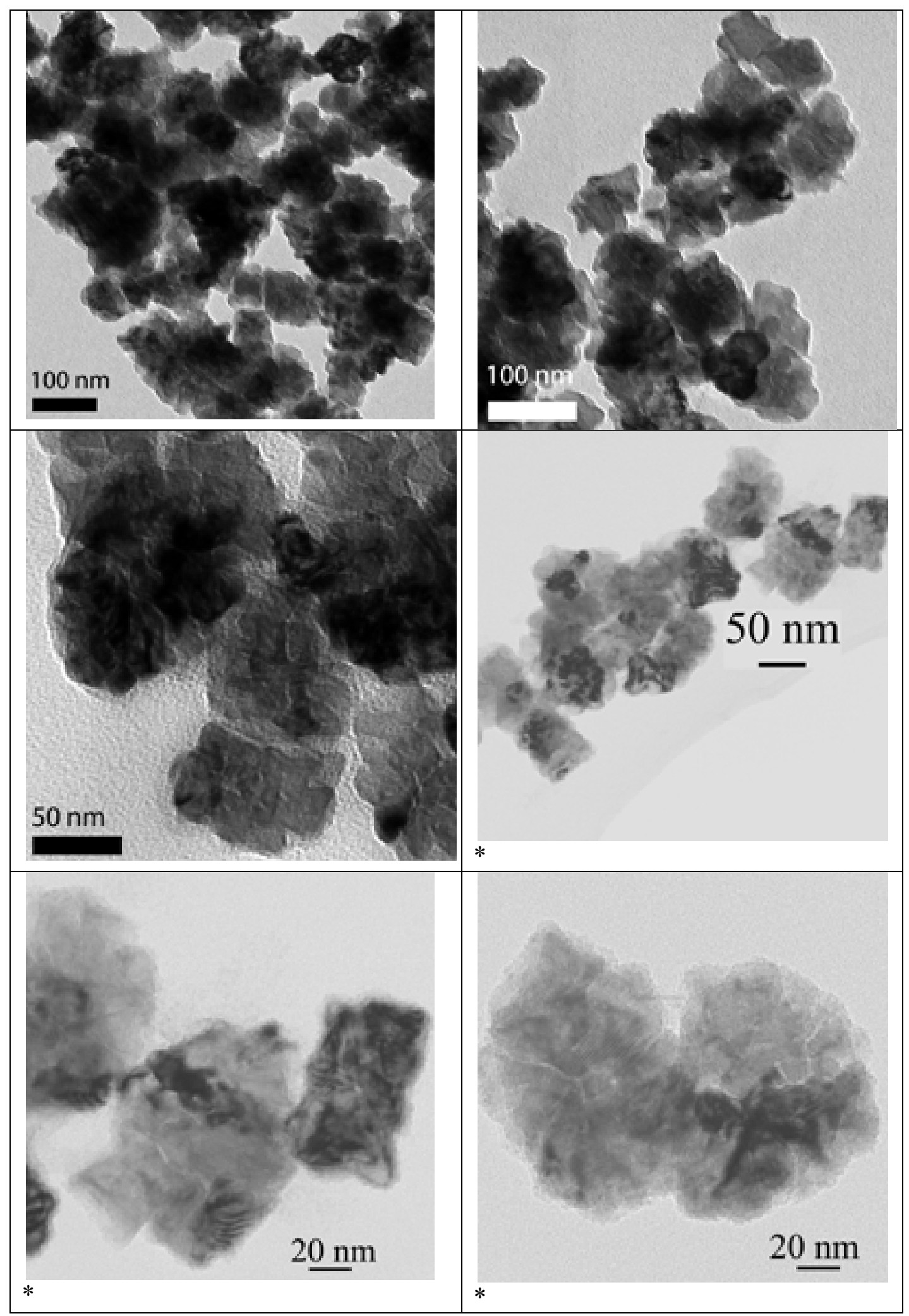




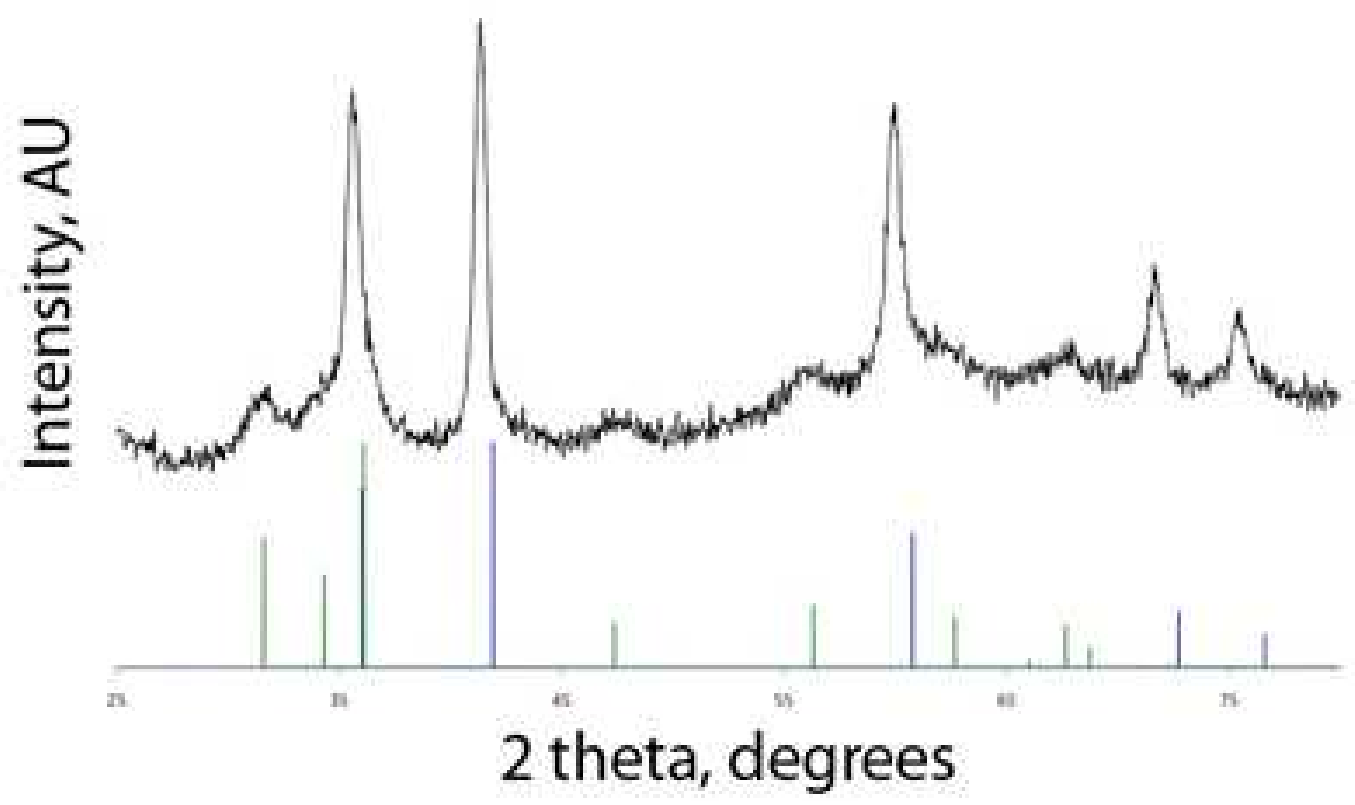

Figure 3.14. XRD pattern of product recovered from supernatant of reaction with 1 mmol metal precursors. Reference pattern for hexagonal $\mathrm{ZnO}$-type lattice is shown in green; for face centered cubic MnO-type lattice in blue.
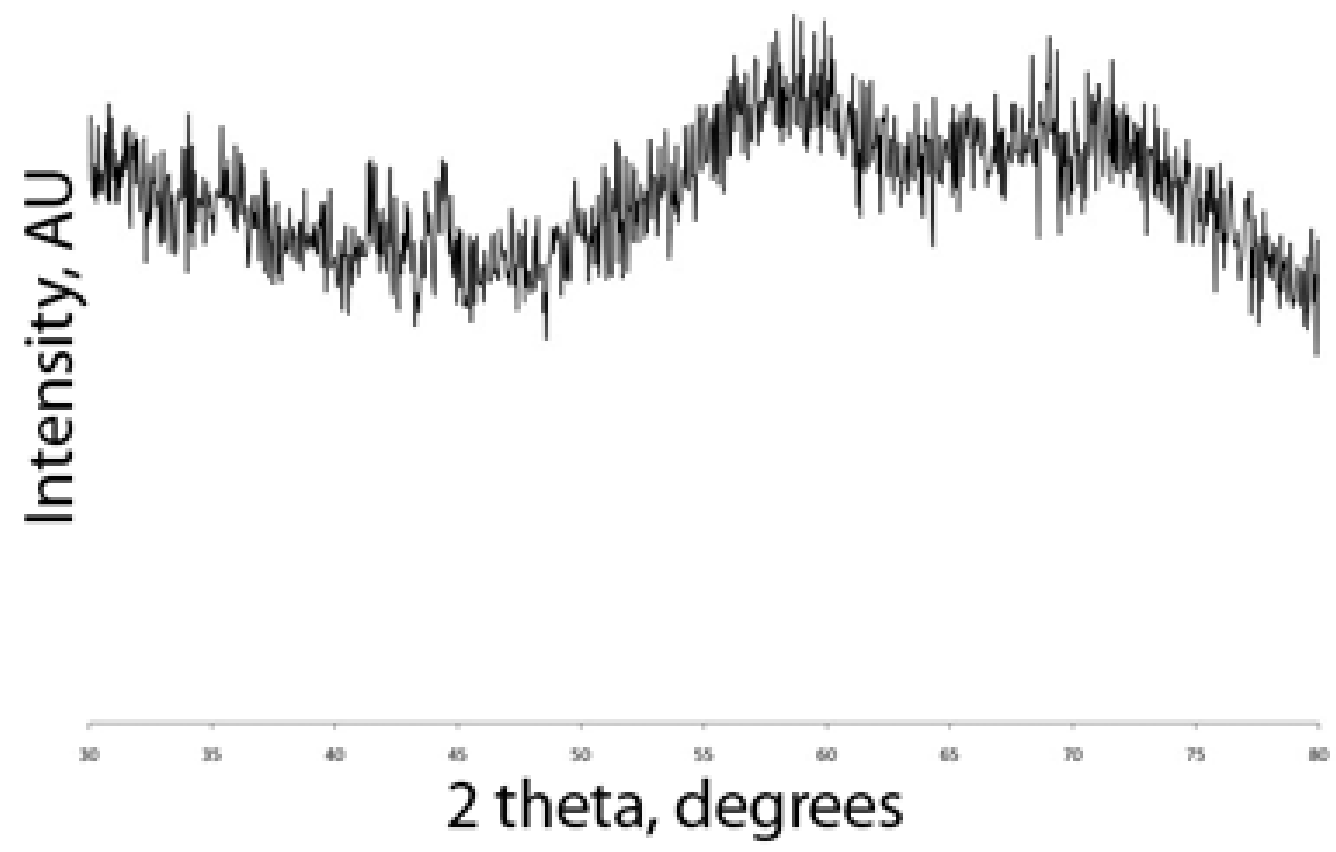

Figure 3.15. XRD pattern of product recovered from precipitate of reaction with $1 \mathrm{mmol}$ metal precursors. The lack of sharp peaks indicates a non-crystalline, amorphous solid. 


\subsection{Effect of Extending Growth Time}

In all reaction presented in the preceding sections, the reaction was heated for two minutes after the color change to allow for nanoparticle growth and ripening. One set of reaction conditions was chosen to examine how longer reaction times might alter nanoparticle formation: $6 \mathrm{~mL}$ TOA, $2 \mathrm{~mL}$ OA with no water and $0.5 \mathrm{mmol}$ each of $\mathrm{Co}(\mathrm{OAc})_{2}$ and $\mathrm{Mn}(\mathrm{HCOO})_{2}$. This reaction condition, discussed earlier and with results in Tables 3.23 and 3.24, resulted in nanoparticles of both types of lattices: rs- and w- $\mathrm{Co}_{1-\mathrm{x}} \mathrm{Mn}_{\mathrm{x}} \mathrm{O}$, with $\mathrm{w}-\mathrm{Co}_{1-\mathrm{x}} \mathrm{Mn}_{\mathrm{x}} \mathrm{O}$ particles retrieved from the supernatant after centrifugation in hexanes. Growth times were extended out to 5 and 10 minutes after solution color change to dark emerald green (at or above $370^{\circ} \mathrm{C}$ ) with solution temperatures kept elevated above $360^{\circ} \mathrm{C}$. Attempts were made to extend the growth time further than 10 minutes, but in every case the heating mantle was unable to consistently keep the solution temperature near the decomposition temperature for that length of time. The case of 2 minutes growth time gave nearly no precipitate upon centrifugation in hexanes, but reactions with extended growth time did yield increasing amounts of material - the amount did not exceed $10 \%$ of that recovered from the supernatant, however. Figure 3.16 shows how the XRD pattern of the material recovered from the supernatant of each of these reactions evolves with increasing growth time. 
Table 3.27. 5 minutes growth for reaction with $6 \mathrm{~mL}$ TOA, $2 \mathrm{~mL} \mathrm{OA}$ with no water and $0.5 \mathrm{mmol}$ of each precursor. This material (5-SN) was recovered from the supernatant after centrifugation in hexanes.

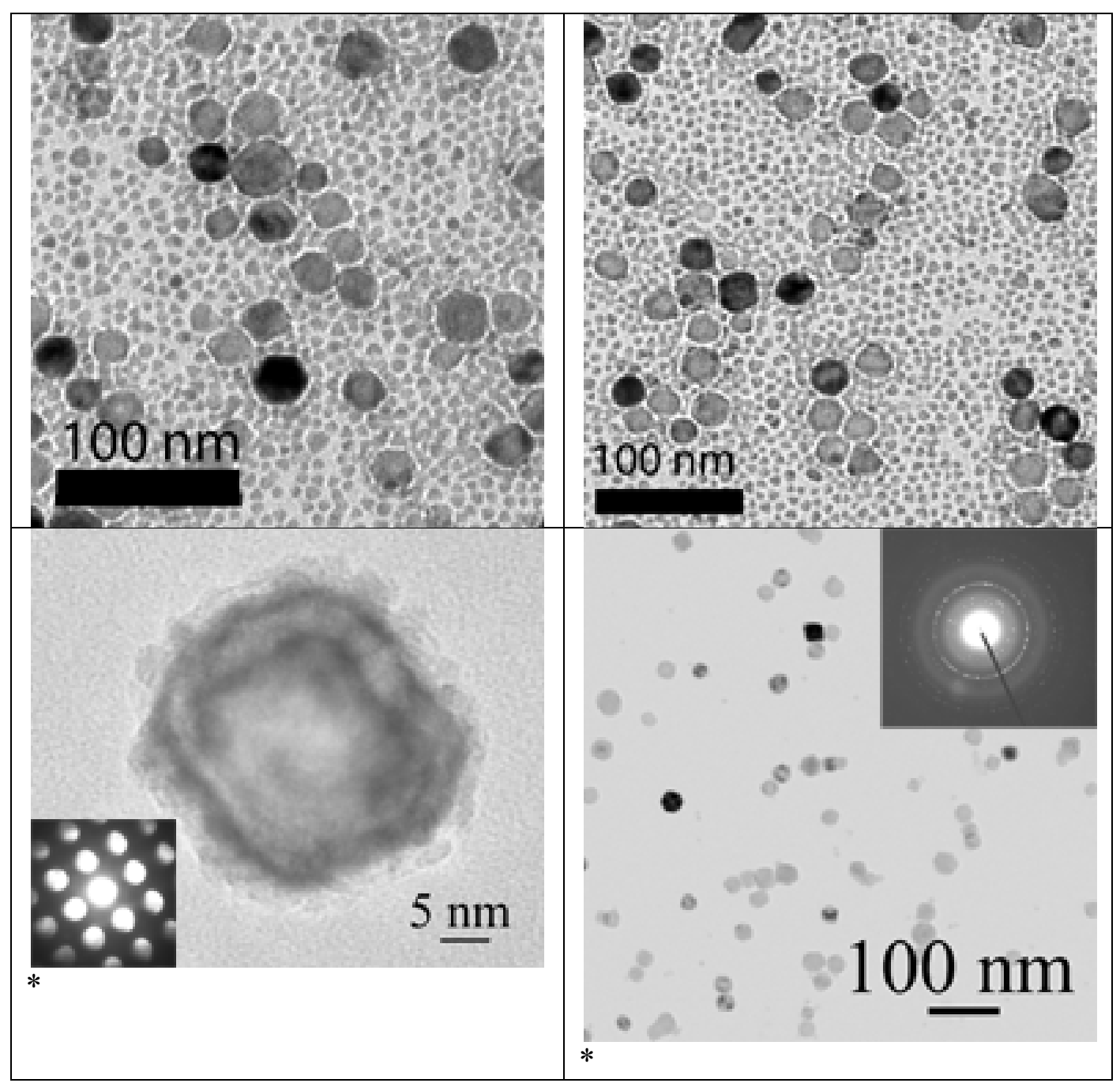


Table 3.28. 5 minutes growth for reaction with $6 \mathrm{~mL}$ TOA, $2 \mathrm{~mL} \mathrm{OA}$ with no water and $0.5 \mathrm{mmol}$ of each precursor. This material (5-PP) was recovered from the precipitate after centrifugation in hexanes.

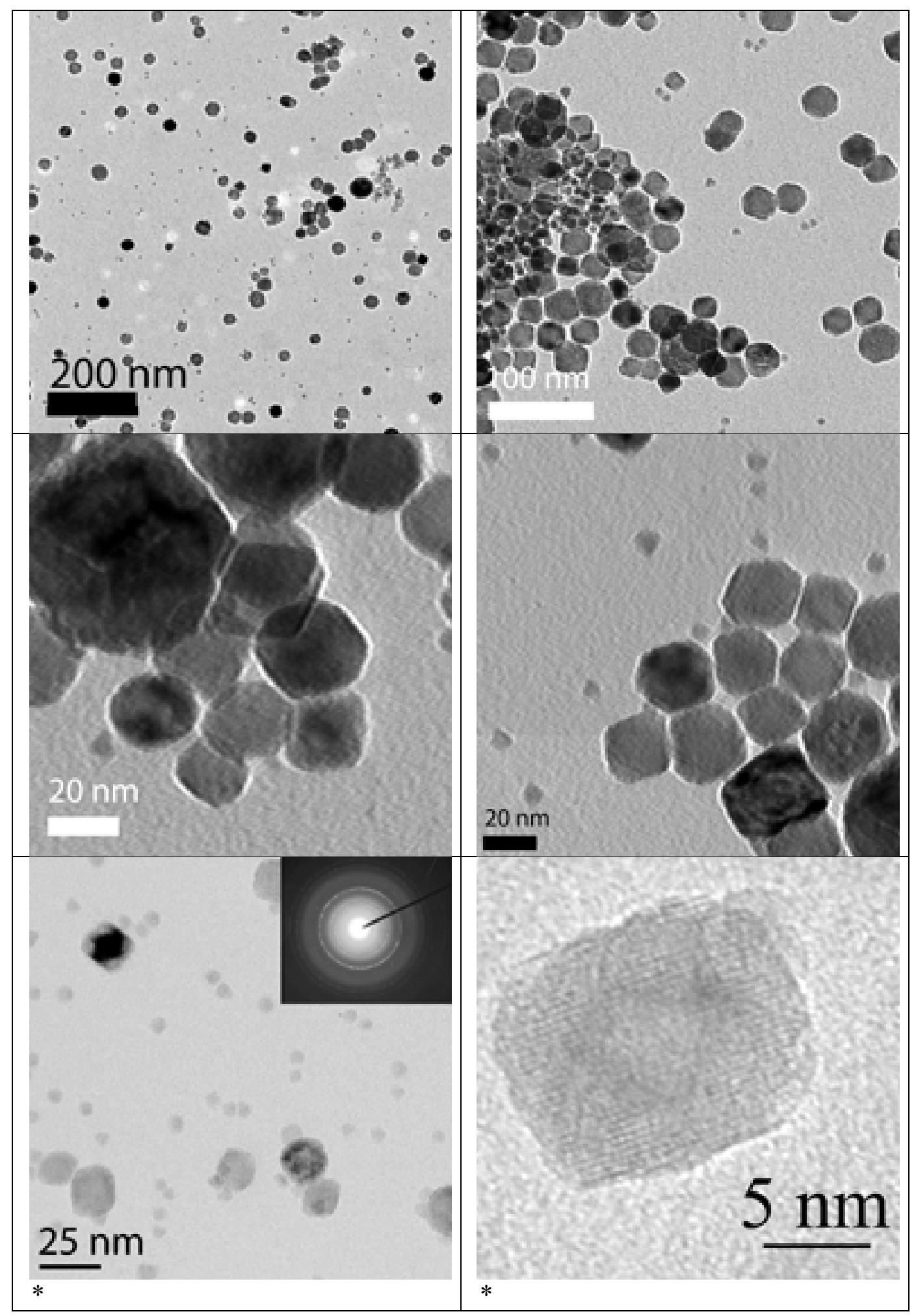


Table 3.29. 10 minutes growth for reaction with $6 \mathrm{~mL}$ TOA, $2 \mathrm{~mL} \mathrm{OA}$ with no water and $0.5 \mathrm{mmol}$ of each precursor. This material (10-SN) was recovered from the supernatant after centrifugation in hexanes.

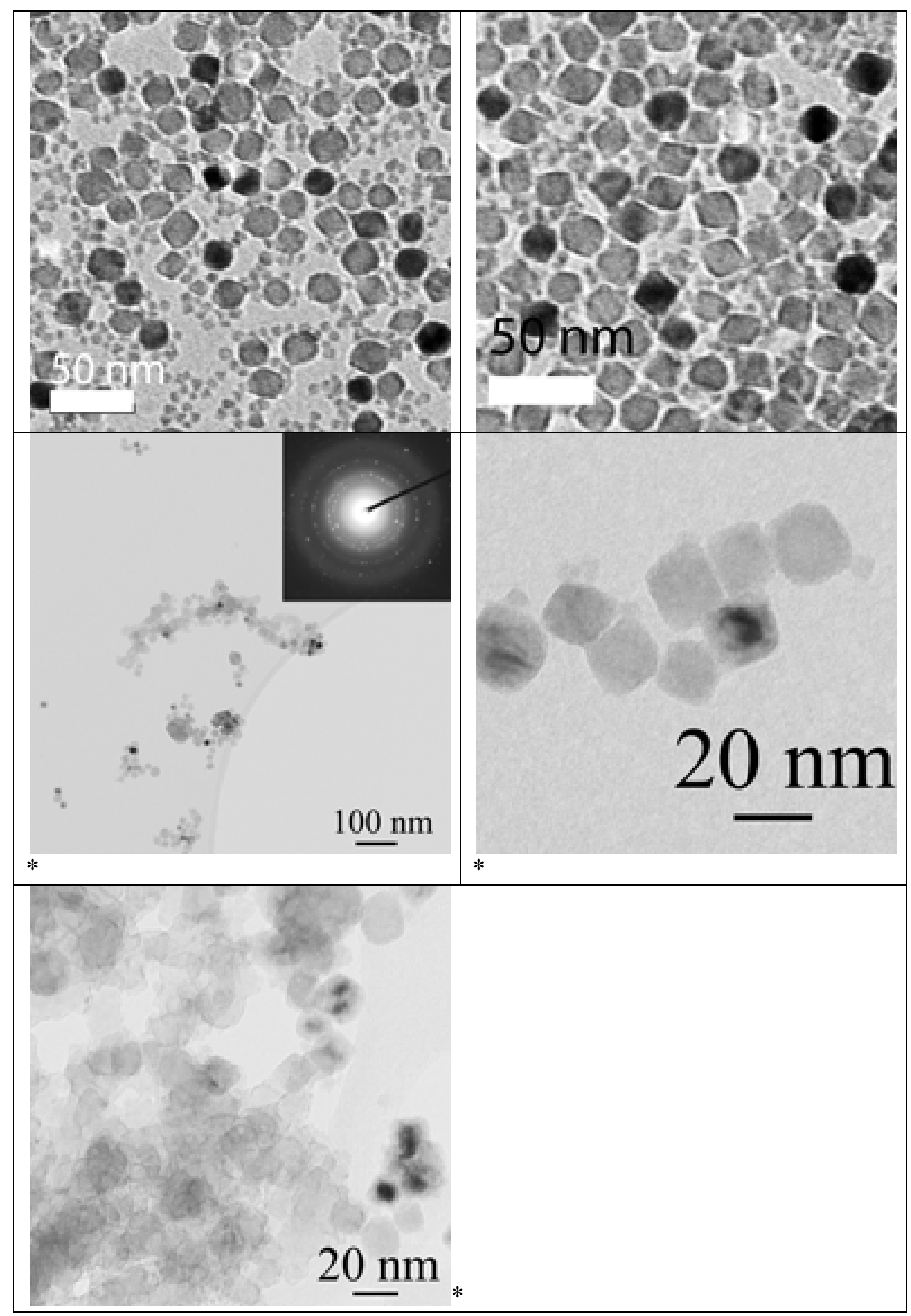


Table 3.30. 10 minutes growth for reaction with $6 \mathrm{~mL}$ TOA, $2 \mathrm{~mL}$ OA with no water and $0.5 \mathrm{mmol}$ of each precursor. This material (10-PP) precipitated upon centrifugation in hexanes.

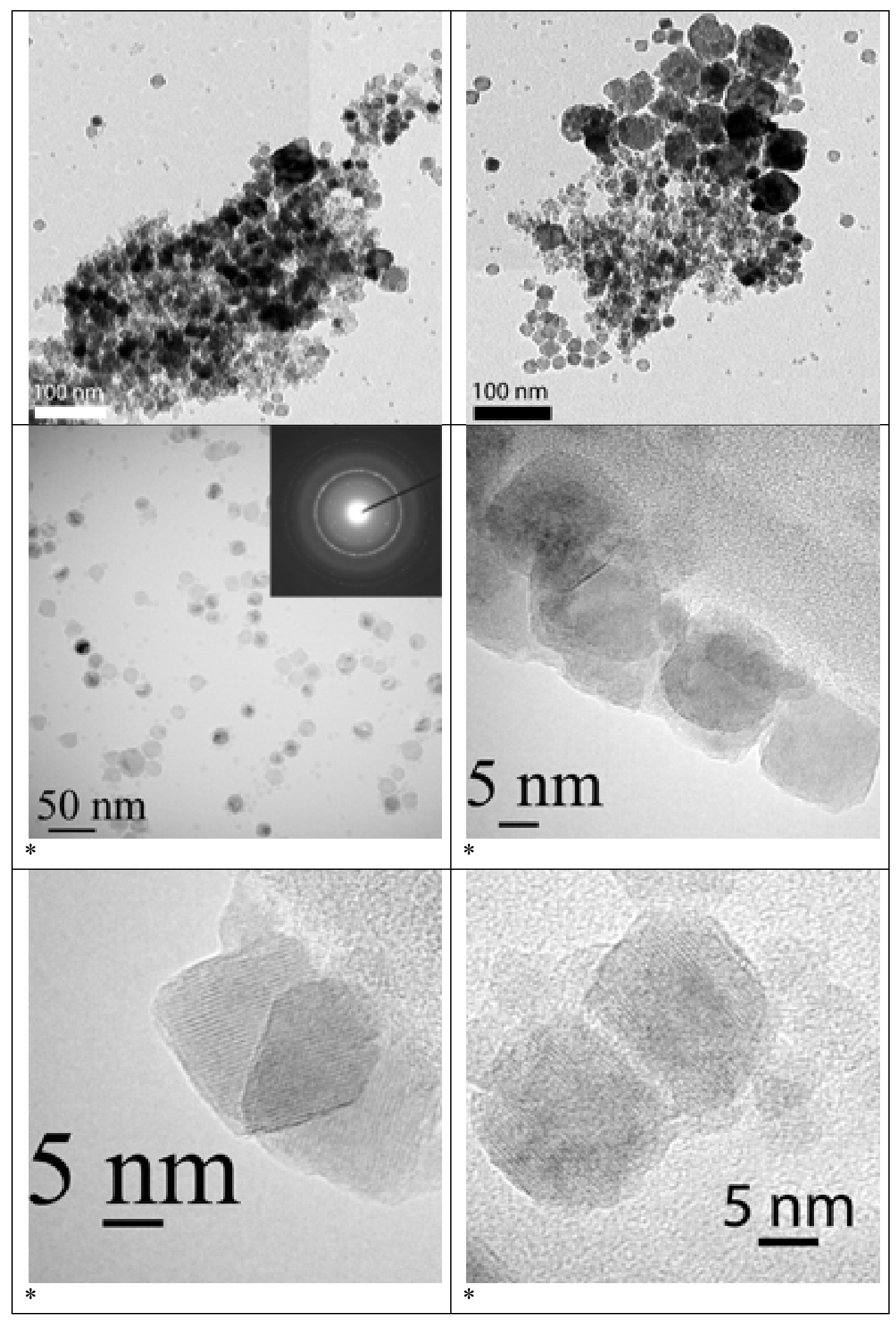




\section{$2 \min$}

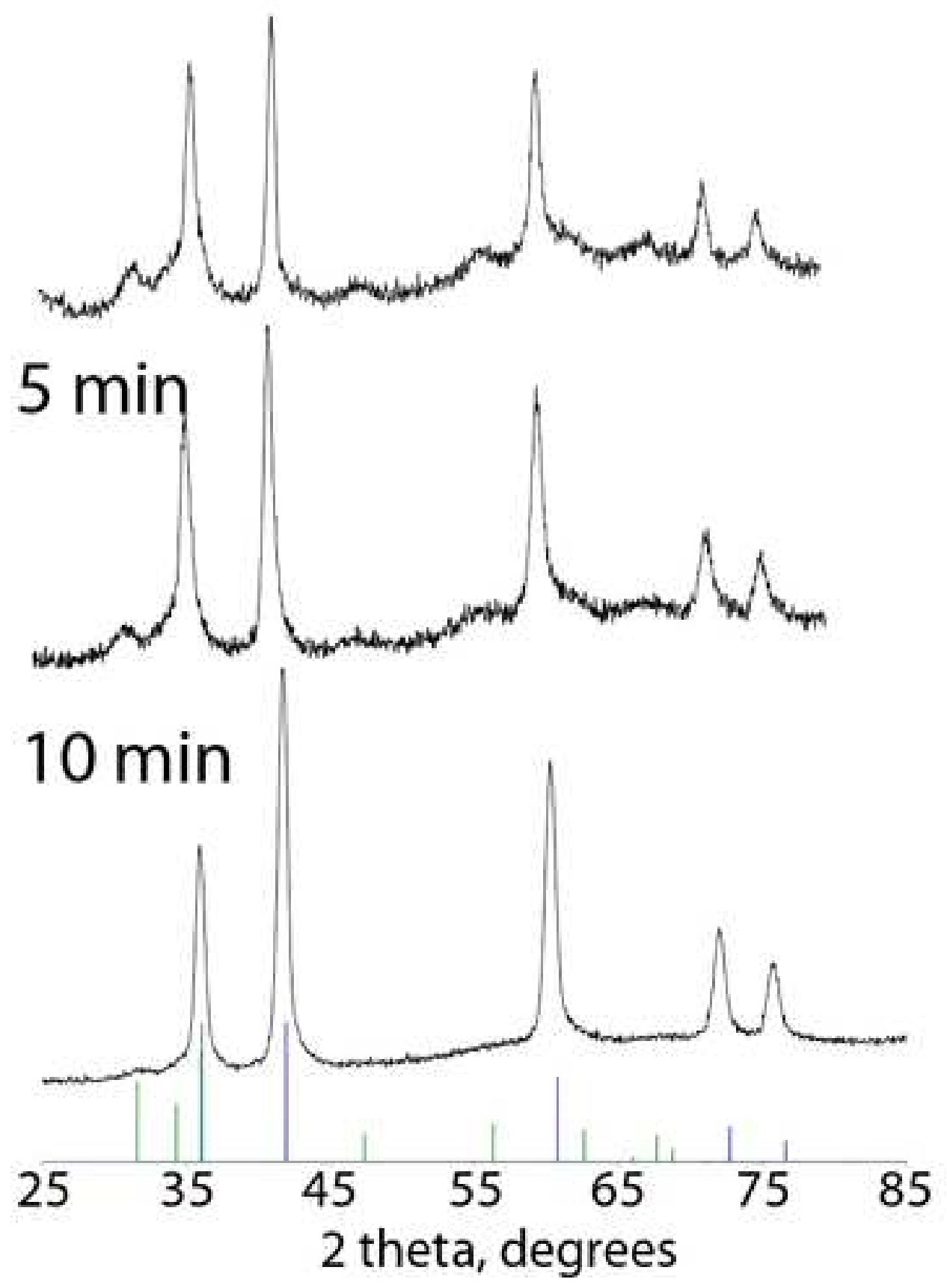

Figure 3.16. Change in XRD patterns for the material collected from the supernatant of reactions with extended growth times under conditions $6 \mathrm{~mL}$ TOA: $2 \mathrm{~mL} \mathrm{OA,} \mathrm{no} \mathrm{water} \mathrm{and} 0.5 \mathrm{mmol}$ each of $\mathrm{Co}(\mathrm{OAc})_{2}$ and $\mathrm{Mn}(\mathrm{HCOO})_{2}$. Reference pattern for a rock salt-structure lattice with $a=4.3 \AA$ is shown in blue; reference $\mathrm{P}_{3} \mathrm{mc}$ lattice with $a=3.2 \AA$ and $c=5.2 \AA$ shown in green. 


\subsection{Effect of Varying the Solution Heating Rate}

One experimental variable (unintentionally) tested was the role consistent heating rates and the ability of the reaction setup to remain at elevated temperatures had on reaction outcomes. This came about due to issues with the inconsistency in heat output of the variable autotransformer-heating mantle setup used to heat the reaction solution. As mentioned in the experimental, all metal precursors and surfactants were mixed together at room temperature and then heated to an elevated temperature, at which a color change occurred marking the decomposition of metallic precursors and beginning of nanoparticle formation. An example of what the heating vs. time curve for a successful reaction is shown in Figure 3.17: the temperature rises at a rate of $25-30^{\circ} \mathrm{C}$ per minute until approximately $300-350^{\circ} \mathrm{C}$, then the heating rate slows due to equipment limitations. Decomposition occurs at $359^{\circ} \mathrm{C}, 14.5$ minutes after heating begins and 2 minutes after reaching $350^{\circ} \mathrm{C}$. The maximum temperature achieved is $363^{\circ} \mathrm{C}$ at 16 minutes; when the heating mantle is removed at 16.5 minutes the temperature is $361^{\circ} \mathrm{C}$.

As mentioned above, in some cases the heating mantle was unable to maintain sufficient output to keep solution temperatures elevated. Typically, a reaction needed to maintain a temperature within $10^{\circ} \mathrm{C}$ of the decomposition temperature for one to three minutes before the color change occurred. Failure to do so generally resulted in three possible outcomes: no solution color change; reduction of the cobalt (II) acetate to cobalt metal; or formation of nanoparticles of different morphology and/or crystal lattice than expected for the reaction 
conditions. Example heating profiles for such reactions are shown in Figure 3.18 and Figure 3.19. In the cases where no color change was observed, the solution would be cooled to room temperature, combined with ethanol and centrifuged to attempt to precipitate nanoparticles. These attempts failed in every case.

Representative TEM images for the products of reactions that had variable heating are shown in Table 3.31. Note that these similar nanoparticle morphologies were the result of a wide variety of starting conditions; the failure to maintain constant heating is the only commonality. Powder XRD analysis of all products resulting from these reactions corresponded to the face-centered cubic lattice seen in previous nanoparticle types. In a few cases the heating mantle output dropped after the solution color change occurred. The solution was kept heated and the reactions were allowed to proceed for various times. Figure 3.20 shows XRD and TEM images for the products of these reactions: Figure 3.20a for $30 \mathrm{~min}$, Figure 3.20b for $45 \mathrm{~min}$, Figure 3.20c for $60 \mathrm{~min}$, and Figure 3.20d for $75 \mathrm{~min}$. The solution temperature did not drop below $345^{\circ} \mathrm{C}$ for of these reactions. 


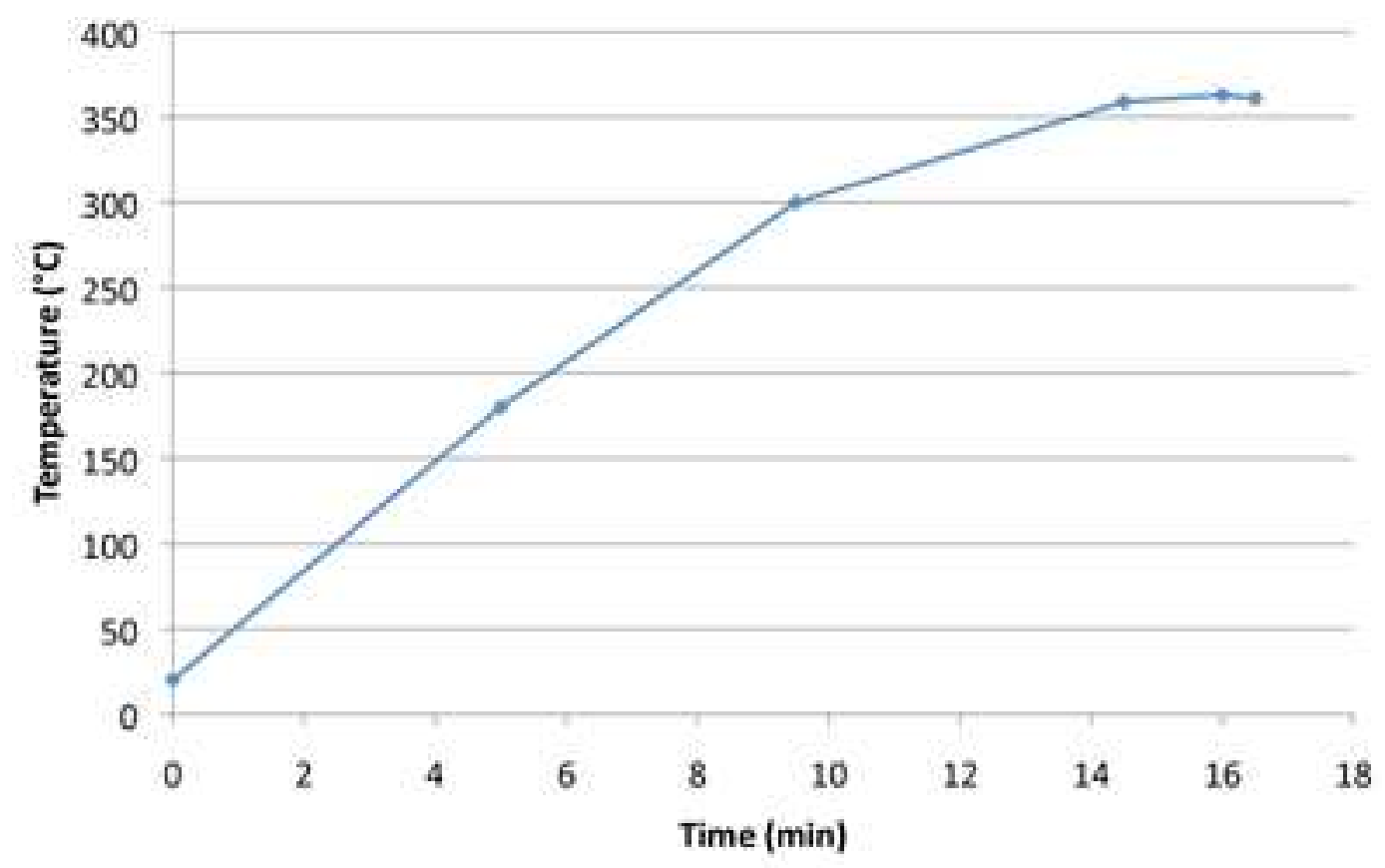

Figure 3.17. Reaction temperature vs. time profile for a standard nanoparticle synthesis reaction. The reaction conditions and results for this particular reaction are discussed along with Table 3.18.

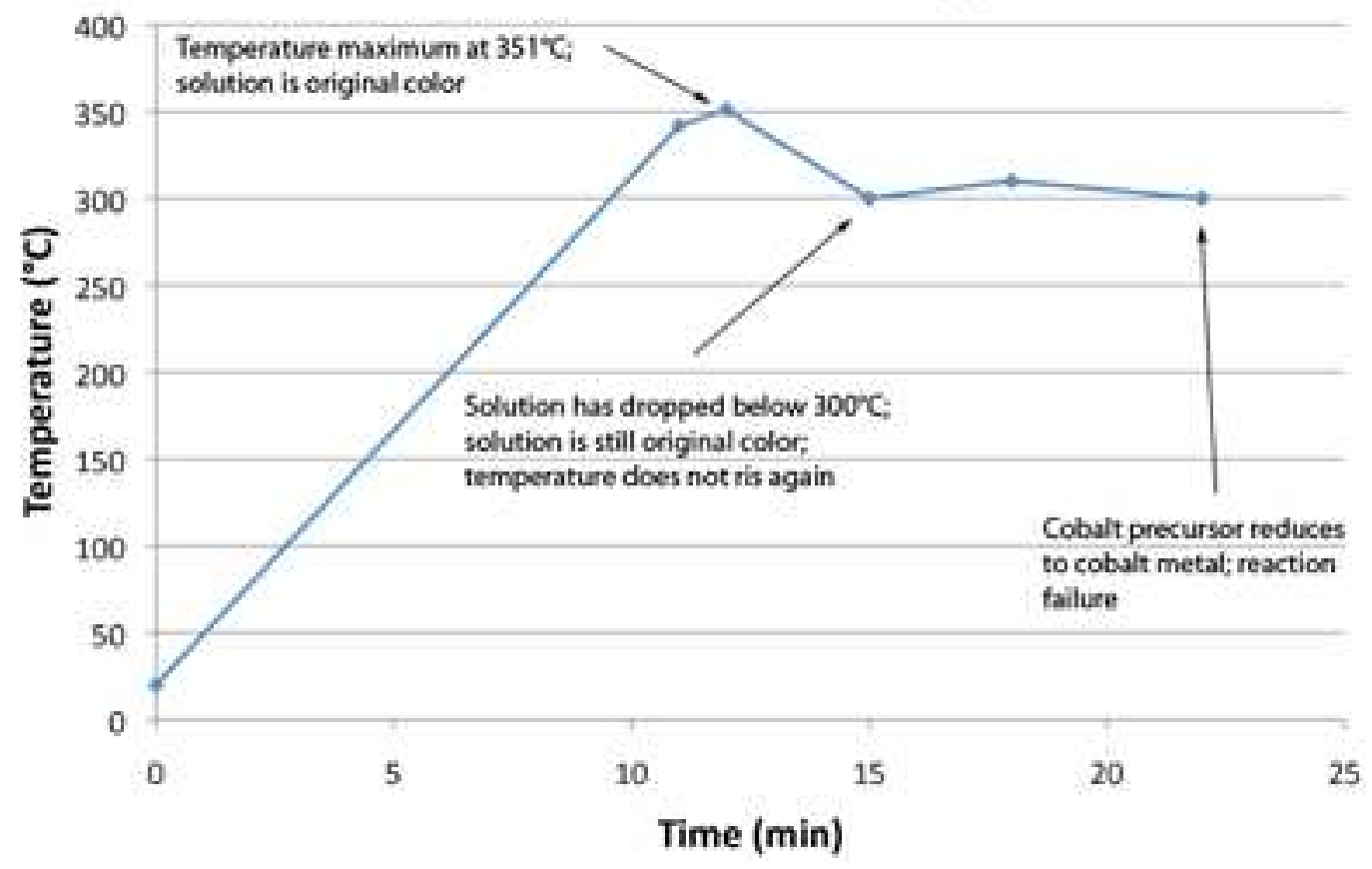

Figure 3.18. Reaction temperature vs. time comparison for a failed nanoparticle synthesis. 


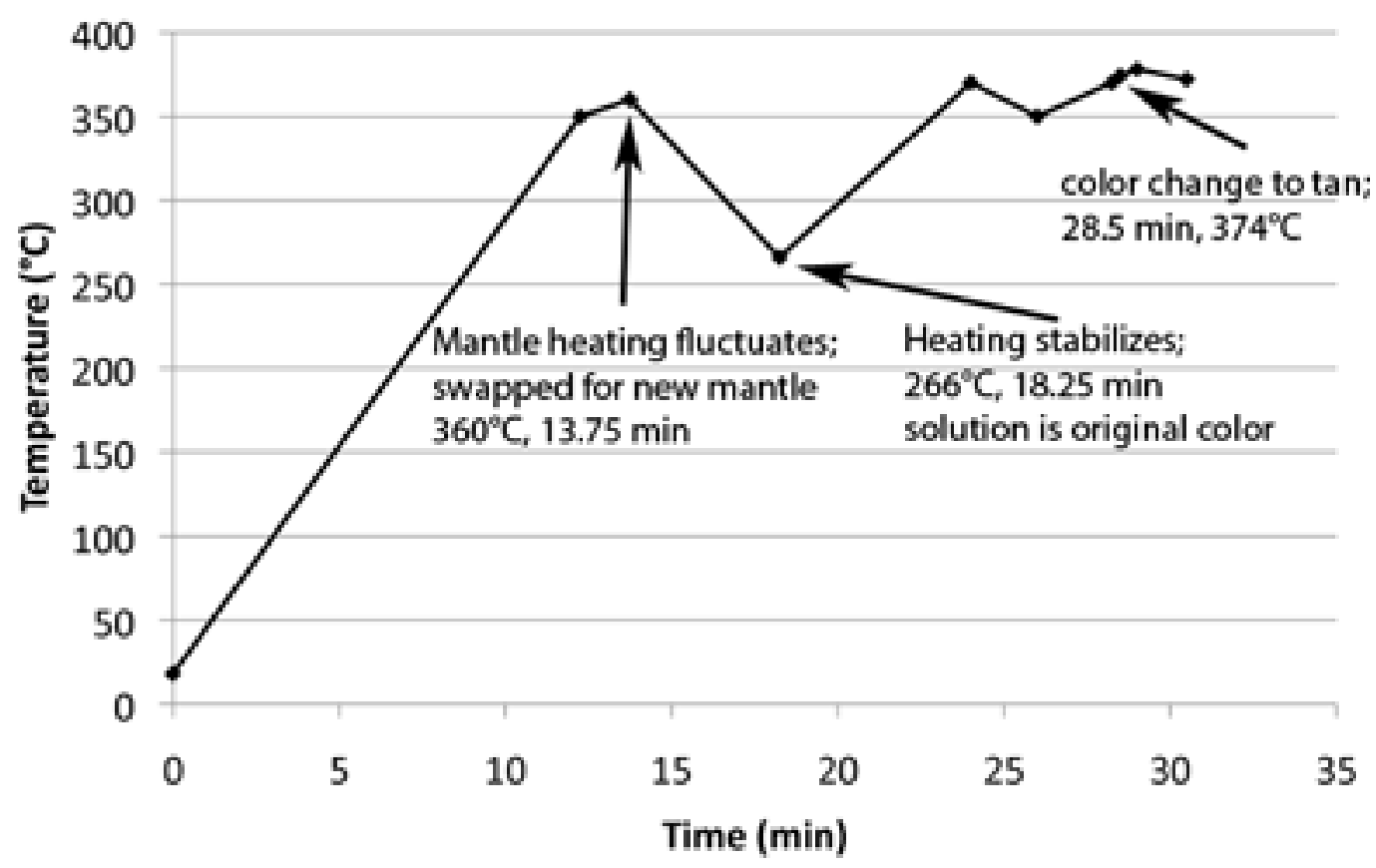

Figure 3.19. Reaction temperature vs. time comparison for a reaction that still yielded some nanoparticles. 
Table 3.31. TEM images of reactions that had inconsistent heating. The pairs of images on each row are from different reactions, with different starting conditions.

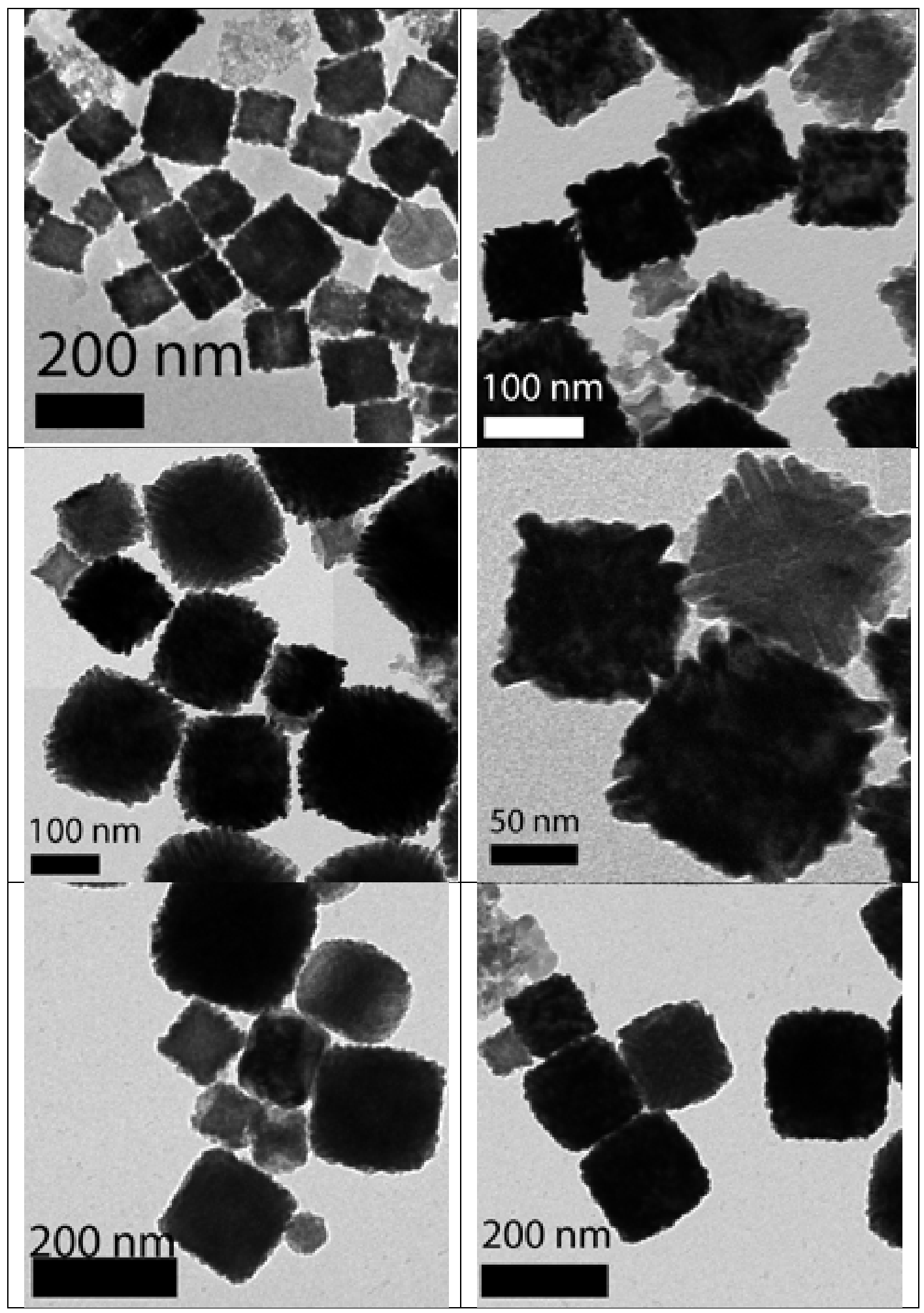



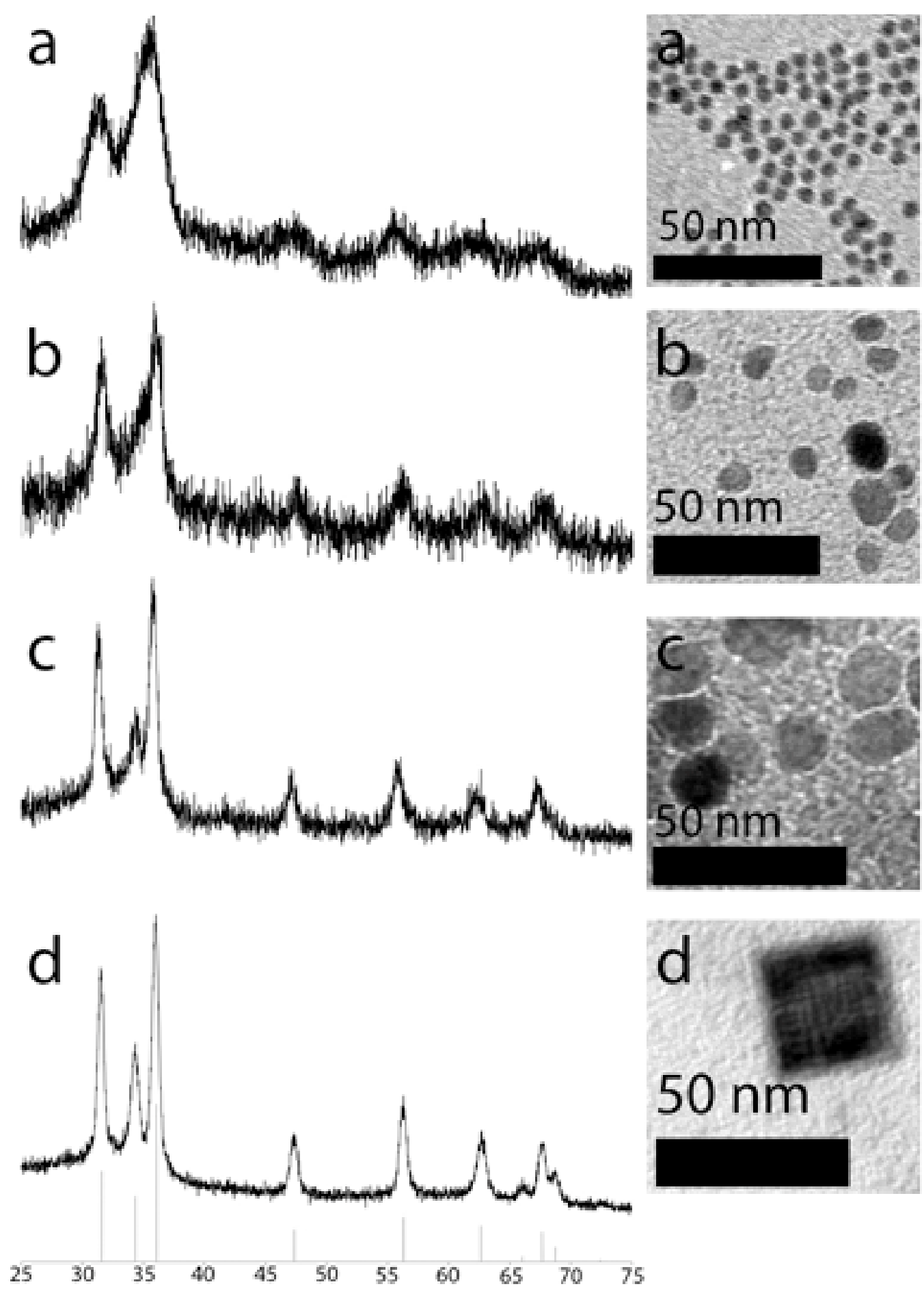

Figure 3.20. Sharpening of $w-\mathrm{Co}_{1-\mathrm{x}} \mathrm{M}_{\mathrm{n}} \mathrm{xO}$ nanoparticle XRD peaks with increasing particle size and crystallinity. Representative TEM image of each sample is shown on the right. The largest particles are 25-30 $\mathrm{nm}$ in diameter, the smallest $5 \mathrm{~nm}$. Reference peaks for hexagonal $\mathrm{ZnO}$ are shown in gray at the bottom. 


\subsection{Grain size dependence on Co-Mn stoichiometry}

The Scherrer equation relates diffraction peak position and width at half intensity (full width at half maximum, FWHM) to determine the size of diffraction domains in each sample. This was done utilizing XRD data in JADE 9. The data is shown in Tables 3.32 through 3.36. The data were plotted against the Co content of the nanoparticles as determined by ICP-OES. Additional data from several $\mathrm{MnO}$ nanoparticle samples were included, due to the imbalance of Co-Mn stoichiometries in samples made in this study (which tended to be Corich). In these tables "XS" stands for crystallite size, "2-peak average" is the average of the sizes based on the (111) and (200) diffraction peaks and " 3 -peak average" is the average of sizes based on the (111), (200) and (220) diffraction peaks. The data were analyzed using both quadratic and cubic relations; the section of $0.1 \leq$ Co $\leq 0.9$ was separately fitted to a linear relation as shown in Figures 3.21 to 3.25 . 
Table 3.32. Scherrer analysis data after processing raw XRD data in JADE 9.

\begin{tabular}{|c|c|c|c|c|c|c|}
\hline Sample & $\begin{array}{l}\text { Co } \\
\text { content }\end{array}$ & $\begin{array}{l}\text { Co content } \\
\text { error }\end{array}$ & $\begin{array}{l}(111) \\
\text { XS }(\AA) \\
\end{array}$ & $\begin{array}{l}(111) \\
\text { error }(\AA)\end{array}$ & $\begin{array}{l}(200) \\
X S(\AA)\end{array}$ & $\begin{array}{l}(200) \\
\text { error }(\AA)\end{array}$ \\
\hline SRW-4-7 & 0.18 & 0.0038 & 209 & 19 & 203 & 13 \\
\hline SRW-4-8 & 0.18 & 0.0024 & 267 & 9 & 278 & 7 \\
\hline SRw-4-13 & 0.75 & 0.0192 & 249 & 10 & 202 & 6 \\
\hline SRW-4-14 & 0.64 & 0.0128 & 131 & 8 & 108 & 5 \\
\hline SRW-4-24 & 0.21 & 0.0346 & 281 & 18 & 299 & 15 \\
\hline SRW-4-27 & 0.95 & 0.012 & 724 & 71 & 550 & 41 \\
\hline SRW-4-28 & 0.93 & 0.0123 & 719 & 23 & 562 & 14 \\
\hline SRW-4-29 & 0.99 & 0 & 1000 & 0 & 867 & 36 \\
\hline SRW-4-32 & 0.75 & 0.0152 & 368 & 11 & 271 & 6 \\
\hline SRW-4-33 & 0.17 & 0.0035 & 300 & 9 & 311 & 7 \\
\hline SRW-4-34 & 0.25 & 0.0025 & 240 & 11 & 263 & 9 \\
\hline SRW-4-36 & 0.44 & 0.0074 & 258 & 11 & 253 & 9 \\
\hline SRW-4-38 & 0.57 & 0.0115 & 202 & 5 & 176 & 4 \\
\hline SRW-4-40 & 0.38 & 0.0069 & 130 & 4 & 145 & 4 \\
\hline SRW-4-41 & 0.45 & 0.0125 & 220 & 8 & 195 & 5 \\
\hline SRW-4-43 & 0.55 & 0.0083 & 196 & 10 & 178 & 6 \\
\hline SRW-4-47 & 0.83 & 0.0108 & 263 & 9 & 148 & 7 \\
\hline SRW-4-49 & 0.82 & 0.0986 & 205 & 12 & 172 & 6 \\
\hline SRW-4-191 & 0.41 & 0.0072 & 200 & 7 & 173 & 5 \\
\hline SRW-4-193 & 0.91 & 0.0178 & 1000 & 0 & 780 & 35 \\
\hline SRW-5-17 & 0.566 & 0.0146 & 160 & 4 & 139 & 3 \\
\hline SRW-5-19a & 0.521 & 0.0132 & 196 & 5 & 191 & 4 \\
\hline SRW-5-19b & 0.656 & 0.0091 & 176 & 4 & 182 & 3 \\
\hline SRW-5-21a & 0.676 & 0.0147 & 153 & 6 & 145 & 5 \\
\hline SRW-5-21b & 0.816 & 0.0187 & 172 & 5 & 149 & 3 \\
\hline SRW-5-22a & 0.768 & 0.0182 & 182 & 7 & 161 & 4 \\
\hline SRW-5-23a & 0.339 & 0.0087 & 159 & 7 & 134 & 4 \\
\hline SRW-5-24b & 0.1 & 0.0025 & 177 & 6 & 185 & 4 \\
\hline SRW-5-25a & 0.236 & 0.0056 & 159 & 4 & 154 & 3 \\
\hline SRW-5-26b & 0.925 & 0.0102 & 229 & 7 & 232 & 5 \\
\hline SRW-5-27b & 0.578 & 0.0081 & 133 & 3 & 135 & 2 \\
\hline SRW-5-28a & 0.101 & 0 & 224 & 7 & 208 & 4 \\
\hline SRW-5-28b & 0.746 & 0 & 240 & 9 & 199 & 5 \\
\hline SRW-5-29a & 0.698 & 0.0207 & 150 & 6 & 158 & 4 \\
\hline SRW-5-32a & 0.69 & 0.0122 & 205 & 5 & 178 & 3 \\
\hline SRW-5-32b & 0.594 & 0.0104 & 204 & 4 & 192 & 3 \\
\hline SRW-5-34a & 0.164 & 0.005 & 156 & 5 & 141 & 3 \\
\hline SRW-5-34b & 0.491 & 0.0104 & 181 & 9 & 163 & 6 \\
\hline
\end{tabular}


Table 3.33. Scherrer analysis data after processing raw XRD data in JADE 9, cont'd.

\begin{tabular}{|c|c|c|c|c|c|c|}
\hline Sample & $\begin{array}{l}\text { Co } \\
\text { content }\end{array}$ & $\begin{array}{l}\text { Co content } \\
\text { error }\end{array}$ & $\begin{array}{l}(111) \\
\text { XS }(\AA)\end{array}$ & $\begin{array}{l}(111) \\
\text { error }(\AA)\end{array}$ & $\begin{array}{l}(200) \\
X S(\AA)\end{array}$ & $\begin{array}{l}(200) \text { error } \\
(\AA)\end{array}$ \\
\hline SRW-5-36b & 0.67 & 0.0101 & 205 & 6 & 201 & 4 \\
\hline SRW-5-37a & 0.534 & 0.0084 & 155 & 5 & 155 & 3 \\
\hline SRW-5-37b & 0.658 & 0.0135 & 171 & 10 & 159 & 7 \\
\hline SRW-5-38a & 0.498 & 0.0223 & 190 & 8 & 178 & 5 \\
\hline SRW-5-38b & 0.592 & 0.014 & 204 & 5 & 178 & 3 \\
\hline SRW-5-40b & 0.284 & 0.0061 & 106 & 3 & 96 & 2 \\
\hline SRW-5-41a & 0.787 & 0.013 & 119 & 7 & 115 & 3 \\
\hline SRW-5-42a & 0.474 & 0.0149 & 97 & 5 & 109 & 9 \\
\hline SRW-5-47b & 0.511 & 0.0071 & 126 & 4 & 121 & 3 \\
\hline $\mathrm{MnOx}-1$ & 0 & 0 & 416 & 0 & 326 & 0 \\
\hline SRW-3-182 & 0 & 0 & 352 & 0 & 240 & 0 \\
\hline SRW-3-187 & 0 & 0 & 400 & 0 & 413 & 0 \\
\hline SRW-3-188 & 0 & 0 & 327 & 0 & 323 & 0 \\
\hline SRW-3-189 & 0 & 0 & 377 & 0 & 359 & 0 \\
\hline SRW-5-91a ox & 0 & 0 & 297 & 0 & 261 & 0 \\
\hline SRW-5-97b & 0 & 0 & 296 & 0 & 285 & 0 \\
\hline
\end{tabular}

Table 3.34. Scherrer analysis data after processing raw XRD data in JADE 9, cont'd.

\begin{tabular}{|l|r|r|r|r|r|r|}
\hline Sample & \multicolumn{1}{l|}{$\begin{array}{l}\text { (220) } \\
\text { XS }(\AA)\end{array}$} & $\begin{array}{l}\text { (220) } \\
\text { error }(\AA)\end{array}$ & $\begin{array}{l}\text { 2 peak } \\
\text { average }(\AA)\end{array}$ & $\begin{array}{l}\text { 2 peak } \\
\text { error }(\AA)\end{array}$ & $\begin{array}{l}\text { 3 peak } \\
\text { average }(\AA)\end{array}$ & $\begin{array}{l}\text { 3 peak } \\
\text { error }(\AA)\end{array}$ \\
\hline SRW-4-7 & 158 & 46 & 206 & 32 & 190.00 & 26.00 \\
\hline SRW-4-8 & 251 & 10 & 272.5 & 16 & 265.33 & 8.67 \\
\hline SRW-4-13 & 169 & 11 & 225.5 & 16 & 206.67 & 9.00 \\
\hline SRW-4-14 & 85 & 6 & 119.5 & 13 & 108.00 & 6.33 \\
\hline SRW-4-24 & 259 & 24 & 290 & 33 & 279.67 & 19.00 \\
\hline SRW-4-27 & 602 & 68 & 637 & 112 & 625.33 & 60.00 \\
\hline SRW-4-28 & 579 & 20 & 640.5 & 37 & 620.00 & 19.00 \\
\hline SRW-4-29 & 1000 & & 933.5 & 36 & 955.67 & 12.00 \\
\hline SRW-4-32 & 229 & 7 & 319.5 & 17 & 289.33 & 8.00 \\
\hline SRW-4-33 & 310 & 13 & 305.5 & 16 & 307.00 & 9.67 \\
\hline SRW-4-34 & 279 & 13 & 251.5 & 20 & 260.67 & 11.00 \\
\hline SRW-4-36 & 267 & 16 & 255.5 & 20 & 259.33 & 12.00 \\
\hline SRW-4-38 & 141 & 4 & 189 & 9 & 173.00 & 4.33 \\
\hline SRW-4-40 & 117 & 5 & 137.5 & 8 & 130.67 & 4.33 \\
\hline SRW-4-41 & 161 & 7 & 207.5 & 13 & 192.00 & 6.67 \\
\hline SRW-4-43 & 158 & 6 & 187 & 16 & 177.33 & 7.33 \\
\hline SRW-4-47 & 204 & 8 & 205.5 & 16 & 205.00 & 8.00 \\
\hline
\end{tabular}


Table 3.35. Scherrer analysis data after processing raw XRD data in JADE 9, cont'd.

\begin{tabular}{|c|c|c|c|c|c|c|}
\hline Sample & $\begin{array}{l}(220) \\
X S(\AA)\end{array}$ & $\begin{array}{l}(220) \\
\text { error }(\AA)\end{array}$ & $\begin{array}{l}2 \text { peak } \\
\text { average }(\AA)\end{array}$ & $\begin{array}{l}2 \text { peak } \\
\text { error }(\AA)\end{array}$ & $\begin{array}{l}3 \text { peak } \\
\text { average }(\AA)\end{array}$ & $\begin{array}{l}3 \text { peak } \\
\text { error }(\AA)\end{array}$ \\
\hline SRW-4-49 & 165 & 6 & 188.5 & 18 & 180.67 & 8.00 \\
\hline SRW-4-191 & 155 & 7 & 186.5 & 12 & 176.00 & 6.33 \\
\hline SRW-4-193 & 803 & 44 & 890 & 35 & 861.00 & 26.33 \\
\hline SRW-5-17 & 143 & 4 & 193.5 & 9 & 176.67 & 4.33 \\
\hline SRW-5-19a & 142 & 3 & 179 & 7 & 166.67 & 3.33 \\
\hline SRW-5-19b & 118 & 7 & 149 & 11 & 138.67 & 6.00 \\
\hline SRW-5-21a & 105 & 3 & 160.5 & 8 & 142.00 & 3.67 \\
\hline SRW-5-21b & 127 & 4 & 171.5 & 11 & 156.67 & 5.00 \\
\hline SRW-5-22a & 99 & 5 & 146.5 & 11 & 130.67 & 5.33 \\
\hline SRW-5-23a & 165 & 9 & 181 & 10 & 175.67 & 6.33 \\
\hline SRW-5-24b & 133 & 3 & 156.5 & 7 & 148.67 & 3.33 \\
\hline SRW-5-25a & 249 & 4 & 230.5 & 12 & 236.67 & 5.33 \\
\hline SRW-5-26b & 111 & 2 & 134 & 5 & 126.33 & 2.33 \\
\hline SRW-5-27b & 175 & 6 & 216 & 11 & 202.33 & 5.67 \\
\hline SRW-5-28a & 159 & 6 & 219.5 & 14 & 199.33 & 6.67 \\
\hline SRW-5-28b & 121 & 5 & 154 & 10 & 143.00 & 5.00 \\
\hline SRW-5-29a & 145 & 2 & 191.5 & 8 & 176.00 & 3.33 \\
\hline SRW-5-32a & 165 & 6 & 188.5 & 18 & 180.67 & 8.00 \\
\hline SRW-5-32b & 155 & 7 & 186.5 & 12 & 176.00 & 6.33 \\
\hline SRW-5-34a & 803 & 44 & 890 & 35 & 861.00 & 26.33 \\
\hline SRW-5-34b & 143 & 4 & 193.5 & 9 & 176.67 & 4.33 \\
\hline SRW-4-49 & 142 & 3 & 179 & 7 & 166.67 & 3.33 \\
\hline SRW-4-191 & 118 & 7 & 149 & 11 & 138.67 & 6.00 \\
\hline SRW-4-193 & 105 & 3 & 160.5 & 8 & 142.00 & 3.67 \\
\hline SRW-5-17 & 127 & 4 & 171.5 & 11 & 156.67 & 5.00 \\
\hline SRW-5-19a & 99 & 5 & 146.5 & 11 & 130.67 & 5.33 \\
\hline SRW-5-19b & 165 & 9 & 181 & 10 & 175.67 & 6.33 \\
\hline SRW-5-21a & 133 & 3 & 156.5 & 7 & 148.67 & 3.33 \\
\hline SRW-5-21b & 249 & 4 & 230.5 & 12 & 236.67 & 5.33 \\
\hline SRW-5-22a & 111 & 2 & 134 & 5 & 126.33 & 2.33 \\
\hline SRW-5-23a & 175 & 6 & 216 & 11 & 202.33 & 5.67 \\
\hline SRW-5-24b & 159 & 6 & 219.5 & 14 & 199.33 & 6.67 \\
\hline SRW-5-25a & 121 & 5 & 154 & 10 & 143.00 & 5.00 \\
\hline SRW-5-26b & 145 & 2 & 191.5 & 8 & 176.00 & 3.33 \\
\hline SRW-5-27b & 165 & 6 & 188.5 & 18 & 180.67 & 8.00 \\
\hline SRW-5-28a & 155 & 7 & 186.5 & 12 & 176.00 & 6.33 \\
\hline SRW-5-28b & 803 & 44 & 890 & 35 & 861.00 & 26.33 \\
\hline SRW-5-29a & 143 & 4 & 193.5 & 9 & 176.67 & 4.33 \\
\hline SRW-5-32a & 142 & 3 & 179 & 7 & 166.67 & 3.33 \\
\hline
\end{tabular}


Table 3.36. Scherrer analysis data after processing raw XRD data in JADE 9, cont'd.

\begin{tabular}{|l|r|r|r|r|r|r|}
\hline Sample & \multicolumn{1}{l|}{$\begin{array}{l}(220) \\
\text { XS }(\AA)\end{array}$} & $\begin{array}{l}\text { (220) } \\
\text { error }(\AA)\end{array}$ & $\begin{array}{l}\text { 2 peak } \\
\text { average }(\AA)\end{array}$ & $\begin{array}{l}\text { 2 peak } \\
\text { error }(\AA)\end{array}$ & $\begin{array}{l}\text { 3 peak } \\
\text { average }(\AA)\end{array}$ & $\begin{array}{l}\text { leak } \\
\text { eror } \\
(\AA)\end{array}$ \\
\hline SRW-5-32b & 162 & 3 & 198 & 7 & 186.00 & 3.33 \\
\hline SRW-5-34a & 131 & 5 & 148.5 & 8 & 142.67 & 4.33 \\
\hline SRW-5-34b & 120 & 9 & 172 & 15 & 154.67 & 8.00 \\
\hline SRW-5-36b & 186 & 4 & 203 & 10 & 197.33 & 4.67 \\
\hline SRW-5-37a & 122 & 4 & 155 & 8 & 144.00 & 4.00 \\
\hline SRW-5-37b & 116 & 6 & 165 & 17 & 148.67 & 7.67 \\
\hline SRW-5-38a & 138 & 6 & 184 & 13 & 168.67 & 6.33 \\
\hline SRW-5-38b & 156 & 3 & 191 & 8 & 179.33 & 3.67 \\
\hline SRW-5-40b & 72 & 3 & 101 & 5 & 91.33 & 2.67 \\
\hline SRW-5-41a & 115 & 3 & 117 & 10 & 116.33 & 4.33 \\
\hline SRW-5-42a & 108 & 4 & 103 & 14 & 104.67 & 6.00 \\
\hline SRW-5-47b & 111 & 4 & 123.5 & 7 & 119.33 & 3.67 \\
\hline MnOx-1 & 342 & 0 & 371 & 0 & 361.3333333 & 0 \\
\hline SRW-3-182 & 269 & 0 & 296 & 0 & 287 & 0 \\
\hline SRW-3-187 & 447 & 0 & 406.5 & 0 & 420 & 0 \\
\hline SRW-3-188 & 324 & 0 & 325 & 0 & 324.6666667 & 0 \\
\hline SRW-3-189 & 337 & 0 & 368 & 0 & 357.6666667 & 0 \\
\hline $\begin{array}{l}\text { SRW-5-91a } \\
\text { ox }\end{array}$ & 293 & 0 & 279 & 0 & 283.6666667 & 0 \\
\hline SRW-5-97b & 311 & 0 & 290.5 & 0 & 297.3333333 & 0 \\
\hline
\end{tabular}




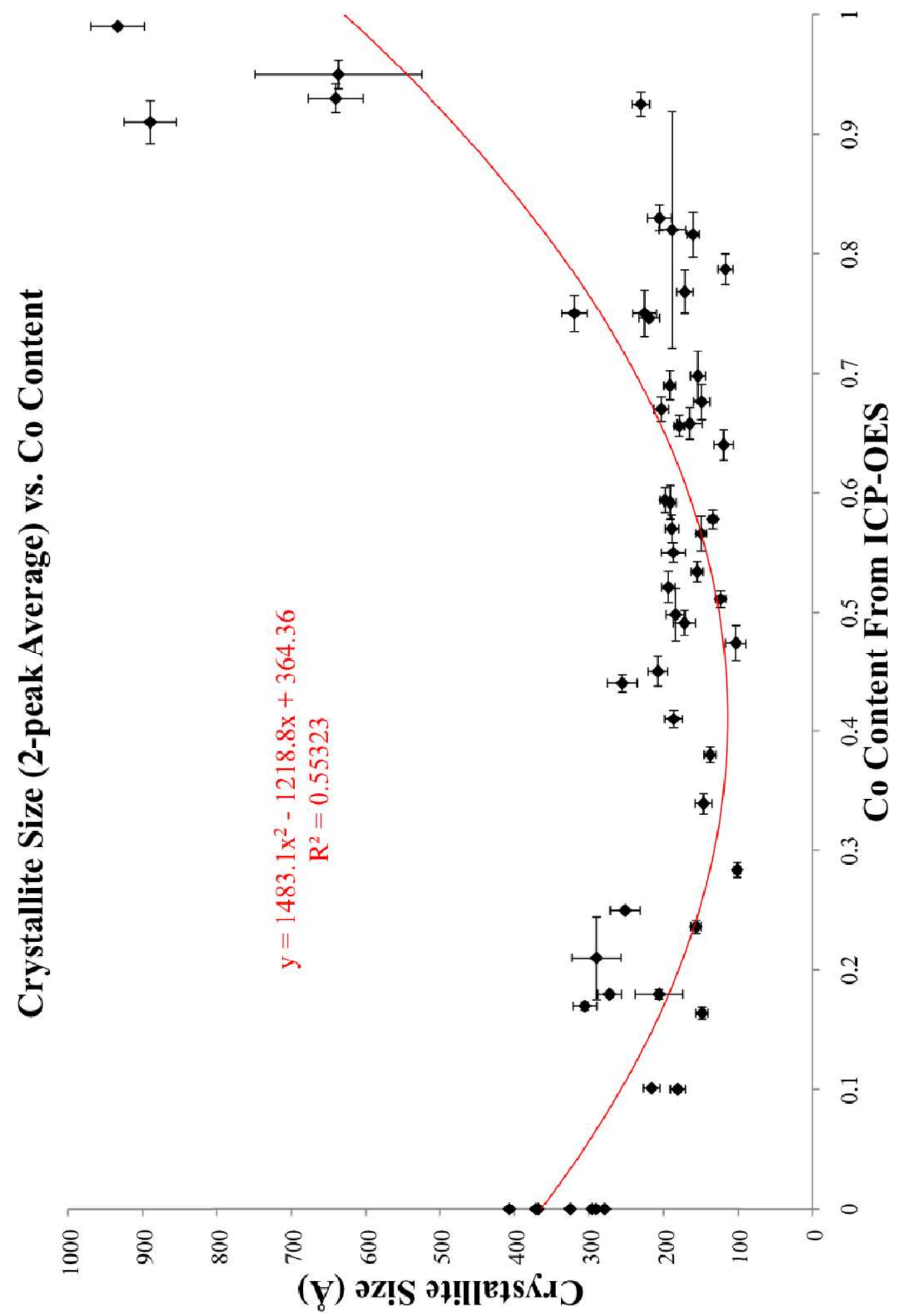

Figure 3.21. Crystallite size (average of Scherrer fit for the (111) and (200) peaks) vs. Co content from ICP-OES with quadratic fit to the data. 


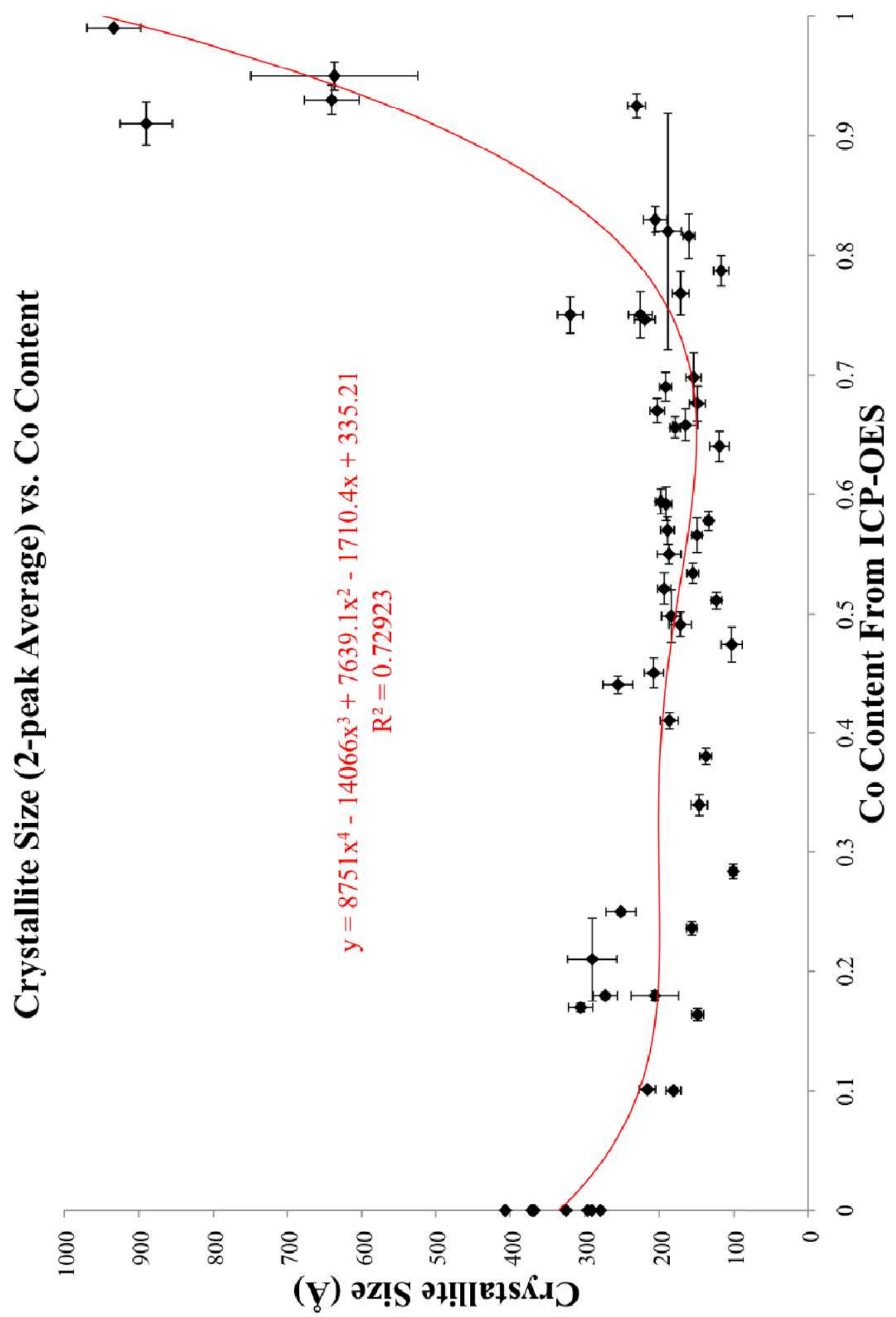

Figure 3.22. Crystallite size (average of Scherrer fit for the (111) and (200) peaks) vs. Co content from ICP-OES with cubic fit to the data. 


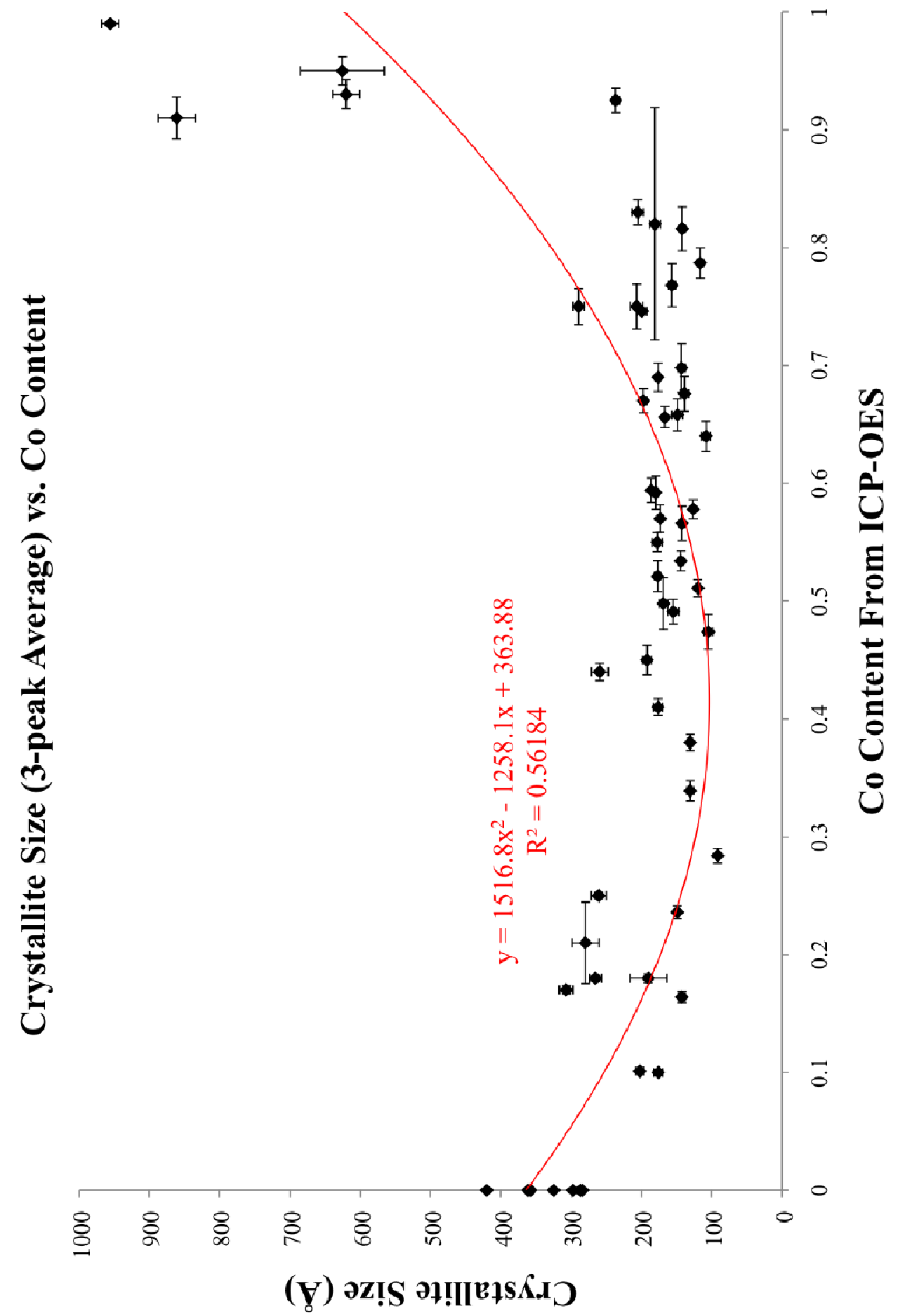

Figure 3.23. Crystallite size (average of Scherrer fit for the (111), (200) and (220) peaks) vs. Co content from ICP-OES with quadratic fit to the data. 


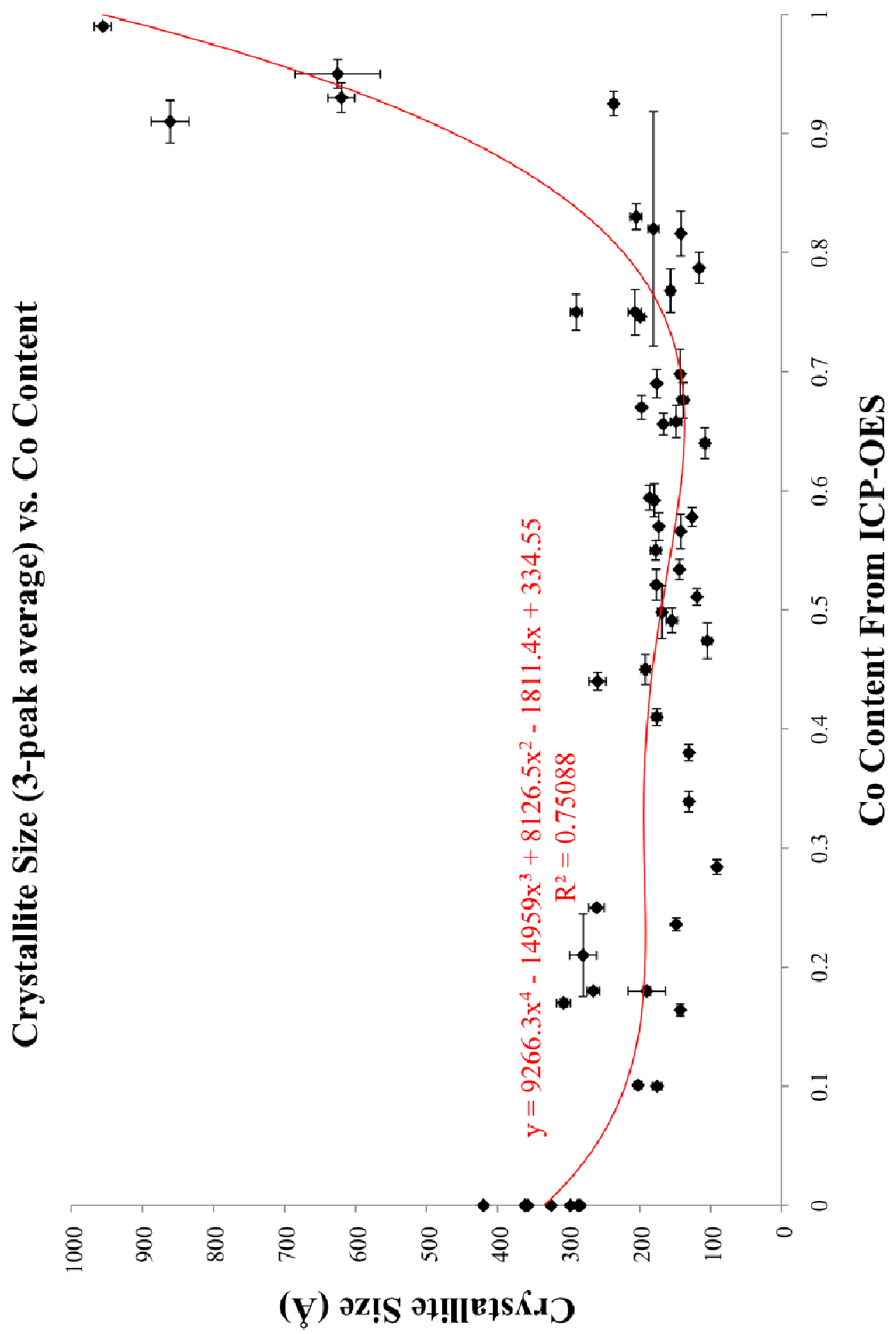

Figure 3.24. Crystallite size (average of Scherrer fit for the (111), (200) and (220) peaks) vs. Co content from ICP-OES with cubic fit to the data. 


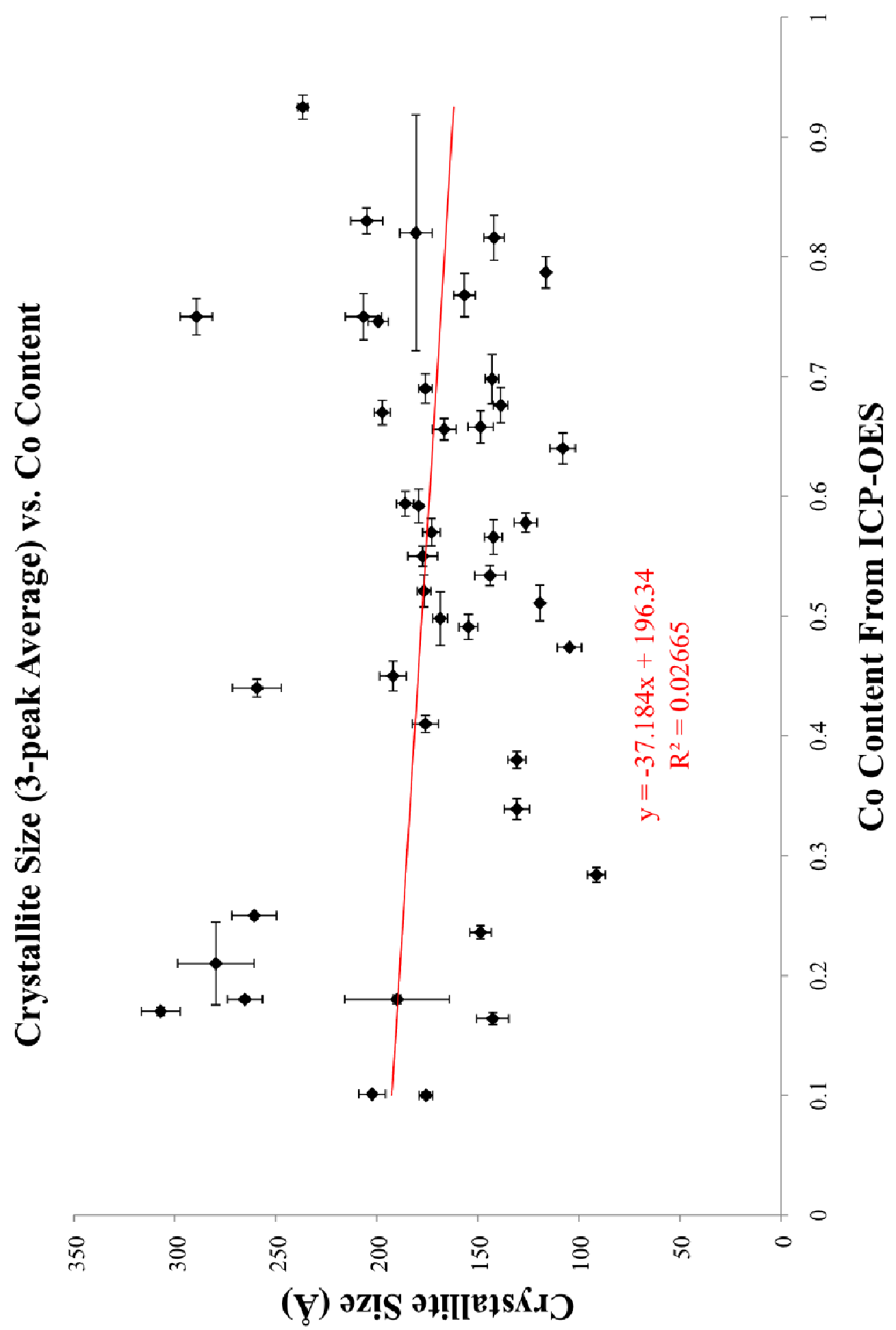

Figure 3.25. Crystallite size (average of Scherrer fit for the (111), (200) and (220) peaks) vs. Co content from ICP-OES. These are $\mathrm{Co}_{1-\mathrm{x}} \mathrm{Mn}_{\mathrm{x}} \mathrm{O}$ particles where $0.1 \leq x \leq 0.9$. The fit is linear. 


\section{Chapter 4. Discussion}

\subsection{Previous work in the Whitmire Lab}

As mentioned in the introduction, the Whitmire lab has synthesized iron and manganese metal oxide nanoparticles in the past. The insights gained during those projects helped guide the exploration of the cobalt-manganese oxide system. First and foremost, the influence that tri-N-octylamine and oleic acid have as surfactants/solvents was such that several base nanoparticle shapes could be made, such as squares and hexagons. Another important lesson learned in these studies was that inclusion of water in the system led to more complex growth processes, giving hexapod, cross and "tetracube"-shaped nanoparticles. Also possible was the synthesis of mixed manganese-iron nanoparticles, which assumed "dogbone" and elongated dogbone shapes.

\subsection{Identification of nanoparticle crystal lattice}

Experiments to explore the $\mathrm{Co}_{1-\mathrm{x}} \mathrm{Mn}_{\mathrm{x}} \mathrm{O}$ system were first performed to determine the feasibility of the project and compare how the system responded to similar reaction conditions to the $\mathrm{MnO}$ and $\mathrm{FeO}$ systems. Initial reactions used the following conditions as a control: $6 \mathrm{~mL}(13.7 \mathrm{mmol}) \mathrm{TOA}, 2 \mathrm{~mL}(6.3 \mathrm{mmol})$ OA, $249 \mathrm{mg}(1 \mathrm{mmol}) \mathrm{Co}(\mathrm{OAc})_{2} \cdot 4 \mathrm{H}_{2} \mathrm{O}, 145 \mathrm{mg}(1 \mathrm{mmol}) \mathrm{Mn}(\mathrm{HCOO})_{2}$ and 2 minutes of growth time after nanoparticle formation. The polycrystalline XRD pattern for the product of this reaction (shown in Figure 3.1) initially corresponded to the solid solution $(\mathrm{FeO})_{0.664}(\mathrm{MnO})_{0.336}(\mathrm{PDF} \# 01-077-2358$; facecentered cubic, space group $F m \overline{3} \mathrm{~m}$, no. $225, \mathrm{a}=4.36 \AA, \mathrm{Z}=4$ ). Further 
reactions corresponded with $\mathrm{Fe}_{0.9712} \mathrm{O}$ (PDF\#01-074-1885; face-centered cubic, space group $\mathrm{Fm} \overline{3} \mathrm{~m}$, no. $225, \mathrm{a}=4.301 \AA, \mathrm{Z}=4)$ and $(\mathrm{NiO})_{0.5}(\mathrm{MnO})_{0.5}(\mathrm{PDF} \# 01-$ 078-0426; face-centered cubic, space group $F m \overline{3} \mathrm{~m}$, no. 225, a = $4.294 \AA, \mathrm{Z}=4$ ). Elemental analysis of these samples, however, confirmed that no iron or nickel was present, only varying amounts of manganese and cobalt.

It should be noted that the JADE search-match function is not itself an elemental analysis. It compares the sample's XRD pattern with experimentally and theoretically derived patterns stored at the International Centre for Diffraction Data (ICDD). The search algorithm uses peak positions and intensities to derive crystal lattice systems and parameters, meaning materials with similar unit cells will be found using the search-match protocol. This led to the determination that the face-centered cubic solid solution $\mathrm{Co}_{1-\mathrm{x}} \mathrm{Mn}_{\mathrm{x}} \mathrm{O}\left(\mathrm{rs}^{-}-\mathrm{Co}_{1-\mathrm{x}} \mathrm{Mn}_{\mathrm{x}} \mathrm{O}\right)$ was being formed - the lattice parameters of the mixture changing proportionally to the makeup of the mixture.

\subsection{Change in crystal lattice with metal content}

Vegard's Law is an observation derived from experimental evidence concerning solid solutions. It states: "in continuous solid solutions of ionic salts...the lattice parameter of the solution is directly proportional to the atomic percent solute present." ${ }^{4}$ This specifically refers to random substitutional solid solutions, where one ion is seen replacing another ion of a similar type. X-ray diffraction data has been correlated with elemental analysis for each sample (via ICP-OES) and is presented in Table 3.2 through Table 3.5 and Figure 3.8 and Figure 3.9. 
There are a few explanations for the observed deviations from a perfect linear proportionality. First is to note that Vegard's Law is not in fact an inviolable physical law; it is, as mentioned above, based solely on empirical observations. Also of importance are the limitations of the analytical methods used. Powder XRD can be used to determine the lattice parameters of the crystalline oxide present, but it will not reveal the presence of amorphous or noncrystalline substances. A common problem encountered was the decomposition of all $\mathrm{Co}(\mathrm{OAc})_{2}$ into metallic cobalt; it is entirely possible that trace amounts convert into amorphous metallic cobalt. This is in fact seen in some samples, as shown in the XRD pattern presented in Figure 3.4. Such samples would register higher values for cobalt than is present in the oxide form, and while WPF was performed to correct for this effect, some bias may have been introduced by excessive manipulation of data

\subsection{Effect of Co:Mn ratio on morphology of products}

Varying the starting amounts of cobalt and manganese substantially altered the resulting nanoparticle morphologies. All of these reaction had the same surfactant ratios and total amount of metal carboxylate precursors: $6 \mathrm{~mL}$ TOA, $2 \mathrm{~mL}$ OA, $2 \mathrm{mmol}$ total precursor, with no water added and 2 minutes of growth time. The control reaction with $1 \mathrm{mmol} \mathrm{Co}(\mathrm{OAc})_{2}$ and $1 \mathrm{mmol}$ $\mathrm{Mn}(\mathrm{HCOO})_{2}$ is shown in Table 3.9. There is a narrow distribution of particle sizes and shapes; nanoparticles are clearly well defined as individual particles or stacks of particles. Surfaces appear to have facets, leading to particles that look like hexagons and rhombohedra. Some nanoparticles appear elongated, but the 
degree of shape anisotropy is minimal. Increasing the amount of manganese relative to cobalt does not significantly affect the nanoparticle morphology except when there is a 1:9 $\mathrm{Co}: \mathrm{Mn}$ ratio. Here the particles formed resemble $\mathrm{MnO}$ crosses and multipod pieces reported previously with the etching of surfaces clearly visible. Moving toward cobalt-heavy reactions, nanoparticles assume shapes very similar to those seen in the $7 \mathrm{~mL}$ TOA: $1 \mathrm{~mL}$ OA reaction condition (Table 3.14), with a similar distribution of nanoparticle sizes. Having even more cobalt precursor present in the reaction solution leads to square- and hexagonshaped particles that are thick enough to be unable to discern features on the inner faces, if any. The distribution of particles heavily favors the larger particles; indeed, the vast majority of these particles appear to have edges longer than 100 $\mathrm{nm}$. Literature reports on the synthesis of pure rock salt $\mathrm{CoO}$ nanoparticles show that rhombohedra and octahedrons of size $30-300 \mathrm{~nm}$ are a common crystal habit. $^{46,75,86}$ To ensure completeness, as rock salt-lattice $\mathrm{CoO}$ nanoparticles have been synthesized in several ways, but not in a TOA-OA surfactant mixture, some example reactions were performed, with TEM results shown in Table 4.1. The conditions were $6 \mathrm{~mL}$ TOA, $2 \mathrm{~mL} \mathrm{OA,} 2 \mathrm{mmol} \mathrm{Co}(\mathrm{OAc})_{2}$ and no water; metal amounts tested were $\mathrm{Co}_{0.95} \mathrm{Mn}_{0.05} \mathrm{O}, \mathrm{Co}_{0.99} \mathrm{Mn}_{0.01} \mathrm{O}$ and $\mathrm{CoO}$. The particles formed in these reactions have very similar morphologies to those seen in Tables Table 3.11 and Table 3.12, and are approaching a size regime where the term "nanoparticle" is a misnomer. The conclusion we may reach is that reaction conditions with an excess of manganese precursor result in shapes similar to those seen in $\mathrm{MnO}$ : crosses, hexagons and rods, which will be of smaller size; whereas 
an excess of cobalt precursor results in large hexagons and cubes. Where the ratios are between $2: 1$ and 1:2, nanoparticles may form with shapes and features that are more complex in nature.

Table 4.1 TEM images of CoO nanoparticles synthesized in $6 \mathrm{~mL}$ TOA, $2 \mathrm{~mL}$ $\mathrm{OA}, 2 \mathrm{mmol} \mathrm{Co}(\mathrm{OAc})_{2}$ and no water.

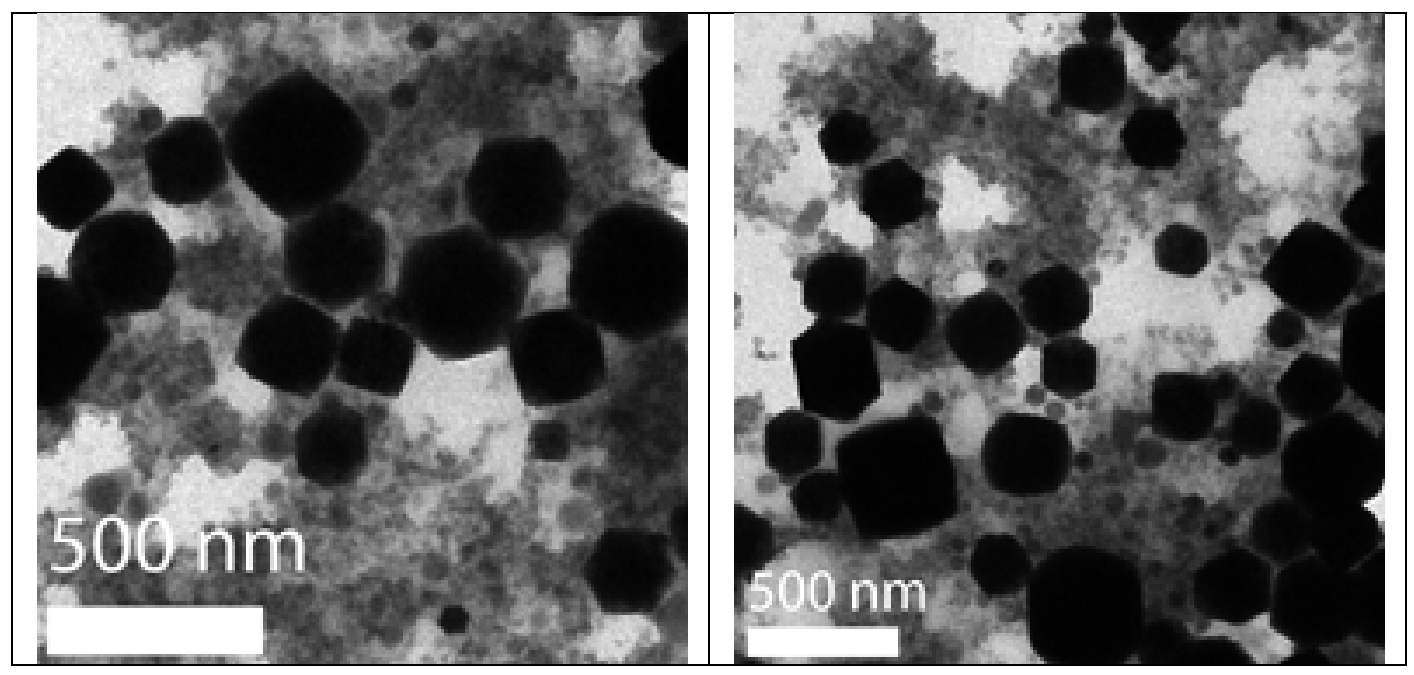

\subsection{Oleic acid and its role in oxide formation}

The initial conclusion that may be drawn from the data presented in Chapter 3 is that oleic acid is the most important factor in the synthesis of these mixed-metal oxide nanoparticles. Example XRD patterns for these reactions are shown in Figure 3.10, Figure 3.11 and Figure 3.12. Decomposition of molecular precursors in the absence of OA leads to manganese and cobalt segregation into their separate rock salt-lattice oxides (Figure 3.12), which are clearly visible as two distinct sets of peaks in the XRD pattern. There is also a slight amount of $\mathrm{w}-\mathrm{CoO}\left(\mathrm{P}_{3} \mathrm{mc}\right)$ present, with the more intense (100) and (002) peaks visible at $2 \theta=32^{\circ}$ and $34^{\circ}$. Introducing $\mathrm{OA}$ into the reaction mixture 
results in a single crystalline phase that is a solid solution of a single $F m \overline{3} m$ lattice. As would be expected of a solid solution, the peak positions lie between those of the binary oxides. The pattern shown (Figure 3.1) corresponds to a product stoichiometry of $\mathrm{Co}_{0.57} \mathrm{Mn}_{0.43} \mathrm{O}$ by ICP-OES analysis. All of the reactions done with varying TOA:OA ratios but constant 1:1 starting Co:Mn ratio were slightly manganese deficient, with the values ranging from $\mathrm{Co}_{0.57} \mathrm{Mn}_{0.43} \mathrm{O}$ to $\mathrm{Co}_{0.51} \mathrm{Mn}_{0.49} \mathrm{O}$. In the $\mathrm{Fe}_{1-\mathrm{y}} \mathrm{Mn}_{\mathrm{y}} \mathrm{O}$ system a similar preference for one metal to be incorporated into the product lattice was observed, with a 1:1 metal precursor ratio yielding particles with a stoichiometry of $\mathrm{Fe}_{0.7} \mathrm{Mn}_{0.3} \mathrm{O}$. This effect was rationalized by the difference in $\mathrm{K}_{\mathrm{sp}}$ values for the respective metal hydroxides. The $\mathrm{K}_{\mathrm{sp}}$ values of $\mathrm{Mn}(\mathrm{OH})_{2}, \mathrm{Fe}(\mathrm{OH})_{2}$ and $\mathrm{Co}(\mathrm{OH})_{2}$ are respectively $1.6 \times 10^{-13}$, $4.9 \times 10^{-16}$ and $1.6 \times 10^{-15} ; \mathrm{Co}(\mathrm{OH})_{2}$ is just over three times as soluble as $\mathrm{Fe}(\mathrm{OH})_{2}$. In $\mathrm{rs}-\mathrm{Co}_{1-\mathrm{x}} \mathrm{Mn}_{\mathrm{x}} \mathrm{O}$ the metal with a more insoluble hydroxide precipitates and is incorporated into the nanoparticle lattice preferentially but to a lesser extent than in $\mathrm{Fe}_{1-\mathrm{y}} \mathrm{Mn}_{\mathrm{y}} \mathrm{O}$, due to the smaller difference in solubility compared to $\mathrm{Mn}(\mathrm{OH})_{2}{ }^{68}$

In the reaction of $5 \mathrm{~mL}$ TOA: $3 \mathrm{~mL} \mathrm{OA}$, the product recovered from the supernatant (Figure 3.11) indexes to the $P 6_{3} m c$ space group, indicating the formation of wurtzite-type mixed manganese cobalt oxide $\left(\mathrm{w}-\mathrm{Co}_{1-\mathrm{x}} \mathrm{Mn} \mathrm{x}\right)$. ICPOES data gives product stoichiometry for this particular sample as $\mathrm{Co}: \mathrm{Mn}=$ 0.64:0.36. Unit cell refinement in JADE gave estimated cell parameters $a=3.265$ $\AA$ and $c=5.210 \AA$. Confirmation of cubic and hexagonal lattices was done with SAED experiments, shown in Figure 3.13. The particles shown in Figure 3.13a are from the sample shown in Table 3.9 synthesized with $6 \mathrm{~mL}$ TOA: $2 \mathrm{~mL}$ OA, 
with the corresponding SAED pattern given in Figure 3.13b. Figure 3.13c and Figure 3.13d likewise correspond to the sample shown in Table 3.16 recovered from the supernatant after centrifugation of the mixture synthesized in $5 \mathrm{~mL}$ TOA: 3mL OA.

Additional evidence of oleic acid's importance in nanoparticle formation is found in the way its quality affected reaction outcomes. Previous work in the Whitmire lab synthesizing $\mathrm{MnO}, \mathrm{FeO}$ and $\mathrm{Fe}_{1-\mathrm{x}} \mathrm{Mn}_{\mathrm{x}} \mathrm{O}$ had used $\mathrm{OA}$ that was dried under vacuum at $110^{\circ} \mathrm{C}$ for $4 \mathrm{~h}$ and then stored under argon gas. Initial experiments, as described in the previous chapter, used this method to purify OA and were successful in yielding nanoparticles. However, attempts to reproduce these results were quickly frustrated due to the tendency for $\mathrm{Co}(\mathrm{OAc})_{2}$ to reduce to metallic cobalt, which occurred in a significant number of reactions. This issue was resolved by distillation of the $\mathrm{OA}$, as mentioned in the results, but the presence of impurities in the oleic acid (and their effects on reaction outcomes) was a major factor in necessitating that each reaction condition be repeated multiple times.

\subsection{Oleic acid and its effect on nanoparticle morphology}

Further reactions in the series shown in Table 3.13 - Table 3.17 show very different results once $\mathrm{OA}$ is introduced and as its concentration increases. In the case of $7 \mathrm{~mL}$ TOA: $1 \mathrm{~mL} \mathrm{OA}$, this leads to square- or cube-shaped nanoparticles with a bimodal distribution of sizes, some $20-30 \mathrm{~nm}$ per side and other 50-250 $\mathrm{nm}$ per side, with the larger particles having some outwardprojecting internal texture visible (Table 3.14) and some appearing to be large 
circles/spheres. There is some ambiguity as to the size of the particles in the direction of the electron beam, but the significant amount of detail visible on the inner texture of the 50-250 $\mathrm{nm}$ per side squares indicates a shallower profile along that axis. These features appear to be growth emanating from the center in a cross-shaped pattern, but still filling the area between each "arm."

As the ratio of TOA:OA is raised to $6.5 \mathrm{ml}: 1.5 \mathrm{ml}$, nanoparticles grow as rods (Table 3.15) that show significant interpenetration. There are no nanoparticles that are clearly recognizable as the squares or cubes seen in the 7 $\mathrm{mL}$ TOA: $1 \mathrm{~mL}$ OA case, and indeed the act of finding individual particles themselves proves to be a challenge. The arms have a narrow distribution of arm widths, $\sim 20 \mathrm{~nm}$, and some be identified to extend upward of $200 \mathrm{~nm}$ in length. Determining the distribution is hindered by the degree of infringement and intergrowth present.

In the $6 \mathrm{~mL}$ TOA: $2 \mathrm{~mL}$ OA case (Table 3.9), the control reaction for all reaction variables, there is a narrow distribution of particle sizes and shapes. Surfaces of nanoparticles are much better defined and appear as facets, leading to particles that look like hexagons and rhombohedra, something not seen in the previous two reaction conditions. Some nanoparticles appear elongated, but the degree of shape anisotropy is also much decreased from the rods seen in Table 3.15 - or, put another way, the "rods" formed in this reaction have aspect ratios much closer to one.

The $5 \mathrm{~mL}$ TOA: $3 \mathrm{~mL}$ OA instance yields two different products - the nanoparticles that remain in the supernatant upon centrifugation in hexanes which 
require addition of ethanol to precipitate (Table 3.16), and the material that precipitates from hexanes (Table 3.17). The material recovered from the supernatant is significantly different from all other products so far - its XRD and SAED patterns correspond to the $\mathrm{P} 6_{3} \mathrm{mc}$ space group, a hexagonal crystal lattice. There is a bimodal mix of nanoparticle sizes, with populations of very small (5 $\mathrm{nm}$ or less) and larger $(20-30 \mathrm{~nm})$ square and rectangular particles that have discreet, well-defined crystallite surfaces. The material that precipitates from hexanes, however, is a complex mixture of small amorphous particles and $50-$ $100 \mathrm{~nm}$ flowerlike particles. XRD analysis of this material shows only the presence of the rock salt-type rs- $\mathrm{Co}_{1-\mathrm{x}} \mathrm{Mn}_{\mathrm{x}} \mathrm{O}$, even though these particles are formed in the same reaction solution as the $\mathrm{w}-\mathrm{Co}_{1-\mathrm{x}} \mathrm{Mn}_{\mathrm{x}} \mathrm{O}$. Closer inspection of the internal features of the flowerlike particles reveals that they are polycrystalline aggregates of smaller, sub-20 nm particles.

From this series of reactions, a few trends become clear. OA must be present to control nanoparticle shape and increasing the amount of OA present leads to smaller particles with narrower size distributions. Also, the issues seen with nanoparticles growing together at lower OA concentrations are gone, leaving distinct separate particles. This only seems to change at the highest levels of OA in the $5 \mathrm{~mL}$ TOA: $3 \mathrm{~mL} \mathrm{OA}$ reaction, and the particles recovered there are aggregates of discreet smaller particles. These aggregates are similar to those seen in pure $\mathrm{CoO}$ by Zhang et al. ${ }^{87}$ This deviation from the observed trend is also concurrent with alternate reaction products $\left(\mathrm{w}-\mathrm{Co}_{1-\mathrm{x}} \mathrm{Mn}_{\mathrm{x}} \mathrm{O}\right)$, so it appears that those reaction conditions create a special case, which may be supported by the 
lack of nanoparticles formed at higher OA levels. The rodlike (Table 3.15) and small hexagon-shaped (Table 3.9) particles are similar in morphology to those seen in the synthesis of $\mathrm{MnO} .^{47}$ The increase in decomposition temperature with increasing OA content is likely due to OA's role as a surface-passivating agent increasing the stability of nucleation clusters.

\subsection{Effect of Added Water on Nanoparticle Morphology}

Water played an important role in the $\mathrm{MnO}, \mathrm{FeO}$ and $\mathrm{Fe}_{1-\mathrm{x}} \mathrm{Mn}_{\mathrm{x}} \mathrm{O}$ nanoparticles synthesized previously in the Whitmire lab. It was found that introducing water into the TOA-OA surfactant mixture promoted the formation of anisotropic nanoparticles. This was hypothesized to be due to enhanced etching of growing crystallite faces, a theory which was supported by the observation of nanoparticles in various stages of being etched from squares into crosses (in the case of $\mathrm{MnO}$ ) and cubes into tetracubes (in the case of $\mathrm{FeO}$ ). Water also clearly has an effect on the morphology of nanoparticles in the $\mathrm{Co}_{1-\mathrm{x}} \mathrm{Mn}_{\mathrm{x}} \mathrm{O}$ system. Adding $1.11 \mathrm{mmol} \mathrm{H}_{2} \mathrm{O}$ to the solution of $6 \mathrm{~mL}$ TOA, $2 \mathrm{~mL} \mathrm{OA}$ and $1 \mathrm{mmol}$ of each metal precursor encourages the growth of faceted hexagon and rhombohedra that are similar to those with no water added (Table 3.18), but some have also begun to extend into rodlike shapes. Further addition of water, however, leads to products that are similar in size, shape and internal structure to those seen in the 7 $\mathrm{mL}$ TOA, $1 \mathrm{~mL}$ OA reaction in Table 3.14 and 1:2 Mn:Co reaction seen in Table 3.10. Whereas adding 2 and $3 \mathrm{mmol}_{2} \mathrm{O}$ to the solution (Table 3.19 and Table 3.20) seems to promote relatively uniform particle sizes, by not drying the $\mathrm{Co}(\mathrm{OAc})_{2} \cdot 4 \mathrm{H}_{2} \mathrm{O}$ (Table 3.21) a bimodal distribution of particle types is 
reintroduced. All of the particles seen in the last three reaction conditions are variations on the same cube/square small particle with growth leading to unusual features and then eventually large spheres/circles. Also of note is that whereas the final Co-to-Mn ratios of the anhydrous and $1.11 \mathrm{mmol} \mathrm{H}_{2} \mathrm{O}$ reactions are approximately $1: 1$, the $2 \mathrm{mmol} \mathrm{H}_{2} \mathrm{O}$ reaction has a stoichiometry of $\mathrm{Co}_{0.58} \mathrm{Mn}_{0.42} \mathrm{O}$, the 3 mmol $\mathrm{H}_{2} \mathrm{O}$ reaction has a stoichiometry of $\mathrm{Co}_{0.75} \mathrm{Mn}_{0.25} \mathrm{O}$. The trend of increasing cobalt amounts is not perfectly linear, though; the nondried reaction has a stoichiometry of $\mathrm{Co}_{0.69} \mathrm{Mn}_{0.31} \mathrm{O}$. This increase in cobalt content with increasing water indicates that more ripeningdissolution/precipitation processes occur with greater water content, based on the hypothesis that the metal hydroxide solubility relates to that metal ion's preferential deposition into the oxide lattice.

Using reaction conditions similar to those by which $\mathrm{MnO}$ hexapods were synthesized $(6 \mathrm{~mL}$ TOA, $2 \mathrm{~mL}$ OA, 9:1 Mn:Co precursor ratio, $100 \mu \mathrm{L}$ added $\mathrm{H}_{2} \mathrm{O}$ ) gives rise to the variety of shapes shown in Table $3.22 ;{ }^{47}$ this reaction has a stoichiometry of $\mathrm{Co}_{0.1} \mathrm{Mn}_{0.9} \mathrm{O}$ from ICP-OES analysis. These NPs are similar to those found in the related $\mathrm{MnO}$ system, however, no actual hexapods are seen in these samples - instead only rodlike and branched structures are present. Some of the rods (see Table 3.22d) lack the characteristic barbell heads at each end as seen in $\mathrm{MnO}$. The maximum number of "arms" per particle is three, resembling a "T;" a higher magnification image of one such branched particle is shown with its SAED pattern. The SAED pattern from this individual particle shows one set of cubic lattice planes, indicating that it is a single crystal. The arms of this 
branched particle are considerably shorter than those seen in other particles in Table $3.22(50 \mathrm{~nm}$ vs. $150 \mathrm{~nm})$, indicating a particle in a different stage of growth than the larger ones. Additionally, the branches are aligned with the $<001>$ diffraction spots, indicating that the arms have grown from the faces of the original cubic seed. Similarities in morphology between $\mathrm{MnO}$ and $r s-\mathrm{Co}_{1-\mathrm{x}} \mathrm{Mn}_{\mathrm{x}} \mathrm{O}$ under these conditions suggest similar growth processes are occurring in each case. However, the introduction of cobalt to the reaction limits the number of faces of the initial seed from which the arms grow. These factors support our hypothesis that the process of $\mathrm{MnO}$ hexapod formation is based on a core nucleation-dendritic arm growth mechanism. ${ }^{47,67,68}$ This is similar to tetrapod formation as observed by Alivisatos and coworkers for the $\mathrm{Cd}$ chalcogenides,${ }^{88}$ in contrast to the oriented-attachment mechanism described by Penn and Banfield ${ }^{89}$ and proposed by Belin and coworkers for $\mathrm{MnO} .{ }^{90}$ The oriented attachment mechanism was based on a presumption that small nanoparticles were defectfree. ${ }^{91}$ Our observations, however, are that even the smallest nanoparticles exhibit a variety of defects.

\subsection{Effect of molecular precursor:OA ratio on nanoparticle}

\section{structure}

The experiments varying the TOA:OA ratio with constant metal precursor indicated that the amount of OA present had a significant effect on nanoparticle size, shape and crystal lattice. The results of further experiments where the amount of TOA:OA was held constant and the amount of precursors varied are displayed in Table 3.23 through Table 3.26 . With $0.5 \mathrm{mmol}$ of each precursor 
present (i.e., $1 \mathrm{mmol}$ total metal carboxylate precursor: $6.3 \mathrm{mmol} \mathrm{OA}$ ), two products are recovered from the reaction, very much like those found when reacting $5 \mathrm{~mL}$ TOA: $3 \mathrm{~mL} \mathrm{OA}$ with $1 \mathrm{mmol}$ of each metal precursor. As in that experiment, the solution color change occurred above $370^{\circ} \mathrm{C}$ with a transition to dark emerald green. One difference is that only a very small amount of material (less than $1 \mathrm{mg}$ ) was recovered after centrifugation in hexanes and no x-ray diffraction could be obtained from the sample (Figure 3.15). TEM analysis (Table 3.23) shows that it consists of a large amount of amorphous solid with a very few 20-30 nm squares or rhombohedra with small $(5-10 \mathrm{~nm})$ spheres. What is recovered from the supernatant of this reaction (Table 3.24) looks very similar to the precipitate: a mixture of 5-10 nm and $20-30 \mathrm{~nm}$ faceted particles; there are however many more of the smaller particles than larger ones. The product recovered from the supernatant was confirmed to be a mixture of rs- and w$\mathrm{Co}_{1-\mathrm{x}} \mathrm{Mn}_{\mathrm{x}} \mathrm{O}$ by XRD (Figure 3.14). Increasing the amount of precursor yields shapes similar to those presented here previously: etched rhombohedra (Table 3.9), with decomposition $\sim 365^{\circ} \mathrm{C}$ to give a green-gray solution; rough squares shapes showing roughened internal texture (Table 3.25), solution color change at $340^{\circ}-345^{\circ} \mathrm{C}$ to green-yellow; and large, randomly-shaped crystallites (Table 3.26), solution color change at $330^{\circ}-335^{\circ} \mathrm{C}$ to gray. Each of the products shown in Table 3.9, Table 3.25 and Table 3.26 precipitated upon centrifugation in

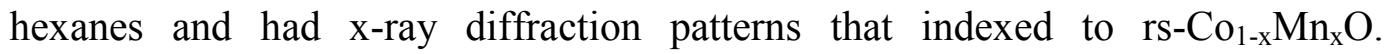
Stoichiometries for the samples shown in Figures Table 3.25 and Table 3.26 are $\mathrm{Co}_{0.67} \mathrm{Mn}_{0.33} \mathrm{O}$ and $\mathrm{Co}_{0.54} \mathrm{Mn}_{0.46} \mathrm{O}$, respectively. These results suggest that while 
the TOA:OA ratio and related acid-base dynamics have a role in nanoparticle formation, the molar ratio of metal to surfactant is more likely to be the underlying cause of the rock salt/wurtzite crystal lattice differentiation as well as playing a part in controlling nanoparticle shape.

\subsection{Extending reaction growth time}

As shown in Table 3.23, Table 3.24 and Table 3.27 through Table 3.30, each of the three reactions done with $6 \mathrm{~mL}$ TOA, $2 \mathrm{~mL}$ OA with no water and 1 mmol total precursor produced two products upon centrifugation in hexanes - the material that precipitated and the material recovered from the supernatant by adding ethanol. These are labeled in their respective Table captions as "\# minutes growth - recovered from precipitate (PP) or supernatant (SN)." All products from each reaction have a mix of particles present: small 5-10 nm spheres and larger 20-50 nm faceted hexagons and rhombohedra. Comparing the PP and SN products from each reaction, there is a difference in the relative distributions of each type of particle - the precipitate contains more of the faceted $20-50 \mathrm{~nm}$ particles than the $5-10 \mathrm{~nm}$ particles and also contains aggregates of $20-50 \mathrm{~nm}$ particles. Extending the nanoparticle growth time from 2 minutes to 5 minutes increases the relative numbers of the $20-50 \mathrm{~nm}$ particles compared to the $5-10 \mathrm{~nm}$ particles in both the SN (Table 3.27) and the PP (Table 3.28). This trend becomes more clear at 10 minutes' growth time (Table 3.29 and Table 3.30); in 10-PP there are aggregates of $20-50 \mathrm{~nm}$ particles that resemble those found in the $5 \mathrm{~mL}$ TOA: $3 \mathrm{~mL}$ OA precipitate (Table 3.17). Only in the $\mathrm{SN}$ is there any trace of a hexagonal lattice XRD pattern, and each growth time shows there to be a 
mixture of both rs- $\mathrm{Co}_{1-\mathrm{x}} \mathrm{Mn}_{\mathrm{x}} \mathrm{O}$ and $\mathrm{w}-\mathrm{Co}_{1-\mathrm{x}} \mathrm{Mn}_{\mathrm{x}} \mathrm{O}$ (Figure 3.16). The amount of hexagonal oxide decreases with increasing growth time with the cubic oxide diffraction pattern overwhelming any hexagonal lattice signal at 10 minutes' growth. SAED patterns of individual faceted $20-50 \mathrm{~nm}$ nanoparticles (as in Table 3.27) index to a face-centered cubic lattice.

Based on these results, some conclusions may be drawn. The nanoparticles in the $20-50 \mathrm{~nm}$ size range with facets and regular shapes are of the rs- $-\mathrm{Co}_{1-\mathrm{x}} \mathrm{Mn}_{\mathrm{x}} \mathrm{O}$ phase and give rise to that XRD pattern. These are clearly related to particles seen in $6 \mathrm{~mL}$ TOA: $2 \mathrm{~mL}$ OA with $2 \mathrm{mmol}$ precursors (Table 3.9), but appear to be at different stages of crystalline growth. Based on Ostwald's step rule, the small particles are $\mathrm{w}-\mathrm{Co}_{1-\mathrm{x}} \mathrm{Mn}_{\mathrm{x}} \mathrm{O}$. The step rule is an empirical observation that metastable crystalline phases nucleate before more stable phases due to the difference in surface area-to-volume ratio altering the energetic favorability at different sizes; i.e. small particles have less stabilization due to internal ionic and crystalline interactions and more stabilization due to surface interactions, such as with the surfactants. ${ }^{92}$ Another conclusion is that the small particles of $\mathrm{w}_{-}-\mathrm{Co}_{1-\mathrm{x}} \mathrm{Mn}_{\mathrm{x}} \mathrm{O}$ are of low crystallinity, due to the weakness of the ${ }^{\mathrm{w}}-\mathrm{Co}_{1-\mathrm{x}} \mathrm{Mn}_{\mathrm{x}} \mathrm{O}$ diffraction signal compared to the rs- $\mathrm{Co}_{1-\mathrm{x}} \mathrm{Mn}_{\mathrm{x}} \mathrm{O}$ even when the smaller particles greatly outnumber the larger (Figure 3.16, 2 min). Extending the time the nanoparticles are allowed to grow causes Ostwald ripening to occur, with the small, metastable $\mathrm{w}_{-}-\mathrm{Co}_{1-\mathrm{x}} \mathrm{Mn}_{\mathrm{x}} \mathrm{O}$ particles to dissolve and redeposit on the larger, more stable rs- $\mathrm{Co}_{1-\mathrm{x}} \mathrm{Mn}_{\mathrm{x}} \mathrm{O}$ particles. The stoichiometries of the particles are shown in Table. More cobalt is present in the samples that precipitated from 
hexanes than those that remained in the supernatants; also, extending the growth time led to greater amounts of cobalt present than at shorter growth times. These results are in agreement with our hypothesis that the relative amounts of each metal incorporated into the oxide lattice correlates to the relative solubilities of hydroxide intermediates.

Table 4.2 Stoichiometries of nanoparticles discussed in Section 4.9.

\begin{tabular}{|l|l|l|l|}
\hline & $2 \mathrm{~min}$ & $5 \mathrm{~min}$ & $10 \mathrm{~min}$ \\
\hline $\mathrm{SN}$ & $\mathrm{Co}_{0.50} \mathrm{Mn}_{0.50}$ & $\mathrm{Co}_{0.49} \mathrm{Mn}_{0.51}$ & $\mathrm{Co}_{0.56} \mathrm{Mn}_{0.44}$ \\
\hline ppt & $\mathrm{N} / \mathrm{A}$ & $\mathrm{Co}_{0.52} \mathrm{Mn}_{0.48}$ & $\mathrm{Co}_{0.64} \mathrm{Mn}_{0.36}$ \\
\hline
\end{tabular}

\subsection{Separation of rs-Co $\mathrm{o}_{1-\mathrm{x}} \mathrm{Mn}_{\mathrm{x}} \mathrm{O}$ and $\mathrm{w}-\mathrm{Co}_{1-\mathrm{x}} \mathrm{Mn}_{\mathrm{x}} \mathrm{O}$}

Nanoparticle separation by centrifugation is dependent on several factors: the density of the material, particle size and the interaction of the surfactant molecules with those of the solution. The densities of $\mathrm{MnO}, \mathrm{FeO}$ and rs- $\mathrm{CoO}$ are 5.37, 5.88 and $6.44 \mathrm{~g} / \mathrm{cm}^{3}$ respectively; zincite (hexagonal-lattice $\mathrm{ZnO}$ ) has a density of $5.66 \mathrm{~g} / \mathrm{cm}^{3}$. Using lattice parameters derived from Risbud et al., ${ }^{37}$ the density of hexagonal-lattice CoO was calculated in Diamond software to be 5.32 $\mathrm{g} / \mathrm{cm}^{3}$. This shows a trend of increasing density with decreasing lattice size, as the packing of atoms improves. As discussed before, the $\mathrm{Mn}^{2+}$ ion has an ionic radius of $0.82 \AA$ versus $0.78 \AA$ for $\mathrm{Co}^{2+}$ and the lattice of $\mathrm{Co}_{1-\mathrm{x}} \mathrm{Mn}_{\mathrm{x}} \mathrm{O}$ will be larger with increasing Mn content; the density of the material should likewise decrease with increasing lattice size. And, using the lattice constants derived by Gopal et al., ${ }^{36}$ it is $\sim 4.9 \mathrm{~g} / \mathrm{cm}^{3}$. The density range for ${ }^{\mathrm{w}}-\mathrm{Co}_{1-\mathrm{x}} \mathrm{Mn}_{\mathrm{x}} \mathrm{O}$ should

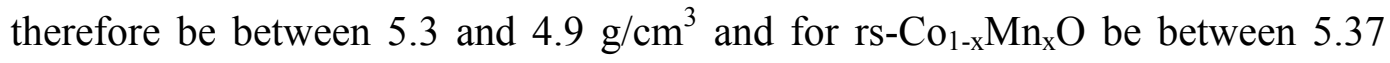


and $6.44 \mathrm{~g} / \mathrm{cm}^{3}$. Additionally, all of the $\mathrm{w}-\mathrm{Co}_{1-\mathrm{x}} \mathrm{Mn}_{\mathrm{x}} \mathrm{O}$ particles are much smaller than the $\mathrm{rs}^{-\mathrm{Co}_{1-\mathrm{x}}} \mathrm{Mn}_{\mathrm{x}} \mathrm{O}$ particles and have higher surface area/volume ratios, meaning they have higher relative amounts of surfactant/oxide ratios. Both of the surfactants used will bind the surfaces with their polar headgroups, exposing their hydrophobic tails to the centrifugation solution. In hexanes the interaction between solution and surfactant tail is strong due to their similar (low) polarities, whereas the 1:1 ethanol:hexanes solution is much more polar. Another point of consideration is that all supernatants in this reaction series contained a mixture of rs- $\mathrm{Co}_{1-\mathrm{x}} \mathrm{Mn}_{\mathrm{x}} \mathrm{O}$ and $\mathrm{w}-\mathrm{Co}_{1-\mathrm{x}} \mathrm{Mn}_{\mathrm{x}} \mathrm{O}$, whereas the $5 \mathrm{~mL}$ TOA: $3 \mathrm{~mL}$ OA reaction condition (Table 3.16 and Table 3.17) had complete segregation between the supernatant and the precipitate; the $5 \mathrm{~mL}$ TOA: $3 \mathrm{~mL}$ OA condition did not give any discreet 20-50 nm particles, only aggregates thereof. Once rs- $\mathrm{Co}_{1-\mathrm{x}} \mathrm{Mn}_{\mathrm{x}} \mathrm{O}$ has been precipitated based on its higher density and average particle size, the addition of ethanol causes all remaining particles to precipitate. This indicates that the separation of $\mathrm{w}-\mathrm{Co}_{1-\mathrm{x}} \mathrm{Mn}_{\mathrm{x}} \mathrm{O}$ and $\mathrm{rs}_{-} \mathrm{Co}_{1-\mathrm{x}} \mathrm{Mn}_{\mathrm{x}} \mathrm{O}$ is achieved due to combination of density, particle size and solvent polarity effects.

\subsection{Nanoparticle growth processes}

In general, there are three types of crystal growth mechanisms: spiral, twodimensional and adhesive. A comparison of how these mechanisms relate to the driving force of crystallization $(\Delta \mu / \mathrm{kT})$ and growth rate is shown in Figure 4.1. Spiral growth is the lowest-energy and involves the formation of a spiral dislocation defect on the surface. This dislocation provides a position for a new surface to grow around, appearing in a spiral pattern; this has the slowest rate. 
Two-dimensional growth arises from the precipitation of a new crystal "growth unit" onto a flat face of the crystal, creating a nucleus on the surface from which further growth arises. Two-dimensional growth tends to produce layer-by-layer growth and has an intermediate rate of growth. Adhesive growth is the deposition of larger crystallite growth units on the surface and is the fastest to occur, giving roughened surfaces and dendritic growth. It has been observed (the Berg effect) that concentrations of growth pieces are not uniform across growing crystal faces, tending to be higher at the edges and corners. This leads to faster growth at those positions of the crystal resulting in more varied morphologies than the three growth mechanisms may suggest; e.g., the spiral growth mechanism is what leads to smooth surfaces and polyhedral morphology. A schematic of how this may present itself is shown in Figure 4.2. 


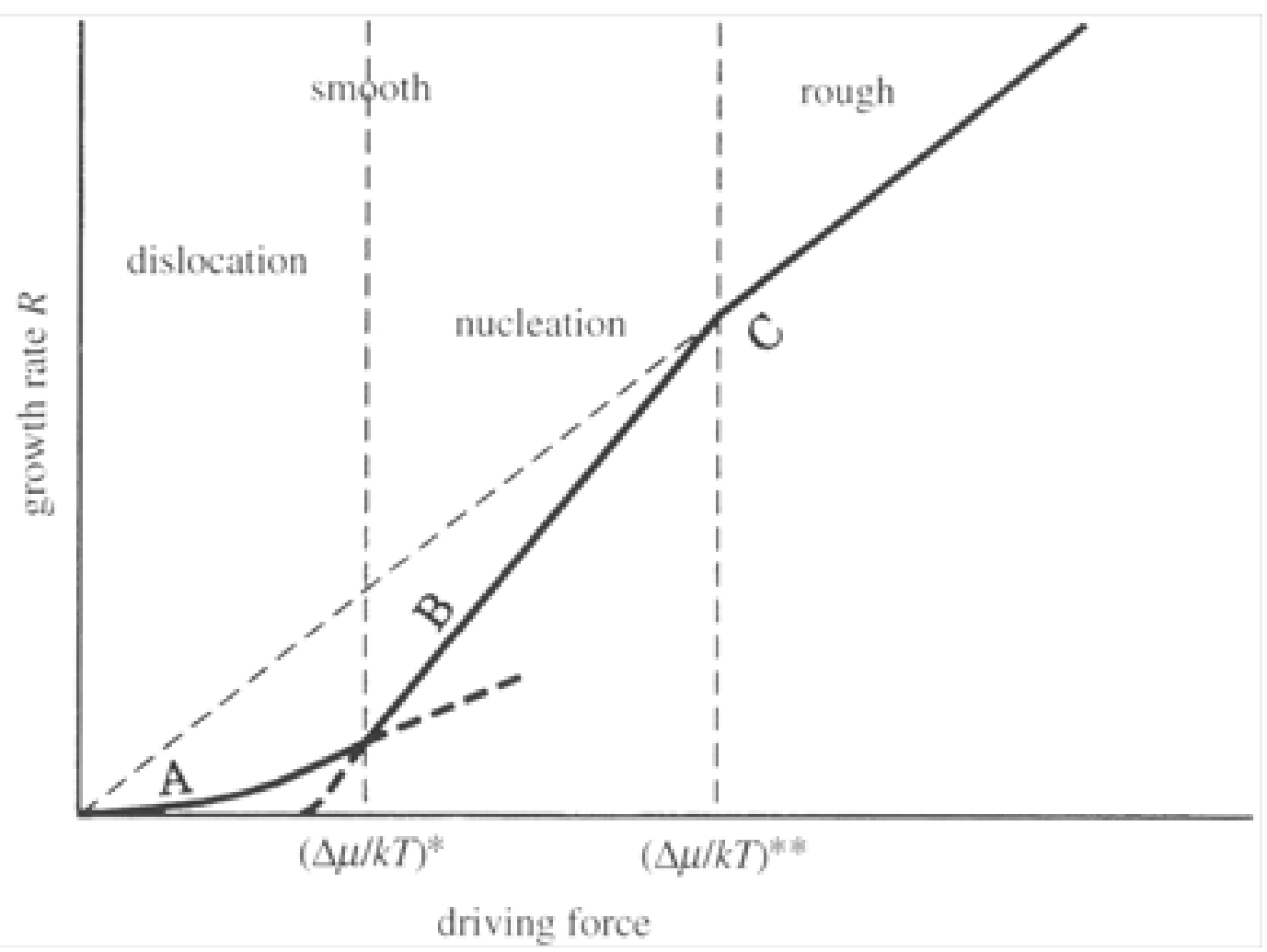

Figure 4.1. Crystal growth rate vs. crystal growth driving force. Curve A depicts spiral growth, curve $B$ two-dimensional layer-by-layer growth and curve $C$ adhesive growth. From Sunagawa p46. ${ }^{92}$

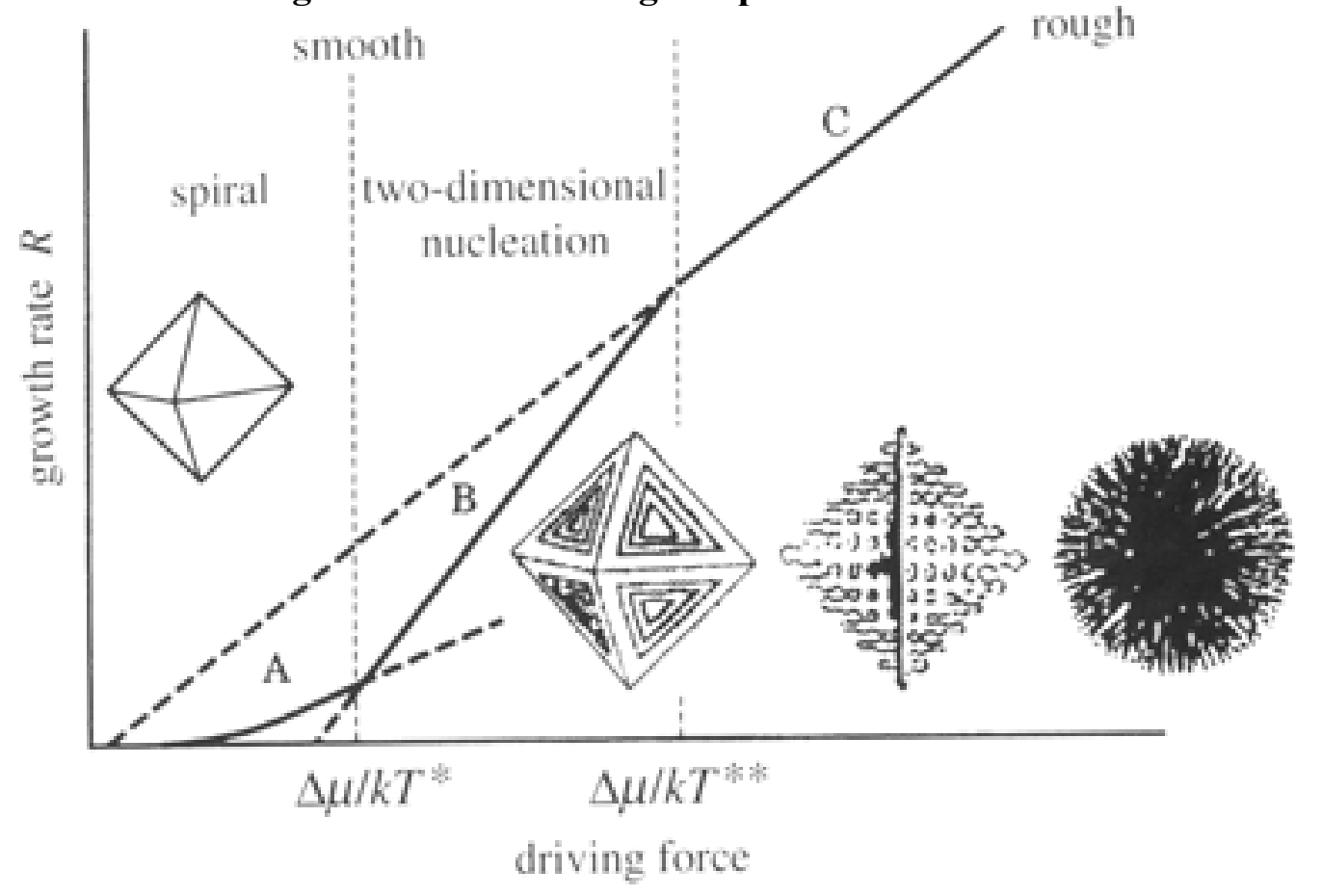

Figure 4.2. Different morphologies achieved under different growth mechanisms from the same cubic seed crystal bounded only by the (111) face. From Sunagawa p 52. ${ }^{92}$ 
There are a few common groupings of crystal types observed in this investigation: small (under $20 \mathrm{~nm}$ per side) squares/cubes, larger squares/cubes up to $200 \mathrm{~nm}$ on a side and spheres over $200 \mathrm{~nm}$ in diameter, all with a cubic lattice; 20-50 nm hexagons and octahedrons with a face-centered cubic lattice; and a mixture of 5-10 nm and 20-30 nm particles with a hexagonal lattice. How these different crystal lattices and morphologies arose can be understood using the mechanisms discussed above.

\subsection{1 "Cuboid"-shaped nanoparticles}

Prototypical nanoparticles displaying the internal textures found in Table 3.10, Table 3.14, Table 3.19, Table 3.20, Table 3.21, Table 3.25 and Table 3.26 are shown in Figure 4.3. They are taken from the $7 \mathrm{~mL}$ TOA: $1 \mathrm{~mL}$ OA with $1 \mathrm{mmol}$ each of $\mathrm{Co}$ and $\mathrm{Mn}$ precursor reaction condition. Close inspection of these rs- $\mathrm{Co}_{1-\mathrm{x}} \mathrm{Mn}_{\mathrm{x}} \mathrm{O}$ nanoparticles show small squares beginning to grow in the direction of their corners (Figure 4.3a) and a later stage in this process (Figure 4.3c) where channels running along the diagonals of the square are visible. These resemble diamond crystals of the "cuboid" type, an illustration of which is shown in Figure $4.3 f .^{92}$ Cuboid crystals arise when the nucleation of a diamond lattice occurs below the crystal growth driving force of $(\Delta \mu / \mathrm{kT})^{*}$, in the spiral growthsmooth surface regime, followed by a rapid shift into the dendritic growth-rough surface regime above $(\Delta \mu / \mathrm{kT})^{* *}$ (Figure 4.3e). This causes the formation of a mantle consisting of a columnar internal texture emanating from the central seed in the $<110>$ and $<100>$ directions giving the cuboid (Figure 4.3f). One of the 
defining characteristics of cuboid is that the cross-section of the dendritic mantle region is much larger than that of the seed polyhedron, as we have observed in this case. The crystal habit and lattice are fundamentally related; the size, shape and symmetry of the crystal lattice will almost always be the basis from which the crystal takes its form or habit. Because both rock salt-type oxides and diamond have face-centered cubic Bravais lattices, crystal growth will proceed along similar directions in both. A growth mechanism that is based upon a transition from slow growth to rapid growth suggests that the decomposition of the metaloleate complex is a rate-determining step, after which precipitation onto the nucleus is very rapid.
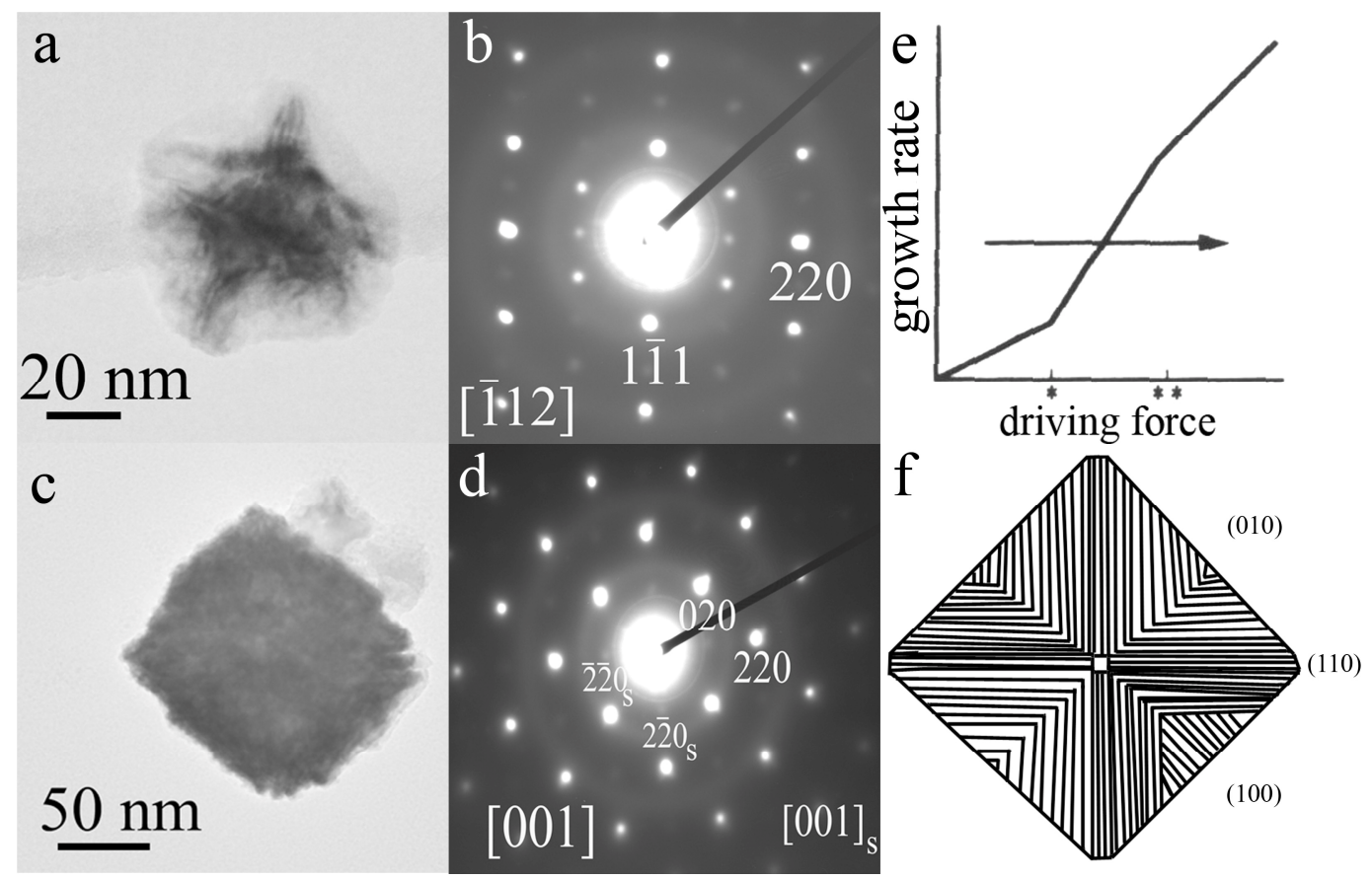

Figure 4.3. TEM images (a) and (c) with SAED patterns (b) and (d) of nanoparticles from reaction of $7 \mathrm{~mL}$ TOA: $1 \mathrm{~mL}$ OA with $1 \mathrm{mmol}$ each of $\mathrm{Co}(\mathrm{OAc})_{2}$ and $\mathrm{Mn}(\mathrm{HCOO})_{2}$. (e) and (f) Schematic illustration of the growth conditions and internal texture of a diamond cuboid (figure derived from literature). ${ }^{92}$ 
Some alternate mechanisms for achieving similar nanoparticle shapes exist. One possibility relates to the spherulite crystal form grown by split growth, (Figure 4.4) which would involve the dendritic growth of arms in a similar manner to the $\mathrm{MnO}$ hexapods, then twinning along the arms to give the bundle of outward-projecting features seen. Another possibility is the formation of a penetration twin (Figure 4.5) where two individual octahedra join along a single face and grow outwards into cubes. SAED analysis of these nanoparticles reveals them to be single crystals, however, which disallow any mechanisms based on crystal twinning. An argument could be made that the textures seen are channels in the crystallite caused by etching or ripening at the corners of the growing particle. This is contrary to the Berg effect, however - the corners are where the primary growth/precipitation of monomers is occurring.
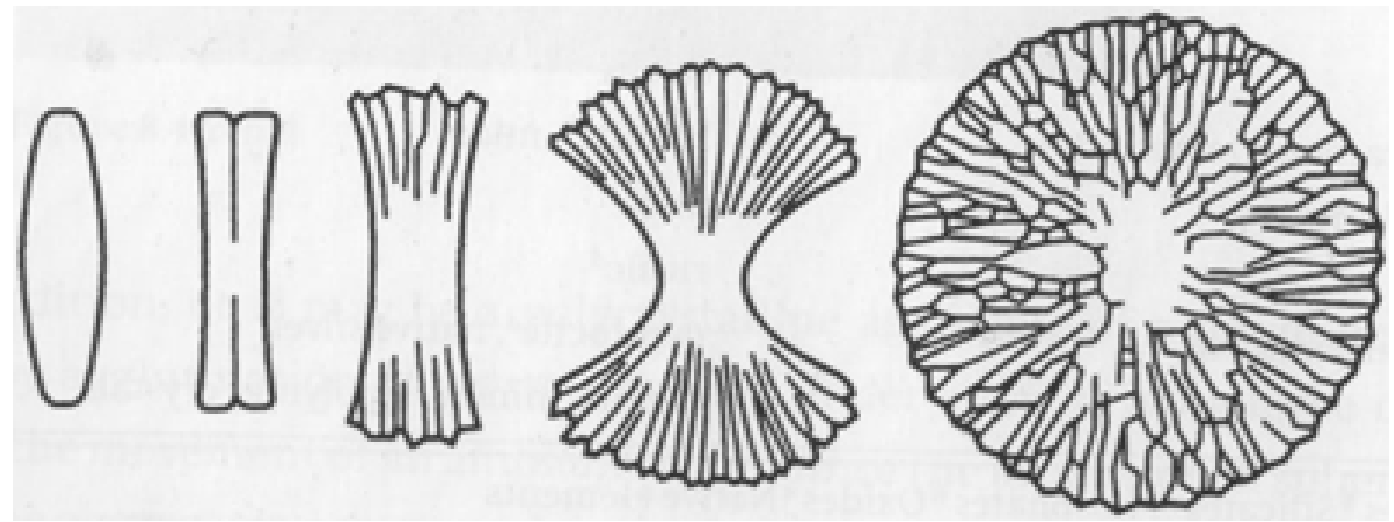

Figure 4.4 Schematic of the growth process of a spherulite formed by split growth. From Sunagawa, p158. ${ }^{92}$ 


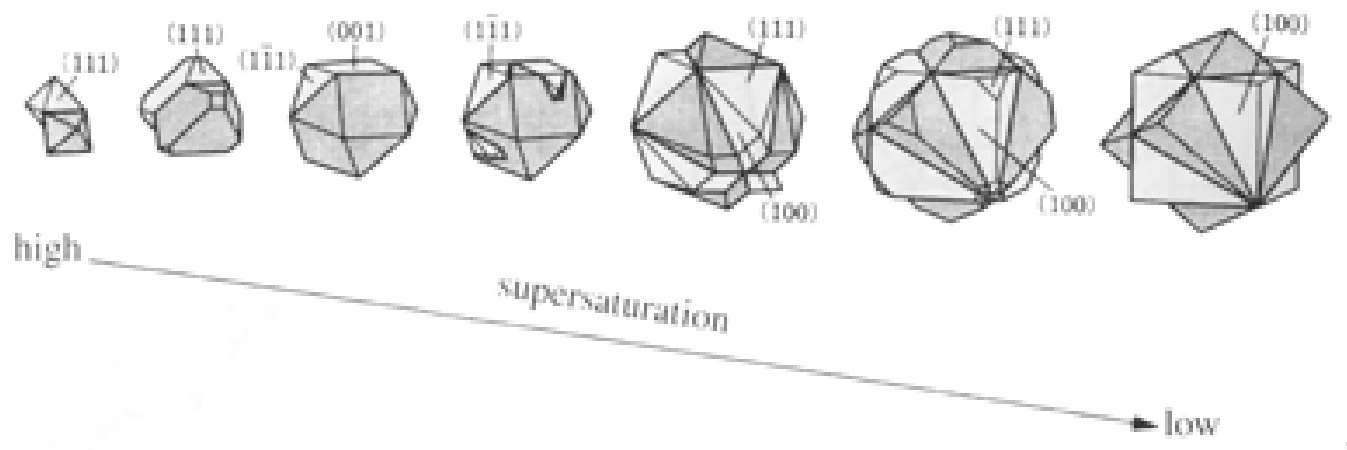

Figure 4.5 Schematic of the growth process for two octahedrons forming interpenetrating cubic crystals. From Sunagawa, p136. ${ }^{92}$

\subsubsection{Faceted particles}

There are three commonalities between the sets of reactions that gave the shapes seen in Figure 4.3: low molar ratio of OA to metals, increased amounts of water present and lower temperatures at which solution color changes occur. The $7 \mathrm{~mL}$ TOA: $1 \mathrm{~mL}(3.15 \mathrm{mmol})$ OA with $2 \mathrm{mmol}$ total metal gives a molar ratio of 1.56 OA per metal ion; the $6 \mathrm{~mL}$ TOA: $2 \mathrm{~mL}(6.3 \mathrm{mmol})$ OA with $3 \mathrm{mmol}$ metal precursor gives an OA/metal ratio of 2.1; and $6 \mathrm{~mL}$ TOA: $2 \mathrm{~mL}$ OA with $4 \mathrm{mmol}$ metal precursor again gives an $\mathrm{OA} /$ metal ratio of 1.56. This indicates that the full replacement of acetate by oleate may be a key step in slowing down nanoparticle growth. Face-centered cubic $\mathrm{CoO}$ nanoparticles synthesized from pre-made $\mathrm{Co}(\text { oleate })_{2}$ in 1-octadecene do, in fact form rhombohedral- and octahedral-shaped nanoparticles. ${ }^{86,93}$ All rs- $\mathrm{Co}_{1-\mathrm{x}} \mathrm{Mn}_{\mathrm{x}} \mathrm{O}$ particles with similar polyhedral shapes arise from reactions with higher $\mathrm{OA} /$ metal molar ratios. For $6 \mathrm{~mL}$ TOA: $2 \mathrm{~mL}(6.3$ mmol) OA with $2 \mathrm{mmol}$ metal precursor, the molar ratio increased a full integer value to 3.2 . 
The addition of water to the reaction gives cuboid-shaped particles and some (Table 3.21) that have anisotropic, unconstrained dendrites, which indicates growth conditions similar to those with a low $\mathrm{OA} /$ metal molar ratio. This is likely due to the increased formation of metal hydroxide intermediates, which are hypothesized to have a role in the formation of these and similar nanoparticles. Metal hydroxides have long been shown to promote the hydrolytic formation of M-O-M bridges important in starting the formation of nanoscale metal oxides. ${ }^{41}$ The lower decomposition temperature is likely the result of incomplete dioleate formation, leaving metals with open coordination sites and enhances the favorability of oxo-metal bridge formation. Another consideration is that several proposed mechanisms for the nonhydrolytic routes to create metal oxides from carboxylates have water as a final product. This is yet another reason why the cuboid forms appear - when OA decomposes, thereby being unable to coordinate nanoaprticle surfaces, it also releases water in doing so and allows hydrolytic processes to occur, which are faster than the nonhydrolytic processes. ${ }^{8,38,94}$

$\mathrm{Co}_{1-\mathrm{x}} \mathrm{Mn}_{\mathrm{x}} \mathrm{O}$ nanoparticles with a hexagonal crystal lattice are only formed in reaction conditions of $5 \mathrm{~mL}$ TOA: $3 \mathrm{~mL}(9.5 \mathrm{mmol})$ OA with $2 \mathrm{mmol}$ precursors and $6 \mathrm{~mL}$ TOA: $2 \mathrm{~mL}(6.3 \mathrm{mmol})$ OA with $1 \mathrm{mmol}$ precursors, with no water, at higher decomposition temperatures than all other reactions and are always produced alongside a face-centered cubic lattice nanoparticle product. These reaction conditions correspond to molar ratios of 6.3 and 4.8 OA molecules per metal ion. Ostwald's step rule states that the earliest phase that appears by nucleation is a metastable phase; this effect has been well investigated at the 
nanoscale in materials such as $\mathrm{ZnS}$, CdSe, and $\mathrm{ZnO}$ which exhibit cubichexagonal polytypism (zinc-blende to wurtzite). ${ }^{1,95-97}$ In this case, the metastable wurtzite-type $\mathrm{Co}_{1-\mathrm{x}} \mathrm{Mn}_{\mathrm{x}} \mathrm{O}$ is only produced under conditions that significantly slow the rate of nuclei precipitation and dissolution. The shapes of NPs formed in these reactions indicate that crystallization is occurring slowly via a spiral or twodimensional growth mechanism, in agreement with the hypothesis that crystal growth is occurring below the driving force $(\Delta \mu / \mathrm{kT})^{*}$. The habits of crystals formed from a cubic lattice growing in the [100] directions via spiral growth are shown in Figure 4.6. All of the faceted particles seen in the 20-50 nm range can be seen as having similar growth processes - rhombohedra and hexagons are the result of growth along one axis stopping at different points. An OA/metal molar ratio higher than 3 and lack of water are what differentiate these reaction conditions from those that form cuboids. The elongated and rodlike particles in Figure 1c, by comparison, have even further growth along one particular axis at the expense of the other two, due to the intermediate $\mathrm{OA} / \mathrm{metal}$ ratio of the reaction.

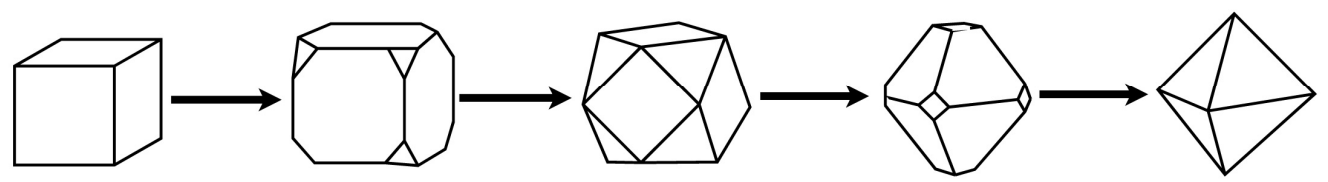

Figure 4.6 Illustration of steps of growth from a cubic lattice nucleus in the [100] directions via a spiral mechanism. Adapted from Sunagawa, p 79. ${ }^{92}$ 
In the reaction condition where no OA is added to the solution, TEM and XRD analysis shows randomly sized and shaped nanoparticles with completely segregated $\mathrm{MnO}, \mathrm{rs}-\mathrm{CoO}$ and $\mathrm{w}-\mathrm{CoO}$ lattices. This indicates that crystallites of each phase are nucleating separately and persist in solution with no selective dissolving/precipitation to form the cubic solid-solution lattice, which means that no Ostwald ripening is occurring. Therefore, OA must play a key role in the mechanism of Ostwald ripening in this system, likely through a strong association between oleate and metal ions during nanoparticle growth. With no OA present in solution, there are no processes by which already-formed hexagonal nuclei can redissolve to give the thermodynamically favored cubic lattice. Addition of OA allows any single-metal lattices to be dissolved and reformed into the entropically favored solid solution $\mathrm{Co}_{1-\mathrm{x}} \mathrm{Mn}_{\mathrm{x}} \mathrm{O}$.

There is also a $35^{\circ} \mathrm{C}$ discontinuity in solution color change temperatures when comparing the $8 \mathrm{~mL}$ TOA: $0 \mathrm{~mL} \mathrm{OA}$ and $7 \mathrm{~mL}$ : $1 \mathrm{~mL}$ OA reaction conditions; the temperature of color change further increases as the $\mathrm{OA}$ concentration increases. The rate of growth also decreases with increasing OA concentration. One explanation for this effect that is suggested by the results is that OA is strongly bound to both the surface of crystallites as well as crystallite growth intermediates, increasing the barrier to nanoparticle nucleation, precipitation and dissolution processes with increasing OA concentration. The inability for OA to completely bind both the nanocrystallite seed as well as "CoMnO" intermediates when the OA/metal ratio is 2 or lower, in addition to increased metal-carboxylate bond cleavage with increased water, leads to the 
heterogeneous nucleation and accelerated growth rates that produce the cuboids found under those conditions. At higher OA/metal ratios, however, OA is better able to bind species in solution, slowing the growth rate and making nucleation more homogeneous.

\subsection{Presence of Multiple Phases}

In most of the electron diffraction patterns of single particles (as performed by Dr. Irene Rusavkoa at the University of Houston), weak spots are seen in addition to the primary pattern. Similar patterns have been observed previously in $\mathrm{MnO}$ and $\mathrm{FeO}$ systems and attributed to the formation of a spinel phase with unit cell edge length $a$ nearly double the size of the cubic lattice. ${ }^{67,68}$ In $\mathrm{MnO}$ and $\mathrm{FeO}$ the spinel phase is the result of oxidation to $\mathrm{Mn}_{3} \mathrm{O}_{4}$ or $\mathrm{Fe}_{3} \mathrm{O}_{4}$ at the surface of the particle, which can be seen by dark field TEM (DF-TEM). In Figure 4.7a-c, a similar effect can be seen. The dark field TEM image recorded

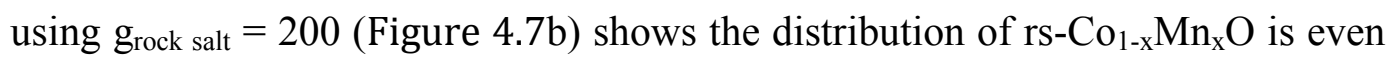
throughout the entire particle; however, DF-TEM on $\mathrm{g}_{\text {spinel }}=2 \overline{2} 0$ (Figure 4.7c) shows that the spinel phase is present at the surface. This is consistent with the previous results and calculated diffraction patterns for the different phases may be found in those reports. There is no evidence in the XRD data to suggest the presence of the spinel phases, indicating the total amount present is very small. However, the XRD analysis does show that the correlation of $\mathrm{rs}_{-}-\mathrm{Co}_{1-\mathrm{x}} \mathrm{Mn}_{\mathrm{x}} \mathrm{O}$ lattice parameters is not perfectly linear between $\mathrm{CoO}$ and $\mathrm{MnO}$. It is possible that $\mathrm{Mn}^{2+}$ and $\mathrm{Co}^{2+}$ could be selectively leeched from the rock salt core as oxidation occurs to give the spinel material. $\mathrm{Mn}_{3} \mathrm{O}_{4}, \mathrm{Mn}_{2} \mathrm{CoO}_{4}, \mathrm{Co}_{3} \mathrm{O}_{4}$ and 
$\mathrm{MnCo}_{2} \mathrm{O}_{4}$ are known and characterized ordered spinels; the Co-heavy structures have face-centered cubic lattices while the Mn-rich structures have tetragonal lattices. The lattice parameters of the cubic spinels $\left(a=8.269 \AA\right.$ for $\mathrm{MnCo}_{2} \mathrm{O}_{4} ; a$ $=8.084 \AA$ for $\left.\mathrm{Co}_{3} \mathrm{O}_{4}\right)$ are almost double that of the rock salt lattices ( $a=4.25$ to $4.45 \AA)$. In fact, the faceted nanoparticles of size $30-50 \mathrm{~nm}$ with Co:Mn stoichiometry of approximately $2: 1$ are where the most amount of surface oxidation is observed. In our system, even the Mn-rich showed cubic spinel rather than the tetragonal structure as found in $\mathrm{Mn}_{3} \mathrm{O}_{4}$. This suggests that there is a difference in the Co:Mn ratio of the spinel phase compared to the bulk measurement, meaning that one ion or the other is selectively leached from the rock salt phase to achieve the correct spinel stoichiometry.

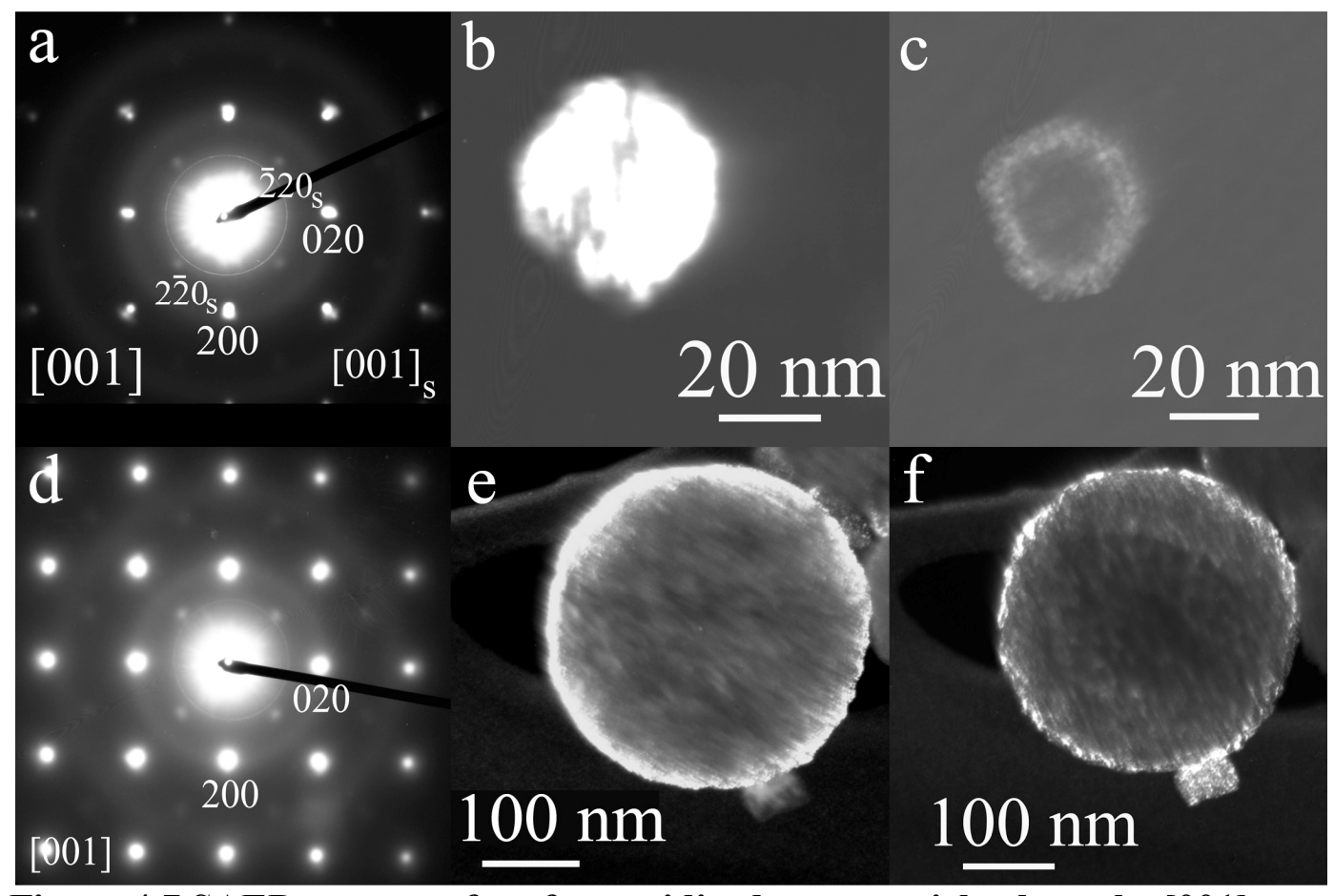

Figure 4.7 SAED pattern of surface-oxidized nanoparticle along the [001] axis (a) and dark field TEM images of a nanoparticle taken with grock salt $=$ 200 (b) and $g_{\text {spinel }}=2 \overline{2} 0$ (c). SAED pattern of a nanoparticle displaying longrange superlattice ordering (d) with dark field TEM images with $g_{\text {intense }}=220$ (e) and $g_{\text {weak }}=110$ (f). 
With a mixed-metal oxide, however, another possible explanation exists for diffraction spots at one-half those of the regular lattice: an ordered solid solution, or "superlattice." Intensity of the superlattice reflections is related to the difference in atomic scattering factors of the ordering elements. So their intensity is weaker compared to the regular reflections. The position of the extra spots in the diffraction pattern depends on the lattice parameter of the new unit cell created by the ordering process. In our case the new unit cell is doubled. Superlattice reflections are observed in materials that have long-range order and their real space unit cell is larger. The images in Figure $4.7 \mathrm{~d}-\mathrm{f}$ illustrate this phenomenon. The electron diffraction pattern shows the superlattice reflections to be at precisely one-half the spacing of the regular reflections. Dark field TEM images (recorded using the basic and superlattice reflections are shown in Figure 4.7e and f (respectively). They show similar intensity distribution across the entire particle image for both reflection types, confirming that they belong to the same crystalline phase, indicating lattice doubling in all directions. SAED patterns taken down the [011] zone axis (Figure 4.8) are consistent with lattice doubling in all directions. This effect was seen in the electron diffraction patterns of multiple nanoparticles from samples with stoichiometries (from ICP) of $\mathrm{c}-\mathrm{Co}_{0.69} \mathrm{Mn}_{0.31} \mathrm{O}, \mathrm{c}-\mathrm{Co}_{0.75} \mathrm{Mn}_{0.25} \mathrm{O}$ and $\mathrm{c}-\mathrm{Co}_{0.93} \mathrm{Mn}_{0.07} \mathrm{O}$. It should be noted that short-range cation ordering has been observed in the related spinels $\mathrm{Fe}_{3} \mathrm{O}_{4}$ and $\mathrm{NiFe}_{2} \mathrm{O}_{4}$, suggesting a similar effect occurs in this system. ${ }^{98,99}$ 


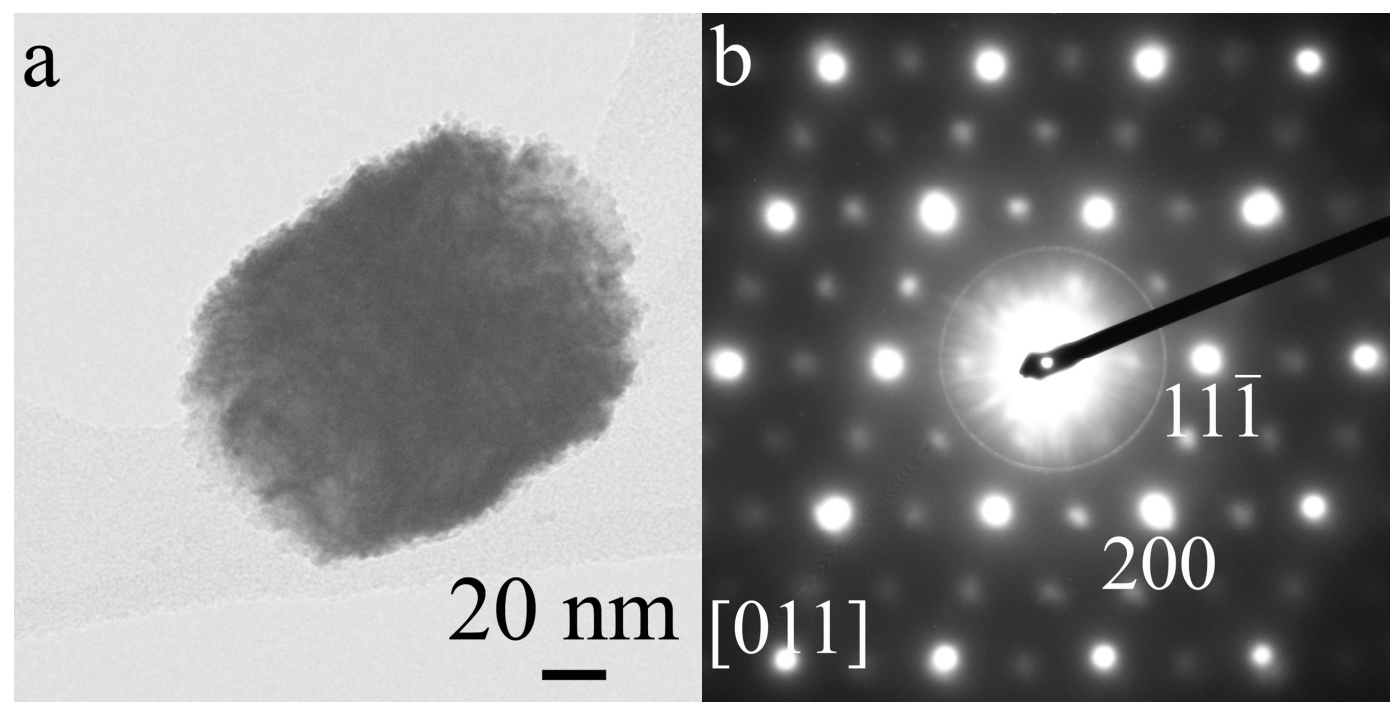

Figure 4.8 Bright field TEM (a) and SAED pattern down the [011] axis showing superlattice ordering (b) of a nanoparticle synthesized $6 \mathrm{ml}$ TOA: 2 ml OA with no water and a 2:1 Co:Mn precursor ratio; final product stoichiometry was $\mathrm{c}-\mathrm{Co}_{0.75} \mathrm{Mn}_{0.25} \mathrm{O}$.

\subsection{Grain size dependence on Co-Mn stoichiometry}

Scherrer analysis of the XRD data shows little variance in the crystallite size at $0.1 \leq \mathrm{Co} \leq 0.9$. Particles with less than $10 \%$ Co had larger grain sizes, and those with more than $90 \%$ present had much larger grain sizes, however. Two main factors likely contribute to this: particle size and metal distribution through the lattice. The large Scherrer crystallite sizes of Co-rich particles is due to their being very large $(>100 \mathrm{~nm})$, solid particles - see Tables 3.11, 3.12 and 4.1. This is in contrast to $\mathrm{MnO}$ hexapods (shown at $0 \%$ Co content on Figures 3.21 through 3.24) and $\mathrm{Co}_{1-\mathrm{x}} \mathrm{Mn}_{\mathrm{x}} \mathrm{O}$ cuboids, which contain many dendritic arms with small cross-sections. Samples with more than $10 \%$ doping of either metal tended to be smaller particles - the maximum size of rhombohedra and hexagons is $50 \mathrm{~nm}$, with most being much smaller. Also, while individual nanoparticles appear to be 
single crystals based on SAED images, it's very possible that not the entire particle is completely crystalline - the surface is still growing and not completely incorporated into the lattice, creating a crystalline core and amorphous shell. This can be seen in some TEM images, for example Tables 3.24, 3.27, 3.28 and 3.30. It is also possible that individual particles have different Co-Mn stoichiometries, which, if similar enough, would give overlapping XRD peaks, causing linebroadening and skewing the Scherrer analysis to smaller particles. If this is occurring, it could be determined using the GIF (Gatan Image Filter) mode on a HRTEM, which allows for the elemental composition of individual particles to be mapped. In general, however, due to the lack of correlation found in the region $0.1 \leq$ Co $\leq 0.9$ it cannot be said that metal content had a significant effect on crystallite size..

\subsection{Heating effects and heterogeneous vs. homogeneous}

\section{nucleation}

It has been shown that variations in solution heating have a significant effect on the outcomes of reactions. It is hypothesized that this is due to the temperature shock causing extremely heterogeneous nucleation of nanoparticles; the local growth conditions will vary wildly, leading to the cuboid nanoparticles seen. The issues encountered with degassing and drying both TOA and OA, and the need to distill OA, are likely due to similar processes. 


\section{Chapter 5. Conclusions}

Rock salt- and wurtzite-type $\mathrm{Co}_{1-\mathrm{x}} \mathrm{Mn}_{\mathrm{x}} \mathrm{O}$ with a wide variety of nanoparticle morphologies, sizes and stoichiometries have been synthesized via a solvothermal route. This is the first report of Mn-doped h-CoO and second report of mixed Mn-Co rock salt oxide. Several types of particle shapes were recurring throughout the investigation and represent different types of crystal growth kinetics: 20-50 $\mathrm{nm}$ cubes with 50-200 $\mathrm{nm}$ cuboids; 20-50 $\mathrm{nm}$ hexagons and rhombohedra; and 5-20 $\mathrm{nm}$ hexagonal-lattice spheres. Oleic acid is shown to have several roles in nanoparticle formation - it is necessary for the incorporation of both metals into the oxide lattice; it inhibits the rate of crystallite nucleation and growth, stabilizing the metastable $\mathrm{w}-\mathrm{Co}_{1-\mathrm{x}} \mathrm{Mn}_{\mathrm{x}} \mathrm{O}$ phase; and also contributes to the Ostwald ripening of particles that selects for $\mathrm{rs}^{-\mathrm{Co}_{1-\mathrm{x}} \mathrm{Mn}} \mathrm{Mn}_{\mathrm{x}} \mathrm{O}$. Water has also been shown to speed the growth rate of crystallites and increase ripening, leading to rs$\mathrm{Co}_{1-\mathrm{x}} \mathrm{Mn}_{\mathrm{x}} \mathrm{O}$ cuboid-shaped particles. The reliable synthesis of $\mathrm{w}-\mathrm{Co}_{1-\mathrm{x}} \mathrm{Mn}_{\mathrm{x}} \mathrm{O}$ required very precise reaction conditions with relatively homogeneous nucleation and no particles ever grew larger than $30 \mathrm{~nm}$ in diameter as a result of its metastable nature. High surface area $\mathrm{Co}_{1-\mathrm{x}} \mathrm{Mn}_{\mathrm{x}} \mathrm{O}$ showing dendritic growth may prove to be of great interest as battery electrode materials. Understanding and overcoming the synthetic challenges presented here will lead to the ability to investigate the physical properties of both rs- and $\mathrm{w}-\mathrm{Co}_{1-\mathrm{x}} \mathrm{Mn}_{\mathrm{x}} \mathrm{O}$ in depth. 


\section{References}

\section{References}

(1) Deer, W. A.; Howie, R. A.; Zussman, J. An Introduction to the Rock-Forming Minerals; 2nd ed.; Longman Group UK Limited, 1992.

(2) Ahrens, T. J. Mineral physics and crystallography: a handbook of physical constants; American Geophysical Union: Washington, D.C., 1995.

(3) Rao, C. N. R. Annu. Rev. Phys. Chem. 1989, 40, 291-326.

(4) Cullity, B. D. Elements of X-Ray Diffraction; 2nd ed.; AddisonWesley Publishing Company, Inc.: Reading, Massachusetts, 1978.

(5) Mutin, P. H.; Vioux, A. Chem. Mater. 2009, 21, 582-596.

(6) Gopalakrishnan, J. Chem. Mater. 1995, 7, 1265-1275.

(7) Rousset, A.; Chassagneux, F.; Paris, J. J. Mater. Sci. 1986, 21, 3111-3115.

(8) Park, J.; Joo, J.; Kwon, S. G.; Jang, Y.; Hyeon, T. Angewandte Chemie International Edition 2007, 46, 4630-4660.

(9) Subramanian, M. A.; Torardi, C. C.; Calabrese, J. C.; Gopalakrishnan, J.; Morissey, K. J.; Askew, T. R.; Flippen, R. B.; Chowdhry, U.; Sleight, A. W. Science 1988, 239, 1015-1017. 153.

(10) Dagottoa, E.; Hotta, T.; Moreo, A. Phys. Rep. 2001, 344, 1-

(11) Imada, M.; Fujimori, A.; Tokura, Y. Rev. Mod. Phys. 1998, 70, 1039-1263.

(12) Voorhoeve, R. J. H.; Johnson, D. W.; Remeika, J. P.; Gallagher, P. K. Science 1977, 195, 827-833.

(13) Kolmakov, A.; Moskovits, M. Annu. Rev. Mater. Res. 2004, $34,151-180$.

(14) Comini, E. Analytica Chimica Acta 2006, 568, 28-40.

(15) Chen, X.; Mao, S. S. Chem. Rev. 2007, 107, 2891-2959.

(16) Huheey, J. E.; Keiter, E. A.; Keiter, R. L. Inorganic Chemistry: principles of structure and reactivity; 4th ed.; HarperCollins College Publishers: New York, Ny, 1993.

(17) Yamanaka, T.; Tokonami, M. Acta Cryst 1985, 298-304.

(18) Yeh, C.-Y.; Lu, Z. W.; Froyen, S.; Zunger, A. Physical Review B 1992, 46, 10086-10097.

(19) Shannon, R. D. Acta Cryst. 1975, A32, 751-767.

(20) Iwasaki, K.; Takizawa, H.; Yamane, H.; Kubota, S.; Takahashi, J.; Uheda, K.; Endo, T. Materials Research Bulletin 2003, 38, 141-148.

(21) Karzel, H.; Potzel, W.; Köfferlein, M.; Schiessl, W.; Steiner, M.; Hiller, U.; Kalvius, G. M.; Mitchell, D. W.; Das, T. P.; Blaha, P.; Schwarz, K.; Pasternak, M. P. Physical Review B 1996, 53, 11425-11438.

(22) Bobade, S. M. Appl. Phys. Lett. 2012, 100, 072102. 
387.

(23) Look, D. C. Materials Science and Engineering: B 2001, 80, 383-

(24) Huang, M. H.; Mao, S.; Feick, H.; Yan, H.; Wu, Y.; Kind, H.; Weber, E.; Russo, R.; Yang, P. Science 2001, 292, 1897-1899.

(25) Wang, Z. L. J. Phys. Cond. Matt. 2004, 16.

(26) Wróbel, J.; Piechota, J. physica status solidi (b) 2007, 244, 15381543.

(27) Wrobel, J.; Piechota, J. Solid State Communications 2008, $146,324-329$.

(28) Clavel, G.; Willinger, M.-G.; Zitoun, D.; Pinna, N. Adv. Funct. Mater. 2007, 17, 3159-3169.

(29) Dietl, T.; Ohno, H.; Matsukura, F.; Cibert, J.; Ferrand, D. Science 2000, 287, 1019-1022.

(30) Kane, M. H.; Shalini, K.; Summers, C. J.; Varatharajan, R.; Nause, J.; Vestal, C. R.; Zhang, Z. J.; Ferguson, I. T. J. Appl. Phys. 2005, $97,023906$.

(31) Kundaliya, D. C.; Ogale, S. B.; Lofland, S. E.; Dhar, S.; Metting, C. J.; Shinde, S. R.; Ma, Z.; Varughese, B.; Ramanujachary, K. V.; Salamanca-Riba, L.; Venkatesan, T. Nature Mater. 2004, 709-714.

(32) Fukumura, T.; Zhengwu, J.; Ohtomo, A.; Koinuma, H.; Kawasaki, M. Appl. Phys. Lett. 1999, 75, 3366-3368.

(33) Fukumura, T.; Zhengwu, J.; Kawasaki, M.; Shono, T.; Hasegawa, T.; Koshihara, S.; Koinuma, H. Appl. Phys. Lett. 2001, 78, 1348323.

(34) Gilliand, S. G.; Sans, J. A.; Sanchez-Royo, J. F.; Almonacid, G.; Segura, A. Appl. Phys. Lett. 2010, 96, 241902.

(35) Schleife, A.; Fuchs, F.; Furthm $\sqrt{ }$ oller, J.; Bechstedt, F. Physical Review $B$ 2006, 73, 245212.

(36) Gopal, P.; Spaldin, N.; Waghamare, U. Phys. Rev. B 2004, 70, 205104.

(37) Risbud, A.; Snedeker, L.; Elcombe, M.; Cheetham, A.; Seshadri, R. Chem. Mater. 2005, 17, 834-838.

(38) Vioux, A. Chemistry of Materials 1997, 9, 2292-2299.

(39) Burda, C.; Chen, X. J.; Narayanan, R.; El-Sayed, M. A. Chem. Rev. 2005, 105, 1025-1102.

(40) Kwon, S. G.; Hyeon, T. Accounts of Chemical Research 2008, 41, 1696-1709.

(41) Niederberger, M.; Garnweitner, G. Chem. Eur. J. 2006, 12, 72827302.

(42) Moritz, T.; Reiss, J.; Diesner, K.; Su, D.; Chemseddine, A. The Journal of Physical Chemistry B 1997, 101, 8052-8053.

(43) Chemseddine, A.; Moritz, T. European Journal of Inorganic Chemistry 1999, 1999, 235-245.

(44) Trentler, T. J.; Denler, T. E.; Bertone, J. F.; Agrawal, A.; Colvin, V. L. J. Am. Chem. Soc. 1999, 121, 1613-1614. 
(45) Joo, J.; Yu, T.; Kim, Y. W.; Park, H. M.; Wu, F.; Zhang, J. Z.; Hyeon, T. Journal of the American Chemical Society 2003, 125, 6553-6557.

(46) Sun, X.; Zhang, Y.-W.; Si, R.; Yan, C.-H. Small 2005, 1, 10811086.

(47) Ould-Ely, T.; Prieto-Centurion, D.; Kumar, A.; Guo, W.; Knowles, W. V.; Asokan, S.; Wong, M. S.; Rusakova, I.; Lüttge, A.; Whitmire, K. H. Chem. Mater 2006, 18, 1821-1829.

(48) Wu, X.-L.; Guo, Y.-G.; Wan, L.-J.; Hu, C.-W. J. PHys. Chem. C 2008, 112, 16824-16829.

(49) Hyeon, T.; Lee, S. S.; Park, J.; Chung, Y.; Bin Na, H. J. Am. Chem. Soc. 2001, 123, 12798-12801.

(50) Jiao, F.; Frei, H. Energy Envir. Sci. 2010, 3, 1018-1027.

(51) Numata, K.; Sakaki, C.; Yamanaka, S. Solid State Ionics $1999,117,257-263$.

(52) Cheng, F.; Shen, J.; Peng, B.; Pan, Y.; Tao, Z.; Chen, J. Nature Chem. 2011, 3, 79-84.

(53) Li, W.-Y.; Xu, L.-N.; Chen, J. Adv. Funct. Mater. 2005, 15, 851-857.

(54) Manthiram, A.; Kim, J. Chem. Mater. 1998, 10, 2895-2909.

(55) Tan, L.; Liu, H. Solid State lonics 2010, 181, 1530-1533.

(56) Thackeray, M. M. Prog. Sold. St. Chem. 1997, 25, 1-71.

(57) Dubal, D. P.; Dhawale, D. S.; Salunkhe, R. R.; Pawar, S. M.; Lokhande, C. D. Appl. Surf. Sci. 2010, 256, 4411-4416.

(58) Lokhande, C. D.; Dubal, D. P.; Joo, O.-S. Curr. Appl. Phys. 2011, 11, 255-270.

(59) Nakayama, M.; Suzuki, K.; Okamura, K.; Inoue, R.; Athouel, L.; Crosnier, O.; Brousse, T. J. Electrochem. Soc. 2010, 157, A1067-A1072. 1008.

(60) Prasad, K. R.; Miura, N. Electrochem. Comm. 2004, 4, 1004-

(61) Ammundsen, B.; Paulsen, J. Adv. Mater. 2001, 13, 943-956.

(62) Armstrong, A. R.; Robertson, A. D.; Bruce, P. G. Electrochimica Acta 1999, 45, 285-294.

(63) Banov, B.; Todorox, A.; Trifonova, A.; Momchilov, A.; Manev, V. J. Power Sources 1997, 68, 578-581.

(64) Kang, S.-H.; Kim, J.; Stoll, M. E.; Abraham, D.; Sun, Y. K.; Amine, K. J. Power Sources 2002, 112, 41-48.

(65) Koksbang, R.; Barker, J.; Shi, H.; Saidi, M. Y. Solid State lonics 1996, 84, 1-21.

(66) Peng, Z. S.; Wan, C. R.; Jiang, C. Y. J. Power Sources 1998, $72,215-220$.

(67) Rusakova, I.; Ould-Ely, T.; Hofmann, C.; Prieto-Centurin, D.; Levin, C. S.; Halas, N. J.; Lüttge, A.; Whitmire, K. H. Chem. Mater. 2007, $19,1369-1375$.

(68) Hofmann, C.; Rusakova, I.; Ould-Ely, T.; Prieto-Centurion, D.; Hartman, K. B.; Kelly, A. T.; Luttge, A.; H., W. K. Adv. Funct. Mater. 2008, 18, 1661-1667. 
(69) Zhang, L.-J.; Wang, J.-Q.; Li, J.; Zhou, J.; Cai, W.-P.; Cheng, J.; Xu, W.; Yin, G.; Wu, X.; Jiang, Z.; Zhang, S.; Wu, Z.-Y. Chemical Communications 2012, 48, 91-93.

(70) Redman, M.; Steward, E. Nature 1962, 48, 867.

(71) Seo, W. S.; Shim, J. H.; Oh, S. J.; Lee, E. K.; Hur, N. H.;

Park, J. T. J. Am. Chem. Soc. 2005, 127, 6188-6189.

(72) Grimes, R.; Fitch, A. J. Mater. Chem 1991, 1, 461-468.

(73) An, K.; Le, N.; Park, J.; Kim, S. C.; Hwang, Y.; Park, J.-G.; Kim, J.-Y.; Park, J.-H.; Han, M. J.; Yu, J.; Hyeon, T. J. Am. Chem. Soc. 2006, 128, 9753-9760.

(74) Han, J. J.; Yu, J. J. Korean Phys. Soc. 2006, 48, 1496-1500.

(75) Liu, J. F.; Yin, S.; Wu, H. P.; Zeng, Y. W.; Hu, X. R.; Wang, Y. W.; Lv, G. L.; Jiang, J. Z. J. Phys. Chem. B 2006, 110, 21588-21592.

(76) Meyer, W.; Hock, D.; Biedermann, K.; Gubo, M.; Muller, S.; Hammer, L.; Heinz, K. Phys. Rev. Lett. 2008, 101, 016103.

(77) Nam, K. M.; Shim, J. H.; Han, D.-W.; Kwon, H. S.; Kang, Y.M.; Li, Y.; Song, H.; Seo, W. S.; Park, J. T. Chem. Mater. 2010, 22, 44464454. 10403.

(78) Wei, W.; Chen, W.; Ivey, D. G. J. Phys. Chem. C 2007, 111, 103981947.

(79) Wei, W.; Chen, W.; Ivey, D. G. Chem. Mater. 2008, 20, 1941-

(80) Wei, W.; Egilmez, M.; Chen, W.; Jung, J. A.; Ivey, D. G. J. Mater. Sci. 2010, 45.

(81) Juita; Dlugogorski, B. Z.; Kennedy, E. M.; Mackie, J. C. Proceedings of the Combustion Institute, 33, 2625-2632.

(82) Wang, Y.; Wang, Q.; Artz, W. E.; Padua, G. W. Journal of Agricultural and Food Chemistry 2008, 56, 3043-3048.

(83) Khan, N. A.; Cone, J. W.; Hendriks, W. H. Animal Feed Science and Technology 2009, 154, 183-192.

(84) Mallégol, J.; Lemaire, J.; Gardette, J.-L. Progress in Organic Coatings 2000, 39, 107-113.

(85) Lazzari, M.; Chiantore, O. Polymer Degradation and Stability 1999, 65, 303-313.

(86) Ye, Y.; Yuan, F.; Li, S. Mater. Lett. 2006, 60, 3175-3178.

(87) Zhang, Y.; Zhu, J.; Song, X.; Zhong, X. J. Phys. Chem. C 2008, 112, 5322-5327.

(88) Manna, L.; Milliron, D. J.; Meisel, A.; Scher, E. C.; Alivisatos, A. P. Nat Mater 2003, 2, 382-385. 969-971.

(89) Penn, R. L.; Banfield, J. F. Science (Washington, D. C.) 1998, 281,

(90) Zitoun, D.; Pinna, N.; Frolet, N.; Belin, C. J. Am. Chem. Soc. 2005, 127, 15034-15035.

(91) Alivisatos, A. P. Ber. Bunsen-Ges. 1997, 101, 1573-1577.

(92) Sunagawa, I. Crystals Growth, Morphology and Perfection; Cambridge University Press, 2005. 
(93) Chen, Z.; Xu, A.; Zhang, Y.; Gu, N. Curr. Appl. Phys. 2010, 10, 967970.

(94) Jun, Y.-w.; Choi, J.-s.; Cheon, J. Angewandte Chemie International Edition 2006, 45, 3414-3439.

(95) Navrotsky, A.; Ma, C.; Lilova, K.; Birkner, N. Science 2010, 330, 199-201.

(96) Özgür, Ü.; Alivov, Y. I.; Liu, C.; Teke, A.; M. A. Reshchikov, M. A.; S. Doğan, S.; Avrutin, V.; Cho, S.-J.; Morkoç, H. Appl. Phys. Rev. 2005, 98, 041301.

(97) Trindade, T.; O'Brien, P.; Pickett, N. L. Chemistry of Materials 2001, 13, 3843-3858.

(98) Ivanov, V. G.; Abrashev, M. V.; Iliev, M. N.; Gospodinov, M. M.; Meen, J.; Aroyo, M. I. Physical Review B 2010, 82, 024104.

(99) Senn, M. S.; Wright, J. P.; Attfield, J. P. Nature 2012, 481, 173-176. 